LBL -32737

DE93 002552

\title{
The Strong Reactions of Lewis-Base Noble-Metals with Vanadium and Other Acidic Transition Metals
}

\author{
Bartley B. Ebbinghaus \\ Ph.D Thesis \\ Department of Chemistry \\ University of California \\ and \\ Materials Science Division \\ Lawrence Berkely Laboratory \\ University of California \\ Berkeley, CA 94720
}

May 1991

This work was supported by the Director, Office of Basic Energy Science, Materials Sciences Division, of the U.S. Department of Energy under Contract No. DE-AC03-76SF00098. 
The Strong Reactions of Lewis-Base Noble-Metals with Vanadium and Other Acidic Transition metals

By

Bartley Bryan Ebbinghaus

\begin{abstract}
The noble metals are often thought of as unreactive solids. However, they are known to react strongly with nearly 40 percent of the elements in the periodic table. This includes the group IIIB-VB transition metals, the lanthanides, the actinides, and the group IILA-IVA non-transition metals. These strong reactions arise from increased bonding which is obtained from electron transfer from nonbonding electrons d electron pairs on the noble metal to vacant orbitals on vanadium and other like elements. This effect is characterized as a generalized Lewis acid-base interaction. To study this interaction the partial Gibbs energy of vanadium in the noble metals has been measured as a function of concentration at a temperature near $1000^{\circ} \mathrm{C}$.

The thermodynamics of the intermetallics are determined by ternary oxide equilibria, ternary carbide equilibria, and the high-temperature galvanic cell technique. These experimental methods use equilibrated solid composite mixtures in which grains of vanadium oxides or of vanadium carbides are interspersed with grains of V-NM(noblemetal) alloys. In equilibrium the activity of vanadium in the oxide or the carbide equals the activity in the alloy. Consequently, the thermodynanics available in the literature for
\end{abstract}


the vanadium oxides and vanadium carbides are reviewed.

A number of test runs on the galvanic cell have been attempted to confirm proper cell behavior. The vanadium oxide electrode is observed to react with $\mathrm{CaF}_{2}, \mathrm{ThO}_{2}$, YDT $\left(0.85 \mathrm{ThO}_{2}-0.15 \mathrm{YO}_{1.5}\right)$, and LDT $\left(0.85 \mathrm{ThO}_{2}-0.15 \mathrm{LaO}_{1.5}\right)$ to interfere with the measured EMF. It is concluded that EMF data observed toward the beginning of a galvanic cell experiment are the most accurate.

The interaction of vanadium at infinite dilution in the noble-metals has been determined as follows: $-\log \gamma_{v}{ }^{-}[\mathrm{V}-\mathrm{Ru}]=3.4 \pm 0.3,-\log \gamma_{\mathrm{v}}{ }^{ }[\mathrm{V}-\mathrm{Rh}]=5.25 \pm 0.25$, $-\log \gamma_{v}{ }^{\circ}[\mathrm{V}-\mathrm{Pd}]=5.93 \pm 0.08,-\log \gamma_{v}{ }^{\circ}[\mathrm{V}-\mathrm{O} s]=3.0 \pm 0.3,-\log \gamma_{v}{ }^{\circ}[\mathrm{V}-\mathrm{Ir}]=8.11 \pm 0.5$, $-\log \gamma_{v}{ }^{\circ}[\mathrm{V}-\mathrm{Pt}]=8.8 \pm 1$. 
Table of Contents

\section{Chapter 1}

\section{Introduction}

1.1. The Noble Metals. 1

1.2. The Fall of the Noble Metals. 3

1.3. Project Overview. 4

1.4. Importance of the Acid-Base Interaction. 8

Chapter 2

Engel-Brewer and Acid-Base Theories

2.1. Phase Diagrams. 13

2.2. The Electronic State of Solids. 14

2.3. Acid-Base Reactions: Atomic Orbitals. 19

2.4. Acid-Base Reactions: Molecular Orbitals. 21

2.5. Predicting Phase Diagrams. 24

2.6. Explaining the Engel-Brewer Correlation. 31

2.7. The Calculation of Phase Boundaries. 40 


\section{Chapter 3}

\section{Characterization Methods}

3.1. Introduction to Thermodynamic Activities. 44

3.2. Ternary Phase Equilibria. 47

3.3. The Galvanic Cell Technique. 51

3.4. The Activity of Vanadium: Sample Calculations. 63

Chapter 4

\section{Experimental}

4.1. Experimental Techniques. 71

4.2. Some Procedures. 76

\section{Chapter 5}

Thermodynamics

5.1. The Thermodynamics of the Vanadium Oxides. 88

5.2. The Thermodynamics of the Vanadium Carbides. 94

5.3. The Thermodynamics of $\mathrm{V}(\mathrm{s}), \mathrm{O}_{2}(\mathrm{~g}), \mathrm{C}(\mathrm{gr})$. 95

5.4. Thermodynamics of the Reference Electrodes. 98

5.5. Thermodynamics for the Galvanic Cell System. 99 
Chapter 6

Results

6.1. The Ternary Equilibrium Phase Diagrams. 103

6.2. The Galvanic Cell Experiments and Results. 111

6.3. The Solution to the Galvanic Cell Problems. 127

6.4. The Electrode-Electrolyte Interfacial Reaction. 129

6.5. Some Other Tests on the Galvanic Cell. 133

Chapter 7

Infinite Dilution Parameters

7.1. Activity Coefficients at Infinite Dilution. 138

7.2. Modeling the Activity Coefficient at Infinite Dilution.

7.3. Calculating Activity Coefficients at Infinite Dilution. 152

Chapter 8

Modeling

8.1. Models of the Activity Coefficient as a Function of Concentration. 164

8.2. Experimental Data: Activity Coefficient versus Concentration. 175

8.3. Fitting the Thermodynamic Data. 181

8.4. Correlations Between Thermodynamics and Alloy Properties. 188 


\section{Chapter 9}

\section{Conclusions}

9.1. Conclusions.

9.2. Remaining Work. 205

9.3. A Long Term Goal.

207

9.4. The End.

207

\section{Appendix A}

A.1. Compilation of Sample Equilibration Histories.

\section{Appendix B}

B.1. Thermodynamics and Assumptions for Solid Phases.

B.2. The Lower Vanadium Oxides: Accuracy of Assumptions.

\section{Appendix C}

C.1. Apparati Descriptions.

C.2. The Thoria Furnace.

C.3. The Hot Press.

C.4. The Brew Annealing Furnace.

C.5. The High-Temperature Galvanic Cell.

C.6. The X-Ray Diffractometer.

C.7. The Electron Microprobe.

C.8. The Scanning Electron Microscope. 
Appendix D

D.1. Equilibration Time versus Diffusion Rate. 234

D.2. Estimation of Equilibration Time. 236

Appendix E

E.1. The Giauque Function. 242

Appendix F

$\begin{array}{ll}\text { F.1. Starting Materials. } & 244\end{array}$

Appendix G

G.1. Comparison of d and I Values for Interfacial Layers. 246

Appendix $\mathrm{H}$

H.1. The Activity Coefficient versus Concentration Data. 257

Appendix I

I.1. Containers Used for Sample Heat Treatments. 260 


\section{Acknowledgements}

I am greatly indebted to every one in the Leo Brewer research group for all of their help and support. I am also indebted to the staff at Lawrence Berkeley Laboratory, Building 62, and to the electron microprobe staff in Earth Sciences, U. C. Berkeley, for their help.

I want to specially acknowledge Professor Leo Brewer for making my graduate career an enjoyable and edifying experience. Special thanks also to John Kouvetakis and Susan Leonard-Steyert who have been very influential to my graduate research and whose friendship has meant a great deal.

This work was supported by the U. S. Department of Energy under Contract Number DE-AC03-76SF00098. 


\section{Chapter 1}

\subsection{The Noble Metals.}

The noble metals although not inert are not expected to form any highly stable compounds. They resist oxidation and corrosion. It is difficult to remove their electrons from the neutral atoms, and their solvated ions in solution are easily reduced to the metallic state. Hence, the term "noble metal" which suggests an unreactive metal in the same way "noble gas" suggests an unreactive gas. The coinage of this term, noble metal, is archaic and was meant to imply that the metal's nature was unchanging and perfect. In the pre-industrial world few materials possessed the permanence and luster of gold and silver. For this reason, they were valued, worshipped, and deemed worthy of kings. Hence they are called noble. In this sense, John de Trevista in 1398 made one of the earliest known references to gold and silver as noble metals. He wrote, "Precious stones...ben ifounde... in passinge grete vertue, whan pey bene noble and verrei.", and "Noble metal is ymynyd oute of veynes and mountayns."[1] Trevista is referring only to gold and silver in these quotes. Later, however, platinum, iridium, rhodium, and palladiun were arscovered and added to the "noble" group.

By . , 76 the term, noble metal, was commonly used for describing the unreactive 
metals. Richard Kirwan wrote, "The three first [Gold, Platina, Silver] and Quicksilver commonly called Noble and Perfect metals." [1]

This is not to say that these metals were ever believed to be totally inert. This is evidenced by the fact that they generally are not found in pure elemental form. Raw gold, for example, often has some platinum, silver, or other noble metal present. In addition, it has been known since the $16^{\text {th }}$ century that platinum dissolves in hot aqua regia. Furthermore, since the time of ancient Egypt, gold was known to dissolve in mercury, a phenomenon which was critical in the separation of the gold from the rock that was mined in the slave mines of Nubia. [2] Although not inert, none of the noble metals were ever observed to react violently with any material, and with most known materials they were observed to be either unreactive or nearly inert.

Because platinum and other noble metals are observed to be unreactive in many common environments, they are used as containers in reactive and corrosive environments. This naive choice of materials is due to a lack of information. The platinum-group metals can and do react with many materials sometimes even with explosive power. For example, Srikrishnan and Ficalora attempted to measure the enthalpy of formation of $\mathrm{HfPt}_{3}$ and $\mathrm{ZrPt}_{3}$ by direct reaction calorimetry. They reported "Although the thermite pellet could successfully initiate the reaction between $\mathrm{Zr}$ or $\mathrm{Hf}$ and $\mathrm{Pt}$, the ensuing, reaction was so violent that it showered the interior of the bomb with unreacted molten metal powder."[3] 


\subsection{The Fall of the Noble Metals.}

The following three experiments are either based on actual experiments or systems where there is enough data known to predict the outcome. The intention is to illustrate the importance of understanding the strong interactions with platinum-group metals, and how their presence in experiments can create unexpected complications.

Experiment 1: A platinum-platinum(10\% rhodium) thermocouple was prepared for high-temperature use. The wires were protected using an alumina casing. The thermocouple was then placed in a vacuum chamber and used to measure the temperature at about $1200^{\circ} \mathrm{C}$ in an atmosphere back-filled with argon. The experiment proceeded for a day or so. Then suddenly, the thermocouple failed. Upon cooling the instrument and removing the thermocouple, the alumina casing had been deteriorated and the thermocouple wires were disconnected.[46]

Experiment 2: The purpose of this experiment was to check the calibration of a optical pyrometer against the melting point of platinum. A crucible manufactured from cerium sulfide was used. At the time, it was believed that a cerium sulfide crucible would be impervious to reactions with most any material, even including corrosive materials at high temperature. A platinum slug was inserted into the crucible and heated. After the experiment, it was noticed that the crucible was marred badly where the platinum had been positioned.[7] 
Experiment 3: Wayne Worrell proposed the following difficulty in a hydrogen-oxygen fuel cell. A cell consists of air at the anode and $\mathrm{H}_{2} / \mathrm{H}_{2} \mathrm{O}$ gas mixture at the cathode. A platinum wire imbedded in the yttria-doped zirconia electrolyte on each side completes electrical contact. At $1000^{\circ} \mathrm{C}$ the cell operates properly for several hours and then fails. On the air side no reaction is observed, but on the $\mathrm{H}_{2} / \mathrm{H}_{2} \mathrm{O}$ side the $\mathrm{Pt}$ wire is broken due to reaction with the electrolyte.[8]

Each of the above experiments fails in some way because in each experiment platinum is used. The difficulties encountered in each experiment are the result of the misconception that platinum has a low reactivity. It is expected to be inert in each case. However, platinum is not inert in these systems and contrary to what is expected platinum can form extremely stable compounds. What about the other noble metals, such as iridium, rhodium, palladium, gold, silver, and osmium? Can they also form extremely stable compounds? Yes, some are more stable than others. Nevertheless, contrary to centuries of belief, the noble metals are not so noble.

\subsection{Project Overview.}

The purpose of our investigation is to further characterize the nature of strong reactions with the noble metals. This is an on-going project which dates back to the 1960's. Paul Wengert and Leo Brewer [9] were the first to work on 
this project and many others have since contributed.[10-14] The particular project undertaken here is the completion of a study initiated by John Kouvetakis [14] on the strength of the reaction of vanadium with the noble metals. To characterize the interaction, the activity of vanadium is determined experimentally as a function of composition. This is achieved by equilibrating vanadium oxides or vanadium carbides with V-NM(NM=noble metal). The thermodynamics of the oxides or carbides fixes the thermodynamics of the alloys. The oxide equilibria experiments are modeled after the method of Cima[13] and the carbide equilibria experiments after the method of Gibson.[10] A high-temperature galvanii cell is used to obtain the partial pressure of oxygen in equilibrium with the oxide-alloy composite at $800-1200^{\circ} \mathrm{C}$ for many alloy compositions. This makes possible the calculation of the activity of vanadium in oxide-alloy ceramics where only one oxide present. This technique aiso follows the method used by Cima.[13]

In general, there are two types of strong reactions with the noble metals. The first is a reaction of group IIIB-VB transition metals, the lanthanides, or the actinides with the noble metals. The second is a reaction of group IILA-IVA nontransition metals with the transition metals. This includes the noble metals. Together these sets include about 40 percent of the elements in the periodic table which react strongly with the noble metals, and only a few which are unreactive. This further stresses the misconception that the noble metals are unreactive. 
The incraased stability can be described by viewing the noble metals either as acids, when reacting with group IIIA-IVA transition metals, or as bases, when reacting with group IIIB-VB transition metals. The concept of acids and bases as used here is considerably generalized from the original Arrhenius model where by definition acids dissociate in solution to yield $\mathrm{H}^{+}$ions and bases dissociate in solution to yield $\mathrm{OH}^{*}$ ions. Historically, the next more general description of acids and bases was proposed by Brönsted and Lowry. They defined acids as proton donors and bases as proton acceptors. Thus, ammonia could be appropriately classified as a base. G. N. Lewis generalized the acid-base concept even further by identifying acids as electron-pair acceptors and bases as electron-pair donors. Thus boron trichloride could be identified as an acid as shown by the following reaction

$$
\mathrm{BCl}_{3}+: \mathrm{NH}_{3}=\mathrm{Cl}_{3} \mathrm{~B}-\mathrm{NH}_{3}
$$

Hence, all reactions involving electron transfer in which nonbonding electron pairs overlap with vacant orbitals are classified as acid-base reactions. It is G. N. Lewis definition of acids and bases that Brewer has extended to apply to intermetallics.[18]

In the first of the two types of interactions the acids, IIIB-VB transition metals, the lanthanides, and the actinides, have vacant $d$ orbitals. The bases, platinum-group metals, have nonbonding electron pairs in d orbitals which can overlap with the vacant $d$ orbitals on a metal such as vanadium to increase the net 
bonding and, hence, the stability. The noble metal is a Lewis-base in these interactions. The high stability of these acid-base stabilized alloys can be demonstrated by comparing the enthalpy of formation of zirconium platinides with other zirconium compounds known for their high stability. Table 1.1 demonstrates how the zirconium platinides can compete in stability with zirconium carbide, zirconium nitride, and even zirconium oxide.

Table 1.1. Stability of zirconium compounds.

\begin{tabular}{lll}
\hline compound & $-\Delta \mathrm{H}_{f}(\mathrm{~kJ} /$ mole $)$ & reference \\
\hline $\mathrm{ZrC}$ & $24.44 \pm 0.32$ & 15 \\
$\mathrm{ZrN}$ & $43.92 \pm 1.01$ & 15 \\
$\mathrm{ZrO}_{2}$ & $131.99 \pm 0.22$ & 16 \\
$\mathrm{Zrt}$ & $23.09 \pm 1.49$ & 17 \\
$\mathrm{ZrPt}_{3}$ & $61.39 \pm 4.04$ & 3
\end{tabular}

The second type of Lewis acid-base interaction is in some ways opposite to the first. The noble metal in this case is the Lewis-acid and the group IIIAIVA non-transition metal is the Lewis-base. The increased stability here arises from the electronic configuration of the intermetallic being closer to the ground state of the gaseous atoms than the average of the elemental fractions. The result is a bonding environment created by electron transfer which is largely ionic in character. The acid-base concept here has been generalized even further and suggests that ionic bonds and Lewis acid-base interactions which both involve 
electron transfer are in essence very similar. This relationship is explored further in Chapter 3. Brewer has discussed this second type of Lewis acid-base interaction in more detail elsewhere.[20] Table 1.2 demonstrates how the aluminum platinides can compete in stability with aluminum carbide, aluminum nitride, and aluminum oxide.

Table 1.2. Stability of aluminum compounds.

\begin{tabular}{lll}
\hline compound & $-\Delta \mathrm{H}_{\mathrm{f}}(\mathrm{kJ} /$ mole $)$ & reference \\
\hline $\mathrm{AlC}_{3 / 4}$ & $6.48 \pm 0.22$ & 15 \\
$\mathrm{AlN}$ & $38.25 \pm 0.31$ & 15 \\
$\mathrm{AlO}_{3 / 2}$ & $100.79 \pm 0.10$ & 16 \\
$\mathrm{AlPt}$ & 16.81 & 19 \\
$\mathrm{AlPt}_{3}$ & 48.93 & 19
\end{tabular}

\subsection{Importance of the Acid-Base Interaction.}

Understanding this acid-base interaction is very important for the prediction of phase diagrams and for the resolution of conflicting phase equilibria in the literature. For systems where there is no electron transfer, the prediction of the equilibrium constitution diagram is greatly simplified through the use of the EngelBrewer and atomic size correlations.[21] Also, the constitution diagrams for the acid-base stabilized alloys where there is electron transfer can also be predicted well. However, the prediction of phase boundaries for these systems is less certain. The main difficulty for acid-base stabilized systems is the inability to predict absolute thermodynamics. These systems put the Engel-Brewer and atomic 
size correlations to the test in the worst cases. By studying these systems, more information can be obtained by which to refine the Engel-Brewer and atomic size correlations into a more encompassing and quantitative theory.

Over the past century, the noble metals have become very useful metals in a variety of applications. In addition to their oxidation and corrosion resistance, they are important materials for use in a variety of applications such as heterogenous catalysis. Consequently, the acid-base stabilization of the noble metals is important to understand because it is an important aspect of their overall chemistry.

Additionally, acid-base stabilized noble metals are excellent although not cheap prospects for a variety of applications. Platinum has been demonstrated to be a good material for bonding zirconium oxide ceramic materials together.[22] Palladium with titanium has been shown to be a good material for thin film resistors.[23] Jacksik has demonstrated a correlation between these alloys and catalytic activity in the hydrogen evolution reaction.[24] Certainly, there are other uses yet to be fully realized for these materials. More specifically, acid- base stabilized alloys are extremely hard, tough, oxidation resistant, and corrosion resistant materials, and these properties give rise to a number of possible material applications. 


\section{References}

1. J. A. Simpson and E. S. C. Weiner, The Oxford English Dictionary, $2^{\text {nd }}$ Ed., Clarendon Press, Oxford (1989).

2. Jenifer Marx, The Magic of Gold, Doubleday \& Company, Inc., Garden City, New York (1978).

3. V. Srikrishnan and P. J. Ficalora, "Measurement of the Enthalpies of Formation of $\mathrm{ZrPt}_{3}$ and $\mathrm{HPPt}_{3}$ by Fluorine Bomb Calorimetry," Metall. Trans., 5, 1471-1475 (1974).

4. A. S. Darling, G. L. Selman, and R. Rushforth, "Platinum and the Refractory Oxides IV -The Performance in Service of Platinum Thermocouples," Platinum Met. Rev., 15(1), 13-18 (1971).

5. A. S. Darling, G. L. Selman, and R. Rushforth, "Platinum and the Refractory Oxides I-Compatibility and Decomposition Processes at High Temperatures," Platinum Met. Rev., 14(2), 54-60 (1970).

6. A. S. Darling, G. L. Selman, and R. Rushforth, "Platinum and the Refractory Oxides II-Constitutional Relationships in the Alloys Formed," Platinum Met. Rev., 14(4), 124-130 (1970).

7. L. Brewer, E. D. Eastman, L. A. Bromley, P. W. Gilles, and N. L. Lofgren, Preparation and Tests of Refractory Sulfide Crucibles," J. Amer. Ceram. Soc., $34,128-134$ (1951).

8. P. J. Meschter and W. L. Worrell, "An Investigation of High Temperature Thermodynamic Properties in the Pt-Zr and Pt-Hf Systems," Metall. Trans. $A$, 8A, 503-509 (1977). 
9. L. Brewer and P. R. Wengert, "Transition Metal Alloys of Extraordinary Stability: An Example of Generalized Lewis Acid-Base Interactions in Metallic Systems," Metall. Trans. 4, 83-104 (1973).

10. J. K. Gibson, L. Brewer and K. A. Gingerich, "Thermodynamics of Several Lewis Acid-Base Stabilized Transition Metal Alloys," Metall. Trans. A 15A, 2075-85 (1984).

11. D. A. Goodman, "High Temperature Thermodynamic Activities of Zirconium in Platinum Alloys Determined by Nitrogen-Nitride Equilibria," Ph. D. Thesis, U. C. Berkeley, LBL-10633 (1980).

12. J. H. Bularzik, "Acid-Base reactions of the Transition Metal Alloys: Thermochemistry of the Base-Rich End," Ph.D. Thesis, U. C. Berkeley, LBL23665 (1987).

13. M. Cima and L. Brewer, "Generalized Lewis Acid-Base Titration of Palladium and Niobium," Metall. Trans. B, 19B, 893-917 (1988)

14. J. Kouvetakis, "I-Stability Range of MoC(hP2), II-Thermodynamic Properties of Generalized Lewis Acid-Base Intermetallics," Ph.D. Thesis, U.C. Berkeley, LBL-25340 (1988).

15. D. R. Stull and H. Prophet, Project Directors, JANAF Thermochemical Tables, 2nd Ed., NSRDS-NBS 37, Catalog Number C13.48:37, U. S. Government Printing Office, Washington, D. C. (1971).

16. L. Brewer, "High Temperature Thermodynamic Properties of Elements and their Oxides," LBL 23019 (1987).

17. L. Topor and O. J. Kleppa, "Standard Enthalpies of Formation of PtTi, PtZr, and PtHf," Metall. Trans. A, 19A, 1827-1831, (1988). 
18. L. Brewer, "The Generalized Lewis Acid-Base Theory," J. Chem. Edu., 61, 101-104 (1984).

19. R. Ferro, R. Capelli, A. Borsese, and G. Centineo, "Research on Noble Metals with Less Electropositive Elements. XII-Heats of Formation of Al-Pt Alloys," Atti Accad. Naz. Lincei, Classe Sci. Fis. Mat. Nat., 45, 54-59 (1968) (German).

20. L. Brewer, "Nature of Bonding in Transition-Metal Aluminides," J. Phys. Chem., 94(3), 1196-1203 (1990).

21. L. Brewer, "Prediction of High Temperature Metallic Phase Diagrams," in High-Strength Materials, V. F. Zackay, ed., Chapter 2, 12-103, John Wiley: New York, UCRL-10701 (1965).

22. R. V. Allen, F. P. Bailey, and W. E. Borbidge, "Solid State Bonding of Ceramics with Platinum Foil," Platinum Met. Rev., 25(4), 152-155 (1981).

23. D. J. Sharp and D. P. Norwood, "Electrochemical Adjustment of Thin Film Ti-Pd Resistors," Thin Solid Films, 153, 387-399 (1987).

24. M. M. Jaksik, "Brewer Intermetallic Phases as Synergetic Electrocatalysts for Hydrogen Evolution," Materials Chemistry and Physics, 22, 1-26 (1989). 


\section{Chapter 2}

\subsection{Phase Diagrams.}

One of the most fundamental thermodynamic properties of alloys is the equilibrium structures they form. In theory, it is possible to calculate equilibrium phases from first principles using the methods of quantum mechanics and statistical mechanics. However, this is usually a time consuming and a complicated endeavor even when a considerable number of simplifying assumptions are used. A more practical approach is a semi-empirical one which combines observed trends with basic chemical principles. The semi-empirical approach is the one we have taken.

A large number of equilibrium phase diagrams can be predicted from correlations involving only the atomic size, the valence electron concentration, and the cohesive energy of the constituent elements. [1-5] These correlations work well for alloy systems if there is no increased stability due to Lewis acid-base electron transfer. The correlation between atomic size and valence electron concentration is in all cases sufficient to limit the number of phases that can be expected to form at a specified concentration in any alloy system. Often there is only one phase that is expected. For many systems, the change in cohesive energy as a function 
of composition can be inferred from the cohesive energy of the constituent elements, and consequently, thermodynamic data are not needed for the alloy system to predict the phases boundaries. In systems where acid-base interactions occur, it is not possible to infer accurately the cohesive energy as a function of composition since the interactions between atoms change dramatically as a function of concentration. In these systems some thermodynamic data as a funcion of concentration is needed to calculate the phas boundaries. For this reason, we have studied the thermodynamic activity of one of the constituent elements, vanadium, in acid-base intermetallics as a function of concentration.

\subsection{The Electronic State of Solids.}

To identify the correlations which occur in the solid state, it is necissary to define the electronic state of the solid. Roughly, this is given by the number and types of valence electrons in the solid. That is the relative $s, p$, and $d$ valence electron concentrations. Brewer has discussed this approach in detail.[1-5]

First, it is very important to note that the ground state electronic configuration in the solid is different from the ground state electronic configuration in the gas. For example, vanadium gas is known to have the ground state electronic configuration of $s^{2} d^{3}$, but if this were the same configuration in the metal, vanadium could only have three $d$ bonds per atom contributing to the bonding stability. If the electronic configuration of vanadium gas is promoted to 
the $\mathrm{sd}^{4}$ state and then condensed to the metal, there would be five bonds per atom. If the increase in energy due to two extra bonds in the solid is greater than the prom tion energy from the $s^{2} d^{3}$ to the $s d^{4}$ state, one would expect the $s d^{4}$ configuration to be preferred over the $\mathrm{s}^{2} \mathrm{~d}^{3}$ configuration in the solid. Figure 2.1 depicts this type of reasoning. The real electronic configuration in the solid will be expected to be that one in which the expected enthalpy of sublimation is largest. Using this type of reasoning, the electronic configuations of all the metals in their standard states can be estimated. As can be seen in Figure 2.1, this methodology is also an effective way to separate the bonding energy from the heat of sublimation.

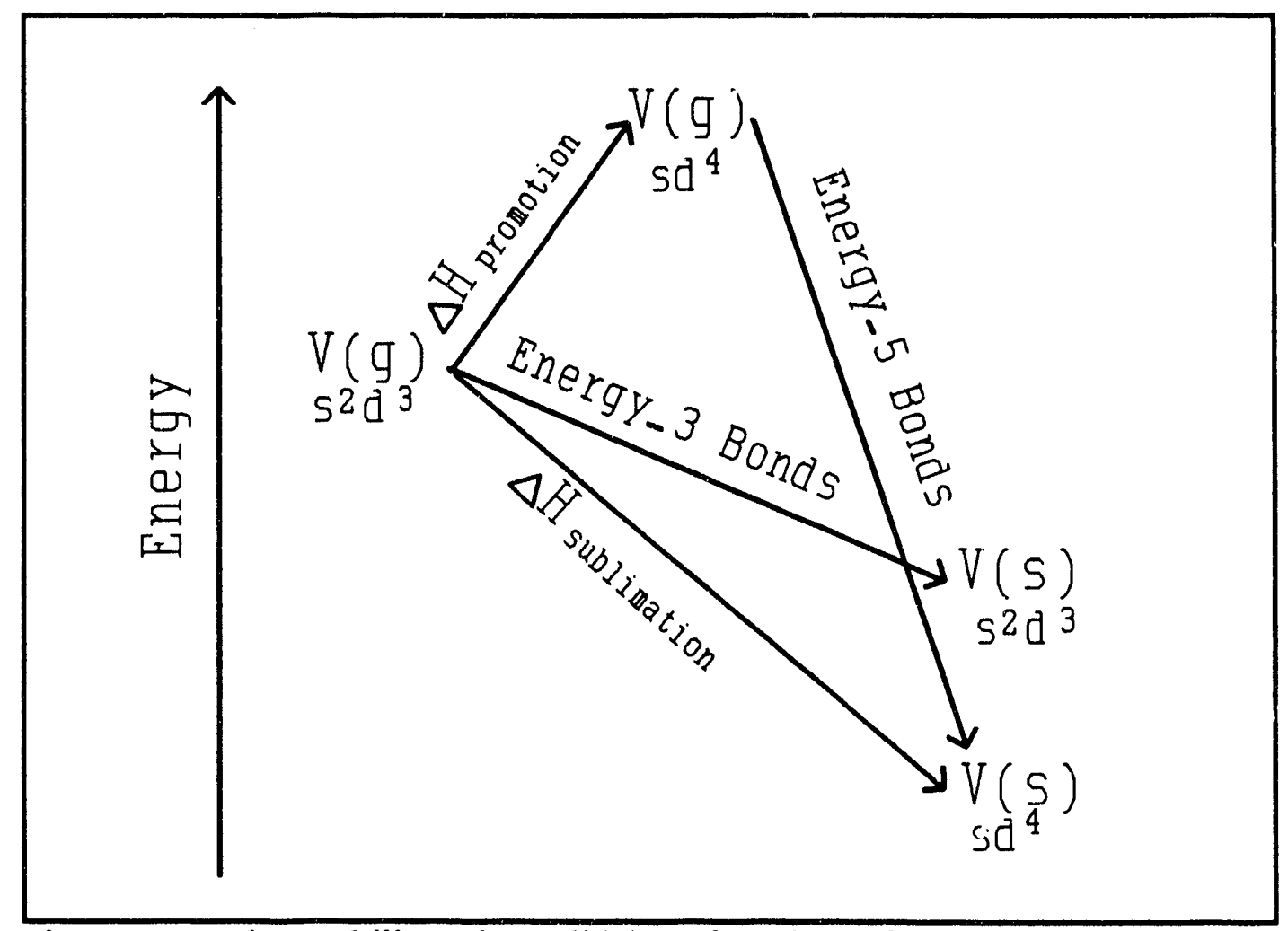

Figure 2.1. The stability of a solid is a function of the promotion energy and the bonding energy. 
It should be noted that every electronic configuration in the gas represents a number of sub-configurations of different energy which correspond to different states of angular momentum and spin. One energy level corresponds to each state of the total orbital angular momentum, $\mathrm{L}$, and the total spin, $\mathrm{S}$, of the valence electrons in the gaseous atom. The standard is to use the energy of the lowest state of each electronic configuration in all calculations. A similar ambiguity arises in the condensed solid since the bonding environment is composed of a large number of factors which contribute to the bonding. A configuration of $\mathrm{sd}^{4}$ would be best visualized by ascribing $1 / 5$ of the valence electrons in molecular orbitals from $s$ atomic orbitals and $4 / 5$ of the valence electrons are in molecular orbitals from $d$ atomic orbitals. Brewrer has explained these assumptions and shown that this approach to separating bonding energy from sublimation energy is internally consistent. [3,4]

The use of a cycle like that in Figure 2.1 can be used to gain insight into the bonding energy of alloys. Figure 2.2 is an example of the Born-Haber cycle, and Figure 2.3 is a variation on Figure 2.1 which shows that the bonding energy in alloys can be obtained in a similar manner as the lattice energy is obtained in ionic solids. The benefit for isolating the lattice energy from the heat of formation is that the lattice energy is a simple electrostatic force which can be correlated to atomic size, charge, and structure. Likewise, Figure 2.3 shows the similarity of the approach for calculating the bonding energy. The bonding energy in turn is a 


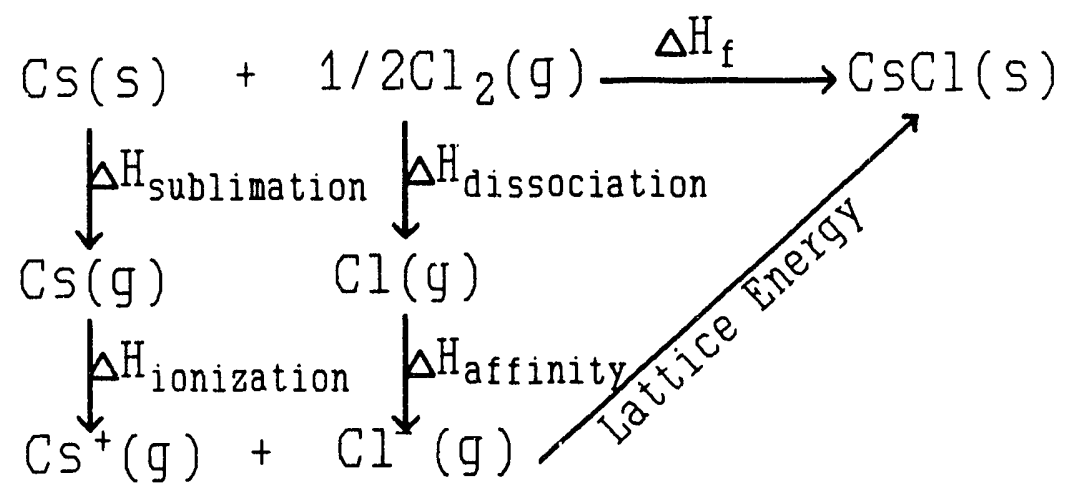

Figure 2.2. The Born-Haber Cycle: Lattice energy can be separated from other factors that contribute to the heat of formation.

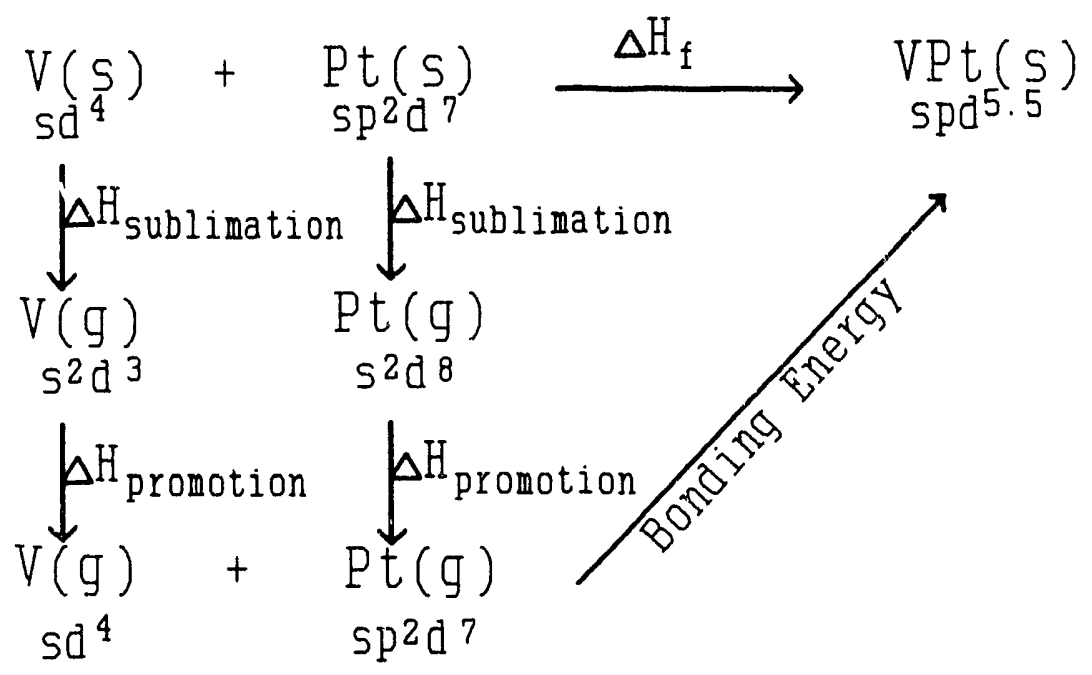

Figure 2.3. A Born-Haber type cycle applied to metals: Bonding energy can be separated from other factors which contribute to the heat of formation. 
better quantity to relate to the number of bonding electrons than the heat of formation. The Born-Haber type cycle as applied to metals can be summarized by the following statement. Paired electrons will be promoted to higher energy levels as long as the increase in bonding energy is greater than the promotion energy. From this process, the final electronic configuration of the metal can be fixed. Some examples are given in Table 2.1. Note that the final state may actually be a mixture of several electronic configurations. Consequently, there can exist fractions of electrons in the final valence electronic configuration of the metal.

Table 2.1. Electronic configurations.

configurations to nearest $1 / 2$ an electron.

\begin{tabular}{lll}
\hline element & gas & metal \\
\hline V & $s^{2} d^{3}$ & $s p^{0.5} d^{3.5}$ \\
$\mathrm{Nb}$ & $s^{2} d^{3}$ & $s p^{0.5} d^{3.5}$ \\
$\mathrm{Ta}$ & $s^{2} d^{3}$ & $s p^{0.5} d^{3.5}$ \\
$\mathrm{Ru}$ & $\mathrm{s}^{2} \mathrm{~d}^{6}$ & $s p d^{6}$ \\
$\mathrm{Rh}$ & $\mathrm{s}^{2} \mathrm{~d}^{7}$ & $s \mathrm{sp}^{1.5} \mathrm{~d}^{6.5}$ \\
$\mathrm{Pd}$ & $\mathrm{s}^{2} \mathrm{~d}^{8}$ & $s p^{1.5} \mathrm{~d}^{7.5}$ \\
$\mathrm{Os}$ & $\mathrm{s}^{2} \mathrm{~d}^{6}$ & \\
$\mathrm{Ir}$ & $\mathrm{s}^{2} \mathrm{~d}^{7}$ & $s p \mathrm{~d}^{6}$ \\
$\mathrm{Pt}$ & $\mathrm{s}^{2} \mathrm{~d}^{8}$ & $s \mathrm{p}^{1.5} \mathrm{~d}^{6.5}$
\end{tabular}




\subsection{Acid-Base Reactions: Atomic Orbitals.}

It is easiest to describe and to visualize the generalized Lewis acid-base interaction from the overlap of the atomic orbitals of the constituent gaseous elements. This is done by relating the interaction through a Born-Haber-type cycle, as shown in Figures 2.1, 2.2, and 2.3.

As mentioned in Chapter 1, the Lewis acid-base interaction arises from nonbonding electron pairs overlapping with vacant orbitals which results in increased bonding and consequently in a net electron transfer. Consider again the example of the reaction of boron trifluoride with ammonia. The nonbonding electron pair on ammonia overlaps with the vacant orbital on boron. The result is a net increase in bonding around each central atom from 3 to 4 bonds and, consequently, a net increase in stability. If the partial charge of this compound is calculated by attributing one electron in each bonding pair to each central atom, then boron has 4 electrons and nitrogen has 4. Boron has one more electron and nitrogen one less. In effect, the nitrogen atom has donated one electron to the boron atom.

It is important to recognize that this type of donation must be distinguished from electron probability density. Simply because one electron in the bonding orbital is associated with boron and one electron is associated with nitrogen does not mean that the orbital is not skewed toward one of the two elements. The amount $\mathrm{of}$ skewing of the orbitals can be related to the difference in 
electronegativity of the two elements. As a result, the electron probability density may not indicate electron transfer in the same magnitude and direction as predicted from the partial charges.

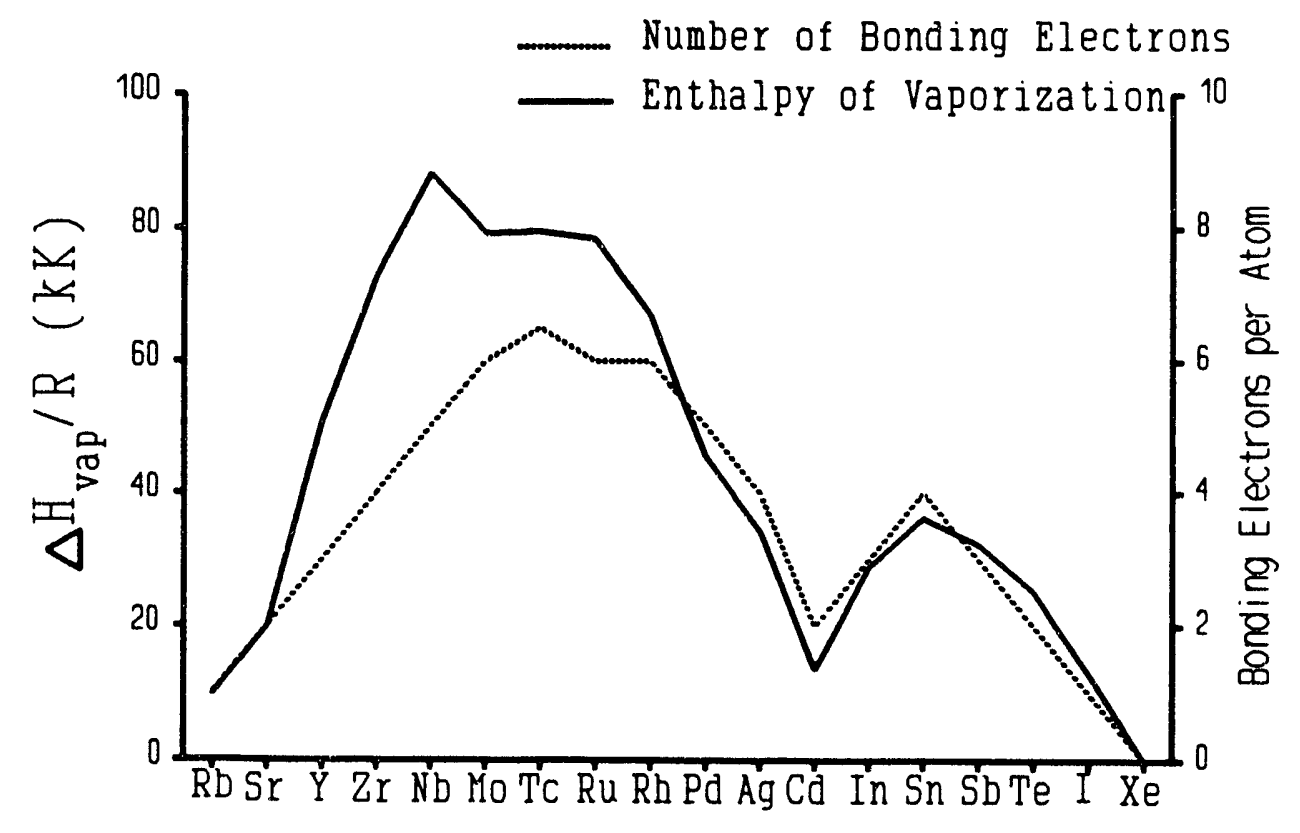

Figure 2.4. Enthalpy of vaporization plotted with the number of bunding electrons per atom.

The phenomena of the acid-base interaction in metals can be clarified by considering Figure 2.4, a superimposed plot of the enthalpy of vaporization as a function of atomic number and the number of bonding electrons as a function of atomic number. Note that Figure 2.4 shows two maximums in the number of bonding electrons: one around technetium and one at tin, the group VIIB-VIIIB and the group IVA metals. The number of bonding electrons per atom are given 
using the ground state electronic configuration for the solid metal calculated from the Born-Haber-type cycle already mentioned. If metals to the left of a maximum are mixed with metals to the right of a maximum, there will be a tendency for electrons to be transferred from the metal on the right to the metal on the left, making the alloy isoelectronic with a metal in between and, consequently, increasing the net bonding. Gallium arsenide is a good example of this tendency. Both gallium and arsenic have three bonding electrons per atom. When the two are mixed, one of the electrons on the arsenic is transferred to the gallium which results in 4 bonding electrons per atom, and a structure which is isoelectronic with silicon.

\subsection{Acid-Base Reactions: Molecular Orbitals.}

Some insight into the misconception of electron transfer can be obtained from a molecular orbital approach to the Lewis acid-base interactions. Three situations are considered in simplified manner in Figure 2.5. If the two overlapping orbitals of interest are the same in energy, then the overlap of a pair of electrons with a vacant orbital results in the two electrons being shared almost equally, case 3. If the orbitals are different in energy, then the electrons will be shifted slightly toward the atom with lower energy, cases 1 and 2. As the energy levels of two overlapping orbitals diverge, then the corresponding overlap decreases. The more the overlapping orbitals differ in energy the more 
nonbonding in character each atomic orbital becomes. Hence, as the overlap decreases the bonding orbital will become less bonding and will be more localized to the lower energy atomic orbital. Likewise, the anti-bonding orbital will become less anti-bonding and will be more localized to the higher energy atomic orbital. Figure 2.5 shows the three possible situations. The first is most like an ionic bond and the second and third are more like acid-base interactions. Interestingly, Figure 2.5 shows how similar electron transfer in acid-base interactions is to the electron transfer in the formation of ionic compounds. The second case is most like the group IIIB-VB with noble metal interactions, and the first case is most like the noble metal with group IIIA-IVA interactions. For the systems we have studied, the energy levels of the noble metals are lower in energy than in vanadium metal or the other Lewis acids. The important result is that the nonbonding orbital on the noble metal which overlaps with the vacant orbital on vanadium is more localized toward the noble metal than toward the vanadium due to this effect. As a result, the net distribution of bonding electrons is shifted toward the lower energy orbital and the anti-bonding electrons are shifted to the higher energy orbital. This is related to the concept of electronegativity because the more electronegative element will generally have bonding orbitals which are lower in energy than the electropositive. The end result is that electron transfer in terms of probability density is a function of two effect. First by nonbonding electrons overlapping with vacant orbitals and second by a redistribution of the electrons 
after the bond is formed. Consequently, the electron probability density is a function both of acid-base electron transfer and electronegativity. Regardless of the later redistribution effect, a net shift of probability density toward the more electropositive element should be observed in systems where there is a strong acidbase interaction.

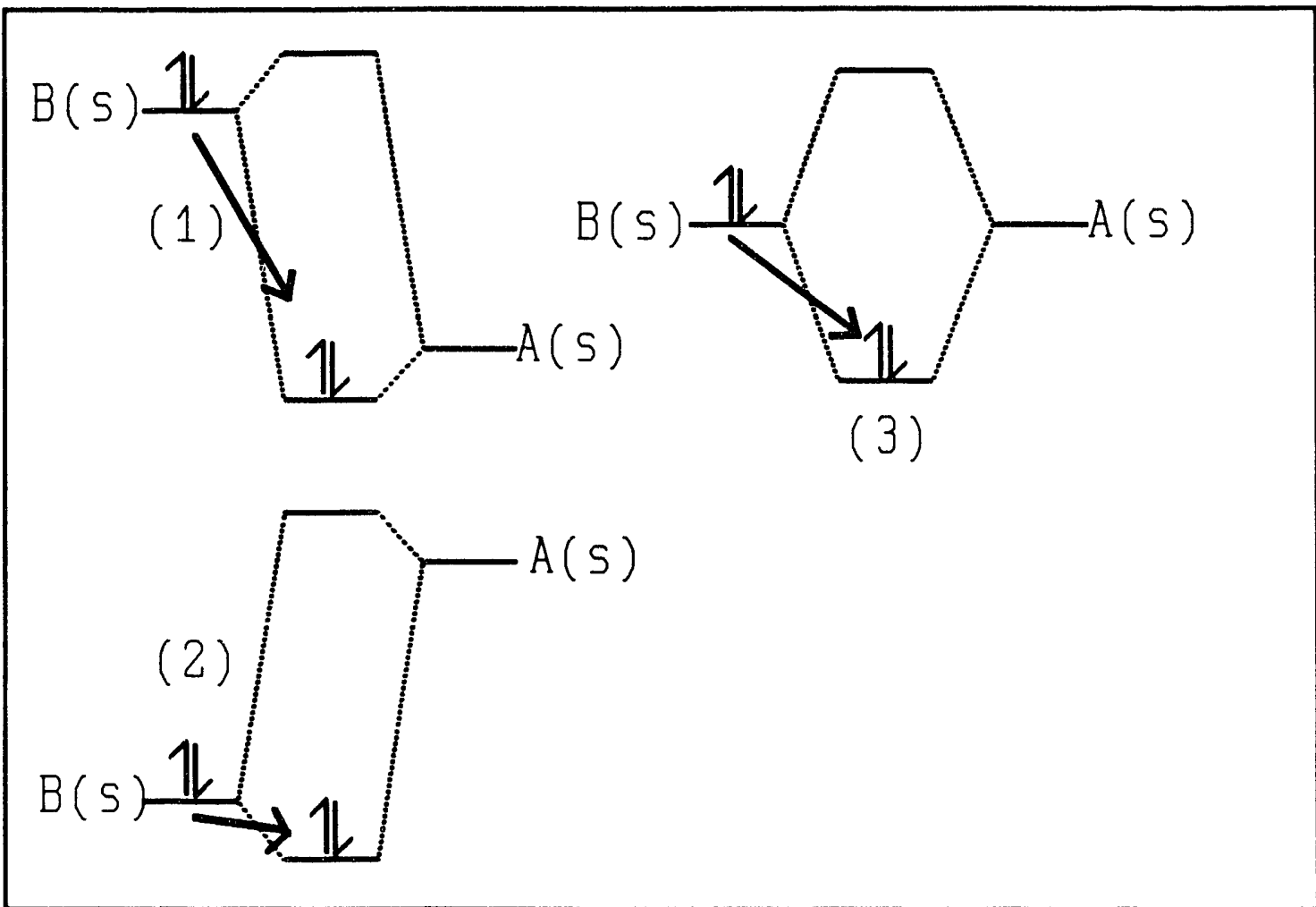

Figure 2.5 Molecular orbitals

A number of authors report a net charge transfer of electrons from the more electropositive to the more electronegative element in some of these acid-base systems. [7-9] This is consistent with what is expected from electronegativity, but this is not consistent with the electron transfer as described here. If the net electron transfer is indeed in the direction of electronegativity as these authors 
report, then these systems are examples where the backbonding factor due to electronegativity difference outweighs electron transfer from the acid-base interaction.

\subsection{Predicting Phase Diagrams.}

The prediction of intermetallic phase diagrams is related to the prediction of the structure of molecular species and ionic solids. Electron pair repulsions in molecular species make it possible to correlate the number of valence electrons with the observed structure. In ionic solids structures can be related to packing density and, consequently, to the relative atomic size.

Molecular Species and Network Covalent Solids-VSEPR

The valence-shell electron-pair repulsion theory, VSEPR, is a set of rules used to predict the structures of molecular species. It can also be applied to network covalent solids. Simply stated, electrons pairs, both bonding pairs and lone pairs, repel each other. The state of minimum energy is the one in which the electron pairs are furthest from each other around the central atom. As a result, geometric considerations are sufficient to predict any structure. Also, it can be observed that in systems where there is no $\pi$ bonding, the observed structure is correlated to the number of valence electrons. This correlation is illustrated in Table 2.2. 
For molecular species or network covalent solids, the valence electron concentration can be used to determine structures. Note that not just the number of electrons is important for determining the structure, but also what types of orbitals and bonds are involved. For example, if solid silicon was in the $s^{2} p^{2}$ configuration instead of in the $\mathrm{sp}^{3}$, then the resulting configuration would have to be one in which each silicon is only bonded to two others. This, of course, is not observed. Similarly, the $\mathrm{p}^{4}$ configuration is not consistent with the observed structure. Only the $\mathrm{sp}^{3}$ configuration can provide a bonding environment which is consistent with the structure of silicon. A more precise approach to correlating the structure to valence electron concentrations would include the relative concentrations of $\mathrm{s}, \mathrm{p}$, and d electrons independently.

Table 2.2. VSEPR-structure correlation.

\begin{tabular}{ll}
\hline valence $s+p e^{-}$ & structure \\
\hline 4 & tetragonal \\
5 & trigonal pyramid \\
6 & bent \\
7 & linear
\end{tabular}

\section{Ionic Solids}

In purely ionic solids, both cations and anions, have filled octets and the force which holds the atoms together is electrostatic and symmetric. Assuming that there are no covalent bonds in these systems to generate directional bonding, 
the relative stability is dominated by the packing density and the occupancy of sites to the overall charge neutrality. If the ions are assumed to be hard spheres and if there is no covalent bonding, the expected phases can be reduced to a correlation involving the relative atomic size of the cation to the anion. Table 2.3 shows the predicted correlations for ionic solids.

Table 2.3. Ideal structure correlation to atomic size.

\begin{tabular}{llll}
\hline $\mathbf{r}^{+} / \mathbf{r}^{-}$ & geometry & $\mathrm{AB}$ & $\mathrm{AB}_{2}$ \\
\hline $0.225-0.414$ & tetrahedral & wurtzite & zinc blende \\
$0.414-0.732$ & octahedral & $\mathrm{NaCl}$ & rutile \\
$0.732-1.000$ & cubic & $\mathrm{CsCl}$ & fluorite \\
$1.000-$ & dodecahedral &
\end{tabular}

Table 2.3 work well for many ionic solids. Some exceptions are $\mathrm{ZnS}$ and $\mathrm{HgS}$ which have $\mathrm{r}^{+} / \mathrm{r}^{-}$ratios of 0.52 and 0.68 respectively. The deviation here can be accounted for because these materials have a large degree of covalent bonding. Additionally, there are a number of solids which are expected to have the $\mathrm{CsCl}$ structure which instead have the $\mathrm{NaCl}$ structure. This is partially accounted for since the percent change in the packing density of $\mathrm{CsCl}$ and $\mathrm{NaCl}$ in the 0.732 1.00 range is very small.

Metallic Solids

In the covalent solids the concentration and types of bonding electrons determines the structure, and in ionic solids the relative atomic sizes and stoichiometry are the dominant factors. For metallic solids, it is reasonable to 
suggest that all of the above factors are correlated to the stability of phases. For systems with the same number and types of valence electrons, different phases that form should be correlated principally with the relative atomic radii. Likewise, for systems with the same relative atomic radii, the observed phases should be correlated principally to the concentration and types of valence electrons. These correlations, in general, are observed. Even systems which have strong Lewis acidbase interactions seem to be subject to these correlations. However, the strength of acid-base interaction can result in strong local ordering. As a consequence, the acid-base alloys form ordered versions of the expected structures. The strength of the interaction, also, can result in increasing or decreasing the normal composition range of stability of the expected phases.

\section{Hume-Rothery rules}

Hume-Rothery observed that for a large number of non-transition metal systems, the observed phases are strongly correlated to the average number of valence electrons per atom. Table 2.4 shows the maximum ranges for which each of the phases are observed.

Table 2.4. The Hume-Rothery rules.

\begin{tabular}{ll}
\hline valence $\mathrm{e}^{-}$ & observed high-temperature structure \\
\hline $0-1.5$ & body-centered cubic (bcc) \\
$1.7-2.12$ & hexagonal close-packed (hcp) \\
$2.5-3.0$ & face-centered cubic (fcc)
\end{tabular}


Hume-Rothery observed that this correlation did not work when transition metals were present in the alloy mixture. Hence, the presence of $d$ electrons in the alloy meant that the phases could not be correlated to the overall valence electron concentration even though most transition metals formed the simple bcc, hcp, and fcc structures.

It should be noted that the ranges given are the maximum ranges. The range of stability is narrowed by lowering the temperature or introducing atoms with different atomic radii. When the relative radii differ, other structures such as the Laves, $\sigma$, and $\mu$ phases are stabilized.

\section{Engel-Brewer extension to transition metals}

Whereas Hume-Rothery considered only the total number of electrons, Engel and Brewer state that not only the number but the types of electrons in bonding affect the observed structure.[1-5] They state that it is the $s$ and $p$ electrons only which affect the structure. The $d$ bonding is considered to be only nearest neighbor bonding and, consequently, it does not fix the long range order. The s and $\mathrm{p}$ orbitals will have some overlap with second nearest neighbors which will be a larger function of orientation than the $\mathrm{d}$ bonding. The end result is that the $\mathrm{s}$ and $\mathrm{p}$ electron concentration independent of the d electron concentration can be correlated to the observed structure. The difficulty in the Engel-Brewer correlation is determining what percentage of the valence electrons are in $\mathrm{s}$ and $\mathrm{p}$ orbitals and what percentage are in $\mathrm{d}$ orbitals. This can be accomplished by using a Born- 
Haber-type cycle as explained in section 2.2.

Summary and Use of the Engel-Brewer Correlation and Atomic Size Correlation

Table 2.5 is a summary of how the valence electron concentration is correlated to the structures which can form. The concentration of the $\mathrm{p}$ valence electrons increases going down the table. The number of $s$ electrons is assumed to be equal to one. For the total number of $s$ and $p$ electrons as correlated to the structure add one to the values listed in the first column.

Table 2.5. Structure-valence electron correlation

\begin{tabular}{lll}
\hline $\mathrm{p}$ & $\mathrm{s}+\mathrm{p}+\mathrm{d}^{*}$ & structure \\
\hline $0-0.5$ & & $\mathrm{bcc}$ \\
$0.5-0.75$ & & $\mathrm{Cr}_{3} \mathrm{Si}$ \\
$0.2-0.9$ & $5.6-7.7$ & $\sigma-$ Sigma \\
$0.2-1.0$ & $7.1-7.8$ & $\mathrm{P}$ \\
$0.2-1.0$ & $7.0-7.7$ & $\mu$ \\
$0.2-1.0$ & $6.4-7.3$ & $\mathrm{R}$ \\
$0.3-1.0$ & $6.3-7.0$ & $\mathrm{x}(\alpha-\mathrm{Mn})$ \\
$0.7-1.1$ & & $\mathrm{hcp}$ \\
$1.5-2.0$ & & $\mathrm{fcc}$
\end{tabular}

" this parameter varies if one component has no $\mathrm{d}$ valence electrons.

In addition to the ranges presented in Table 2.5, the structures, if they form, will appear in the following order of increasing $s+p$ electron concentration. $\mathrm{bcc} \leq \mathrm{Cr}_{3} \mathrm{Si} \leq \sigma \leq \mathrm{P} \leq \mu \leq \mathrm{R} \leq \chi(\alpha-\mathrm{Mn}) \leq \mathrm{hcp} \leq \mathrm{fcc}$ In conjunction with the information in Table 2.5 and the above trend, Talie 2.6 
shows how the relative atomic ratios and stoichiometry are related to the observed structures.

Table 2.6. Structure-relative atomic size correlation. $[13,14]$

\begin{tabular}{|c|c|c|}
\hline$r_{A} / r_{B}$ & stoichiometry & structure \\
\hline $1.00-1.37$ & Any & bcc(cI2) \\
\hline $1.00^{*}$ & Any & hcp(hP2) \\
\hline $1.00^{*}$ & Any & fcc(cF4) \\
\hline$>0.81$ & $A_{3} B^{*}$ & $\mathrm{Cr}_{3} \mathrm{Si}-\mathrm{A} 15(\mathrm{cP} 8)$ \\
\hline$\sim 1.0-1.1$ & $0.15 B-0.88 B$ & $\sigma-\mathrm{D} 8_{b}(\mathrm{tP} 30)$ \\
\hline $1.09-1.12$ & $0.14 \mathrm{~B}-0.40 \mathrm{~B}$ & $P(o P 56)$ \\
\hline $1.10-1.18$ & $0.50 \mathrm{~B}-0.57 \mathrm{~B}$ & $\mu-\mathrm{D} 8_{5}(\mathrm{hR} 13)$ \\
\hline $1.05-1.12$ & $0.10 \mathrm{~B}-0.82 \mathrm{~B}$ & R(hR53) \\
\hline $1.02-1.21$ & $A_{2} B_{3}-A_{3} B_{2}$ & $\mathrm{x}-\mathrm{A} 12(\mathrm{cl} 58)$ \\
\hline 1.19 & $A_{2} B$ & $\mathrm{Ti}_{2} \mathrm{Ni}-\mathrm{E} 9_{3}(\mathrm{cF} 112)$ \\
\hline 1.00 & $A_{2} B, A B_{2}^{*}$ & $\mathrm{Mo}_{2} \mathrm{Si}-\mathrm{C} 11_{b}(\mathrm{tI} 6)$ \\
\hline $1.081-1.499$ & $A_{2} B$ & $\mathrm{Cu}_{2} \mathrm{Al}-\mathrm{C} 16(\mathrm{tI} 12)$ \\
\hline 1.225 & $\mathrm{AB}_{2}$ & Laves \\
\hline
\end{tabular}

" emphasizes that one factor is dominant over the other.

bcc: random mixing favors the 1.00 and ordered mixing favors the 1.37

$A$ is the more electropositive element

$B$ is the more electronegative element

The use of Table 2.5 and Table 2.6 is sufficient to limit, often uniquely, the number of phases that are expected at any specified alloy composition. There are a number of areas where apparent conflicts in stability can uccur. If a conflict 
in stability is expected at a specified size ratio and $s+p$ electron concentration, the simple phases, body centered cubic, hexagonal close packed, and face centered cubic, are normally preferred to the other more complicated structures. The EngelBrewer correlation, although not absolutely precise, allows a simple and remarkably accurate method for predicting many equilibrium phase diagrams.

\subsection{Explaining the Engel-Brewer Correlation}

At this point, it is important to elucidate the factors underlying the EngelBrewer correlation so that the extent of its validity can be clearer. The correlation, although remarkably accurate, has limitations, for there sise some examples in which the correlation is inconsistent with the observed structures. Hume-Rothery in a review of the Engel-Brewer discusses some apparent limitations of the correlation in the following examples.[6]

$\mathrm{Na}$ and Li have been reported to have close-packed structures at low temperatures.[10-11] Since each has only one electron, the $1.7 \mathrm{~s}+\mathrm{p}$ electron limit is obviously not reached in these structures. Brewer has noted that these phases were obtained only by cold working the alkali metals at low temperatures, and consequently, he has expressed reservations about the hcp phase being the stable phase at low temperatures.[12] Another contradictory example is $\mathrm{Bc}$ which has a bec structure above $1250^{\circ} \mathrm{C}$, and this structure is expected to have $2 \mathrm{~s}+\mathrm{p}$ electrons which exceeds the 1.5 electron limit for the bcc structure. However, the 
promotion energy to transform $s^{2}$ to $s p$ is large. A better representation for this phase may be $s^{1.5} p^{0.5}$. This configuration is more consistent with that of the observed bec structure in the Engel-Brewer correlation.

Ti e bce versus close packed structures( $h c p$ and fcc)

Since the 1 electron metals, namely $\mathrm{L}$ and $\mathrm{Na}$, are the ones which seem to oppose the Engel-Brewer correlation, an explanation for their behavior is of most interest and will be pursued here. For the alkali metals, there will be very little difference in stability between the hcp and fcc phases since there is no directional bonding and the nearest neighbor bonding is identical in the two phases. However, the Donding in the bec structure differs significantly from that of the close-packed phases. In every system where a close packed phase and the bcc phase compete in stability, the bec structure is always more stable at hightemperatures. The only exception is iron which is stable in the bec phase at low temperatures, transfcrms to the fcc phase as the temperature is increased, and finally transforms back to the bec phase at high-temperatures. The stabilization of the bcc phase over the close-packed phases with increasing temperature can be explained by considering the enthalpy at $\mathrm{OK}$ and the heat capacity as a function of temperature for each of the phrses.

The greater packing density of the close-packed phases would be expected to yield a more negative enthalpy for the close-packed phase at $0 \mathrm{~K}$. There is an effect on the stability as the temperature is raised due to the change of the 
entropy and the enthalpy. This contribution is a function of the difference in the heat capacity of the two phases. The heat capacity of each phase is in turn related to the frequency of vibrations in the lattice by the Debye theory of solids.

Consider the following reaction

$2.1 \quad \mathrm{~A}(\mathrm{bcc})=\mathrm{A}(\mathrm{fcc}) ; \quad \Delta \mathrm{G}=\Delta \mathrm{H}_{0}^{\circ}-\mathrm{T} \Delta \mathrm{S}_{0}^{\circ}+\Delta \mathrm{C}^{\circ}$

$\Delta \mathrm{H}_{0}^{\circ}=$ enthalpy difference at absolute zero, negative

$\Delta S_{0}^{\circ}=0$ from the third law

$\Delta C^{\circ}=\Delta C_{\top}^{\circ}-\Delta C_{0}^{\circ}=$ entropy and enthalpy change as the temperature is increased, positive.

$2.2 \Delta C^{\circ}={ }_{0}^{\top} \Delta C_{p} d t-T_{0} \int^{\top} \Delta c_{p} / T d t$

From the Debye theory of solids the following is given

$2.3 \quad c_{p} \approx c_{v}=9 R(T / \theta)^{3} \int^{\int / T} x^{6} e^{x} /\left(e^{x}-1\right)^{2} d x$

If this equation is integrated numerically as a function of $T / \theta$ then $\Delta C^{\circ}$ can be accurately fit by the following polynomial equation

$2.4 \Delta C_{T}^{\circ}-\Delta C_{0}^{\circ}=A\left(T / \theta_{b c c}\right)\left(\theta_{b c c} / \theta_{f c c}-1\right)+B\left(T / \theta_{b c c}\right)^{3}\left(\theta_{b c c} / \theta_{f c c}-1\right)^{3}$

$A=-12.1915 ; B=-12.3826$

$R^{2}=1.000000=$ correlation coefficient squared

range $0.0<\mathrm{T} / \theta<10.0$

$\boldsymbol{\theta}_{\mathrm{fcc}}=$ Debye temperature for the fcc phase

$\theta_{b e c}=$ Debye temperature for the bcc phase

Also note that 


$$
\Theta=h w_{0} / 2 \pi k_{B}
$$

where

$h=$ Plank's constant; $w_{0}=$ Debye frequency; $k_{b}=$ Boltzman's constant

The Debye temperature is related to the structure, the strength of the bonds, and the reciprocal of the mass of the atoms. Since there is no mass change, only the structure and the bond strength vary between the fcc and bcc phases. Because of the denser packing of the fcc structure and because there is expected to be greater bond energy for the fcc structure, the value of $\theta_{f c c}$ is expected to be larger than $\theta_{\mathrm{bcc}}$. This implies that $\Theta_{\mathrm{bcc}} / \theta_{\mathrm{fcc}}<1$ which results in a positive contribution to the stability in Equation 2.4. Consequently, increasing the temperature will favor the bec structure.

From packing density considerations, the close-packed phases are expected to be more stable at lower temperatures. This condition seems to be true for $\mathrm{Li}$ and $\mathrm{Na} . \mathrm{K}, \mathrm{Rb}$, and $\mathrm{Cs}$, however, have not been observed to transform to either of the close-packed phases at lower temperatures. Either the transformaticn temperature is to low for atomic rearrangement to occur, or these phases are stable in the bec structure down to OK. The latter possibly implies that the enthalpy of formation for the bcc phase at OK is more negative than for the fcc phase. This is may be possible since the orbitals in $\mathrm{K}, \mathrm{Rb}$, and $\mathrm{Cs}$ are more delocalized than in $\mathrm{Li}$ and $\mathrm{Na}$. The increased packing density of the fcc phase may not provide any increased overlap for $K, R b$, and Cs. Regardless of which phase 
is stable at low temperatures, increasing the temperature always stabilizes the less dense bcc structure because $\theta_{\mathrm{bcc}} / \Theta_{\mathrm{fcc}}<1$.

The stability of hcp versus $f c c$

Since the packing density for spherical particles is nearly identical in these two structures, one would expect that the difference in stability is due primarily to the difference in directional bonding of the two systems. By examining the symmetry of the two systems, fcc and hcp, one will note that there is a difference in the orbital splitting due to the crystal field effect. For visual simplicity the orbitals in Figure 2.6 are drawn discretely rather than as bands. The point group of the fcc structure is $F m \overline{3} \mathrm{~m}$ with the point symmetry $O_{h}$. The point group in the hcp phase is $\mathrm{P} 6_{3} /$ mmc with a point symmetry of $\mathrm{D}_{6 h}$. The splitting of the orbitals from group theory is given in Table 2.7.

Table 2.7. Orbital splitting in fec and hep.

\begin{tabular}{lll}
\hline orbital & FCC & HCP \\
\hline$s$ & $A_{1 g}$ & $A_{1 g}$ \\
$p$ & $T_{1 u}$ & $A_{2 u}-p_{z}$ \\
& & $E_{1 u}-p_{x}, p_{y}$ \\
$d$ & $T_{2 g}-d_{x y}, d_{y z}, d_{x z}$ & $E_{1 g}-d_{x z}, d_{y z}$ \\
& $E_{g}-d_{z}^{2}, d_{x}^{2-y z}$ & $E_{2 g}-d_{x}^{2-y z}, d_{x y}$ \\
& & $A_{1 g}-d_{z}^{2}$
\end{tabular}


Note that there is a difference in the orbital splitting in the $\mathrm{p}$ and $\mathrm{d}$ orbitals. Suppose that the $A_{24}$ orbital in hcp is lower in energy than the $E_{14}$ orbital in hcp, and that the $A_{2 u}$ orbital in hcp is lower than the $T_{14}$ in fcc but less than the $E_{14}$ in hcp. Figure 2.6 shows this schematically. It can be seen that if about $1 \mathrm{p}$ electron is present then the hcp phase will be favored, but if their are 2 or more p electrons present then the fcc will tend to be favored. This, of course, will vary slightly due to the relative position of the orbitals, and this also assumes that splitting in the $d$ orbitals does not contribute substantially to the stability. However, a similar argument with the $d$ orbitals will result in the same conclusion if the $d_{z}^{2}$ orbital is lowest in energy.

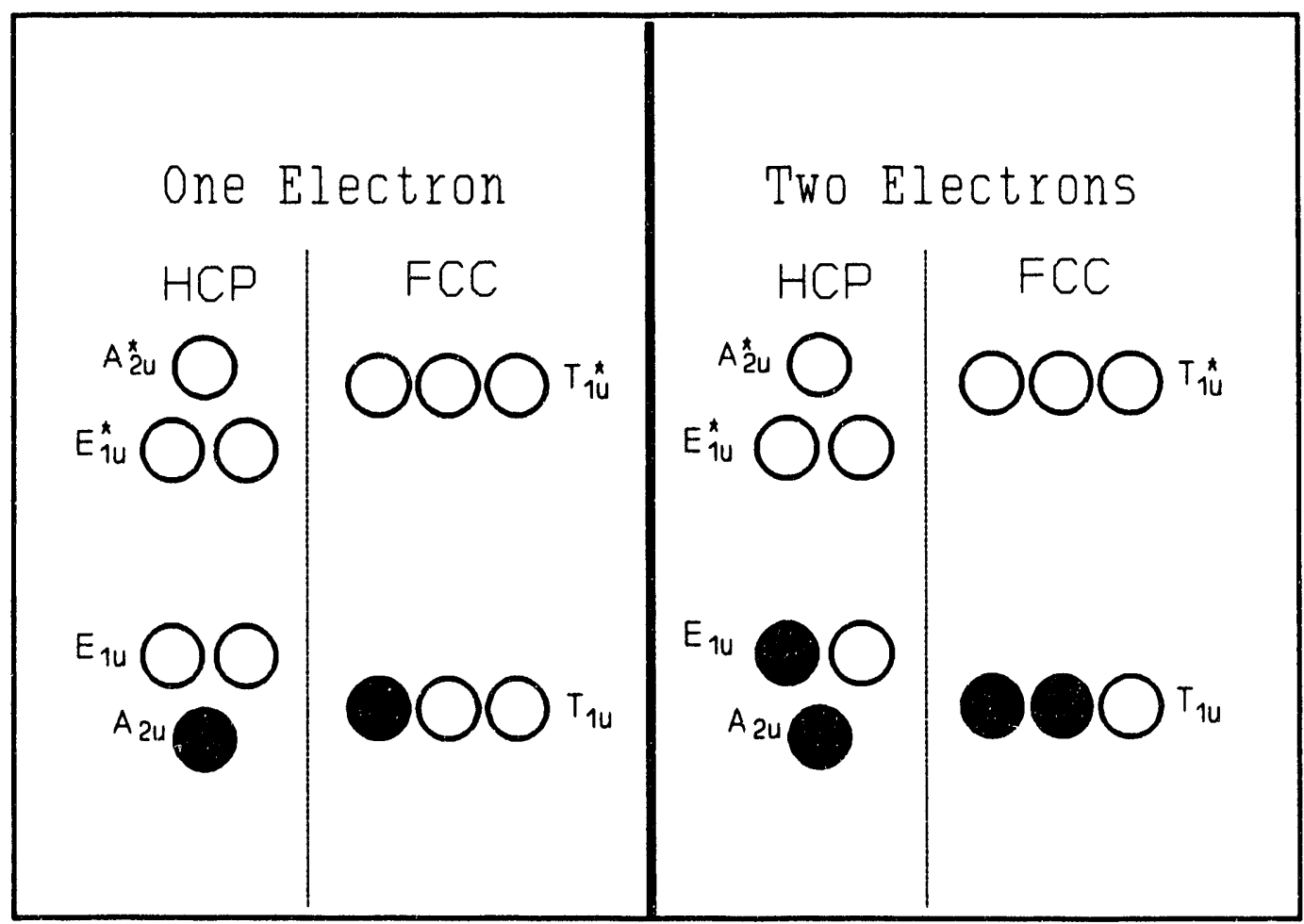

Figure 2.6. One $p$ electron suggests that the hcp phase has the minimum energy whereas two $p$ electrons suggest that the fcc phase has the minimum energy. 
As supporting evidence, it is common to observe in the hcp structures that the $c / a$ ratio is smaller than the ideal. This is consistent with the stronger overlap of the $\mathrm{p}_{2}$ orbital with second nearest neighbors that is suggested here. Table 2.8 shows a few examples comparing the ideal $c / a$ ratio to the observed $c / a$ ratio reported in Pearson's handbook of lattice parameters.[15]

Table 2.8. Ideal versus observed $c / a$ ratio.

\begin{tabular}{|c|c|c|c|}
\hline phase & $c / a$ & electro & onic configuration \\
\hline hcp(ideal) & 1.633 & & \\
\hline $\mathbf{L i}$ & 1.637 & $\mathbf{s}$ & \\
\hline $\mathrm{Na}$ & 1.634 & $\mathbf{s}$ & \\
\hline $\mathrm{Be}$ & 1.5681 & sp & \\
\hline $\mathbf{M g}$ & 1.6236 & sp & \\
\hline $\mathrm{Ba}$ & 1.578 & sp & -stable at high pressures \\
\hline $\mathrm{Sr}$ & 1.63 & sp & -stable only if $\mathrm{H}$ added \\
\hline Sc & 1.592 & spd & \\
\hline $\mathbf{Y}$ & 1.5719 & spd & \\
\hline La & 1.637 & spd & \\
\hline $\mathrm{Ti}$ & 1.5879 & $\mathrm{spd}^{2}$ & \\
\hline $\mathrm{Zr}$ & 1.593 & $\mathrm{spd}^{2}$ & \\
\hline Hf & 1.583 & $\mathrm{spd}^{2}$ & \\
\hline Tc & 1.605 & $\mathrm{spd}^{5}$ & \\
\hline $\operatorname{Re}$ & 1.6146 & $\mathrm{spd}^{5}$ & \\
\hline $\mathrm{Fe}$ & 1.603 & $\mathrm{spd}^{6}$ & -stable at high pressure \\
\hline $\mathbf{R u}$ & 1.583 & $\mathrm{spd}^{6}$ & \\
\hline Os & 1.5790 & $\mathrm{spd}^{6}$ & \\
\hline Co & 1.623 & $\mathrm{spd}^{7}$ & \\
\hline $\mathrm{Zn}$ & 1.8562 & $\mathrm{spd}^{10}$ & \\
\hline Cd & 1.8856 & spd $^{10}$ & \\
\hline
\end{tabular}


The only exceptions to the c/a ratio being less than ideal seem to be $\mathrm{Zn}$ and $\mathrm{Cd}$ which have a considerably larger than ideal $\mathrm{c} / \mathrm{a}$ ratio. For these systems the $\mathrm{p}$ orbitals are more contracted relative to the $\mathrm{s}$ orbital. It may be that the $\mathrm{p}$ orbitals do not extend far enough in space to overlap with second nearest neighbors. To compensate for this the opposite effect occurs. The c/a ratio increases to align the $\mathrm{p}_{2}$ orbitals on the first nearest neighbors for better overlap. This, however, does not explain why $\mathrm{Zn}$ and $\mathrm{Cd}$ would prefer the hcp structure unless the $\mathrm{p}_{2}$ overlap is better in the distorted hcp structure than for the degenerate $p$ overlap in the fcc structure.

Note, also, in Table 2.8 that the $\mathrm{c} / \mathrm{a}$ ratio for both $\mathrm{Li}$ and $\mathrm{Na}$ in the hcp structure are close to the ideal. Since there is no $\mathrm{p}$ or $\mathrm{d}$ bonding in these systems, a distortion of the c/a ratio from the ideal is not expected.

The effect of $d$ electrons

The effect of $d$ electrons on the structure is uncertain. It is known that for a large number of systems that the $s+p$ valence electron concentration alone is sufficient to determine the equilibrium structure. For the hep and fcc systems, the nearest neighbor environment is similar enough so that the $d$-d bonding would be nearly the same in energy. Hence, one would not expect the $d$ bonding to make a large difference in the relative stability of the hcp and fcc phases. For the close packed relative to the bcc phases, the $d$ electrons probably play some roll. For example, lithiurn has already been mentioned as having the cubic closed packed 
structure at low temperatures and the body centered cubic structure at high temperatures. The electronic configuration is $s^{1}$ for lithium. Vanadium solid, however, is in the bce structure at high temperatures and at low temperatures. Vanadium has the configuration $s^{1} d^{4}$. Perhaps the $d-d$ bonding in vanadium is stabilizing the bcc structure. Still the $s$ and $p$ orbitals should tend to dominate the stability since their orbitals are more extended in space relative to the $d$ orbitals.

\section{Correlation using Hybridization}

Hume-Rothery has approached the topic of explaining the Engel-Brewer correlation between electron concentration and structure.[16] His approach is to consider all hybrids which direct their orbitals toward the nearest neighbor atoms for each of the three common structures: bcc, hcp, and fcc. The closer the electronic configuration of the metal matches those of the hybrids which direct their orbitals toward nearest neighbors, the more that that particular structure will tend to be favored. Considering the electronic configurations of the hybrids should give some idea as to the number of $\mathrm{s}, \mathrm{p}$, and $\mathrm{d}$ electrons as they correlate to the observed structure. Table 2.9 summarizes the hybrids suggested by Hume-Rothery that are directed toward nearest neighbor atoms.

Note that in the configurations which have their orbitals directed to the nearest neighbors, the real configuration would be expected to be a mixture of these configurations. Looking only at the number of $\mathrm{p}$ electrons, it can be seen that if there are no $\mathrm{p}$ electrons, the expected structure tend to be bcc. As the 
number of $p$ electrons is increased the expected structure would tend to change to hcp, around one $\mathrm{p}$ electron. As the number of $\mathrm{p}$ electrons is further increased, the fcc structure will be stabilized. This trend is consistent with the Engel-Brewer correlation. The weakest point to this approach is that the stability is attributed entirely to $\sigma$ bonding. Some stability will, of coarse, be due to $x$ bonding of the orbitals. These hybrids also indicate that the $s$ and $\mathrm{d}$ electron concentrations will also contribute to the relative stability.

Table 2.9. Structure - Hybrids Correlation.[18]

\begin{tabular}{|c|c|}
\hline crystal structure & hybrids assumed \\
\hline \multirow[t]{3}{*}{ bcc } & $\mathrm{sd}^{3}$ closest neighbor(pure $\mathrm{g}$ ) \\
\hline & $d^{4}$ closest neighbor(pure g) \\
\hline & $d^{3}$ second closest neighbor(pure g) \\
\hline \multirow[t]{2}{*}{ hcp } & $s d^{2}$ neighbor in basal plane(pure $g$ ) \\
\hline & $\begin{array}{l}\mathrm{pd}^{5} \text { neighbors in planes above and below } \\
\operatorname{spd}^{4} " \quad \text { (mixed } \mathrm{g} \text { and } \mathrm{u} \text { ) }\end{array}$ \\
\hline fcc & $p^{3} d^{3}$ mixed $g$ and $u$ \\
\hline
\end{tabular}

\subsection{The Calculation of Phase Boundaries}

Knowledge of atomic size and electronic configuration can be used to predict which structures can or cannot form. These parameters are sufficient for the prediction of the maximum range of stability of a phase within an intermetallic system. To predict the real range of stability, some knowledge of the cohesive 
energy as a function of concentration is necessary. This is often reduced to a simple pairwise interaction model. The simplest non-ideal case is Hildebrand's regular solution theory which is reviewed later.[17] From his theory, the interaction can be priedicted from the enthalpy of vaporization and the molar volume of the constituent elements. For a large number of systems, this approach or slight modifications to it are sufficient to complete the information needed to predict phase diagrams.

Currently, the acid-base interactions which occur in intermetallics cannot be modeled quantitatively. As a consequence, to obtain intermetallic phase diagrams of these alloy systems, either they must be determined experimentally or some model of the cohesive energy as a function of composition must be generated. This is one of the specific goals for which this project is aimed. The end result would be the ability to predict a reasonable equilibrium phase diagram for any intermetallic system. 


\section{References}

1. L. Brewer,"Prediction of Transition Metal Phase Diagrams," J. Nuclear Mater., 51, 2-11 (1974).

2. L. Brewer, "Transition Metal Alloys - A Chemist's View," AIP Conference Proceedings No. 10, Magnetism and Magnetic Materials (1972).

3. L. Brewer, "Viewpoints on the Stability of Metallic Structures," paper in Phase Stability in Metals and Alloys, P. Rudman, J. Stringer, and R.I. Jaffe, eds., McGraw-Hill Book Co., New York, NY, 39-61 (1967).

4. L. Brewer, "Prediction of High Temperature Metallic Phase Diagrams," paper in High Strength Materials, V.F. Zackay, ed., John Wiley and Sons, New York, NY, Chapter 2, 12-103 (1965).

5. L. Brewer, "The Role and Significance of Empirical and Semiempirical Correlations," paper in Structure and Bonding in Crystals, Vol 1, Chapter 7, 155-174, Academic Press, New York (1981).

6. W. Hume-Rothery, "The Engel-Brewer Theories of Metals and Alloys," Prog. Mat. Sci., 13(5), 231-265 (1967).

7. C. Koenig, "Self Consistent Band Structure of Ordered $\operatorname{ScPd}_{3}$ and $\mathrm{YPd}_{3}$," $Z$. Phys. B, 50, 33-38 (1983).

8. M. Domke, C. Laubschat, E. V. Sampathkumaran, M. Prietsch, T. Mandel, G. Kaindl, and H. U. Middelmann, "Bulk and Surface Valence in $\mathrm{YbPd}_{x}$ Compounds," Phys. Rev. B, 32(12), 8002-8006 (1985).

9. A. Amamou and R. Kuentzler, "Electronic Structure and Atomic Arrangement in VPt System," Solid Stale Commun., 43(6), 423-429 (1982).

10. C. S. Barrett, "X-ray Study of the Alkali Metals at Low Temperatures," Acta Cryst., 9, 671-677 (1956). 
11. A. P. Frolov and K. P. Rodionov, "High-Pressure phase Transitions in Lithium," Soviet Physics - Solid State, 16(11), 2297-2298 (1975).

12. L. Brewer, "A Most Striking Confirmation of the Engel Metallic Correlation," Acta Metall., 15, 553-556 (1967).

13. M.V. Nevit, "Alloy Chemistry of Transition Elements," paper in Electronic Structure and Alloy Chemistry of the Transition Elements, Paul A. Beck, ed., Interscience Publishers, New York, 63 (1963).

14. R.E. Watson, L.H. Bennett, "Overview No. 36, Transition-Metal Alloy Formation. The Occurrence of Topologically Close Packed Phases-I," Acta Metall., 32.(4), 477-489 (1984).

15. P. Villars and L. D. Calvert, Pearson's Handbook of Crystallographic Data for Intermetallic Phases, American Society for Metals, Metals Park, OH (1985).

16. S. L. Altmann, C. A. Coulson, and W. Hume-Rothery, "On the Relation Between Bond Hybrids and the Metallic Structures," Proc. Roy. Soc., 240A, 145-159 (1957).

17. J. H. Hildebrand, Solubility of Non-Electrolytes, $2^{\text {nd }}$ Ed., American Chemical Society Monograph Series, Reinhold Publishing Corp., New York (1936). 


\section{Chapter 3}

\subsection{Introduction to Thermodynamic Activities.}

The thermodynamic quantity that is of interest in this work is the partial molar Gibbs energy of vanadium in the noble metals as a function of concentration. Normally the parameter called activity or fugacity is used in place of the partial molar Gibbs energy. The relationship between the activity or fugacity and the partial molar Gibbs energy is given below.

$$
\left(\partial G / \partial X_{A}\right)_{T, P}=\mu_{A}=\mu_{A}^{\circ}+R T \ln a_{A}
$$

or equivalently as

$$
\left(\partial G / \partial X_{A}\right)_{T, P}=\mu_{A}=\mu_{A}^{\prime}+R T \ln f_{A}
$$

Note that the Gibbs energy in Equations 3.1 and 3.2 and also elsewher? is divided by the total number of moles in the system.

The relationship between activity and fugacity is

$$
a_{A}=f_{A} / f_{A}
$$

when

$$
\begin{aligned}
& a^{\circ}=1=\text { the activity of the pure component } A \\
& \mathrm{f}_{A}^{A}=\text { the fugacity of } A \text { under standard conditions }
\end{aligned}
$$

Note that

$$
\mu_{A}^{\prime}=\mu_{A}^{\circ}-R T \ln f_{A}
$$


and

$$
\mu_{A}^{\circ}=\text { the chemical potential of the pure element }
$$

the fugacity $f$ is defined such that

$$
f_{A} \rightarrow P_{A} \text { as } P_{A} \rightarrow 0
$$

$P_{A}$ is the partial pressure of the gaseous species $A$.

The activity is defined here such that

$$
a_{A} \rightarrow X_{A} \text { as } X_{A} \rightarrow 1
$$

where

$$
X_{A}=\text { the mole fraction of substance } A
$$

In some cases, such as dilute solutions, it is more convenient to define the limiting conditions on the activity as follows

$$
a_{A} \rightarrow X_{A} \text { as } X_{A} \rightarrow 0
$$

Note that the activity coefficient for alloys is defined

$$
\boldsymbol{\gamma}_{\mathbf{A}}=\mathbf{a}_{\boldsymbol{A}} / \mathrm{X}_{\mathrm{A}}
$$

where

$$
\gamma_{A}=\text { the activity coefficient of component } A
$$

The physical meaning of activity is less clear than the physical meaning of mole fraction. One way to describe activity is as the escaping ability of an atom in a solution relative to its escaping ability in the defined reference state. The activity coefficient is a measure of the interactions of $A$ atoms with its neighbors relative to the interactions of $\mathrm{A}$ atoms with its neighbors in the defined reference 
state. The activity coefficients of A and B can be approximately related to the enthalpy of formation by the following equation if the excess entropy is neglected.

$$
\Delta H_{f} \approx R_{A X} \ln \gamma_{A}+R_{B X} \ln \gamma_{B}
$$

Vapor pressure measurements

One way to obtain activities of constituent elements in alloys is through the measurement of gaseous species in equilibrium with an alloy solid at a specified remperature.

For

3.9

$$
\mathbf{A}(\mathbf{s})=\mathbf{A}(\mathbf{g})
$$

using $P_{A}=f_{A}$ the activity is given by

$$
a_{A}=P_{A} / P_{A}^{\circ}
$$

where $P_{A}^{\circ}$ is the partial pressure of $A(g)$ in equilibrium with $A(s)$ in its standard state. J. Bularzik[1], D. E. Peterson[2-4], and K. A. Gingerich, et al.[5] have used this approach to measure activities of the elemental constituents in these acidbase stabilized alloys.

\section{Equilibration measurements}

An alternate method for obtaining thermodynamic activities is to equilibrate the alloy with a material of known thermodynamic properties. More specifically we equilibrate the alloy with an oxide or carbide of known thermodynamics. This is a good approach for the systems studied here because the thermodynamics of the group IV and V transition metal oxides and carbides are well known. Also the platinum-group metals have the fortunate property that their oxides and carbides 
are either barely stable or unstable. Because the noble metal oxides and carbides have small heats of formation, the high noble metal content alloys are fairly resistent to ternary oxide or carbide formation. In general, for many of the acidbase(NM)-O or acid-base(NM)-C ternary phase diagrams few ternary phases have been found.[6,7] In the V-NM-O and the V-NM-C systems no ternary phases have been found which might interfere with equilibration measurements. Fortunately, for these systems when ternary alloy formation does not occur, alloys nearly void of oxygen(carbon) can be equilibrated with oxides(carbides) nearly void of noble metal. In this way, the thermodynamics of the binary oxide(carbide) fix the thermodynamics of the ternary system to a good approximation since little noble metal is observed to be present in these oxides. The activity calculated by considering the binary V-O or the V-C equilibria can be used in the equilibria of the ternary V-O-NM or the V-C-NM systems.

\subsection{Ternary Phase Equilibria.}

As mentioned, there are two types of equilibria used here, the carbide equilibria, and the oxide equilibria. The V-O, the V-C binary phase diagrams are presented in Figures 3.1 and 3.2 respectively.

The Oxygen-Vanadium System

The vanadium oxides have a number of interesting properties and, consequently, have been proposed for a variety of uses. For example, they have 
been proposed for use as the internal lining in nuclear reactors. [9] Also, they have been proposed for use as thermochromic switches on solar cells to keep them from overheating.[10] Many of the vanadium oxides undergo semiconductor to metal transitions which affect both the electrical conductivity and the optical reflectivity. This system contains two series of Magnelli phases. One series, which extends from $\mathrm{V}_{2} \mathrm{O}_{3}$ to $\mathrm{VO}_{2}$, is of the form $\mathrm{V}_{n} \mathrm{O}_{2 n-1}$ and it is structurally similar to the $\mathrm{TiO}_{2-\mathrm{x}}$ phases. Another series, which appears in the range $\mathrm{VO}_{2}$ to $\mathrm{V}_{2} \mathrm{O}_{5}$, is of the form $\mathrm{V}_{n} \mathrm{O}_{2 n+1}$. There are actually two structural forms of $\mathrm{VO}_{2}$ reported in the literature, one corresponding to the limiting condition of each Magnelli series.[11] Of primary interest in this system is the large number of stable oxides which occur. Consequently, there are many two phase equilibria where the activity of vanadium is fixed and readily calculated.

The stable oxides of interest in the oxygen-vanadium system at $1000^{\circ} \mathrm{C}$ are, $\mathrm{V}_{4} \mathrm{O}, \mathrm{V}_{2} \mathrm{O}, \mathrm{VO}, \mathrm{V}_{2} \mathrm{O}_{3}, \mathrm{~V}_{3} \mathrm{O}_{5}, \mathrm{~V}_{4} \mathrm{O}_{7}, \mathrm{~V}_{5} \mathrm{O}_{9}, \mathrm{~V}_{6} \mathrm{O}_{11}, \mathrm{~V}_{7} \mathrm{O}_{13}, \mathrm{~V}_{8} \mathrm{O}_{15}, \mathrm{VO}_{2}$. As seen in the phase diagram there are some additional phases which are stable at lower temperatures. The large number of phases would at first seem to imply that a large number of points in the activity versus concentration curve can be obtained for vanadium with noble metals. This, unfortunately, is not the case. There is a very small activity drop across the $\mathrm{V}_{2} \mathrm{O}$ phase. Hence, the $\mathrm{V}_{4} \mathrm{O}-\mathrm{V}_{2} \mathrm{O}$ equilibria and $\mathrm{V}_{2} \mathrm{O}$-VO equilibria yield two points very close in activity and therefore in composition of the alloy phase in equilibrium with oxide or carbide pairs. In 
addition, there is an enormous activity drop across the $\mathrm{V}_{2} \mathrm{O}_{3}$ phase, about six orders of magnitude at $1000^{\circ} \mathrm{C}$.[12] The activity of vanadium is so low in phases which contain higher than $1.5 \mathrm{~V} / \mathrm{O}$ atom ratios that they are in equilibrium with nearly pure noble metals. Generally, these points yield no useful information. Since the equilibrated alloy has so little vanadium in it, the amount cannot be measured accurately and, consequently, the activity coefficient cannot be accurately obtained. Consequently, there are really only 3 useful points obtained from ternary oxide equilibria in the vanadium-oxygen system. For noble metals which interact very strongly with vanadium, the $\mathrm{V}_{2} \mathrm{O}_{3} / \mathrm{V}_{3} \mathrm{O}_{5}$ equilibria is also useful. Consequently, for the V-Pt and the V-Ir systems the fourth equilibria point is useful.

The Carbon-Vanadium System

There are four carbide phases of interest in the V-C carbon system at $1000^{\circ} \mathrm{C}, \mathrm{V}_{2} \mathrm{C}, \mathrm{V}_{4} \mathrm{C}_{3}, \mathrm{VC}$, and $\mathrm{C}$. Consequently, there are three different equilibria of interest in the V-C system: $\mathrm{V}_{2} \mathrm{C} / \mathrm{V}_{4} \mathrm{C}_{3}, \mathrm{~V}_{4} \mathrm{C}_{3} / \mathrm{VC}$, and $\mathrm{VC} / \mathrm{C}$. In other words, there are three pairs of alloy compositions for which the activity of vanadium can be obtained from ternary carbide equilibria. However, the activity drop across $\mathrm{V}_{4} \mathrm{C}_{3}$ is extremely small.[13] Therefore, the equilibria $\mathrm{V}_{2} \mathrm{C} / \mathrm{V}_{4} \mathrm{C}_{3}$ and $\mathrm{V}_{4} \mathrm{C}_{3} / \mathrm{VC}$ are nearly identical in activity and hence in composition. The two equilibria in effect yield only one datum point. Consequently, the ternary V.C-NM(noble metal) equilibria can only provide two useful points of the activity versus concentration of vanadium curve. 


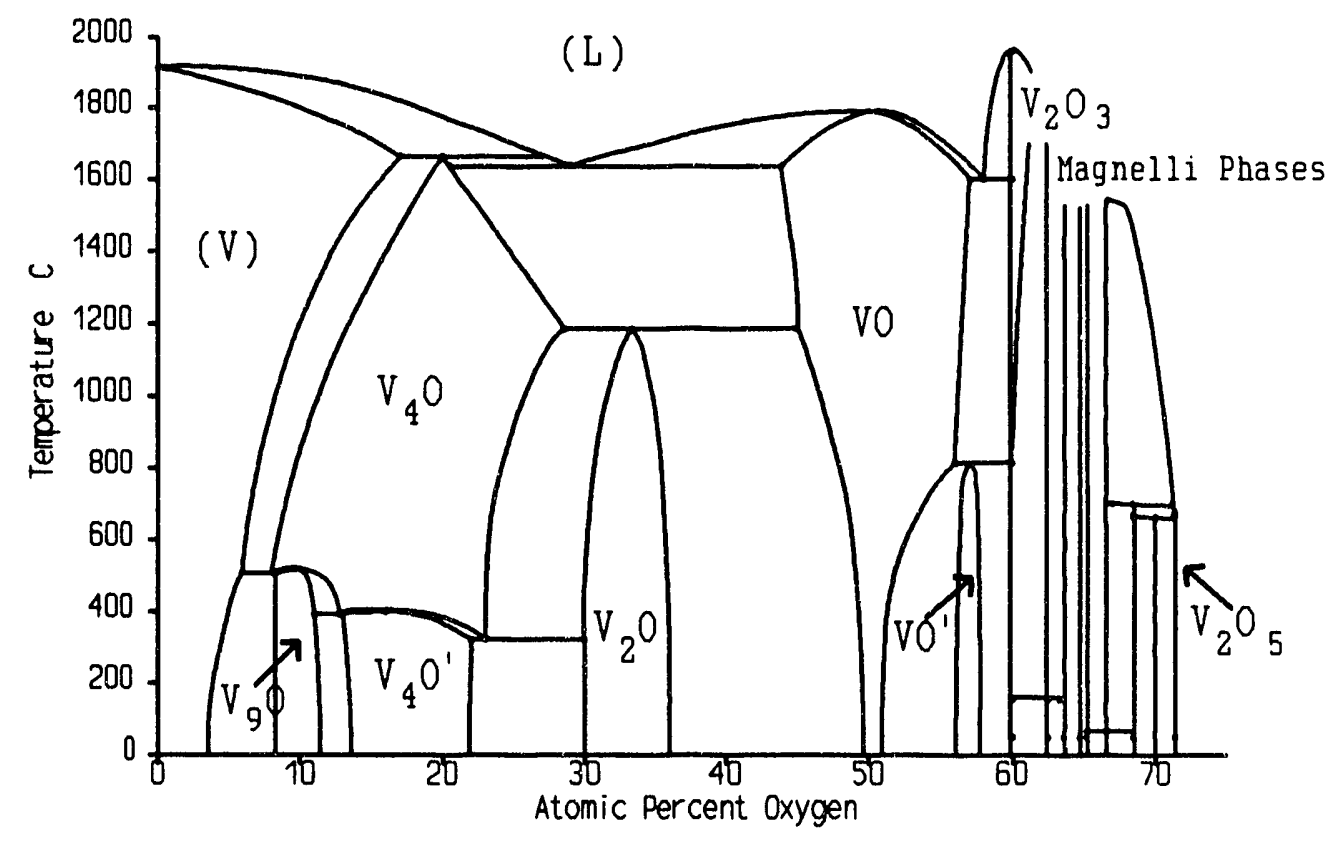

Figure 3.1. The oxygen - vanadium system [8]

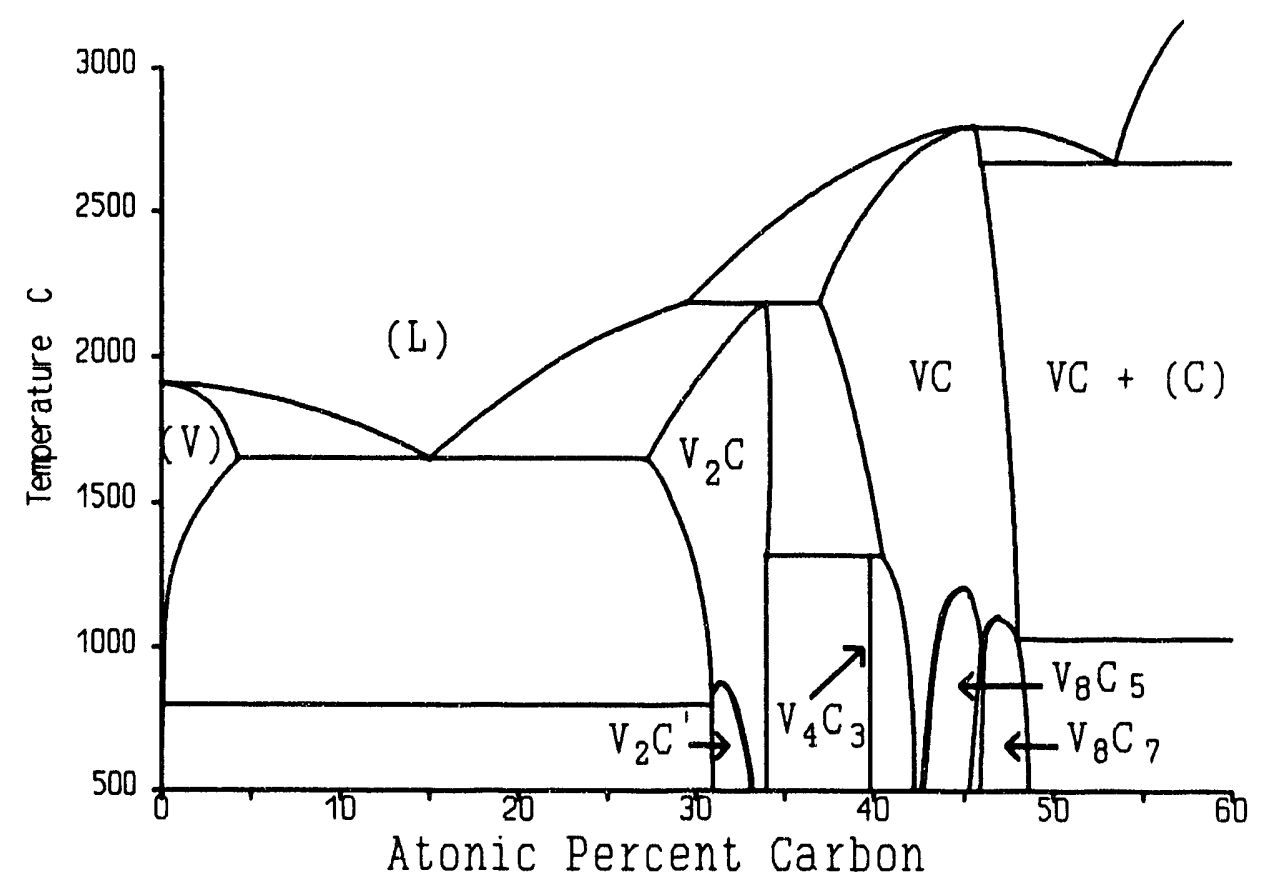

Figure 3.2 The carbon - vanadium system [13] 
By using both carbide and oxide equilibria a total of five useful data points can be obtained. Consequently, other experiments are required in order to obtain a more complete picture of the interaction of vanadium with the platinum-group metals. To achieve this, the high-temperature galvanic cell is used.

\subsection{The Galvanic Cell Technique.}

Ternary oxide and carbide equilibria are only able to give a few points in the V-NM titration curves. To obtain data points at other compositions, that is points where only one oxide phase is present in the composite, the high temperature galvanic cell is needed. Using the Gibbs phase rule we know that for a two component system, if the temperature and pressure are fixed, then there can only be two phases in equilibrium. More importantly, for a two phase mixture at a constant temperature and pressure, the activities of each of the components are fixed since the degree of freedom is zero. If there is only one oxide phase present, then more information is needed to fix the activity since the degree of freedom is one, but only the activity of one component is needed since it will fix the activity of the other.

The Gibbs Phase rule is

$$
C-P+2=F
$$

$\mathrm{C}=$ the number of components, $\mathrm{P}=$ the number of phases, $\mathrm{F}=$ the number of degrees of freedom. For a two component system $C=2$. With two phases $P=$ 
2. This implies that $\mathrm{F}=2$. Or if temperature and pressure are fixed $\mathrm{F}=0$.

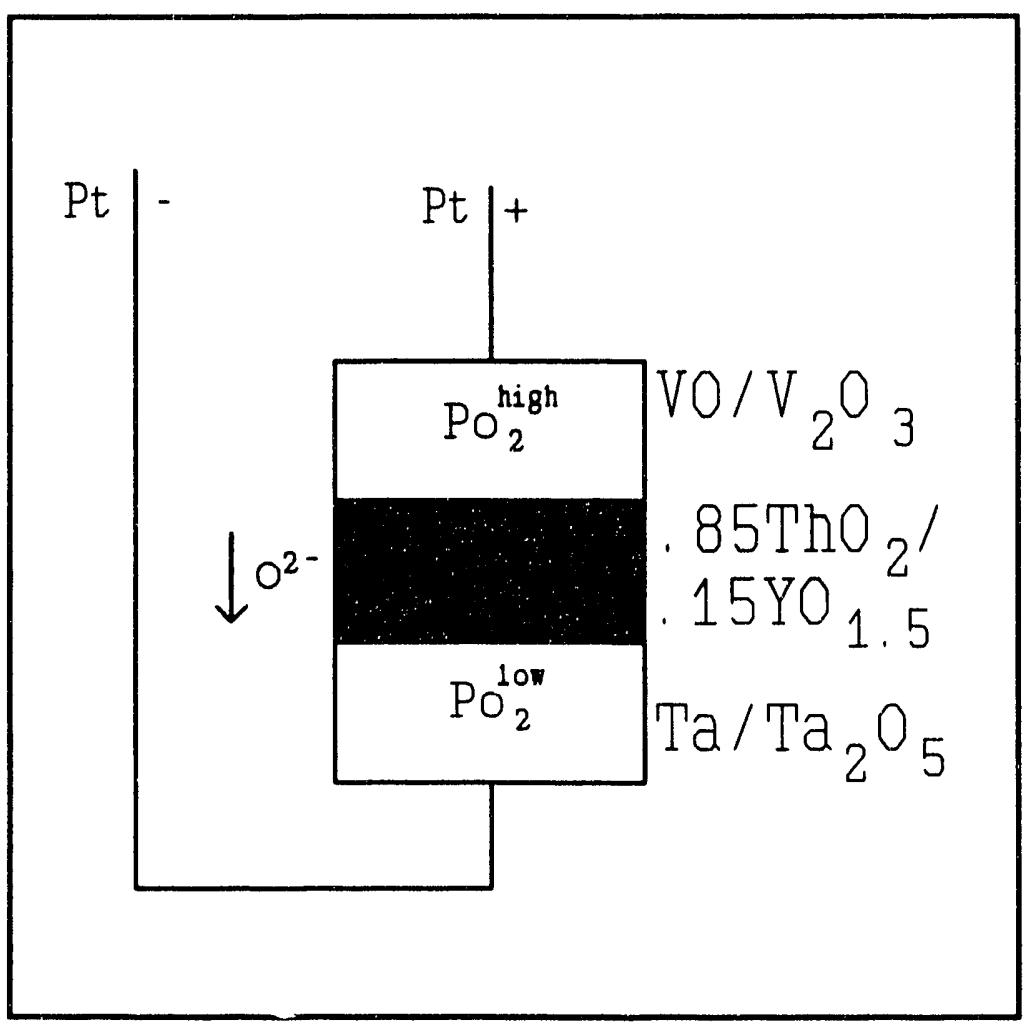

Figure 3.3. A schematic of the electrodes an electrolyte in a high-temperature galvanic cell.

In oxide systems, the activity of oxygen can be calculated using a hightemperature EMF technique. This is an electrochemical cell which measures the ratio of the partial pressure of oxygen at the two electrodes. Figure 3.3 outlines the basic concept behind the galvanic cell operation. The electrolyte is an ionic conductor for oxygen ions. The electrodes on each side of the electrolyte contain various oxides which have a fixed $\mathrm{Po}_{2}$ in equilibrium with them at a specified temperature. For the reference electrode, the partial pressure of oxygen that is equilibrium with it must be well known at the temperatures of interest. The 
Nernst equation relates the EMF generated to the difference in the natural log of the partial pressure of oxygen. See Equations 3.13 and 3.14.

\section{Ionic Conductors}

The operation of the galvanic cell requires an electrolyte which ionically conducts the species of interest and additionally has a low electronic conductivity. In this case, $\mathrm{O}^{2-}$ ions are the conducted species. This typically requires a temperature greater than $800^{\circ} \mathrm{C}$ for adequate conduction in the thoria based electrolytes. The electrolytes used here are all based upon the fluorite structure, $\mathrm{CaF}_{2}$, yttria doped thoria(YDT), lanthana doped thoria(LDT), and $\mathrm{ThO}_{2}$. The electronic conductivity is low compared to the ionic conductivity in these systems. Consequently, these materials make good electrolytes for measuring electrochemically the partial molar Gibbs energy of oxygen in various systems.

Table 3.1. Pressure of $\mathrm{CaF}_{2}(\mathrm{~g})$ in equilibrium with $\mathrm{CaF}_{2}(\mathrm{~s}) .[14]$

\begin{tabular}{ll} 
temperature $\left({ }^{\circ} \mathrm{C}\right)$ & pressure of $\mathrm{CaF}_{2}(\mathrm{~g})$ \\
\hline 800 & $4.0 \times 10^{-13}$ \\
900 & $2.2 \times 10^{-10}$ \\
1000 & $6.3 \times 10^{-9}$ \\
1100 & $1.1 \times 10^{-7}$
\end{tabular}

For YDT, $\mathrm{LDT}$, and $\mathrm{ThO}_{2}$, the amount of vaporization of the electrolyte is insignificant at these temperatures. 
In many ways the best electrolyte to be used for our experiments would seem to be $\mathrm{CaF}_{2}$. However, this electrolyte does not work well at temperatures nearing $1100^{\circ} \mathrm{C} . \mathrm{CaF}_{2}$ vaporizes causing a depletion of the electrolyte during an experiment. Table 3.1 shows that the partial pressure of $\mathrm{CaF}_{2}(\mathrm{~g})$ in equilibrium with $\mathrm{CaF}_{2}(\mathrm{~s})$ at temperatures nearing $1100^{\circ} \mathrm{C}$ is large enough that a significant loss of the electrolyte will be observed.

For the proper use of ionic conductors, it is necessary that the ionic conductivity of the electrolyte is large compared to the electron conductivity of the electrolyte. The ionic transference number is the parameter of an electrolyte system which is used to describe the ionic conductivity relative to the total conductivity. It is defined as follows.

$$
\mathrm{t}_{\text {ion }}=\sigma_{\text {ion }} / \sigma_{\text {total }} ; \sigma_{\text {total }}=\sigma_{\text {ion }}+\sigma_{\mathrm{h}}+\sigma_{\mathrm{e}}
$$

where

$$
\begin{aligned}
& \sigma_{i o n}=\text { the ionic conductivity } \\
& \sigma_{\mathrm{h}}=\text { the conductivity of holes } \\
& \sigma_{\mathrm{e}}=\text { the conductivity of electrons }
\end{aligned}
$$

There are two factors which contribute to the non-ionic conductivity, the conductivity of holes which is dominant at high $\mathrm{Po}_{2}$, and the conductivity of electrons which is dominant at low $\mathrm{Po}_{2}$. The EMF is related to the difference in the logarithms of the partial pressure of oxygen of the two electrodes and to the ionic transference number by the following equation. 


$$
\mathrm{E}=\mathrm{RT} / 4 \mathrm{~F}_{\mathrm{PO2low}}{ }^{\mathrm{pO2hi} \text { igh }} \mathrm{t}_{\text {ion }} \mathrm{d} / \mathrm{m} \mathrm{Po}_{2}
$$

If $t_{i \text { on }} \geq 0.99$ over the range of oxygen partial pressure, then the EMF is given accurately by the following equation.

$$
\mathrm{E}=(\mathrm{RT} / 4 \mathrm{~F}) \ln \left(\mathrm{Po}_{2}{ }^{\text {high }} / \mathrm{Po}_{2}{ }^{\text {low }}\right)
$$

The ionic transference number is a function of temperature and partial pressure of oxygen in equilibrium with the electrolyte. The plot of $t_{\text {ion }}=0.99$ as a function of reciprocal temperature versus partial pressure of oxygen is the electrolytic domain of the electrolyte. Some plots for these systems are given in Figure 3.4. The lower sloped line divides the electron conduction region below it from the ionic conduction region above it. The upper horizontal line divides the hole conduction region above it from the ionic conduction region below it. Note that doping $\mathrm{ThO}_{2}$ with $\mathrm{Y}_{2} \mathrm{O}_{3}$ increases the range in which the electrolyte is useful. The plot for $\mathrm{CaF}_{2}$ in Figure 3.4 is the electrolytic domain for the conduction of fluoride ions not oxide ions. Worrell, however, has shown that the electrolytic domain for $\mathrm{CaF}_{2}$ for the conduction of oxide ions is nearly the same as for the conduction of fluoride ions.[15]

Doping of the fluorite structure phases will in general increase the ionic conductivity of the electrolyte. $\mathrm{Y}_{2} \mathrm{O}_{3}$ and $\mathrm{La}_{2} \mathrm{O}_{3}$ have structures similar to the fluorite structure and, consequently, a large amount of these phases can be dissolved in $\mathrm{ThO}_{2}$. The result is the increased production of vacancies suitable for oxygen ion conduction and, as a result, an increase in the net mobility of oxygen 
ions. This can be seen by comparing the electrolytic domain of YDT with that of pure $\mathrm{ThO}_{2}$ in Figure 3.4. The increased conductivity of YDT makes it useful at higher temperatures and larger ranges of oxygen pressures. The degree of change in the ionic conductivity can be calculated as a function of doping concentration.

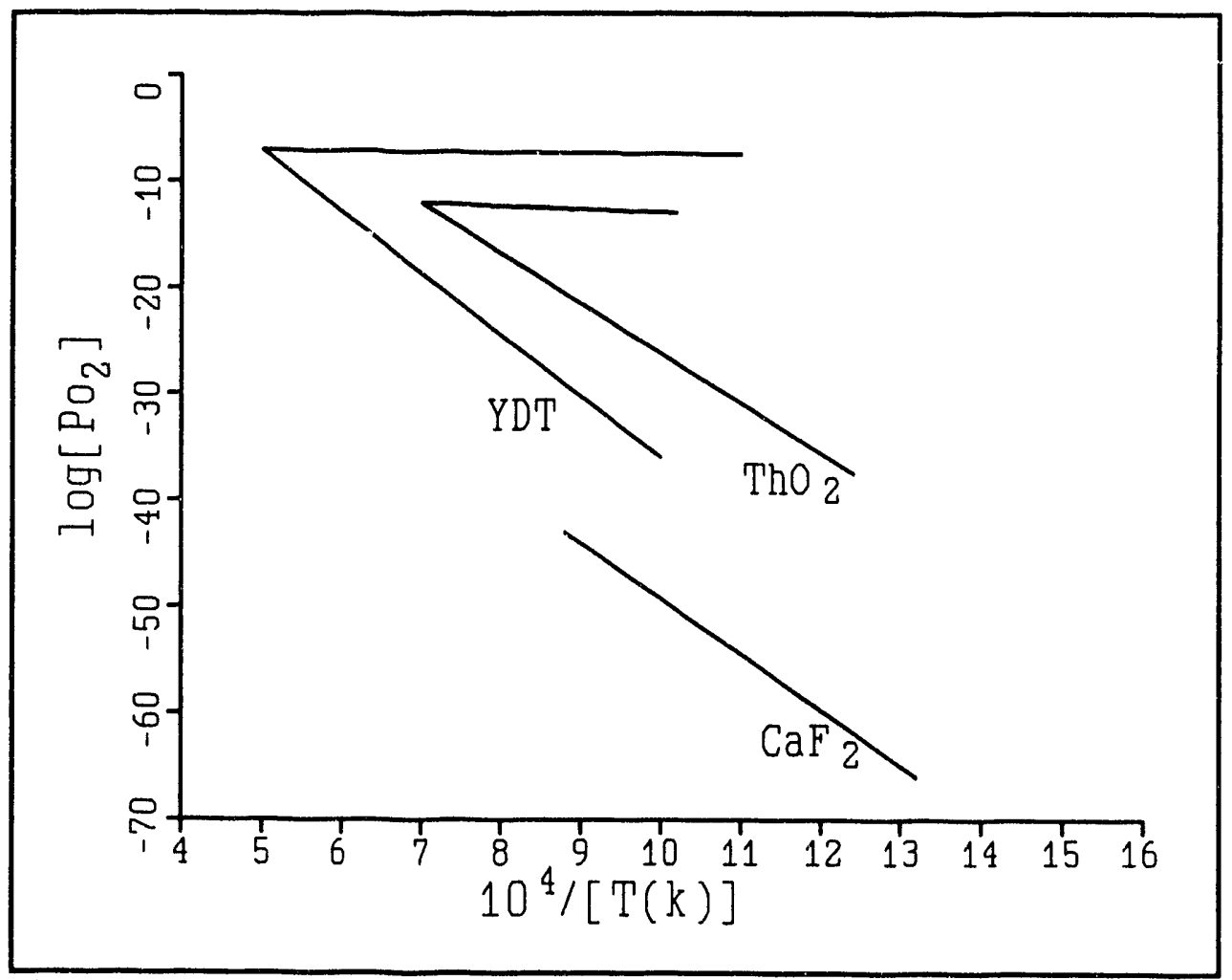

Figure 3.4 The electrolytic domain for some electrolytes

Mechanism of Ionic Conduction

Lasker and Rapp have used the mechanism of oxygen transfer to derive the relationship between $t_{i o n}$ and the mole fraction of the doping material.[16] This approach uses the theory of vacancies and interstitials developed by Wagner and Schottkey.[17] An important conclusion in Wagner's and Schottkey's theory is that defect concentrations can be understood thermodynamically by treating them 
as chemical components. More specifically, the equilibrium concentrations of defects can be related through a balanced chemical equation and the law of mass action.

Consider a solid electrolyte such as YDT. At any oxygen pressure, an oxygen on an oxygen lattice site can break away as a doubly charged oxygen ion leaving a doubly ionized vacancy on an oxygen site. The equation for this process is written as the following.

$$
\mathrm{O}_{0}=\mathrm{v}_{0} \cdot \cdot+\mathrm{O}_{\mathrm{i}}{ }^{\prime \prime}
$$

$O_{0}=$ oxygen on an oxygen lattice site

$\mathrm{V}_{\circ} \cdot=$ doubly charged(positive) vacancy on an oxygen site

$O_{i}{ }^{\prime \prime}=$ doubly charged(negative) oxygen interstitial(i.e. not on an oxygen site)

Using the law of mass action the equilibrium constant is expressed as follows

$$
\mathrm{K}_{1}=\left[\mathrm{V}_{0} \cdot \cdot\right]\left[\mathrm{O}_{\mathrm{i}}{ }^{\prime \prime}\right]
$$

The activity of oxygen on oxygen sites can be incorporated into the equilibrium constant since this is essentially constant if the formation of $\mathrm{V}_{0} \cdot{ }^{\prime}$ and $\mathrm{O}_{\mathrm{i}}{ }^{\prime \prime}$ is small.

At high partial pressures of oxygen, electronic conduction is primarily through positively charged holes. They are created by oxygen extracting electrons while being incorporated into the solid. This is given by the following equation.

$$
1 / 2 \mathrm{O}_{2}(\mathrm{~g})=\mathrm{O}_{\mathrm{i}}{ }^{\prime \prime}+2 \mathrm{~h}
$$

The law of mass action yields the following relationship

$$
\mathrm{K}_{2}=\left[\mathrm{O}_{1}{ }^{\prime \prime}\right] \mathrm{n}_{\mathrm{h}}{ }^{2} \mathrm{Po}_{2}^{-1 / 2} ; \mathrm{n}_{\mathrm{h}}=\text { concentration of holes }
$$


At low partial pressures of oxygen, the predominate electrical conduction is through electron conduction. Oxygen atoms on lattice sites will have a tendency to leave to form oxygen gas. This results in a doubly charged vacancy remaining. This is described in the following equation.

$$
\mathrm{O}_{0}=1 / 2 \mathrm{O}_{2}(\mathrm{~g})+\mathrm{V}_{0} \cdot \cdot+2 \mathrm{e}
$$

Again the law of mass action gives the following

$$
\mathrm{K}_{3}=\left[\mathrm{V}_{0} \cdot \cdot \mathrm{n}_{\mathrm{e}}{ }^{2} \mathrm{PO}_{2}{ }^{1 / 2} ; \mathrm{n}_{\mathrm{e}}=\right.\text { the concentration of electrons }
$$

As in Equation 3.16, the activity of oxygen on oxygen sites can be incorporated into the equilibrium constant. The three relationships, 3.16, 3.18, and 3.20 are all necessary to relate the ionic transference number to the three equilibrium constants and the concentration of dopant.

The general equation for conductivity is defined in arbitrary units as

$$
\sigma=[\text { charge }][\text { concentration }][\text { mobility }]
$$

For oxygen ions this equation becomes the following

$$
\sigma_{\text {ion }}=2|e|\left(\left[\mathrm{V}_{0} \cdot{ }^{\cdot}\right] u_{v}+\left[O_{i}{ }^{\prime \prime}\right] u_{i}\right)
$$

$|e|=$ the magnitude of the charge of an electron in appropriate units.

$u_{v}=$ the mobility of $v_{0}{ }^{\prime}$, and $u_{i}=$ the mobility of $O_{i}{ }^{\prime \prime}$

In equation 3.21 only the magnitude and not the direction is of interest.

Since

$$
\left[\mathrm{V}_{0} \cdot \cdot\right]=1 / 2\left[\mathrm{YO}_{1.5}\right]
$$


for $\mathrm{ThO}_{2}$ doped with $\mathrm{Y}_{2} \mathrm{O}_{3}$ or $\mathrm{La}_{2} \mathrm{O}_{3}$. This equation will deviate some for large dopings of $\mathrm{YO}_{1.5}$ and $\mathrm{LaO}_{1.5}$

$$
\left[\mathrm{V}_{0} \cdot \cdot\right]>>\left[\mathrm{O}_{\mathrm{i}}{ }^{\prime \prime}\right]
$$

Hence, the equation for ionic conductivity simplifies to the following

$$
\sigma_{\text {ion }}=|\mathrm{e}| \mathrm{u}_{\mathrm{v}}\left[\mathrm{YO}_{1.5}\right]
$$

For n-type conductivity, the electrical conductivity is given by the following

$$
\sigma_{e}=|e| n_{e} u_{e}
$$

By substituting the value of $n_{e}$ from Equation 3.20 the following is obtained

$$
\sigma_{e}=2^{1 / 2} \mathrm{~K}_{3}^{1 / 2}|\mathrm{e}| \mathrm{u}_{\mathrm{e}} \mathrm{Po}_{2}^{-1 / 4}\left[\mathrm{YO}_{1.5}\right]^{-1 / 2}
$$

This results in the transference number for low oxygen potentials

$$
t_{i o n}=1 /\left[1+\alpha \mathrm{Po}_{2}^{-1 / 4}\left[\mathrm{YO}_{1.5}\right]^{-3 / 2}\right.
$$

where

$$
\alpha=2^{1 / 2} K_{3}^{1 / 2} u_{e} / u_{v}
$$

and $a$ is a constant if $u_{e}$ and $u_{v}$ are independent of the $\mathrm{Y}_{2} \mathrm{O}_{3}$ concentration.

For p-type conductivity, the process is similar

$$
\sigma_{h}=|e| n_{h} u_{h}
$$

Substituting for $n_{n}$ the following is obtained

$$
\sigma_{h}=2^{-1 / 2} \mathrm{~K}_{2}{ }^{1 / 2} \mathrm{~K}_{1}{ }^{-1 / 2}|\mathrm{e}| \mathrm{u}_{\mathrm{h}} \mathrm{Po}_{2}{ }^{1 / 4}\left[\mathrm{YO}_{1.5}\right]^{1 / 2}
$$

This gives the ionic transference number for high oxygen potentials

$$
t_{\text {ion }}=1 /\left[1+\beta \mathrm{Po}_{2}{ }^{1 / 4}\left[\mathrm{YO}_{1.5}\right]^{-1 / 2}\right]
$$

where 


$$
\beta=\left(\mathrm{K}_{2} / 2 \mathrm{~K}_{1}\right)^{1 / 2} \mathrm{u}_{h} / \mathrm{u}_{v}
$$

and $\beta$ is a constant if $u_{h}$ and $u_{v}$ are independent of $Y_{2} O_{3}$ concentration.

From Equations 3.25 and 3.29 the electrolytic domain as a function of dopant can be obtained. In this way the variation of an electrolyte performance can be inferred as the dopant concentration changes. Note that the constants $\alpha$ and $\beta$ can vary some with large changes in the doping concentration of $\mathrm{YO}_{1.5}$ or $\mathrm{LaO}_{1.5}$ Interfacial Kinetics

Not only is the mechanism of ionic transfer important to the performance of solid electrolytes, the interfacial equilibrium between the electrolyte and the electrode can be very important. Several studies have been performed on the interfacial equilibrium between a gas and the electrolyte for applications in fuel cells.[18,19] These studies report that the interfacial equilibrium is in general much faster for solid electrodes than for gaseous electrodes. This indicates that interfacial equilibrium is not a problem in our experiments. In other words, there will be no appreciable voltage drop due to non-equilibrium conditions at the interfaces. In addition, the $\mathrm{Ta} / \mathrm{Ta}_{2} \mathrm{O}_{5}$ electrode used here is known to be a good reversible reference electrode.[20] Additionally, the apparatus is operated under an extremely high impedance, on the order of $10^{15} \mathrm{ohms}$. Because of this the flow of ions through the electrolyte is very small which further reduces to possibility of interfacial non-equilibrium. Consequently, the mechanism of oxygen 
transfer at the electrode-electrolyte interface is not expected to have any influence on the measured EMF.

Source of Errors

There are a variety of errors which can affect the accuracy of galvanic cell measurements. The three most common are mixed conduction, reactions at electrode-electrolyte interface, and reaction short circuiting caused either by porosity of the electrolyte or by contaminates present in the helium carrier gas. Note the following definition for description.

$$
\mathrm{EMF}_{\text {cell }}=\mathrm{EMF}_{\text {net }}+\mathrm{EMF}_{\text {applied }}
$$

where

$$
\mathrm{EMF}_{\text {cell }}=\text { the voltage generated by the galvanic cell. }
$$$$
\mathrm{EMF}_{\text {net }}=\text { the total voltage read by the voltmeter. }
$$

$\mathrm{EMF}_{\text {appl ied }}=$ the voltage applied in opposition to the galvanic cell.

$\mathrm{EMF}_{\text {true }}=$ the voltage the galvanic cell is expected to produce.

Mixed conduction: In this case $t_{\text {iori }}<1$ and $\mathrm{EMF}_{\text {cell }}<\mathrm{EMF}_{\text {true }}$. This is usually a consequence of one or more of the following problems: impurities in the electrolyte obtained during fabrication, interdiffusion of impurities from the solid electrodes during use, or operation of the galvanic cell outside the electrolytic domain of the electrolyte. Mixed conduction can be identified by applying a known EMF in series with the galvanic cell. If the $\mathrm{EMF}_{\text {cell }}$ does not vary as a

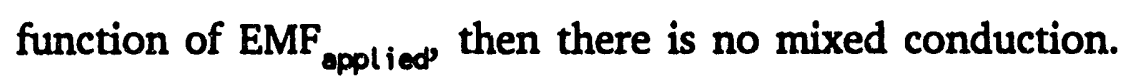


Gaseous Short Circuiting: In general $\mathrm{EMF}_{\text {cell }}<\mathrm{EMF}_{\text {true }}$ for this error, but this is not strictly the case. One cause of this error arises from diffusion of neutral $\mathrm{O}_{2}(\mathrm{~g})$ through a porous electrolyte. The effect of this mechanism is to reduce the measured EMF. Another common example of this error arises from the vaporization of the electrode materials or from reactions with gaseous impurities. Carbon monoxide or carbon dioxide are common impurities in carrier gas systems. Consider this reaction

$$
\mathrm{CO}(\mathrm{g})+1 / 2 \mathrm{O}_{2}(\mathrm{~g})=\mathrm{CO}_{2}(\mathrm{~g})
$$

If $\mathrm{CO}(\mathrm{g})$ or $\mathrm{CO}_{2}(\mathrm{~g})$ is present in a significant quantity, then it will interfere with the measured EMF. Because of the difference in $\mathrm{Po}_{2}$ between the electrodes, one electrode will favor the formation of $\mathrm{CO}_{2}$ and the other electrode will favor the formation of $\mathrm{CO}$. The result is that the $\mathrm{EMF}_{\text {net }}$ will be lowered.

If there is vaporization of one electrode or if the impurities in the carrier gas are at different concentrations surrounding each electrode, then it is possible for the $\mathrm{EMF}_{\text {cell }}$ to be larger than the real $\mathrm{EMF}_{\text {true. }}$ To help prevent the problem of gaseous short circuiting, it is important to use dense electrolytes and a pure carrier gas environment.

In general, the error of gaseous short circuiting can be identified by varying the gas flow rate and looking for any change in the $\mathrm{EMF}_{\text {celll}}$.

Electrode/Electrolyte Interfacial Reaction: If there is an interfering chemical reaction at the interfacial surface, this can usually be identified by a slow drift of 
the EMF over the duration of the experiment. This drift must last significantly longer than the normal drift expected for the cell to reach a steady-state EMF in the system. The best way to check for this problem is to look for discoloring of the electrolyte after the experiment and to check the observed EMF with that calculated from other data like heat capacity and enthalpy of formation data. More details on the effects of this error are given in Chapter 6 .

Other Interferences: There are numerous other effects which can add to the uncertainty of galvanic cell measurements. They, however, seldom cause large errors. A partial list is as follows: electrode-electrolyte interface non-equilibrium, bulk non-equilibrium of electrodes, diffusion potentials, contact potentials, and thermoelectric potentials.

3.4. The Activity of Vanadium: Sample Calculations.

To calculate the activity of vanadium in the composites, the proper reaction equilibria must be considered.

Calculating the activity in the oxide or carbide equilibria

To demonstrate how the activity is calculated in the two phase oxide or the two phase carbide in equilibrium with a one phase alloy, the following sample calculation is presented.

Using the well known equation

$$
\Delta \mathrm{G}=\Delta \mathrm{G}^{\circ}+\mathrm{RT} \ln \mathrm{Q} ; \quad \mathrm{Q}=\mathrm{K} \text { if } \Delta \mathrm{G}=0
$$


For the composition where VO and $\mathrm{V}_{2} \mathrm{O}_{3}$ are in equilibrium with a V-NM(noble metal) alloy, the proper reaction to consider is as follows.

$$
3 \mathrm{VO}(\mathrm{s})=\mathrm{V}_{2} \mathrm{O}_{3}(\mathrm{~s})+\mathrm{V} \text { (alloy) }
$$

if

$$
\Delta G=0
$$

and assuming

$$
a_{v 203}=1 \text { and } a_{v 0}=1
$$

then

$$
0=\Delta G_{f}{ }^{\circ}\left(V_{2} O_{3}\right)-3 \Delta G_{f}{ }^{\circ}(V O)+R T \ln a_{v}
$$

This equation is temperature dependent. However, the Gibbs energy of formation of VO, and $\mathrm{V}_{2} \mathrm{O}_{3}$ are well known as functions of temperature. By inserting the values of the free energy of formation for the oxides at the temperature of interest into Equation 3.34, the activity of vanadium is readily obtained.

Calculating the activity when using the galvanic cell.

For alloy compositions in equilibrium with only one oxide, further information is needed to calculate the activity of vanadium. In this case, we use the high temperature galvanic cell to obtain the fugacity of oxygen in the oxide phase. The cell data can be used in conjunction with the Gibbs free energy of formation data for the oxide to obtain the activity of the vanadium.

For a V-MN(noble metal) alloy in equilibrium with one oxide a sample calculation is given. The most common case here is $\mathrm{V}_{2} \mathrm{O}_{3}$ as the oxide which is 
in equilibrium with the alloy(s).

Consider the following equation

$$
1 / 2 \mathrm{~V}_{2} \mathrm{O}_{3}(\mathrm{~s})=\mathrm{V}(\text { alloy })+3 / 4 \mathrm{O}_{2}(\mathrm{~g})
$$

in equilibrium

$$
\Delta \mathrm{G}=0
$$

and assuming

$$
a_{\text {y203 }}=1
$$

then

$$
0=-1 / 2 \Delta \mathrm{G}_{\mathrm{f}}{ }^{\circ}\left(\mathrm{V}_{2} \mathrm{O}_{3}\right)+\mathrm{RT} \ln \mathrm{a}_{\mathrm{v}}+3 / 4 \mathrm{RT} \ln \mathrm{Po}_{2}
$$

Once again, the Gibbs energy of formation for $\mathrm{V}_{2} \mathrm{O}_{3}$ is well known and the partial pressure of oxygen in equilibrium with the composite can be obtained from the high temperature galvanic cell. This results in the activity of vanadium being fixed and easily calculated.

The calculation of thermodynamics in this fashion involves several assumptions. First is that the oxide or carbide can be properly equilibrated with the alloy. If there are any ternary phases present, some alloy compositions will not equilibrate with pure oxides. The second simplifying assumption is that the activity of $\mathrm{V}_{2} \mathrm{O}_{3}$ and $\mathrm{VO}$ are nearly equal to 1 . This causes these terms to be dropped in the calculations given. This latter assumption is described in more detail in Appendix B. 
Calculation of the partial pressure of oxygen using the galvanic cell.

A typical cell will have two solid oxide electrodes. The cell we studied most thoroughly is the

$$
\mathrm{Pt} / \mathrm{Ta} / \mathrm{Ta}_{2} \mathrm{O}_{5} / / \mathrm{YDT} / / \mathrm{NO} / \mathrm{V}_{2} \mathrm{O}_{3} / / \mathrm{Pt}
$$

cell. The operation of the galvanic cell is in essence an instrument which measures the difference in the logarithms of the oxygen partial pressures between the two electrodes(see Figure 3.3). Remember that the EMF is given by the Nernst equation as a concentration cell where the concentration difference is in the natural log of partial pressures of oxygen.

$$
\mathrm{E}=-(\mathrm{RT} / 4 \mathrm{~F}) \ln \left[\mathrm{Po}_{2}{ }^{\text {high }} / \mathrm{Po}_{2}{ }^{\text {low }}\right]
$$

This is the general equation obtained when $\mathrm{t}_{\mathrm{ion}} \approx 1$ over the range of $\mathrm{PO}_{2}^{\text {low }}$ to $\mathrm{PO}_{2}^{\text {high }}$. At the $\mathrm{Ta} / \mathrm{Ta}_{2} \mathrm{O}_{5}$ electrode, the following reaction occurs in either forward or reverse direction.

$$
0.8 \mathrm{Ta}(\mathrm{s})+\mathrm{O}_{2}(\mathrm{~g})=0.4 \mathrm{Ta}_{2} \mathrm{O}_{5}(\mathrm{~s})
$$

and at the $\mathrm{VO} / \mathrm{V}_{2} \mathrm{O}_{3}$ electrode this reaction will likewise occur

$$
4 \mathrm{VO}(\mathrm{s})+\mathrm{O}_{2}(\mathrm{~g})=2 \mathrm{~V}_{2} \mathrm{O}_{3}(\mathrm{~s})
$$

The partial molar quantities of reference electrodes are often found in the literature. If $\Delta \bar{G}_{02}$ is not available, it is easy to calculate. In Equation 3.24 the following is true

$$
\Delta G^{\circ}=-R T \ln \left(\mathrm{a}^{0.4}{ }_{T_{0205}}\right) /\left(\mathrm{Po}_{2} \mathrm{a}_{T_{0}}^{0.8}\right)=\Delta\left(\partial \mathrm{G} / \partial \mathrm{X}_{02}\right)
$$

assuming 


$$
a_{\mathrm{TQ205}}=1
$$

$$
\mathrm{a}_{\mathrm{Ta}} \approx \mathrm{x}_{\mathrm{Ta}} \text { (given from the phase diagram of } \mathrm{Ta}-\mathrm{O} \text { ) }
$$

$$
0=0.4 \Delta \mathrm{G}_{f}^{\circ}\left(\mathrm{Ta}_{2} \mathrm{O}_{5}\right)-0.8 \mathrm{RT} \ln \mathrm{X}_{\mathrm{Ta}}-\mathrm{RT} \ln \mathrm{Po}_{2}
$$

Equation 3.43 can be solved to give the relationship for $\ln \mathrm{PO}_{2}$ as a function of temperature for the $\mathrm{Ta} / \mathrm{Ta}_{2} \mathrm{O}_{5}$ electrode. Likewise a similar treatment yields the $\mathrm{PO}_{2}$ in equilibrium with the VO/ $\mathrm{N}_{2} \mathrm{O}_{3}$ electrode. In the $\mathrm{Ta} / \mathrm{Ta}_{2} \mathrm{O}_{5} / / \mathrm{YDT} / / \mathrm{VO} / \mathrm{N}_{2} \mathrm{O}_{3}$ system, the EMF is fixed and can be readily calculated. The calculated EMF can in turn be checked against the observed reading to confirm that the galvanic cell is functioning properly. 


\section{References}

1. J. H. Bularzik, "Acid-Base Reactions of the Transition Metal Alloys: Thermochemistry of the Base-Rich End," Ph.D. Thesis, U. C. Berkeley, LBL23665 (1987).

2. D. E. Peterson, "Sublimation Thermodynamics of the $P u R u_{2}$ Intermetallic Compound," J. Nuclear Mater., 91, 306-310 (1980).

3. D. E. Peterson, "Thermodymanics of Pu-Pt and Pu-Rh Intermetallic Compounds," J. Nuclear Mater., 131, 44-52 (1985).

4. D. E. Peterson and J. S. Starzynski, "Thermodynamics of the PuIr Intermetallic Compound," J. Less-Common Met., 105, 273-281 (1985).

5. M. Pelino, S. K. Gupta, L. R. Cornwell, and K. A. Gingerich, "High Temperature Thermodynamic Investigation of the Titanium-Rich Portion of the Titanium-Iridium System by the Knudsen Cell Mass Spectrometry," $J$. Less-Common Met., 68, P31-P38 (1979).

6. M. V. Nevit, "Alloy Chemistry of Transition Elements," paper in Electronic Structure and Alloy Chemistry of the Transition Elements, Paul A. Beck, Ed., Interscience Publishers, New York, 63 (1963).

7. S. R. Leonard, B. S. Snyder, L. Brewer, and A. M. Stacy, "Structure of Two Ternary Oxides: $\mathrm{Ti}_{3} \mathrm{PdO}$ and $\mathrm{Ti}_{4} \mathrm{Pd}_{2} \mathrm{O}$," J. Solid Sate Chem., in press

8. H. A. Wriedt, "The O-V(Oxygen-Vanadium) System," Bull. Alloy Phase Diag., 10(3), 271-277 (1989).

9. C. B. Alcock and C. Ji, "The Vanadium - Oxygen System - A Review," High Temp.-High Press., 21, 139-147 (1990). 
10. S. M. Babulanam, T. S. Eriksson, G. A. Niklasson, and C. G. Granqvist, "Thermochromic $\mathrm{VO}_{2}$ Films for Energy-Efficient Windows," Solar Energy Mater., 16, 347-363 (1987).

11. F. Théobald, R. Cabala, and J. Bernard, "Essai sur la Structure de $\mathrm{VO}_{2}(\mathrm{~B})$," J. Solid State Chem., 17, 431-438 (1976)(French).

12. S. A. Shivashankar, R. Aragón, H. R. Harrison, C. J. Sandberg, and J. M. Honig, "Preparation and Electrical Properties of $\mathrm{V}_{2} \mathrm{O}_{3}$ Single Crystals of Controlled Stoichiometry," J. Electrochem. Soc., 128(11), 2472-2475 (1981).

13. O. N. Carlson, A. H. Ghaneya, and J. F. Smith, "The C-V(Carbon-Vanadium) System," Bull. Alloy Phase Diag., 6(2), 115-124 (1985).

14. D. R. Stull and H. Prophet, Project Directors, JANAF Thermochemical Tables, $2^{\text {nd }}$ Ed., NSRDS-NBS 37, Catalog Number C13.48:37, U. S. Government Printing Office, Washington, D. C. (1971).

15. W. L. Worrell, "Galvanic-Cell Investigations with a $\mathrm{CaF}_{2}$ Solid Electrolyte at Elevated Temperatures," Solid State Ionics, 3/4, 559-562 (1981).

16. M. F. Lasker and R. A. Rapp," Mixed Conduction in $\mathrm{ThO}_{2}-\mathrm{Y}_{2} \mathrm{O}_{3}$ Solutions," Zeitschrift fur Physikalische Chemie Neue Folge, 49, 198-221 (1966).

17. C. Wagner and W. Schottkey, "Theory of Arranged Mixed Phases," Z. Physik. Chem., Abt. B, 11, 163-210 (1930).

18. J. Fouletier, P. Fabry, and M. Kleitz, "Electrochemical Semipermeability and the Electrode Microsystem in Solid Oxide Electrolyte Cells," J. Electrochem. Soc., 123(2), 204-213 (1976).

19. N. L. Robertson and J. N. Michaels, "Oxygen Exchange on Platinum Electrodes in Zirconia Cells: Location of Electrochemical Reaction Sites," J. Electrochem. Soc., 137(1), 129-135 (1990). 
20. R. Tetot, C. Picard, and P. Gerdanian, "Determination of Oxygen Partial Free Energy for Non-Stoichiometric TiO by E.M.F. Measurements," J. Phys. Chem. Solids, 44(11), 1059-1068 (1983). 


\section{Chapter 4}

\subsection{Experimental Techniques.}

Many of the experimental techniques for the study of ternary oxide or carbide equilibria and galvanic cell measurements have been described previously by Cima, Kouvetakis, and Gibson.[1-3] Consequently, procedures will be reviewed but not discussed in detail unless they deviate significantly from those of the aforementioned.

Before Sample Preparation

Our goal in sample preparation is to make dense pellets in which the oxide or carbide grains have good interfacial contact with the alloy. The close contact ensures that equilibrium between the alloy and the oxide or carbide really makes the activity of vanadium equal throughout the sample. In addition, high porosity in the composite would mean more surface area where contaminants and surface thermodynamics could interfere with the bulk properties.

The first step in sample preparation is to create a series of three phase equilibria for the ternary system. These compositions should cover all reasonable possibilities of the ternary phase equilibria. For the V-O-Pd diagram this involves guessing the composition of the alloy that would be in equilibrium with the following oxide pairs: $\mathrm{V}_{4} \mathrm{O}-\mathrm{V}_{2} \mathrm{O}, \mathrm{V}_{2} \mathrm{O}-\mathrm{VO}$, VO- $\mathrm{V}_{2} \mathrm{O}_{3}$, and $\mathrm{V}_{2} \mathrm{O}_{3}-\mathrm{V}_{3} \mathrm{O}_{5}$. Also, this 
involves guessing what composition of oxide will be in equilibrium with the two phase alloy mixture, $V(P d)-P d(V)$. Samples are created over the entire range of possibilities with at least one representative of each possible ternary equilibrium. After the true ternary equilibrium diagram is completed, then any alloy-oxide or alloy-carbide composition, if needed, is easily prepared.

\section{Sample Preparation and Analysis}

Figure 4.1 outlines the schematic for sample preparation used here. Some of the specifics of the instruments used in each step of preparation are described in appendix C. In the first step, appropriate amounts of powder are mixed and pressed to yield a pellet with the desired overall composition. (The starting materials used are given in Appendix A, and the purity and particle size of the starting materials are given in Appendix F) Six to twelve glass beads are put in each sample vial to help homogenization. The powders are then mixed for 3 to 5 hours on a mixer. In addition, some mixtures are ground in a mortar and pestle before and after mixing to help decrease the particle size and complete the homogenization.

In the second step, the powders are pressed in a 7/16" steel die with 10000 to $15000 \mathrm{lb}$ loads to make a pellet composite. Smaller loads are used on powders composed of smaller particle sizes, and larger loads are used on powders composed of larger particle sizes. 


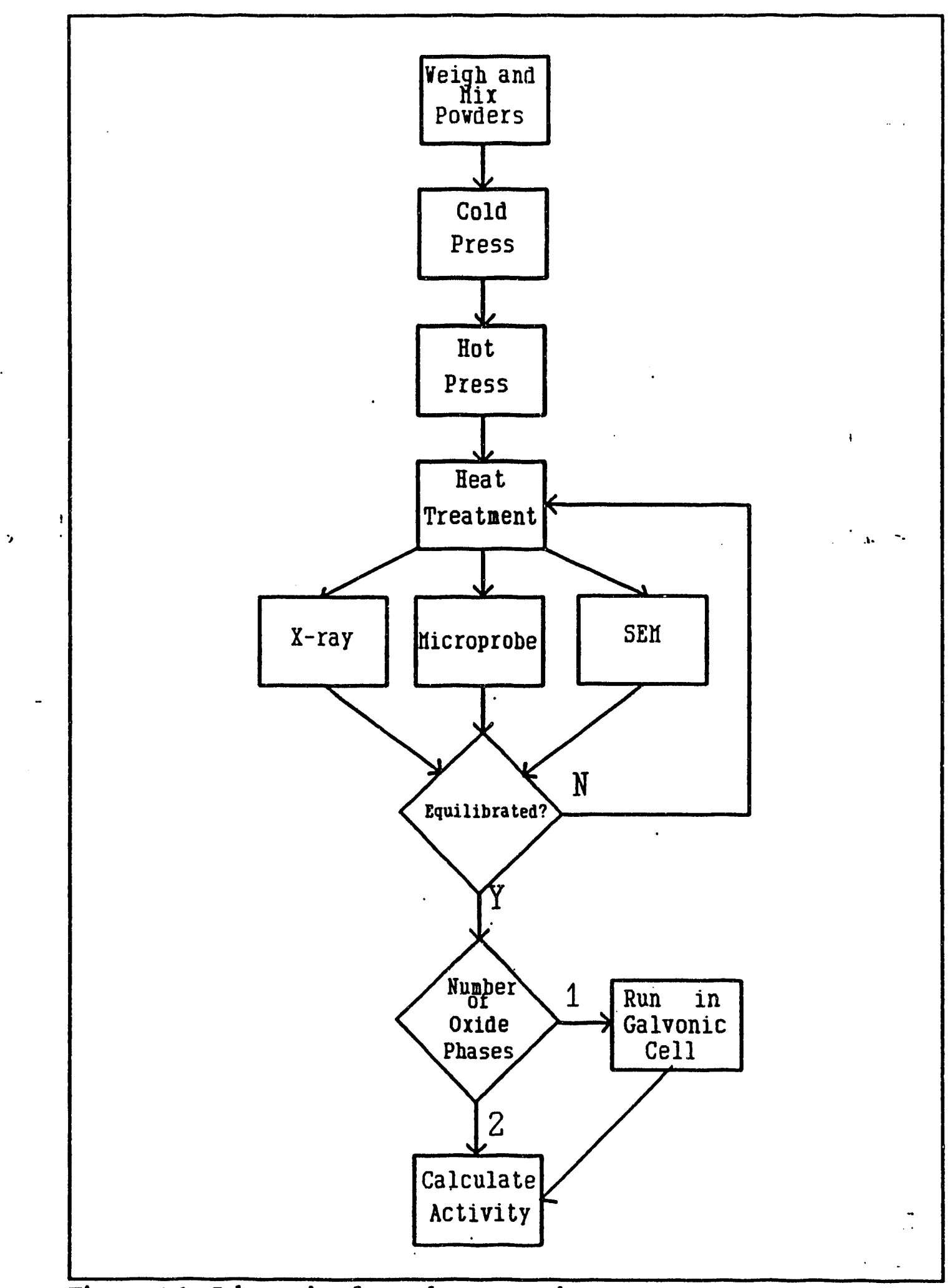

Figure 4.1. Schematic of sample preparation 
In the third step, the sample is sintered under heat and pressure to maximize the density of the composite material. This step is described further under hot pressing in section 4.2.

Fourth, the sample is equilibrated around $1000^{\circ} \mathrm{C}$ under a vacuum. The necessary equilibration time is somewhat uncertain for these systems. For some systems enough data are available tu cstimate the time necessary. (Appendix D) Weight losses and equilibration times of all samples prepared are given in Appendix A.

In the fifth step, the sample is analyzed. The constituent phases are identified by X-ray diffraction, and the compositional analysis is done by wavelength dispersive X-ray analysis (microprobe analysis), or by energy dispersive X-ray analysis(EDAX) on the scanning electron microscope(SEM). The best technique for composicional analysis is the electron microprobe analysis technique which can provide the composition of the oxide or carbide grains as well as the alloy grains.

Lastly, to confirm the phases present in the composite, X-ray powder diffraction is used. From these three techniques, it can be determined if the composite is satisfactorily equilibrated. Equilibration is suggested in X-ray diffraction by sharp well defined peaks. In addition, the X-ray diffraction pattern should be comprised of a maximum of three phases. If four phases can be identified, the sample needs further heat treatment. Unequilibrated samples are 
easiest to identify from microprobe analysis.

A line scan of a the sample shown in Figure 4.2 shows if the grains are homogenous and hence equilibrated. The line scan shown shows a sample which is well equilibrated. The line scan is a good indicator of sample equilibrium, but it is not sufficient to prove that the sample as a whole is in equilibrium. The compositional analysis of the oxide, carbide, and alloy grains should be uniform for each phase throughout the sample. If a significant deviation in composition through out the sample is observed, the sample needs further heat treatment.

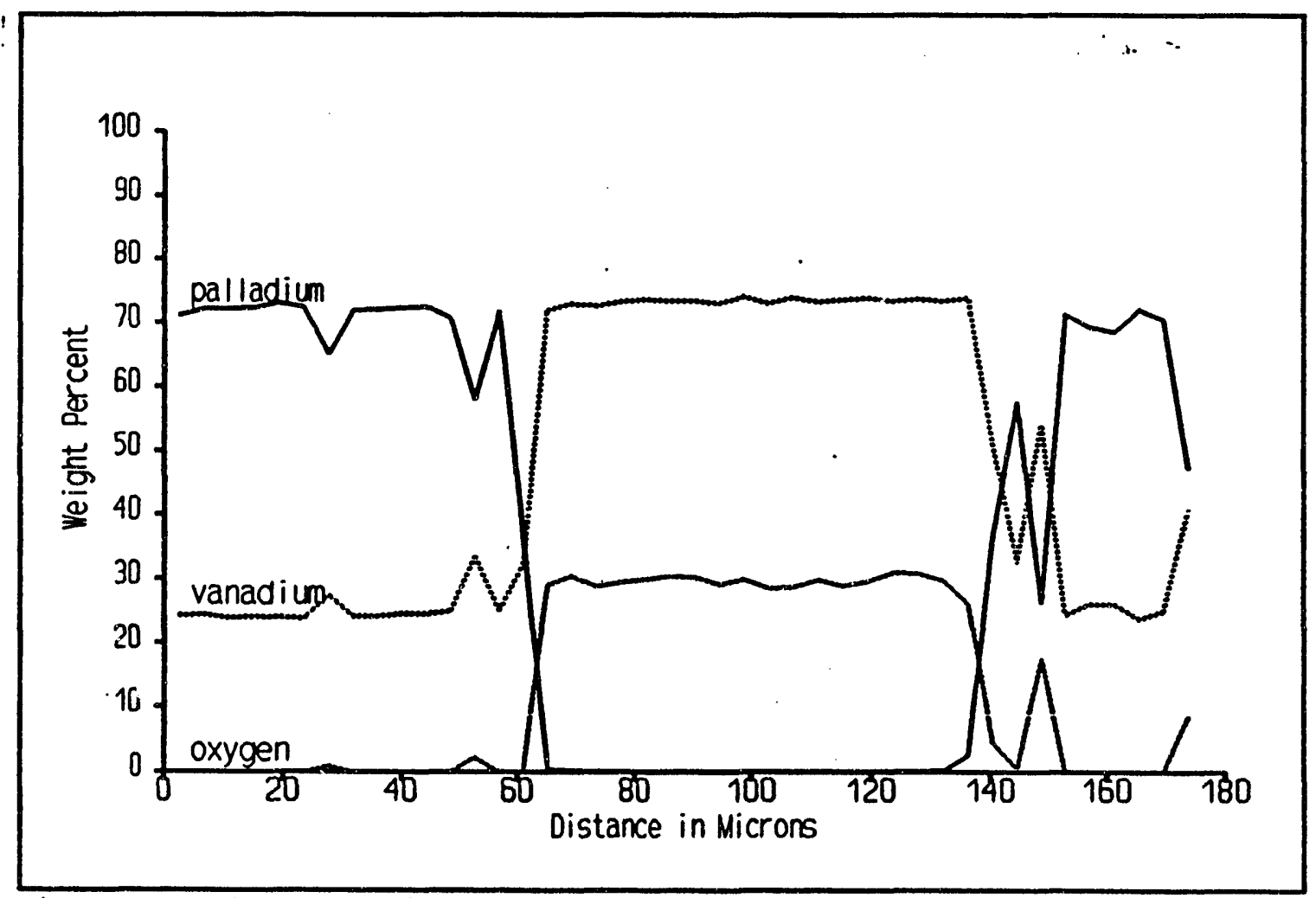

Figure 4.2. Line scan of an equilibrated V-Pd-O sample.(237B) 
If the sample is equilibrated, then the number of oxide, carbide, and alloy phases are determined. If there are two oxides or two carbides and only one alloy phase then the activity in the alloy is fixed and calculated as demonstrated in section 3.4. If there is only one oxide in equilibrium with either one or two alloy phases, then the partial pressure of oxygen in equilibrium with the sample is determined by using the galvanic cell technique. The calculations for this procedure are also demonstrated in section 3.4. The mole fraction of the alloy(s) in the composite is given by the microprobe analysis and in two cases by energy dispersive X-ray analysis on the scanning electron microscope. comprise all the information that is needed to compose the activity versus concentration titration curve for vanadium in any of the noble metals.

\subsection{Some Procedures.}

Hot pressing.

Hot pressing is a technique through which dense sample pellets are prepared. This is done by simultaneously heating the sample and applying pressure. Almost all samples prepared were imbedded in boron nitride powder before hot pressing. This technique follows the method of Cima.[4] The 7/16" size pellet is imbedded in boron nitride powder which in turn is inside a 1/2" graphite die. A few samples which are intended to be in equilibrium with graphite are imbedded in graphite powder instead of boron nitride before hot pressing. 
The hot pressing cycle begins by heating the graphite die slowly to the desired temperature. Usually it takes about $10-20$ minutes for the system to reach temperature, $1000^{\circ} \mathrm{C}-1200^{\circ} \mathrm{C}$. The sample is then pressed for $10-20$ minutes at loads around 4,300 lbs for the oxides and $5,400 \mathrm{lbs}$ for the carbides. The temperature is maintained around $1000^{\circ} \mathrm{C}-1200^{\circ} \mathrm{C}$. Finally, the sample is annealed for 5-15 minutes at $1000^{\circ} \mathrm{C}-1300^{\circ} \mathrm{C}$ before turning off the filament. The annealing alleviates any residual strain in the pellet from hot pressing.

After removal, the pellet is cleaned, and as much of the boron nitride is ' removed as possible. Next, the pellet is sanded to remove the outer layer of the pellet, and lastly, it is sonically cleaned in alcohol.

Polishing by impregnation.

The standard polishing procedure used by Cima and Kouvetakis has been improved. Since the samples prepared are composites of an alloy and an oxide or an alloy and a carbide, obtaining a smooth polished surface is very difficult because the ceramic component tended to be very brittle and the alloy component tended to be very tough. Typically the surface is pitted after polishing and only a few areas of the sample are satisfactorily polished. If the mount is impregnated with Crystal Bond 501(Aremco) before polishing, the pores of the carbide or the oxide are filled and the ceramic part is strengthened.

The preparation of a sample for microprobe analysis or EDAX begins by cutting a pieces from the sample pellet and mounting it in Konductomet I(Epoxy 
or Bakelite is also used). The surface is lightly sanded to expose the samples in the mount. Next the mount is placed on a hot plate and Crystal Bond 501 is melted into the surface of the sample. The mount is left on the hot plate until bubbles cease forming from the seepage of the Crystal Bond into the mount. At this point, the Crystal Bond has filled up the pores in the oxide or carbide. This strengthens the carbide or oxide and decreases the amount of pitting which occurs during polishing. Consequently, a much smother polished surface is obtained.

Besides the impregnation of the sample, the remaining part of the procedure

' is identical to that of Cima and Kouvetakis.[2,4] The mount is placed in a brass holder to keep the surface flat and to prevent rounding during polishing. The sample is polished down to a 1 micron or to $1 / 4$ micron diamond paste on a nylon cloth. After polishing, the mount is placed in acetone for at least 20 minutes to remove the Crystal Bond. This material is soluble in acetone and will leach out of the mount during this time. Lastly, the mount is sonically cleaned before preparing it for use in microprobe analysis or the scanning electron microscope.

\section{Making Solid Electrolytes}

Yttria doped thoria(YDT), lanthana doped thoria(LDT), and pure thoria electrolytes are made according to Cima's method.[4] The YDT used is composed of 15 mole $\% \mathrm{YO}_{1.5}$ and 85 mole $\% \mathrm{ThO}_{2}$. Likewise, the LDT used is composed of 15 mole $\% \mathrm{LaO}_{1.5}$ and 85 mole $\% \mathrm{ThO}_{2}$. The mixed powder of the electrolyte 
is cold pressed at about $12,000 \mathrm{lbs}$ load in $1 / 2$ " steel die. The surfaces of the cold pressed electrolyte are cleaned using the edge of a glass slide. The samples are then placed, usually three at a time, in the Thoria furnace (A high temperature vacuum furnace see appendix $\mathrm{C})$. The chamber is backfilled about $50 \%$ with hydrogen.(In the future $3-4 \%$ hydrogen in argon will be used) The furnace is ramped up to about $1900^{\circ} \mathrm{C}$ over a period of about 4 hours. The samples are left at about $1900^{\circ} \mathrm{C}$ for $20-60$ minutes, then cooled slowly over a period of about 4 hours. Occasionally the electrolytes were left too long in the furnace and when : removed they were observed to be blackened. The blackened electrolytes are heated in air at about $900^{\circ} \mathrm{C}$ for 1 day to reoxidize the electrolyte. Reduced electrolytes are black and oxidized electrolytes are cream colored. Normally, the electrolyte that is used in the galvanic cell is white. Also, occasionally, a small amount of contamination can be seen on the electrolyte after sintering. This is usually caused by contamination with the steel die or from handling the electrolyte with steel tweezers. The contaminated area is sanded off before use if the area is small. If the contaminated area is large, then the sample is discarded.

Since $\mathrm{CaF}_{2}$ is not radioactive, preparing it for use as an electrolyte is much easier. $\mathrm{CaF}_{2}$ powder is cold pressed with at least $10000 \mathrm{lbs}$ load in a $7 / 16^{\mathrm{N}}$ steel die. The pellet is then hot pressed according to the procedures outlined in hot pressing. Boron nitride was used to encase the pellet, and the temperature at which the sample was hot pressed is around $900^{\circ} \mathrm{C}$. The $\mathrm{CaF}_{2}$ electrode was then 
heated in air for 1 day to encourage the growth of small amounts of $\mathrm{CaO}$ in the electrolyte since the $\mathrm{CaF}_{2}$ is to be used as an oxygen conductor.[5]

Flow Diagram of the Galvanic Cell

The schematic for the galvanic cell is shown in Figure 4.3. The design is Cima's[1] with some modifications. Helium is used as the carrier gas. The helium first flows through a liquid nitrogen trap, which acts as a first stage gettering system for impurities. Secondly, the helium flows over hot zirconium in two gettering furnaces. The first is held at $900^{\circ} \mathrm{C}$ throughout the experiment. The second is held at $600^{\circ} \mathrm{C}$ throughout the experiment. The zirconium foil in the gettering furnace picks up impurities such as carbon monoxide and oxygen. The purpose of the two furnaces held at different temperatures is to facilitate the gettering of the hydrocarbons such as methane gas. The first furnace is held at $900^{\circ} \mathrm{C}$ to induce cracking of the hydrocarbon to graphite and hydrogen. The second furnace is held at lower temperatures since hydrogen is soluble in zirconium at lower temperatures. Inside the main furnace, there is some additional zirconium foil to getter any oxygen or other contaminants that may degas from the walls or the ceramic components during the experiment. On the helium exit line the total pressure and flow rate are measured. 


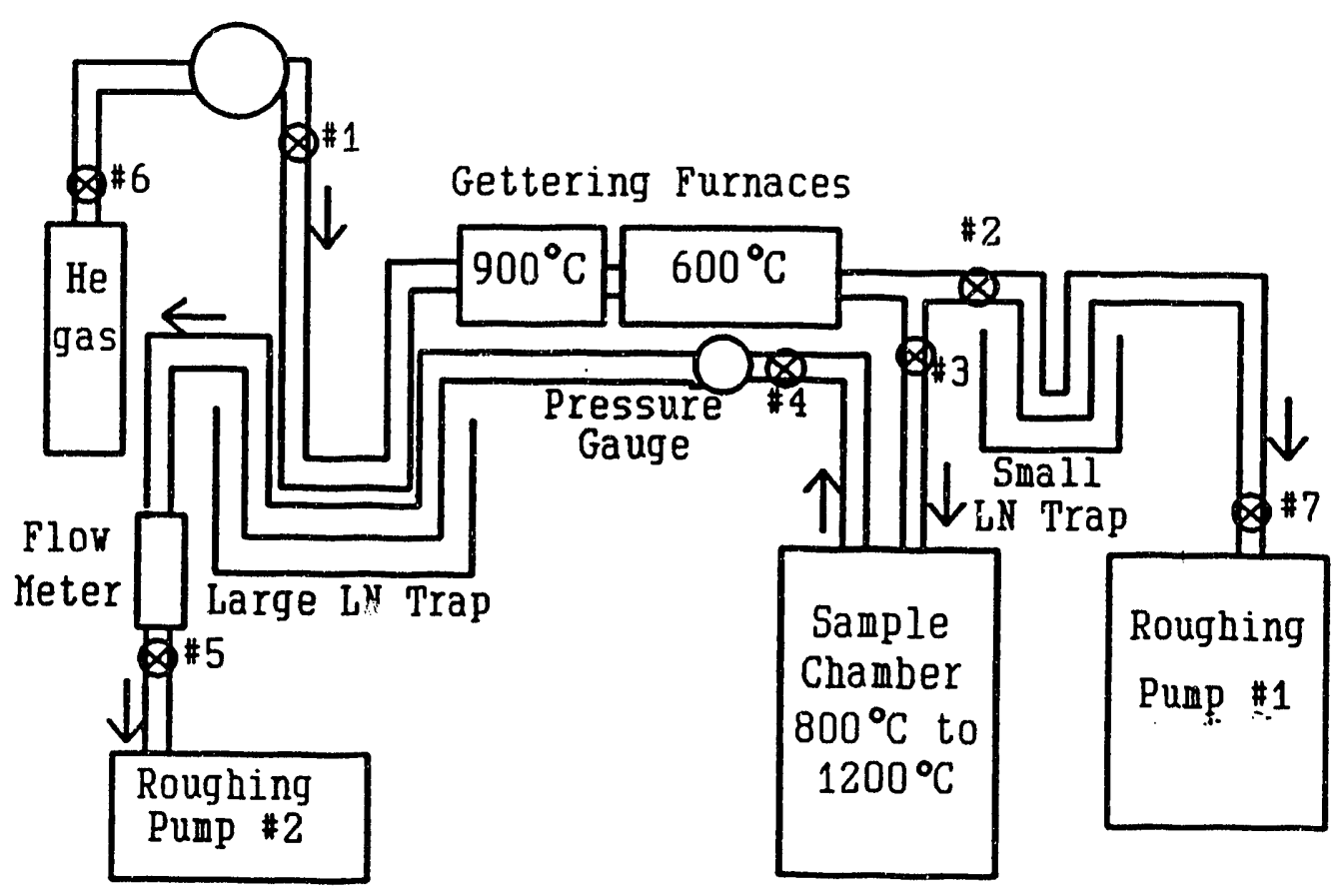

Figure 4.3. Schematic of galvanic cell internals

Internal Assembly of the Galvanic Cell.

The internal setup of the galvanic cell is depicted in Figure 4.4. Two sets of paired alumina disks were prepared such that the two electrodes and the electrolyte could be assembled as a unit outside the apparatus. There were two reasons for this. First, the unit could be preassembled while another experiment was running. Second, this also permitted the electrodes and the electrolyte to be annealed before inserting into the inconel chamber. Assembling the apparatus in this manner was easier than the previous method of Cima. In Figure 4.4 some of the main components of the inner assembly are depicted and labeled. The whole 
assembly is held together by tension rods which are not pictured. Stainless steel springs are used to hold the tension rods during the experiment. Their purpose is to help maintain good contact between the electrodes and the electrolyte throughout the experiment.

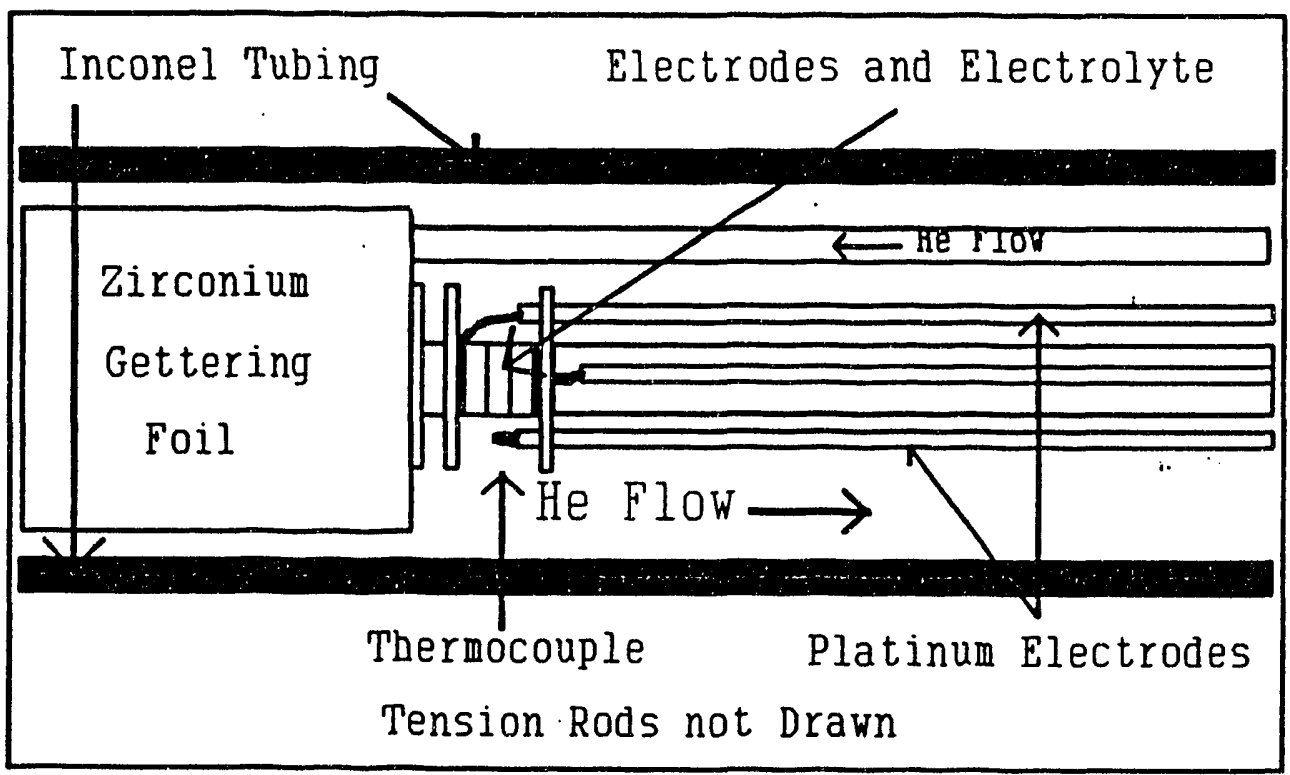

Figure 4.4. Innerassembly of the galvanic cell.

Data acquisition in the galvanic cell.

Since Cima's use of the galvanic cell apparatus, a new data acquisition system has been installed. A series of four computer cards, two internal and two external, obtained from MetraByte Corporation are used to interface our IBM PC with the furnace, voltmeter, and thermocouple for data acquisition and experiment automation.

The system was updated with a 12 bit D/A converter with 2 channels. One is for controlling the power to the furnace, and the other is for running automated 
polarization experiments. Also, the system was updated with an 8 channel 12 bit $A / D$ converter for measuring the cell voltage and temperature. Some parameters on the data acquisition system and its accuracy are given in Appendix C. The system is designed for a remote voltage setpoint to control the main furnace. The voltage output is -5 to +5 volts. -5 volts corresponds to zero power and +5 volts corresponds to full power. The first channel on the D/A converter remotely controls the furnace power, and the second channel on the D/A converter is hooked in series with the cell for use in the polarization experiments. Figure 4.5 shows the schematic of how the D/A and the A/D converters are wired to the cell and voltmeter.

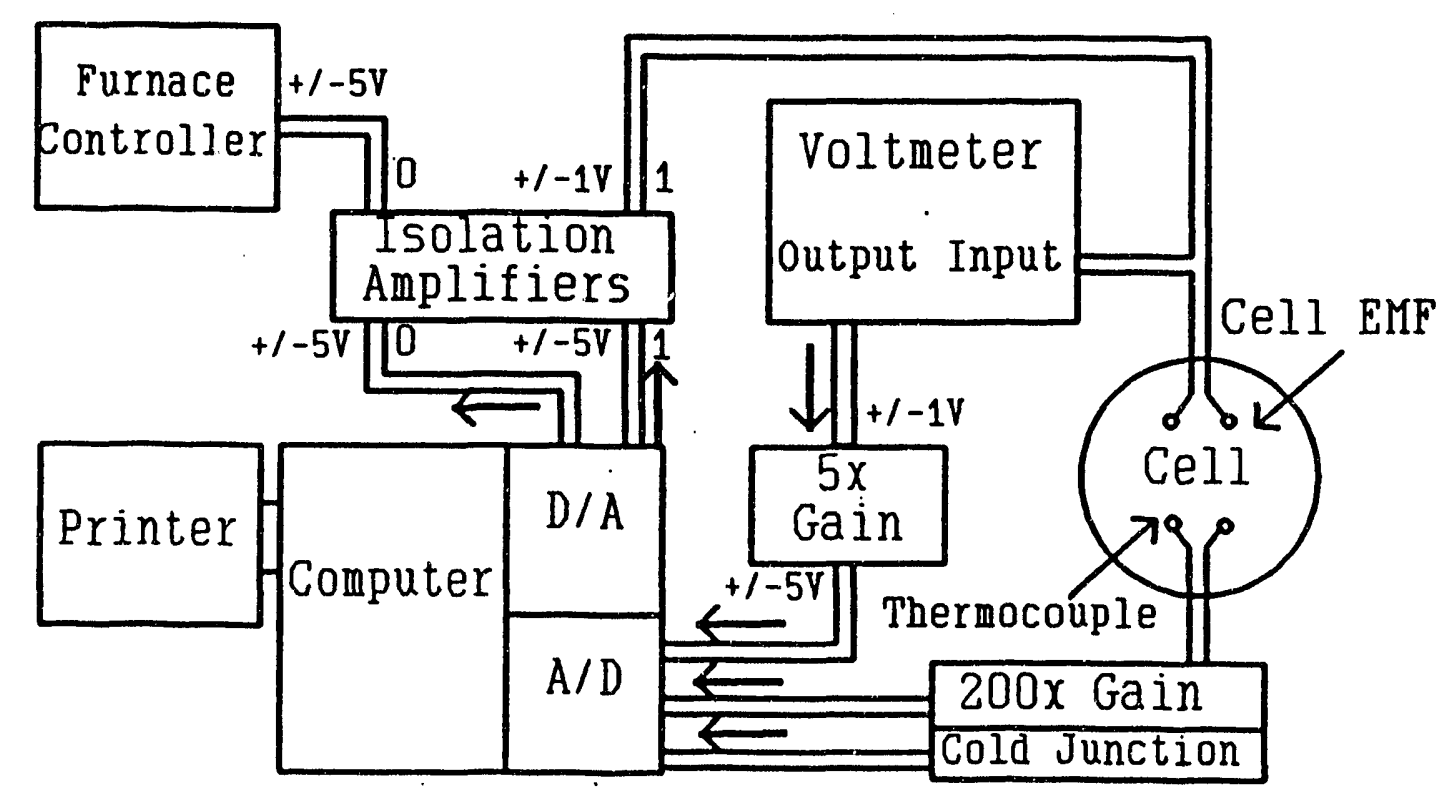

Figure 4.5. The electrical schematic of the galvanic cell. 
The polarization routine

As mentioned in Chapter 3, a mixed conductor can be identified by applying a known EMF in series with the galvanic cell and measuring the total EMF. Such a routine has been implemented. The voltage source is driven by the second channel on the D/A converter, and any voltage can be output to within $\pm 1 \mathrm{mV}$ of the desired value. The program "RUNCELL" is designed to implement this routine either automatically or manually. If automatically done, the applied EMF is maintained ruring the experiment such that the net EMF of the cell plus the applied EMF will be near zero. If manually done, the EMF applied remains constant, but it is adjustable at any time throughout the experiment.

The microprobe analysis.

Microprobe analysis was the primary technique used for obtaining the alloy compositions in equilibrium with the oxide or carbides. This technique was also used to confirm the phases which were identified by X-ray diffraction. This technique, in general, was very successful, except for identifying the oxides above $\mathrm{V}_{2} \mathrm{O}_{3}$. They were usually too porous to get accurate compositional measurements. In addition, $\mathrm{V}_{2} \mathrm{O}$ and $\mathrm{V}_{4} \mathrm{O}$ are very difficult to differentiate by $\mathrm{X}$-ray diffraction. Their structures are very similar, and from X-ray diffraction, the multicrystaline pellet does not give accurate enough intensity measurements to differentiate the two phases. The microprobe analysis, however, used in conjunction with the $\mathrm{X}$ ray data is helpful for differentiating the two phases.

An important problem in microprobe analysis is the difficulty of measuring 
oxygen in vanadium. This is the worst case for measuring oxygen by microprobe analysis in the periodic table. The $K_{\alpha}$ line in oxygen is absorbed by the $L_{\alpha}$ line in vanadium. The $K_{\alpha}$ oxygen line is so close to the $L_{\alpha}$ line in vanadium that about $95 \%$ of the photons emitted from oxygen are absorbed by vanadium. This makes the compositional analysis for oxygen very difficult.

To check the accuracy of the measurements on the vanadium oxides, a series of standards were made: $\mathrm{V}_{4} \mathrm{O}, \mathrm{V}_{2} \mathrm{O}, \mathrm{VO}, \mathrm{V}_{2} \dot{\mathrm{O}}_{3}, \mathrm{VO}_{2}, \mathrm{~V}_{2} \mathrm{O}_{5^{\circ}}$. The composition of oxygen and vanadium was within .1 percent of the formulas as written. It was observed that the oxygen analysis was always too low, but the vanadium analysis was still accurate. By adjusting the mass absorption coefficient of oxygen in vanadium, the oxygen analysis could be fit within 2 mole percent in the range 0 60 atomic percent oxygen. Above this composition, the mass absorption coefficient of oxygen in vanadium could not be adequately adjusted. The vanadium compositional analysis was always within .5 percent of the known composition of the standards. Consequently, the oxygen composition could be obtained by difference.

Carbon and oxygen contamination was cherked for in several samples. Some carbon samples were checked for oxygen. The limit of detectability is about 5 atomic percent oxygen, and no appreciable amount of oxygen was ever detected in the carbon samples. Likewise, some oxygen samples were checked for carbon. The limit of detectability for carbon is around 1 atomic percent, and no 
appreciable amount of carbon was ever detected in any of the samples.

See Appendix C for additional information on instrument specifications. 


\section{References}

1. M. Cima and L. Brewer, "The Generalized Lewis Acid-Base Titration of Palladium and Niobium," Met. Trans. B, 19B, 893-917 (1988).

2. J. Kouvetakis, "I-Stability Range of MoC (hP2), II-Thermodynamic Properties of Generalized Lewis Acid-Base Intermetallics," Ph.D. Thesis, U. C. Berkeley, LBL-25340 (1988).

3. J. Gibson, "Thermochemistry of Acid-Base Stabilized Transition Metal Alloys by Carbide and Nitride Equilibria and Knudsen Effusion Vapor Pressures," Ph.D. Thesis, LBL-16233 (1983).

4. M. J. Cima, "Thermochemical Properties of Group IVB and VB Transition Metal Alloys with Platinum Group Metals: Acid-Base Stabilization," Ph.D. Thesis, U. C. Berkeley, LBL-21951 (1986).

5. W. L. Worrell, "Galvanic-Cell Investigations with a $\mathrm{CaF}_{2}$ Solid Electrolyte at Elevated Temperatures," Solid State Ionics; 3/4, 559-562 (1981). 


\section{Chapter 5}

\subsection{The Thermodynamics of the Vanadium Oxides}

In order for accurate determinations to be made of the activities of vanadium in the noble metals by oxide and carbide equilibria, the thermodynamics of the oxides and carbides of vanadium must be known accurately. Fortunately there is a considerable amount of data available for these systems. However, there is considerable discrepancy in the literature over the correct values. Several authors have reviewed the available thermodynamics of the vanadium oxides[13], and the discrepancy in the literature is apparent in each review. Briefly the thermodynamic data will be reviewed here.

\section{The Higher Oxides}

Thermodynamic data for many compounds can be compiled in a dense form by the use of the Giauque function, $-\left(G^{\circ}-H^{\circ}{ }_{298}\right) / R T$. Basically this function is the entropy at $298 \mathrm{~K}$ plus the change in enthalpy and entropy as a function of temperature. This function is considered a good function for fitting by polynomials because the function changes slower with temperature than either the entropy or the enthalpy components. (Appendix E) For $\mathrm{VO}, \mathrm{VO}_{3 / 2}, \mathrm{VO}_{2}$, the Giauque function is obtained primarily from data tabulated by Gurvich. [4] For 
the Magnelli phases, the Giauque function was taken as a linear function of the $\mathrm{VO}_{3 / 2}$ and the $\mathrm{VO}_{2}$ functions. The justification for this is given by Brewer and Ebbinghaus.[1]

To complete the thermodynamic data the enthalpy of formation at $298 \mathrm{~K}$ is needed to calculate activities. It is important to note that $\mathrm{VO}_{2}$ and $\mathrm{VO}_{5 / 3}$ undergo phase transitions at $339 \mathrm{~K}$ and $430 \mathrm{~K}$ respectively. The enthalpies of formation extrapolated to $298 \mathrm{~K}$ and listed for these two compounds correspond to the high temperature structure. There are two reasons for doing this. First, the high temperature phase is structurally similar to the other Magnelli phases. Second, the 8 assumption that the Giauque function is a linear function of oxygen concentration would not be valid if the enthalpy of formation for the low temperature phase is used. The enthalpies of formation with their reference sources are listed in Table 5.5. For the Magnelli phases the enthalpy of formation was calculated from galvanic cell and gas equilibration data.[5-7] Kleppa also measured the enthalpy of formation for many of these phases.[8] It was concluded that a more accurate representation of the Gibbs energy could be obtained if the enthalpies calculated from gas equilibration and cell measurements were used. Table 5.1 lists the Giauque function for most of the oxide phases of vanadium. 
Table 5.1. Giauque function of the vanadium oxides.[1] $-\left(G^{\circ}-H^{\circ}{ }_{298}\right) / R T=A+B T+C T^{2}+D^{3}(k K /$ mole of species as written $)$

\begin{tabular}{lllllll}
\hline species & $\mathrm{T}_{\min } \mathrm{T}_{\max }$ & $\mathrm{A}$ & $10^{3} \mathrm{~B}$ & $10^{6} \mathrm{C}$ & $10^{9} \mathrm{D}$
\end{tabular}

$\begin{array}{lllllll}\mathrm{VO}(\mathrm{s}) & 1000 & 2100 & 1.316 & 7.004 & -1.359 & 0.1476\end{array}$

$\begin{array}{lllllll}\mathrm{VO}_{3 / 2}(\mathrm{~s}) & 1000 & 2300 & 2.516 & 8.576 & -1.999 & 0.2372\end{array}$

$\begin{array}{lllllll}\mathrm{VO}_{5 / 3}(\mathrm{~s}) & 1000 & 2100 & 2.843 & 9.013 & -2.075 & 0.2461\end{array}$

$\begin{array}{lllllll}\mathrm{VO}_{7 / 4}(\mathrm{~s}) & 1000 & 2100 & 3.006 & 9.321 & -2.113 & 0.2506\end{array}$

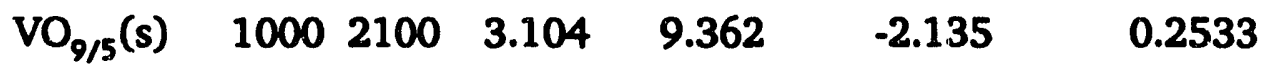

$\begin{array}{lllllll}\mathrm{VO}_{11 / 6}(\mathrm{~s}) & 1000 & 2100 & 3.169 & 9.449 & -2.150 & 0.2551\end{array}$

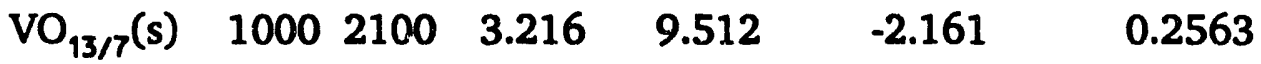

$\begin{array}{lllllll}\mathrm{VO}_{15 / 8}(\mathrm{~s}) & 1000 & 2100 & 3.251 & 9.559 & -2.169 & 0.2573\end{array}$

$\begin{array}{lllllll}\mathrm{VO}_{17 / 9}(\mathrm{~s}) & 1000 & 2000 & 3.278 & 9.595 & -2.176 & 0.2580\end{array}$

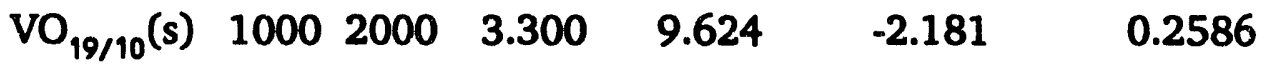

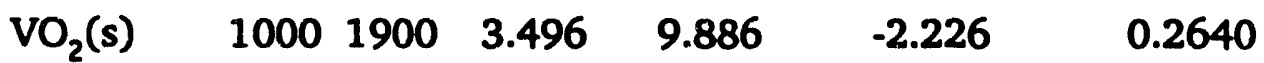

The Lower Oxides

For the lower oxide thermodynamics, there are many conflicting reports. [13,9-16] Tetot and Picard $[9,10]$ have extensively reviewed the existing data and have done their own painstaking analysis of the suboxide systems. They used

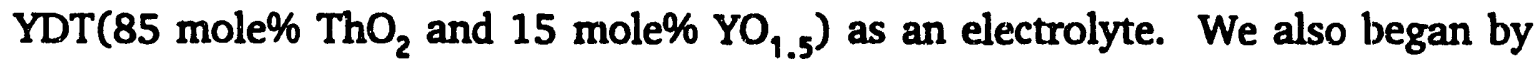
using YDT as the electrolyte in our experiments. YDT is known to be a good electrolyte for solid state systems with low partial pressures of oxygen. Additionally, we were encouraged by Tetot and Picard's apparent success with the electrolyte when used with the vanadium oxides. However, it was discovered 
during our experiments that this electrolyte is a poor choice for the vanadiumoxygen system because there is a reaction at the electrode-electrolyte interface. As a result, the data of Tetot and Picard have been assessed as inaccurate and have been discarded. More will be said about this in Chapter 6. The data which seemed to be most reliable and reasonable are the data of Vasil'eva.[11-13] They used a $\mathrm{ThO}_{2}$ electrolyte which was doped with $1 \%$ CaO. Most importantly, they took their data toward the beginning of the experiment which is consistent with our conclusions in Chapter 6 that only data toward the beginning of the experiment is reliable.

The activity of vanadium in the $\mathrm{V}_{4} \mathrm{O}-\mathrm{V}_{2} \mathrm{O}$ and the $\mathrm{V}_{2} \mathrm{O}-\mathrm{VO}$ equilibria were calculated in two ways. The first way follows.

The partial Gibbs energy of oxygen in vanadium for the two phase mixtures is given below using Vasil'eva's data.

$5.18 \mathrm{~V}(\mathrm{~s})+\mathrm{O}_{2}(\mathrm{~g})=8 \mathrm{VO}_{1 / 4}(\mathrm{~s})$

$$
\Delta \mathrm{G}^{\circ}{ }_{02} / \mathrm{R}(\mathrm{kK})=-116.79+22.610(\mathrm{~T} / 1000) ; \quad 1147-1336 \mathrm{~K}
$$

$5.2 \quad 8 \mathrm{VO}_{1 / 4}(\mathrm{~s})+\mathrm{O}_{2}(\mathrm{~g})=8 \mathrm{VO}_{1 / 2}(\mathrm{~s})$

$\Delta G_{02}^{o} / R(k K)=-101.02+21.875(T / 1000) ; \quad 1123-1370 \mathrm{~K}$

$5.3 \quad 4 \mathrm{VO}_{1 / 2}(\mathrm{~s})+\mathrm{O}_{2}(\mathrm{~g})=4 \mathrm{VO}(\mathrm{s})$

$\Delta G_{02}^{\circ} / R(k K)=-95.556+18.166(\mathrm{~T} / 1000) ; 1138-1328 \mathrm{~K}$

The Gibbs energy of formation for $\mathrm{VO}_{1 / 2}$ can be obtained simply by adding 5.1 and 5.2 then dividing by eight. The Gibbs energy of formation for VO can be obtained by adding 5.1, 5.2, and 2 times 5.3 then dividing by eight. The free energy of formation data for $\mathrm{VO}_{1 / 4}$ and $\mathrm{VO}_{1 / 2}$ are given in Table 5.3. The formation data 
for $\mathrm{VO}$ and $\mathrm{VO}_{3 / 2}$ are given by Brewer.[17]

Using the Gibbs energy of formation data evaluated from Equations 5.1-

5.3, the Gibbs energy for the following reactions can be obtained.

$5.42 \mathrm{VO}_{1 / 4}(\mathrm{~s})=\mathrm{VO}_{1 / 2}(\mathrm{~s})+\mathrm{V}(\mathrm{s})$

$\Delta G^{\circ} / R(k K)=1.97065-0.09189(T / 1000)$

$5.52 \mathrm{VO}_{1 / 2}(\mathrm{~s})=\mathrm{VO}(\mathrm{s})+\mathrm{V}(\mathrm{s})$

$\Delta \mathrm{G}^{\circ} / \mathrm{R}(\mathrm{kK})=3.3369-1.0204(\mathrm{~T} / 1000)$

For each of these equations the activity of vanadium is readily calculated by assuming that the activity of the oxides are equal to 1(Appendix B). The results are given in Table 5.2.

There are considerable homogeneity ranges in the lower oxides. Consequently, the activity of the oxide may change significantly as a function of composition. Not only does this affect the assumption that the activity of the oxide is unity, it also affects the accuracy of adding Equations 5.1, 5.2, and 5.3 together because $\mathrm{VO}_{1 / 2}$ in equilibrium with $\mathrm{VO}_{1 / 4}$ is different from $\mathrm{VO}_{1 / 2}$ in equilibrium with VO. However, there are some data by Naito,et al.[17-19] on the vaporization of the vanadium oxides that implies that the activities of the phases $\mathrm{VO}_{1 / 4}$ and $\mathrm{VO}_{1 / 2}$ vary little as a function of composition. Consequently, little error is introduced by the first method.(See Appendix B)

The second approach is to use the Gibbs-Duhem relation. Vasil'eva[11-13] has evaluated the partial pressure of oxygen in equilibrium with vanadium-oxygen alloys for a considerable number of compositions. These data can be fit and 
integrated to give the activities of vanadium in equilibrium with the lower oxides.(Table 5.2.) Comparing these values with those values obtained in the first method one can see that the difference is relatively small. The final value taken is obtained by averaging the log of the activity of the values obtained from each technique. The resulting averages are tabulated in Table 5.7.

Table 5.2. Activity of the two phase lower oxides.

\begin{tabular}{|c|c|c|}
\hline $\begin{array}{l}\mathrm{T}=900^{\circ} \mathrm{C} \\
\text { phases }\end{array}$ & $a_{v}$ (1 $1^{\text {st }}$ Method) & $\begin{array}{l}\text { Gibbs-Duhem } \\
a_{v} \text { ( } 2^{\text {nd }} \text { Method) }\end{array}$ \\
\hline $\mathrm{V}-\mathrm{V}_{4} \mathrm{O}$ & $7.4849 \mathrm{E}-01$ & \\
\hline $\mathrm{V}_{4} \mathrm{O}-\mathrm{V}_{2} \mathrm{O}$ & 2.0431E-01 & $1.4402 \mathrm{E}-01$ \\
\hline $\mathrm{V}_{2} \mathrm{O}-\mathrm{VO}$ & $1.6112 \mathrm{E}-01$ & $1.1690 \mathrm{E}-01$ \\
\hline $\begin{array}{l}\mathrm{T}=1000^{\circ} \mathrm{C} \\
\text { phases }\end{array}$ & $a_{v}\left(1^{\text {st }}\right.$ Method) & $\begin{array}{l}\text { Gibbs-Duhem } \\
a_{v}\left(2^{\text {nd }} \text { Method) }\right.\end{array}$ \\
\hline $\mathrm{V}-\mathrm{V}_{4} \mathrm{O}$ & $7.4670 \mathrm{E}-01$ & \\
\hline $\mathrm{V}_{4} \mathrm{O}-\mathrm{V}_{2} \mathrm{O}$ & $2.3313 E-01$ & 2.0357E-01 \\
\hline $\mathrm{V}_{2} \mathrm{O}-\mathrm{VO}$ & $2.0147 \mathrm{E}-01$ & $1.7358 \mathrm{E}-01$ \\
\hline $\begin{array}{l}\mathrm{T}=1100^{\circ} \mathrm{C} \\
\text { phases }\end{array}$ & $a_{v}$ ( $1^{\text {st }}$ Method) & $\begin{array}{l}\text { Gibbs-Duhem } \\
a_{v}\left(2^{\text {nd }} \text { Method) }\right.\end{array}$ \\
\hline $\mathrm{V}-\mathrm{V}_{4} \mathrm{O}$ & 7.4498E-01 & \\
\hline $\mathrm{V}_{4} \mathrm{O}-\mathrm{V}_{2} \mathrm{O}$ & $2.6096 \mathrm{E}-01$ & $2.7352 \mathrm{E}-01$ \\
\hline $\mathrm{V}_{2} \mathrm{O}-\mathrm{VO}$ & $2.4385 \mathrm{E}-01$ & $2.4326 \mathrm{E}-01$ \\
\hline
\end{tabular}


Table 5.3. Thermodynamics of formation at 1273K

\begin{tabular}{lllll}
\hline phases & $\Delta G^{\circ} / R(\mathrm{kK})$ & $\Delta H^{\circ} / R(\mathrm{kK})$ & $\Delta S^{\circ} / \mathrm{R}$ & reference \\
\hline $\mathrm{VO}_{1 / 4}(\mathrm{~s})$ & $-10.997 \pm 0.55-14.60$ & -2.83 & 1 \\
$\mathrm{VO}_{1 / 2}(\mathrm{~s})$ & $-20.152 \pm 0.60-27.23$ & -5.56 & 1 \\
$\mathrm{VO}(\mathrm{s})$ & $-38.014 \pm 0.16-50.31$ & -9.65 & 17 \\
$\mathrm{VO}_{3 / 2}(\mathrm{~s})$ & $-53.692 \pm 0.13-72.03$ & -14.40 & 17
\end{tabular}

\subsection{The Thermodynamics of the Vanadium Carbides}

The thermodynamics of the vanadium carbides are calculated similarly to the thermodynamics of the higher vanadium oxides. The Giauque function for $\mathrm{C}(\mathrm{gr})$ is given by Brewer.[17] The data for $\mathrm{VC}_{0.88}$ were obtained from data tabulated by Storms.[21] For $\mathrm{VC}_{0.46}\left(\mathrm{~V}_{2} \mathrm{C}\right)$ and $\mathrm{VC}_{0 . \pi}(\mathrm{VC})$, to obtain an accurate Giauque function was more difficult. Carlson, Ghaneya, and Smith [22] have reviewed the thermodynamics of the V-C system. From the $S_{298}$ values and the heat capacity equations they give, a Giauque function for these phases was calculated. Between these two phases there is the $\mathrm{V}_{4} \mathrm{C}_{3}$ phase. They have calculated the Gibbs energy of formation of this phase from a linear interpolation of $\mathrm{V}_{2} \mathrm{C}$ and $\mathrm{VC}$. This indicates that the activity drop across this phase is expected to be very small. Consequently, the equilibria between $\mathrm{VC} / \mathrm{N}_{4} \mathrm{C}_{3}$ and $\mathrm{V}_{4} \mathrm{C}_{3} / \mathrm{N}_{2} \mathrm{C}$ are nearly identical. This means that the value of the activity for either equilibria can be obtained by considering only the equilibria $\mathrm{V}_{2} \mathrm{C} / \mathrm{VC}$. 
Table 5.4. The Giauque function for the vanadium carbides.

$-\left(\mathrm{G}^{\circ}-\mathrm{H}^{\circ}{ }_{298}\right) / \mathrm{RT}=\mathrm{A}+\mathrm{BT}+\mathrm{CT}^{2}+\mathrm{DT}^{3}(\mathrm{kK} /$ mole of species as written $)$

$\begin{array}{llllll}\text { species } & \mathrm{T}_{\min } \mathrm{T}_{\operatorname{mx}} & \mathrm{A} & 10^{3} \mathrm{~B} & 10^{6} \mathrm{C} & 10^{9} \mathrm{D}\end{array}$

$\begin{array}{lllllll}\mathrm{VC}_{0.88}(\mathrm{~s}) & 1000 & 2500 & 1.286 & 5.3200 & -1.006 & 0.10278 \\ \mathrm{VC}_{0.46}(\mathrm{~s}) & 1000 & 1600 & 1.7259 & 10.2944 & -3.8252 & 0.66624 \\ \mathrm{VC}_{0.7 \pi}(\mathrm{s}) & 1000 & 1600 & 1.3855 & 10.2656 & -3.6191 & 0.62773\end{array}$

5.3. The Thermodynamics of $V(s), O_{2}(g)$, and $C(g r)$.

The thermodynamics of $\mathrm{V}(\mathrm{s}), \mathrm{O}_{2}(\mathrm{~g})$, and $\mathrm{C}(\mathrm{gr})$ are needed to calculate thermodynamic equilibria of our carbide and oxide equilibria. The Giauque functions for the elements are given in Table 5.5. Also, Table 5.6 lists all the enthalpies and entropies at $298 \mathrm{~K}$ for the elements, oxides, and carbides of interest.

From all the thermodynamic data the activity of vanadium can be calculated in the binary oxide and binary carbide equilibria of interest. Table 5.7 lists the activity of vanadium in each potentially useful equilibrium.

Table 5.5. The Giauque function for related elements.[17]

$-\left(\mathrm{G}^{\circ}-\mathrm{H}^{\circ}{ }_{298}\right) / \mathrm{RT}=\mathrm{A}+\mathrm{BT}+\mathrm{CT}^{2}+\mathrm{DT}^{3}+\mathrm{ET}^{4}(\mathrm{kK} /$ mole of species as written $)$

$\begin{array}{lllllll}\text { species } & \mathrm{T}_{\min } \mathrm{T}_{\max } \mathrm{A} & 10^{3} \mathrm{~B} & 10^{6} \mathrm{C} & 10^{9} \mathrm{D} & 10^{12} \mathrm{E}\end{array}$

$\begin{array}{llllllll}\mathrm{C}(\mathrm{gr}) & 1000 & 3000 & -0.1600 & 1.9380 & -0.2790 & 0.0206 & \\ \mathrm{O}_{2}(\mathrm{~g}) & 1000 & 3000 & 22.987 & 4.5769 & -1.2107 & 0.2154 & -0.01686 \\ \mathrm{~V}(\mathrm{~s}) & 1000 & 2300 & 2.023 & 3.942 & -1.141 & 0.2465 & -0.0224 \\ \mathrm{~V}(\mathrm{l}) & 2000 & 3800 & 0.037 & 5.164 & -1.119 & 0.1542 & -0.00923\end{array}$


Table 5.6. Entropy and enthalpy at 298K.

\begin{tabular}{llll}
\hline species & $\Delta \mathrm{H}_{f, 298}^{\circ} / \mathrm{R}(\mathrm{kK})$ & $\mathrm{S}_{298}^{\circ} / \mathrm{R}$ & reference \\
\hline $\mathrm{VC}_{0.88}(\mathrm{~s})$ & $-12.25 \pm 0.40$ & $3.326 \pm 0.015$ & 23 \\
$\mathrm{VC}_{0.46}(\mathrm{~s})$ & $-8.046 \pm 0.31$ & $3.236 \pm 0.015$ & 22 \\
$\mathrm{VC}_{0 . \pi}(\mathrm{s})$ & $-11.95 \pm 0.72$ & $3.1536 \pm 0.005$ & 22 \\
$\mathrm{VO}(\mathrm{s})$ & $-51.927 \pm 0.11$ & $4.030 \pm 0.048$ & 1 \\
$\mathrm{VO}_{3 / 2}(\mathrm{~s}, 1)$ & $-73.293 \pm 0.10$ & $5.691( \pm 0.02)$ & 1 \\
$\mathrm{VO}_{5 / 3}(\mathrm{~s})$ & $-77.728( \pm 0.03)$ & $6.164( \pm 0.02)$ & 1 \\
$\mathrm{VO}_{7 / 4}(\mathrm{~s})$ & $-79.884( \pm 0.03)$ & $6.414( \pm 0.02)$ & 1 \\
$\mathrm{VO}_{9 / 5}(\mathrm{~s})$ & $-81.107( \pm 0.03)$ & $6.564( \pm 0.02)$ & 1 \\
$\mathrm{VO}_{11 / 6}(\mathrm{~s})$ & $-81.915( \pm 0.03)$ & $6.664( \pm 0.02)$ & 1 \\
$\mathrm{VO}_{13 / 7}(\mathrm{~s})$ & $-82.402( \pm 0.03)$ & $6.735( \pm 0.02)$ & 1 \\
$\mathrm{VO}_{15 / 8}(\mathrm{~s})$ & $-82.868( \pm 0.03)$ & $6.789( \pm 0.02)$ & 1 \\
$\mathrm{VO}_{17 / 9}(\mathrm{~s})$ & $-83.139( \pm 0.03)$ & $6.830( \pm 0.02)$ & 1 \\
$\mathrm{VO}_{19 / 10}(\mathrm{~s})$ & $-83.357( \pm 0.03)$ & $6.863( \pm 0.02)$ & 1 \\
$\mathrm{VO}_{2}(\mathrm{~s})$ & $-85.311 \pm 0.10$ & $7.189 \pm 0.015$ & 1 \\
$\mathrm{~V}^{(s, 1)}$ & 0.00 & $3.573 \pm 0.01$ & 17 \\
$\mathrm{O}_{2}(\mathrm{~g})$ & 0.00 & $24.661 \pm 0.0006$ & 17 \\
$\mathrm{C}(\mathrm{gr})$ & 0.00 & $0.69 \pm 0.01$ & 17 \\
& & &
\end{tabular}

values given are per mole of species as written 
Table 5.7. Activity in two phase regions at selected temperatures.

\begin{tabular}{|c|c|c|c|c|}
\hline phases & $\mathrm{T}(\mathrm{K})$ & $\Delta \bar{G}_{\checkmark} / R$ & $a_{v}$ & reference \\
\hline \multirow[t]{3}{*}{$\mathrm{V}_{4} \mathrm{O}-\mathrm{V}_{2} \mathrm{O}$} & 1173 & $-2.068 \pm 0.30$ & $1.715 \mathrm{E}-01$ & $11-13$ \\
\hline & 1273 & -1.934 & $2.178 \mathrm{E}-01$ & \\
\hline & 1373 & -1.812 & 2.672E-01 & \\
\hline \multirow[t]{3}{*}{$\mathrm{V}_{2} \mathrm{O}-\mathrm{VO}$} & 1173 & $-2.330 \pm 0.35$ & $1.372 \mathrm{E}-01$ & $11-13$ \\
\hline & 1273 & -1.940 & $2.178 \mathrm{E}-01$ & \\
\hline & 1373 & -1.948 & $2.421 \mathrm{E}-01$ & \\
\hline \multirow[t]{3}{*}{$\mathrm{VO}-\mathrm{V}_{2} \mathrm{O}_{3}$} & 1173 & $-6.330 \pm 0.46$ & $4.533 E-03$ & $1,5-7$ \\
\hline & 1273 & -6.297 & 7.106E-03 & \\
\hline & 1373 & -6.299 & $1.018 \mathrm{E}-02$ & \\
\hline \multirow{3}{*}{$\mathrm{V}_{2} \mathrm{O}_{3}-\mathrm{V}_{3} \mathrm{O}_{5}$} & 1173 & $-30.678 \pm 0.25$ & $4.383 E-12$ & $1,5-7$ \\
\hline & 1273 & -30.682 & $3.409 \mathrm{E}-11$ & \\
\hline & 1373 & -30.696 & $1.952 \mathrm{E}-10$ & \\
\hline \multirow[t]{3}{*}{$\mathrm{V}_{3} \mathrm{O}_{5}-\mathrm{V}_{4} \mathrm{O}_{7}$} & 1173 & $-32.993 \pm 0.25$ & $6.092 \mathrm{E}-13$ & $1,5-7$ \\
\hline & 1273 & -32.292 & $9.621 \mathrm{E}-12$ & \\
\hline & 1373 & -32.090 & $9.378 \mathrm{E}-11$ & \\
\hline \multirow[t]{3}{*}{$\mathrm{V}_{2} \mathrm{C}-\mathrm{VC}$} & 1173 & $-7.425 \pm 0.90$ & $1.783 \mathrm{E}-03$ & 17,22 \\
\hline & 1273 & -8.042 & $1.805 E-03$ & \\
\hline & 1373 & -8.661 & $1.822 \mathrm{E}-03$ & \\
\hline \multirow[t]{3}{*}{ VC-C } & 1173 & $-11.458 \pm 0.32$ & 5.727E-05 & 17,22 \\
\hline & 1273 & -11.395 & $1.295 \mathrm{E}-04$ & \\
\hline & 1373 & -11.333 & $2.601 \mathrm{E}-04$ & \\
\hline
\end{tabular}


5.4. The Thermodynamics of the Reference Electrodes.

The thermodynamics of the reference electrodes used in the galvanic cell are also important. The primary quantities of interest are the partial pressures of oxygen that are in equilibrium with the reference electrodes at a specified temperature. For some systems like $\mathrm{Ta} / \mathrm{Ta}_{2} \mathrm{O}_{5}$ this information is well known. If the partial Gibbs energy of oxygen in to the reference electrode is not known, it can be calculated using the method outlined in section 3.4. Table 5.8 lists the thermodynamics for the reference electrodes which are used here.

Table 5.8. Partial molar quantities for some two phase oxides at $1273 \mathrm{~K}$.

\begin{tabular}{|c|c|c|c|c|c|}
\hline phases & $\begin{array}{c}1273 \mathrm{~K} \\
\Delta \overline{\mathrm{G}}_{\mathrm{o2}} / \mathrm{R}(\mathrm{kK})\end{array}$ & $\begin{array}{c}1273 \mathrm{~K} \\
P_{02}(\mathrm{~atm} .)\end{array}$ & $\Delta \overline{\mathrm{H}}_{\mathrm{o} 2} / \mathrm{R}(\mathrm{kK})$ & $\Delta \bar{S}_{02} / R$ & reference \\
\hline VO- $\mathrm{V}_{2} \mathrm{O}_{3}$ & $-62.492 \pm 0.20$ & $4.789 \mathrm{E}-22$ & -93.497 & -24.356 & 7 \\
\hline $\mathrm{V}_{2} \mathrm{O}_{3}-\mathrm{V}_{3} \mathrm{O}_{5}$ & $-30.591 \pm 0.15$ & $5.770 \mathrm{E}-11$ & -53.985 & -18.720 & 7 \\
\hline $\mathrm{V}_{3} \mathrm{O}_{5}-\mathrm{V}_{4} \mathrm{O}_{7}$ & $-25.070 \pm 0.10$ & $2.800 \mathrm{E}-9$ & -47.866 & -21.739 & 7 \\
\hline $\mathrm{Ta}-\mathrm{Ta}_{2} \mathrm{O}_{5}$ & $-71.579 \pm 0.15$ & $3.803 E-25$ & -96.819 & -19.83 & 24 \\
\hline $\begin{array}{l}\mathrm{NbO}-\mathrm{NbO}_{2} \\
\text { values give }\end{array}$ & $\begin{array}{l}-63.839 \pm 0.15 \\
\text { en per mole of spe }\end{array}$ & $\begin{array}{l}1.663 \mathrm{E}-22 \\
\text { ies as writte }\end{array}$ & -81.905 & -14.19 & 2 \\
\hline
\end{tabular}




\subsection{Thermodynamics for the Galvanic Cell System.}

From the method outlined in section 3.4, a relationship between the activity of vanadium and the observed EMF can be derived where the reference electrode is $\mathrm{Ta} / \mathrm{Ta}_{2} \mathrm{O}_{5}$. The partial thermodynamics of this reference electrode are given by Tetot and Picard.[9] The thermodynamics of the vanadium oxides are obtained from the review by Brewer and Ebbinghaus.[1] Since the cell data was only valid at one temperature namely $1273 \mathrm{~K}$ (see Chapter 6 ), these equations are only for $\mathrm{T}$ $=1273 \mathrm{~K}$.

\section{A system with $\mathrm{V}_{2} \underline{\mathrm{O}}_{3}(\mathrm{~s})$}

For a composite which contains $\mathrm{V}_{2} \mathrm{O}_{3}$ and an alloy

$$
\mathrm{V}_{2} \mathrm{O}_{3} / \mathrm{V}(\mathrm{NM}) / / \mathrm{YDT} / / \mathrm{Ta} / \mathrm{Ta}_{2} \mathrm{O}_{5}
$$

where $\mathrm{V}(\mathrm{NM})$ is one or two vanadium noble metal alloys and YDT is yttria doped thoria or another electrolyte where $t_{\text {ion }}=1$, the equation that relates the EMF, $E$ in volts, to the activity of vanadium is given by

$$
5.6 \quad \ln \mathrm{a}_{\mathrm{v}}=-27.3473 \mathrm{E}-0.00607 \pm 0.5
$$

\section{For a system with VO(s)}

For a composite which contains VO equilibrated with one or more alloys

$$
\mathrm{VO} / \mathrm{V}(\mathrm{NM}) / / \mathrm{YDT} / / \mathrm{Ta} / \mathrm{Ta}_{2} \mathrm{O}_{5}
$$

the following is the equation used which relates the activity of vanadium to the EMF observed.

$5.7 \quad \ln \mathrm{a}_{\mathrm{v}}=-18.23151 \mathrm{E}-1.74725 \pm 0.5$ 


\section{References}

1. L. Brewer and B. B. Ebbinghaus, "The Thermodynamics of the Solid Oxides of Vanadium," Thermochima Acta, 129, $49-55$ (1988).

2. T. Matsui and K. Naito, "Thermodynamic Properties of the Phases in the V$\mathrm{O}$ and $\mathrm{Nb}-\mathrm{O}$ Systems at High Temperature," Netsu Sokutei, 15(1), 27-41 (1988) (Japanese).

3. C. B. Alcock and C. Ji, "The Vanadium - Oxygen System - A Review," High Temp.-High Press., 21, 139-147 (1990).

4. V. P. Glushko, L. V. Gurvich, G. A. Bergman, I. V. Veitz, V. A. Medvedev, G. A. Khachkuruzov, and V. S. Yungman, Thermodynamic Properties of Individual Substances, Vol. IV, High-Temperature Institute, State Institute of Applied Chemistry, National Academy of Sciences of the U.S.S.R., Moscow (1982) (Russian).

5. H. Endo, M. Wakihara, M. Tanigughi, and T. Katsura, "Phase Equilibria in the $\mathrm{V}_{2} \mathrm{O}_{3}-\mathrm{VO}_{2}$ System at High Temperatures," Bull. Chem. Soc. Japan, 46, 2087-2090 (1973).

6. J. S. Anderson and A. S. Kahn, "Phase equilibria in the Vanadium-Oxygen System," J. Less-Comm. Met., 22, 209-218 (1970).

7. H. Okinaka, K. Kosuge, and S. Kachi, "Phase Equilibria and Thermodynamic Properties in the $\mathrm{V}_{\mathrm{n}} \mathrm{O}_{2 \mathrm{n}-1}$ System," Trans. Jap. Inst. Metals, 12(1), 44-48 (1971).

8. T. V. Charlu and O. J. Kleppa, "High-Temperature Combustion Calorimetry. II Enthalpies of Formation of the Vanadium Oxides," High Temp. Sci., 5, 260-268 (1973). 
9. R. Tetot and C. Picard, "High Temperature Thermodynamics of the Vanadium-Oxygen System for $0<0 / V<1.5$, Part I," J. Solid State Chem., 66, 324-331 (1987).

10. R. Tetot and C. Picard, "High Temperature Thermodynamics of the Vanadium-Oxygen System for 0<O/V<1.5, Part II," J. Solid State Chem., 68, 88-93 (1987).

11. I.A. Vasil'eva and A.N. Seregin, "Partial Thermodynamic Properties of Vanadium Oxides in the Homogeneity Region of the $\gamma$ - and $\delta$ - Phases," Russ. J. Phys. Chem., 56(6), 837-839 (1982).

12. I.A. Vasel'eva and A.N. Seregin, "Partial Thermodynamic Properties of Vanadium Oxides in the Homogeneity Region of the $\beta$ - Phase $\left(V_{4} O\right), " R u s s$. J. Phys. Chem., 56(6), 945-946 (1982).

13. I.A. Vasel'eva and A.N. Seregin, "Partial Thermodynamic Properties of Oxides in the Region of $\alpha$-Solid Solutions of Oxygen at High Temperatures," Russ. J. Phys. Chem., 56(7), 986-988 (1982).

14. G.L. Steckel and C.J. Altstetter, "Solubility and Thermodynamic Properties of Vanadium-Oxygen Solid Solutions," Acta Metall., 24, 1131-1136 (1976).

15. D. L. Smith, "Investigation of the Thermodynamics of V-O Solid Solutions by Distribution Coefficient Measurements in the V-O-Na System," Met. Trans., 2, 579-583 (1971).

16. E. Fromm and R. Kirchheim, "E.M.F. Measurements in Vanadium-Oxygen Solid Solutions with $\mathrm{ThO}_{2}-\mathrm{Y}_{2} \mathrm{O}_{3}$ Electrolytes," J. Less-Comm. Met., 26, 403406 (1972).

17. L. Brewer, "High Temperature Thermodynamic Properties of Elements and their Oxides," LBL-23019 (1987). 
18. W. Banchorndhevakul, T. Matsui, and K. Naito, "Vaporization Study on Vanadium Monoxide and Two-Phase Mixture of Vanadium and Vanadium Monoxide by Mass-Spectrometric Method," J. Nucl. Sci. Technol., 23(7), 602611 (1986).

19. W. Banchorndhevakul, T. Matsui, and K. Naito, "Vaporization Study on Vanadium-Oxygen Solid Solution by Mass Spectrometric Method," J. Nucl. Sci. Technol., 23(10), 873-882 (1986).

20. W. Banchorndhevakul, T. Matsui, and K. Naito, "Vaporization Study on $\mathrm{V}_{2} \mathrm{O}_{3}$ and Two-Phase Mixture of $\mathrm{V}_{2} \mathrm{O}_{3}$ and VO by Mass Spectrometric Method," Thermochim. Acta, 88, 301-306 (1985).

21. E. K. Storms, The Refractory Carbides, Vol. 2, Academic Press, New York (1967).

22. O. N. Carlson, A. H. Ghaneya, and J. F. Smith, "The C-V(Carbon-Vanadium) System," Bull. Alloy Phase Diag., 6(2), 115-124 (1985).

23. M. W. Chase,Jr., J. L. Curnutt, H. Prophet, R. A. McDonald, and A. N. Syverud, JANAF Thermochemical Tables, 1975 Supplement, J. Phys. Chem. Ref. Data, 4 (1975) 1.

24. R. Tetot, C. Picard, and P. Gerdanian, "Determination of Oxygen Partial Free Energy for Non-Stoichiometric TiO by E.M.F Measurements," J. Phys. Chem. Solids, 44(11), 1059-1068 (1983). 


\section{Chapter 6}

\subsection{The Ternary Equilibrium Phase Diagrams.}

The phase equilibria obtained from the equilibrated phases given in Appendix A for ten ternary systems, V-NM-C and V-NM-O, are shown in Figures 6.1-6.10. No isolated ternary phases were found in any of the systems. However, not every possible equilibrium has been determined. It is possible that some ternary phases may yet be found. A large intersolubility of the rutile structures was discovered. $\mathrm{VO}_{2}$ dissolves into $\mathrm{IrO}_{2}$ and $\mathrm{IrO}_{2}$ dissolves into $\mathrm{VO}_{2}$. Whether or not the phases are completely miscible has not yet been determined. Likewise, the degree of solid solubility of $\mathrm{VO}_{2}$ in $\mathrm{RhO}_{2}$ and $\mathrm{RhO}_{2}$ in $\mathrm{VO}_{2}$ has not been determined. There is a similar intersolubility behavior of the rutile structures in the $\mathrm{Cr}-\mathrm{Ir}-\mathrm{O}$ and the $\mathrm{Cr}-\mathrm{Rh}-\mathrm{O}$ systems. Maestro, et al report a complete miscibility of $\mathrm{CrO}_{2}$ in $\mathrm{IrO}_{2}$ and $\mathrm{CrO}_{2}$ in $\mathrm{RhO}_{2}$.[1] As a result, it would not be surprising to find that the systems $\mathrm{RhO}_{2}-\mathrm{VO}_{2}$ and $\mathrm{IrO}_{2}-\mathrm{VO}_{2}$ are in actuality completely intermiscible.

All tie lines for the three phase equilibria have not been experimentally determined, yet some of the tie lines have been inserted since other known equilibria fix their location. 


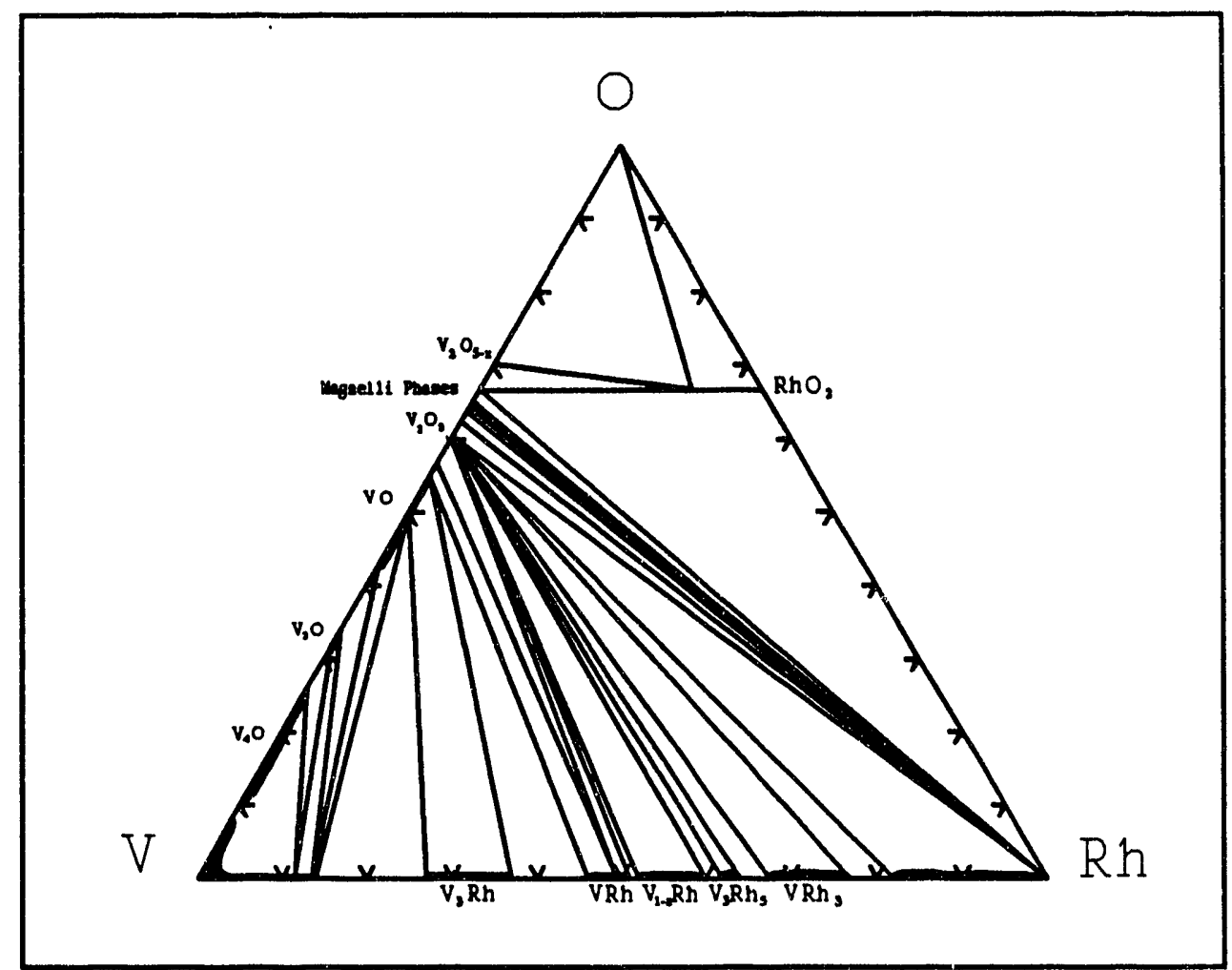

Figure 6.1 . The vanadium-rhodium-oxygen system at $1000^{\circ} \mathrm{C}$

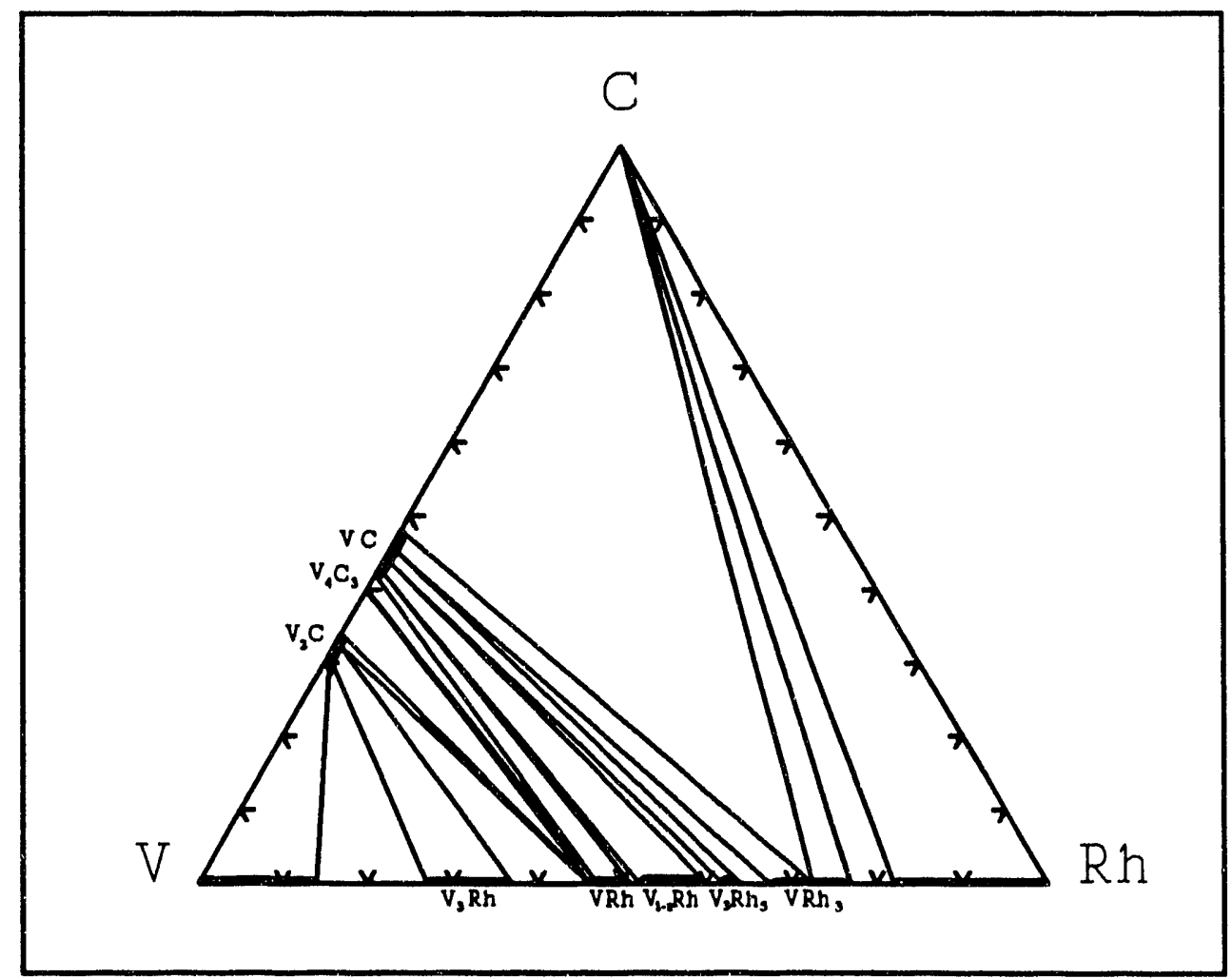

Figure 6.2 . The vanadium-rhodium-carbon system at $1000^{\circ} \mathrm{C}$ 104 


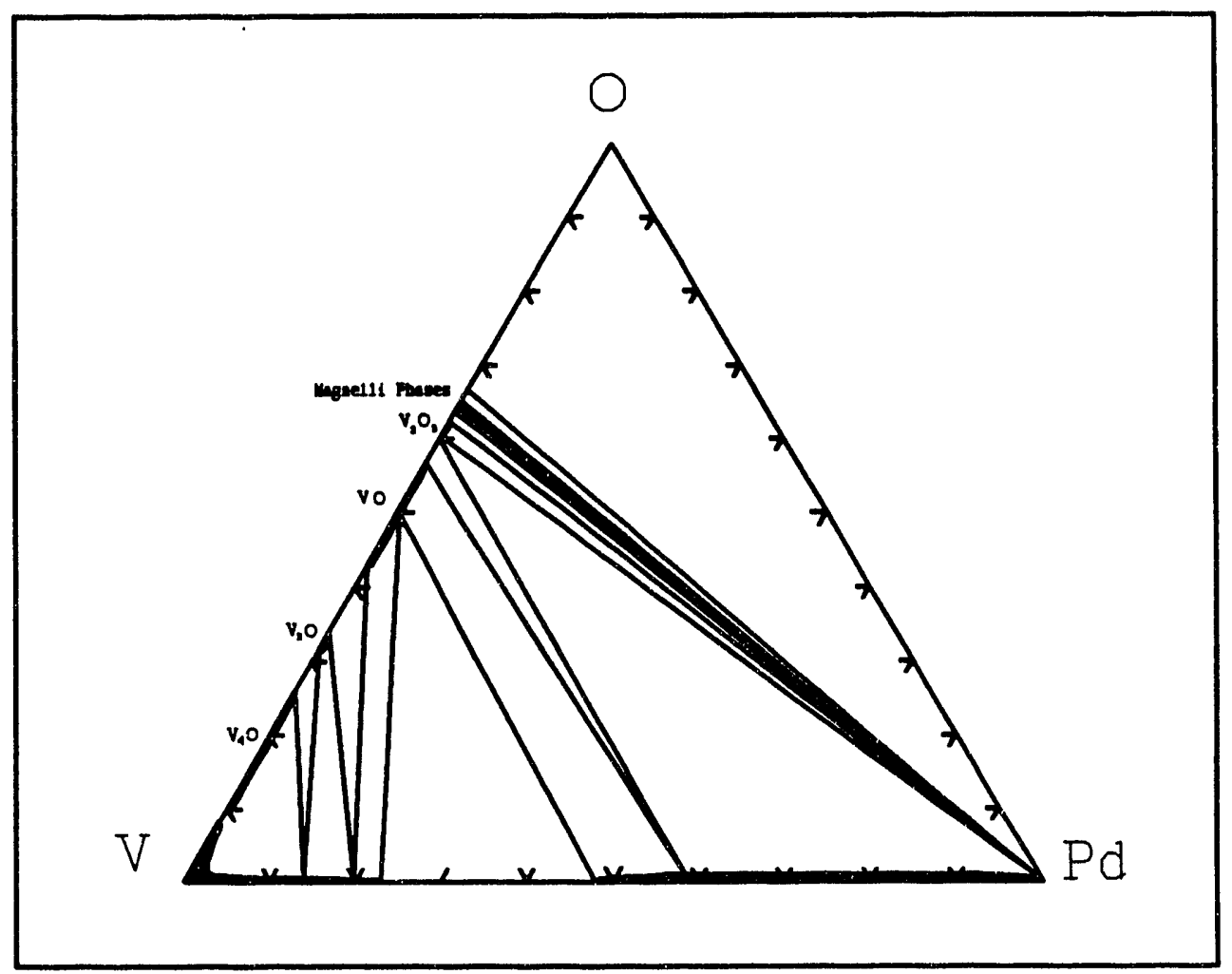

Figure 6.3. The vanadium-palladium-oxygen system at $1000^{\circ} \mathrm{C}$

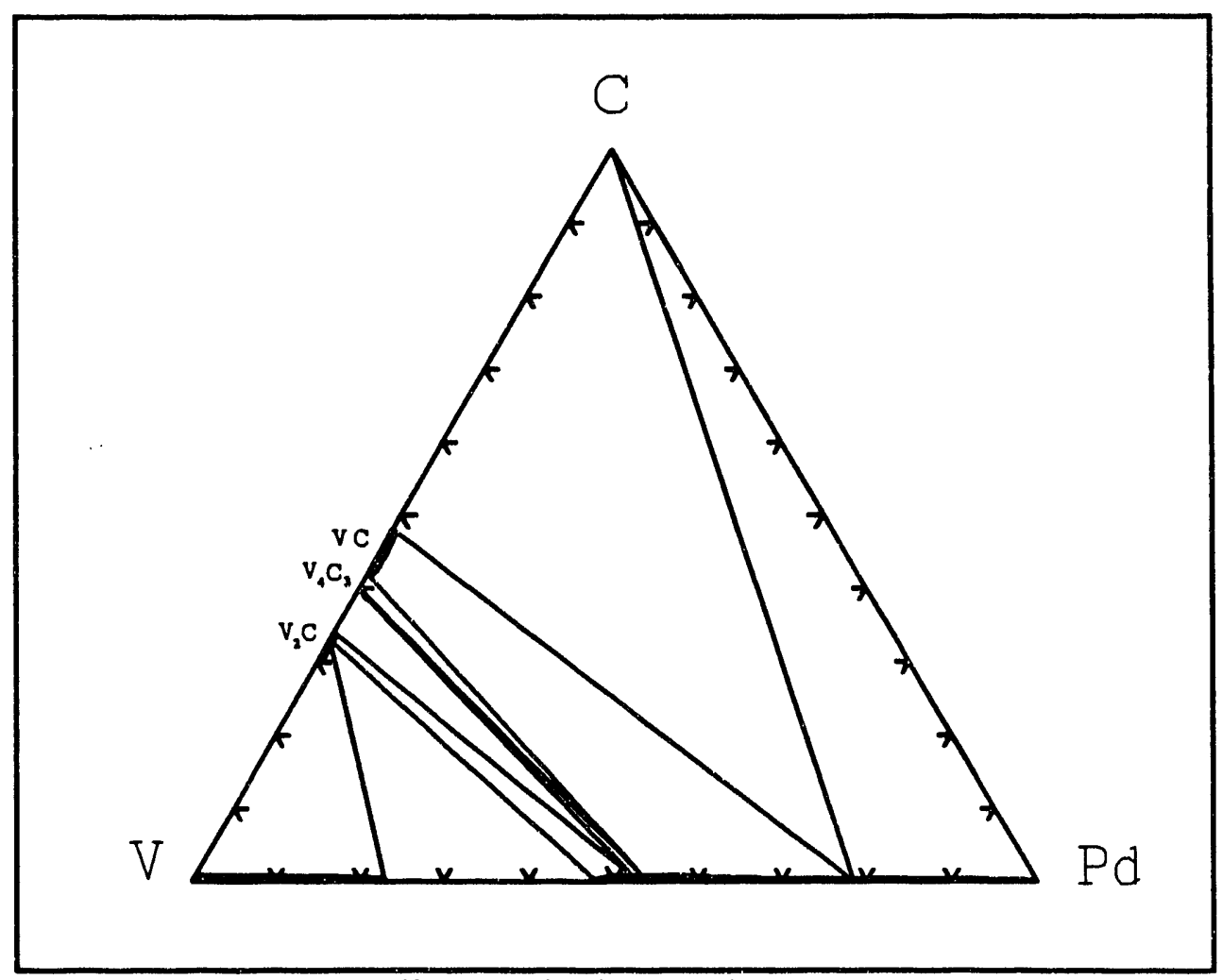

Figure 6.4. The vanadium-palladium-carbon system at $1000^{\circ} \mathrm{C}$

105 


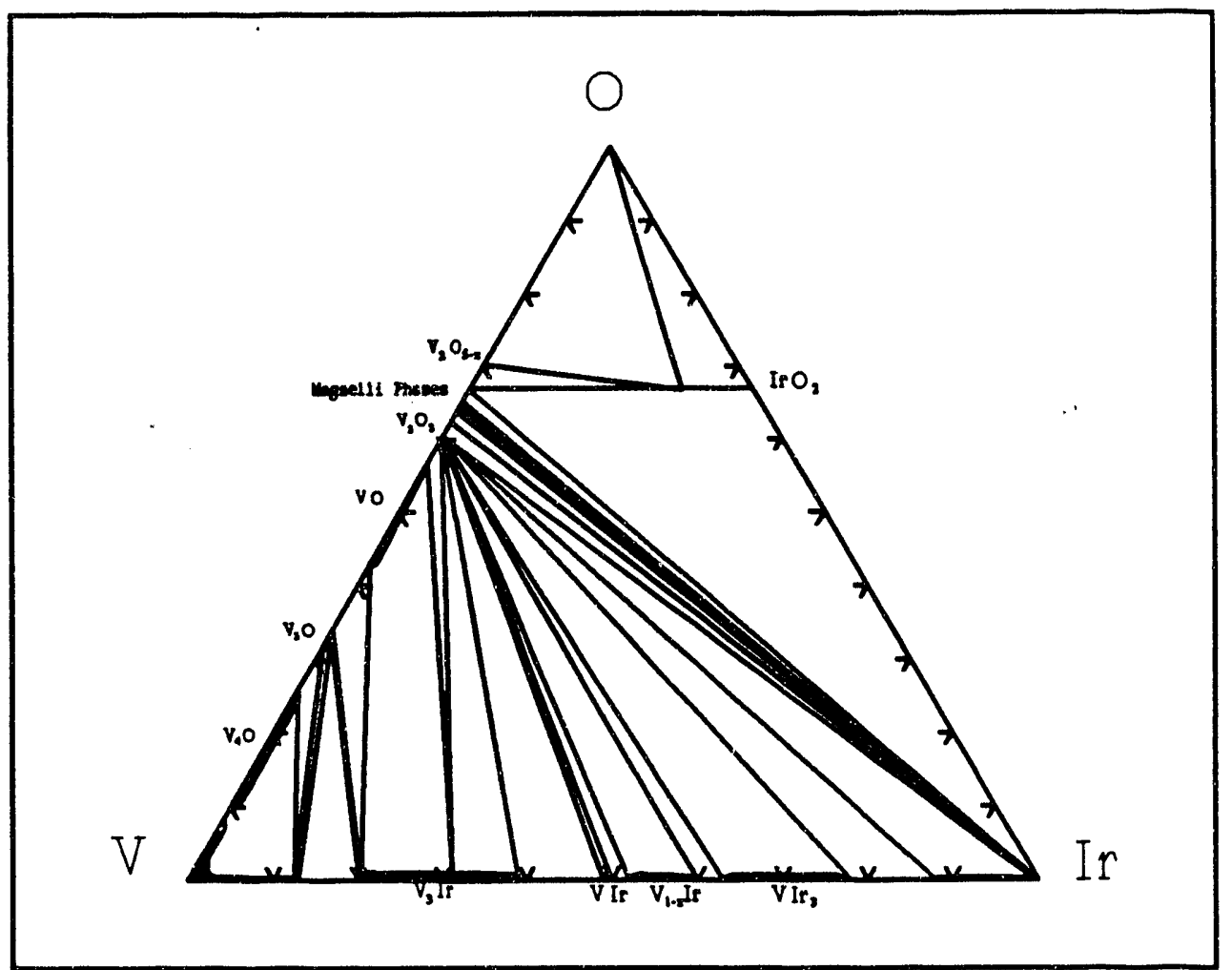

Figure 6.5 . The vanadium-iridium-oxygen system at $1000^{\circ} \mathrm{C}$

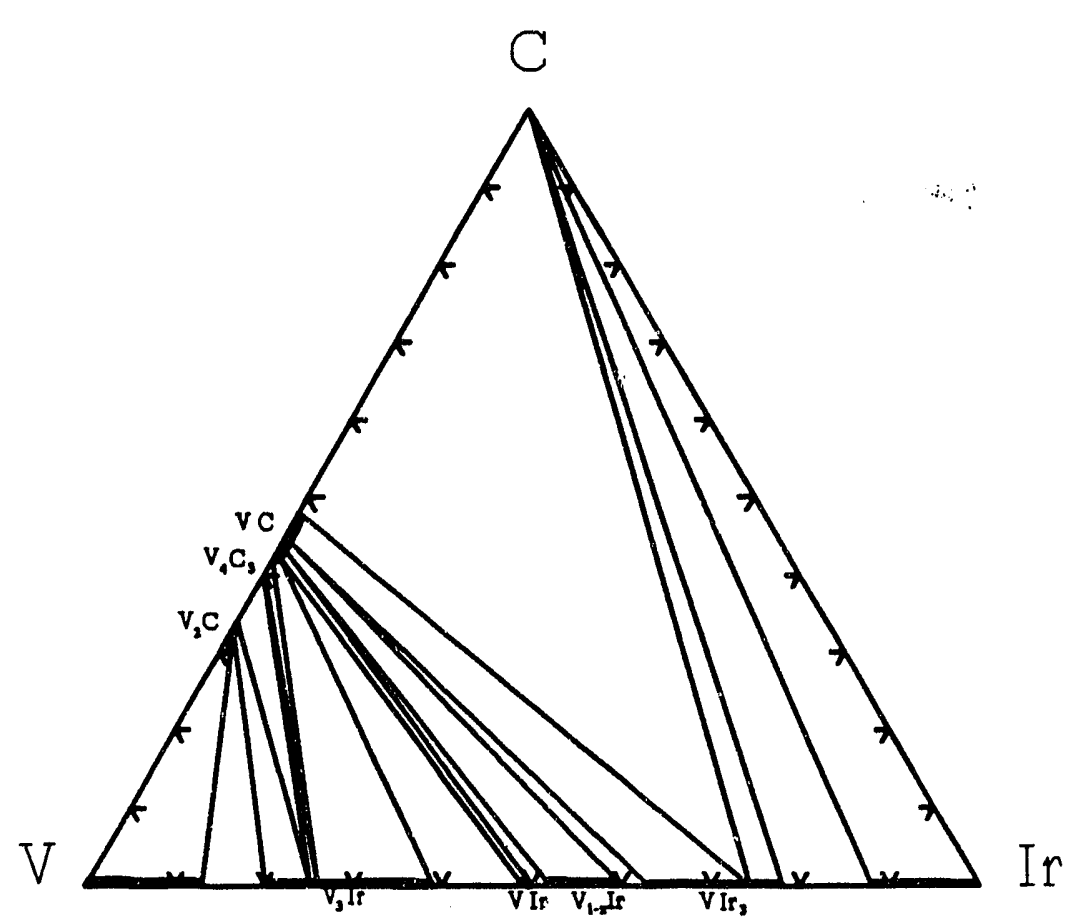

Figure 6.6. The vanadium-iridium-carbon system at $1000^{\circ} \mathrm{C}$ 106 


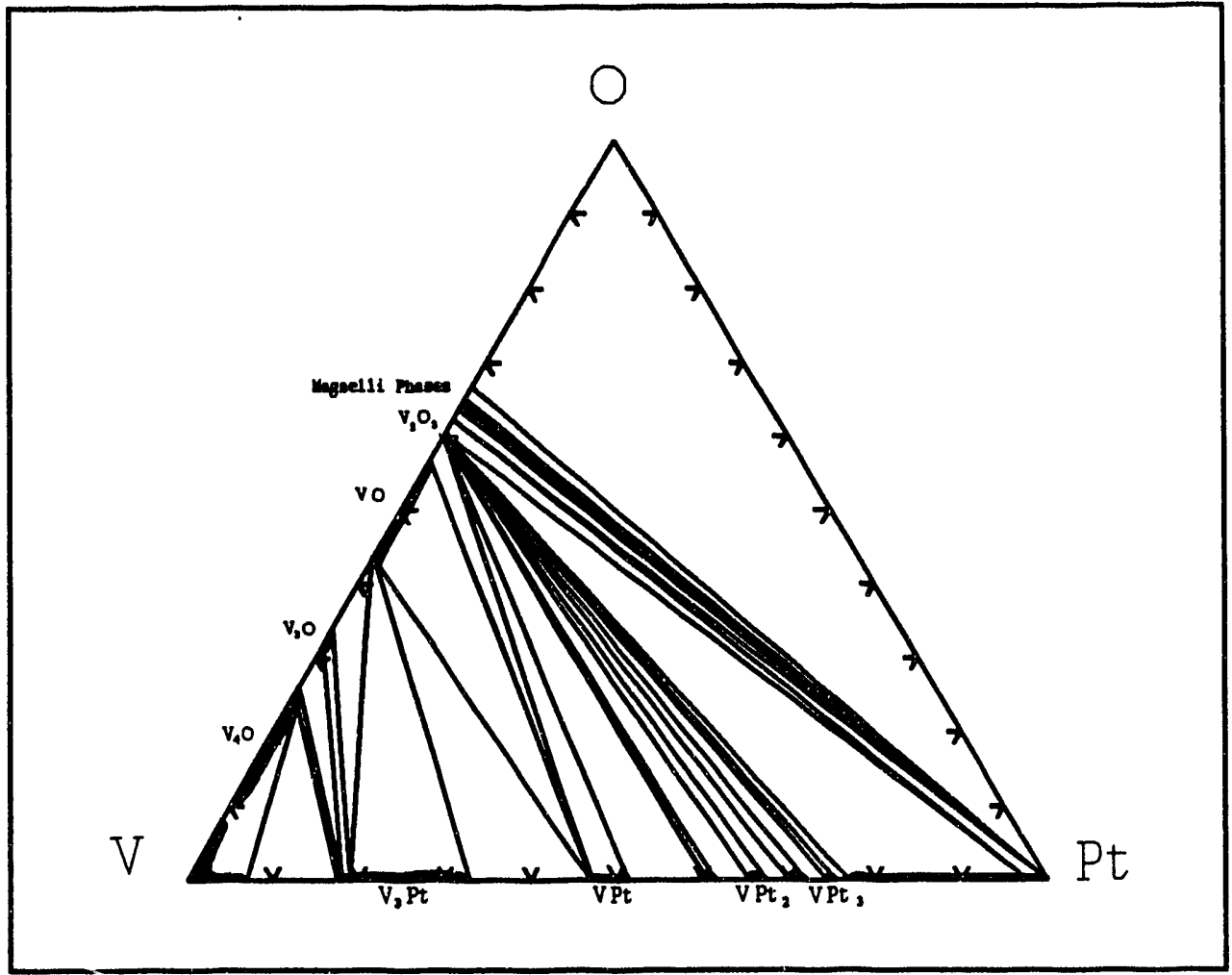

Figure 6.7. The vanadium-platinum-oxygen system at $1000^{\circ} \mathrm{C}$

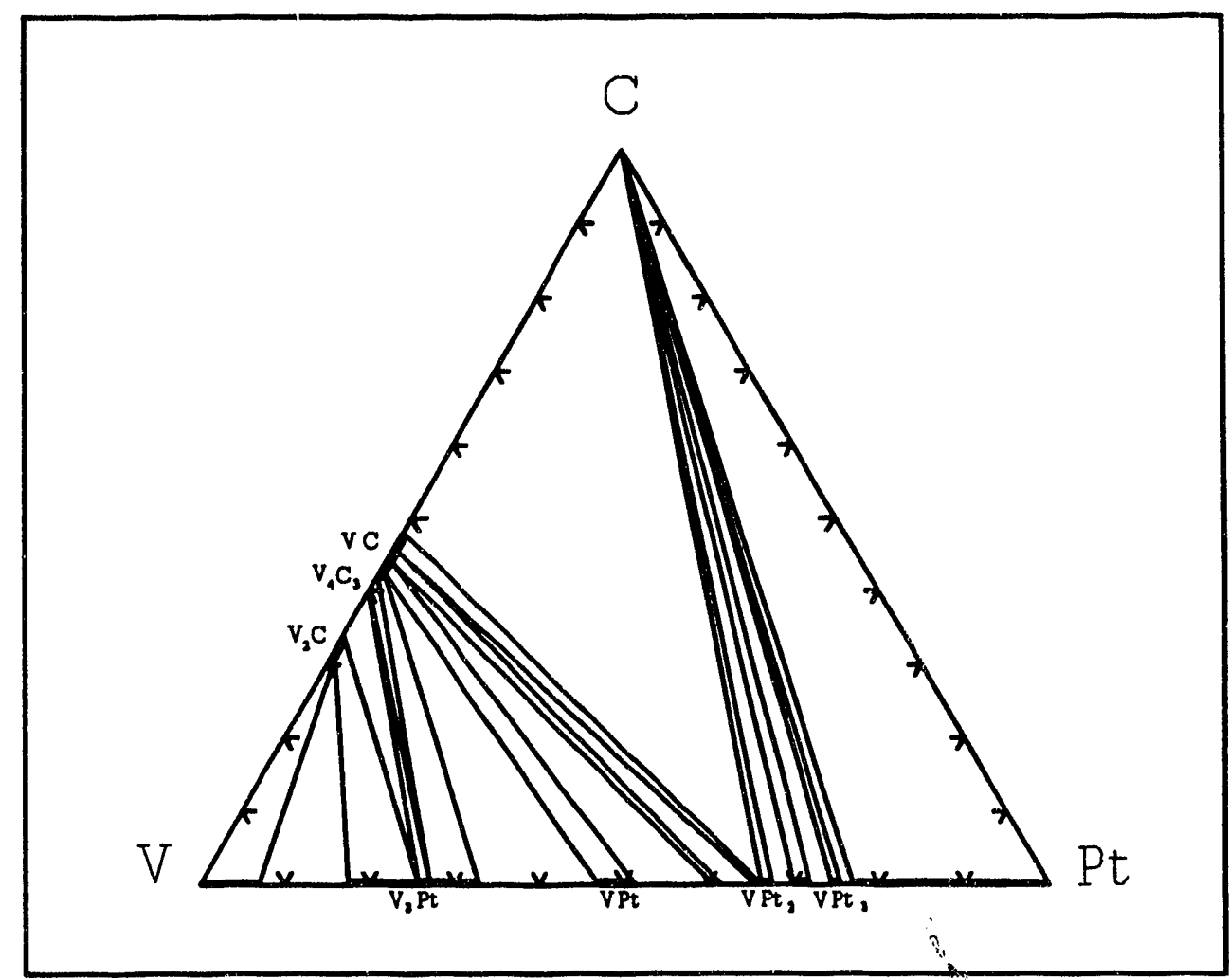

Figure 6.8. The vanadium-platinum-carbon system at $1000^{\circ} \mathrm{C}$ 107 


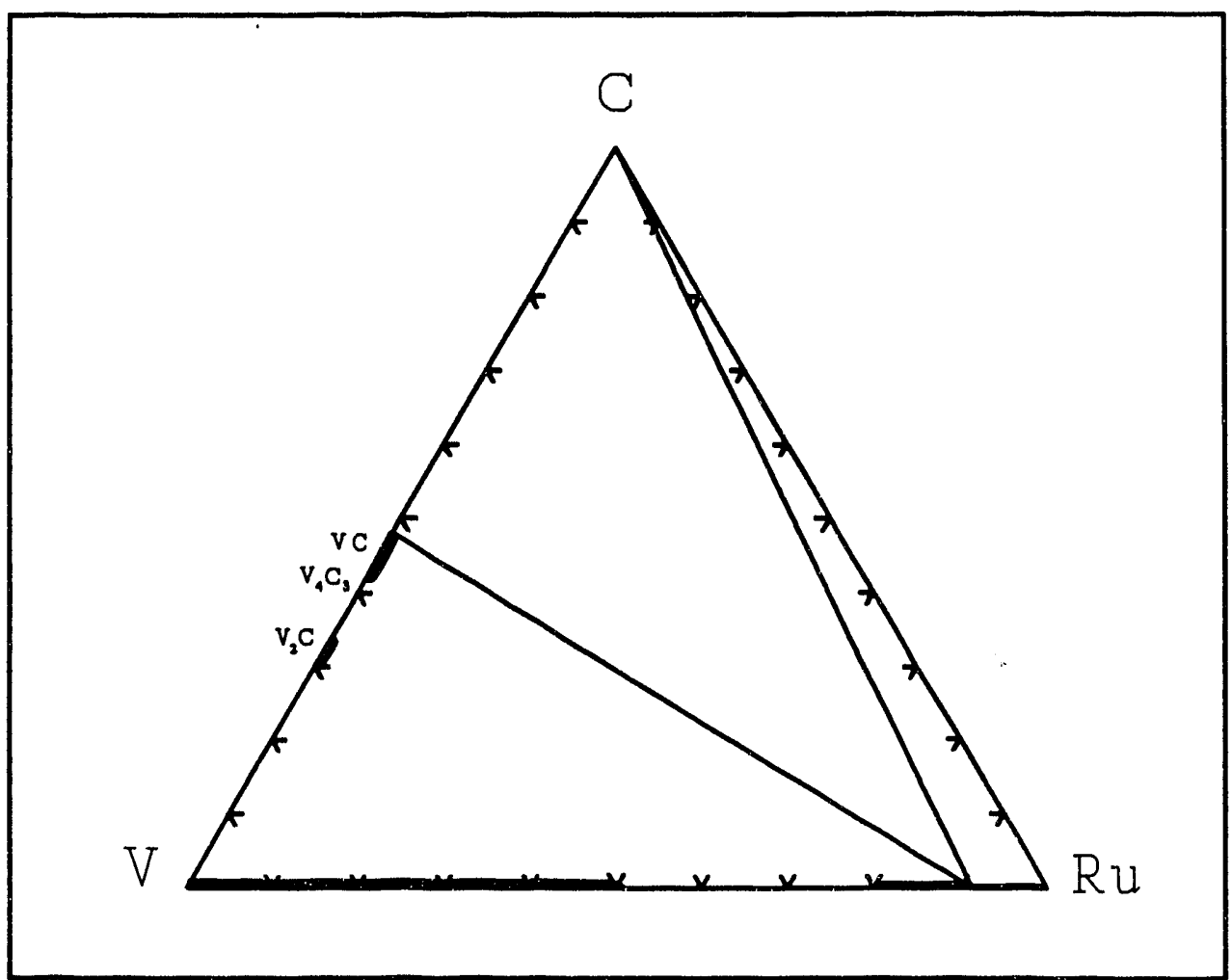

Figure 6.9 . The vanadium-ruthenium-carbon system at $1000^{\circ} \mathrm{C}$

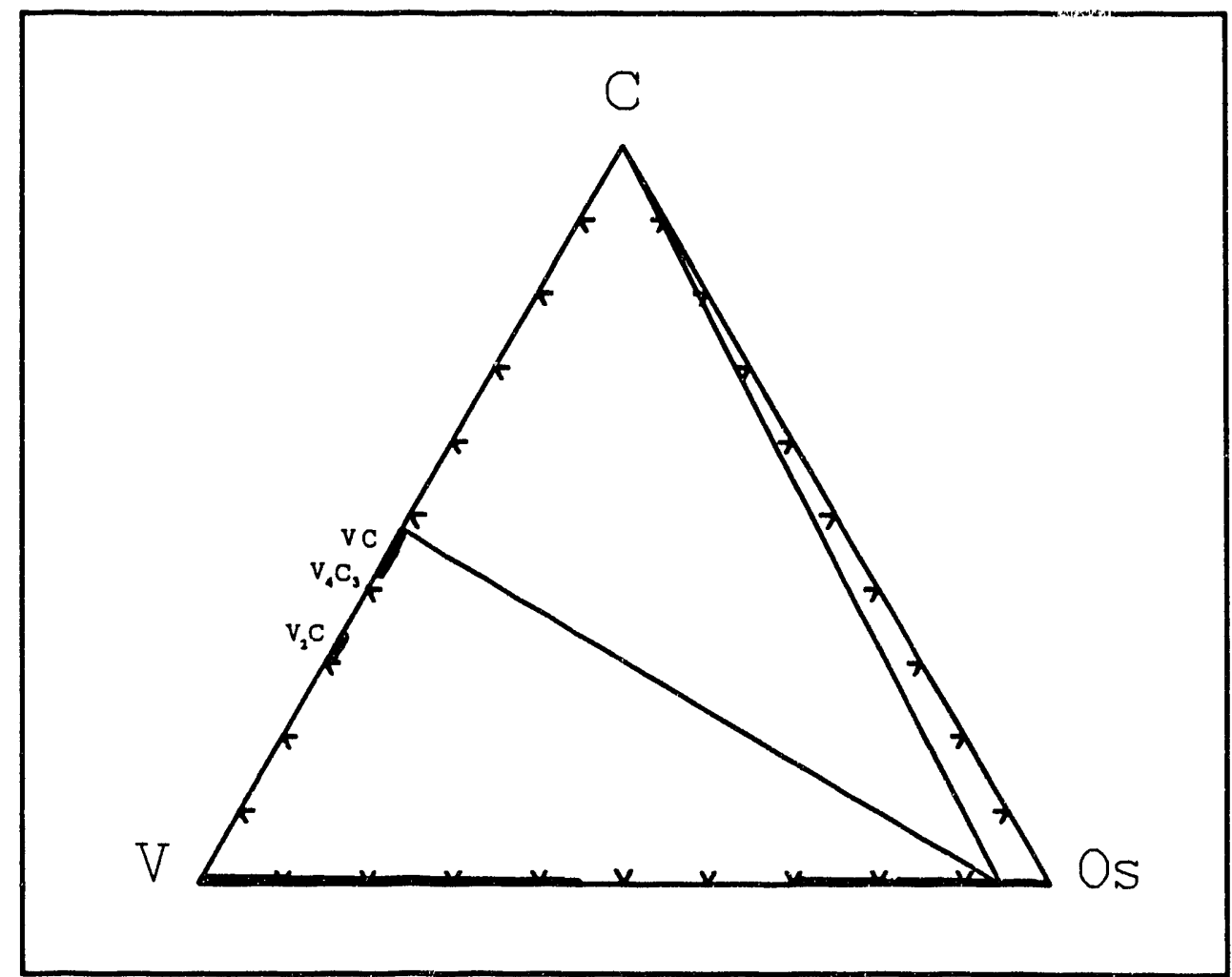

Figure 6.10 . The vanadium-osmium-carbon system at $1000^{\circ} \mathrm{C}$ 108 
Comparisons of Diagrams

A considerable amount of information about the relative strength of $\mathrm{V}$ $\mathrm{NM}$ (noble metal) interactions can be determined from the ternary equilibria alone. For example, the carbide equilibria show that nearly pure Os and $\mathrm{Ru}$ are in equilibrium with $\mathrm{VC}$ and $\mathrm{C}$, whereas the compounds $\mathrm{VIr}_{3}$ and $\mathrm{VRh}_{3}$ are in equilibrium with VC and C in the V-Ir-C and the V-Rh-C system respectively. These facts imply that the interactions with Ir and $\mathrm{Rh}$ are stronger than the interactions with $\mathrm{Ru}$ and $\mathrm{Os}$ at the activity of vanadium fixed by the VC/C equilibria. In other words, the larger the fraction of vanadium needed in a noble metal alloy to reach a specified activity of vanadium the stronger are the V$\mathrm{NM}$ (noble metal) bonds at that activity. Using this type of reasoning the relative strengths of interaction can be determined at the fixed activity of vanadium given by each binary oxide or binary carbide equilibria. Table 6.1 depicts all the relative strengths of the interaction according to this method. From Table 6.1 it can be seen that the relative strength of interaction varies as a function of the activity of vanadium. For example, the ternary phase equilibria demonstrates that V-Rh interactions are stronger than V-Pt interactions at high activities of vanadium, and at low activities of vanadium V-Pt interactions are stronger than V-Rh interactions.

It should be noted that the change in the order of the relative strengths of interactions is due partly to a mismatch of the phase equilibria in the binary intermetallic systems being compared. More specifically, a slight change in activity 
can correspond to a large change in composition across a two phase boundary. For example, the activity change across the two phase region of $\mathrm{VRh}_{3}-\mathrm{Rh}$ is zero, but in the V-Pd system at this composition range there is a single phase and the activity changes considerably over this region. Comparing the relative strengths of interactions as has been done in Table 6.1 could only be completely valid if the phase diagrams were identical for each of the V-NM(noble metal) systems. For this reason, the comparisons in Table 6.1 should only have a moderate emphasis. The activities and compositions of all the points obtained by ternary oxide or ternary carbide equilibria are given in Appendix $\mathrm{H}$.

Table 6.1. Relative strengths of interactions at each birary equilibria near $1000^{\circ} \mathrm{C}$. Lowest activity of $V$

Highest activity o; $V$

$\mathrm{V}_{2} \mathrm{O}_{3}-\mathrm{V}_{3} \mathrm{O}_{5} \quad \mathrm{VC}-\mathrm{C} \quad \mathrm{VO}_{2} \mathrm{~V}_{2} \mathrm{O}_{3} \quad \mathrm{~V}_{2} \mathrm{C}-\mathrm{VC} \quad \mathrm{V}_{2} \mathrm{O}-\mathrm{VO} \quad \mathrm{V}_{4} \mathrm{O}-\mathrm{V}_{2} \mathrm{O}$

Strongest

Pt,Ir

Pt

Ir

Ir,Pt

Rh

Rh, Ir

Pd,Rh

$\mathrm{Ir}, \mathrm{Rh}$

Pt

Rh

Pt

Pd

(Ru)

Pd

Rh

Pd

Ir,Pd

Pt

(Os)

$\begin{array}{ll}\text { Ru } & \text { Pd } \\ \text { Os } & \text { Ru,Os }\end{array}$

Weakest 


\subsection{The Galvanic Cell Experiments and Results.}

Since all useful ternary oxide and carbide equilibria have been experimentally determined, the high temperature galvanic cell must be used to determine any additional points in the activity versus concentration curve. The experiments performed here were modeled after those of Tetot and Picard.[2] Using a 15 mole percent $\mathrm{YO}_{1.5}$ stabilized $\mathrm{ThO}_{2}$ electrolyte, $\mathrm{YDT}$, they measured the partial free energy of oxygen in the lower vanadium oxides, $O / V<1.5$. They report that long equilibration times are required to reach the "true" EMF. For the system

$$
\mathrm{VO} / \mathrm{N}_{2} \mathrm{O}_{3} / / \mathrm{YDT} / / \mathrm{Ta} / \mathrm{Ta}_{2} \mathrm{O}_{5}
$$

they obtained a value of $73 \mathrm{mV}$ at $1050^{\circ} \mathrm{C}$. The identical experiment was undertaken here, and the value obtained was $73.1 \pm 0.8 \mathrm{mV}$ at $1050^{\circ} \mathrm{C}$. Our result was taken after the EMF stopped decaying which took several days. This observation is consistent with Tetot's and Picard's. Our reproducibility of their experiment is encouraging but misleading. The observed value of $73 \mathrm{mV}$ at $1050^{\circ} \mathrm{C}$ is inconsistent with the EMF which is calculated from heat capacity and enthalpy of formation data of $\mathrm{VO}, \mathrm{V}_{2} \mathrm{O}_{3}, \mathrm{Ta}$, and $\mathrm{Ta}_{2} \mathrm{O}_{5}$. From the thermodynamics of the electrodes, a value of $191 \pm 30 \mathrm{mV}$ is expected. This drastically differs from what is observed. To explain and resolve this discrepancy a number of tests and comparisons have been performed on the galvanic cell. 
Testing the Galvanic Cell

The First Test-Addition of cell voltages.

The first test experiment was somprised of three cell runs in which the addition of the net reaction of two runs will yield the net reaction of the third. For this reason, the EMF of the two cells should add up to the EMF of the third.

Each of three systems are listed along with the EMF as a function of temperature. The correlation coefficient, $r$, is given to indicate both the linearity and the reproducibility of the EMF.

$$
\text { [high } \left.\mathrm{Po}_{2}\right] / /\left[\text { electrolyte] } / / \text { low } \mathrm{Po}_{2}\right]
$$

$$
\begin{aligned}
& \mathrm{VO} / \mathrm{V}_{2} \mathrm{O}_{3} / / \mathrm{YDT} / / \mathrm{Ta} / \mathrm{Ta}_{2} \mathrm{O}_{5} \\
& \text { EMF }=141.35(\mathrm{~T} / 1000)-114.9 ; 1173-1373 \mathrm{~K} \\
& \mathrm{r}=0.994
\end{aligned}
$$

$$
\begin{aligned}
& \mathrm{VO} / \mathrm{N}_{2} \mathrm{O}_{3} / / \mathrm{YDT} / / \mathrm{NbO} / \mathrm{NbO}_{2} \\
& \mathrm{EMF}=-56.56(\mathrm{~T} / 1000)+37.5 ; 1173-1373 \mathrm{~K} \\
& \mathrm{r}=0.97
\end{aligned}
$$

$$
\begin{aligned}
& \mathrm{NbO} / \mathrm{NbO}_{2} / / \mathrm{YDT} / / \mathrm{Ta} / \mathrm{Ta}_{2} \mathrm{O}_{5} \\
& \mathrm{EMF}=-35.56(\mathrm{~T} / 1000)+177.8 ; 1173-1373 \mathrm{~K} \\
& \mathrm{r}=-0.998
\end{aligned}
$$

The uncertainty in the EMF in each case is $\pm 1 \mathrm{mV}$. Adding the reactions for cell 6.2 and 6.3 yields the following.

$$
\mathrm{VO} / \mathrm{V}_{2} \mathrm{O}_{3} / \mathrm{MDT} / / \mathrm{NbO} / \mathrm{NbO}_{2}
$$

plus

$$
\mathrm{NbO} / \mathrm{NbO}_{2} / / \mathrm{YDT} / / \mathrm{Ta} / \mathrm{Ta}_{2} \mathrm{O}_{5}
$$

yields 
6.4

$\mathrm{VO} / \mathrm{N}_{2} \mathrm{O}_{3} / \mathrm{YDT} / / \mathrm{NbO} / \mathrm{NbO}_{2} / / \mathrm{YDT} / / \mathrm{Ta} / \mathrm{Ta}_{2} \mathrm{O}_{5}$

$\mathrm{EMF}=-92.12(\mathrm{~T} / 1000)+215.3$

The EMF in Equation 6.4 deviates significantly from the EMF in Equation

6.1. The deviation is easier to see in Table 6.2.

Table 6.2. EMF comparison.(mV)

\begin{tabular}{lll}
\hline T(K) & Eqn. 6.1 & Eqn. 6.4 \\
\hline & & \\
\hline 1123 & 43.8 & 111.9 \\
1173 & 50.9 & 107.2 \\
1223 & 58.0 & 102.6 \\
1273 & 65.0 & 98.0 \\
1323 & 72.1 & 93.4 \\
1373 & 79.2 & 88.8 \\
1423 & 86.2 & 84.2
\end{tabular}

If the cell were behaving properly, the EMF of Cells 6.2 and 6.3 should add up to that of Cell 6.1. As can be seen in Table 6.2, this is not the case. However, it is interesting to note that the EMF values are in closer agreement at higher temperatures.

Since the voltage cannot be thermodynamically added, there must be some problem within the experiment. This result was our first indication that the values obtained from Tetot and Picard are incorrect. What is the cause of the discrepancy? The first likely possibility is short circuiting due to mixed conduction within the YDT electrolyte. For several of the above experiments, the cell was polarized with a known voltage. This technique is described in Chapter 4, and the 
symbols and definitions are the same as used in Chapter 3. Note that

$$
\mathrm{EMF}_{\text {eell }}=\mathrm{EMF}_{\text {not }}+\mathrm{EMF}_{\text {epplied }}
$$

The EMF cell $_{\text {remained unchanged as a function of EMF }}$ mpliod. Consequently, there is no mixed conduction. Since the problem is not due to mixed conduction, it must be due either to gaseous short circuiting or to an interfacial reaction. No change in $\mathrm{EMF}_{\text {cell }}$ was ever observed with the helium flow rate. Consequently, the problem is not likely to be due to gaseous short circuiting, but rather to an interfacial reaction.

The Second Test - Interfacial Reactions

There are a variety of factors which can affect the EMF of the galvanic cell, $\mathrm{EMF}_{\text {cell }}$. One factor is the reaction of the electrode with the electrolyte to yield a compound which interferes with the measured EMF. R. L. Jones, et al have studied the reaction of sodium vanadium bronzes with $\mathrm{Y}_{2} \mathrm{O}_{3}, \mathrm{CeO}_{2}, \mathrm{ZrO}_{2}, \mathrm{GeO}_{2}$, and $\mathrm{Ta}_{2} \mathrm{O}_{5}$.[3] They show that at $700^{\circ} \mathrm{C}$ all these phases will react with $\mathrm{V}_{2} \mathrm{O}_{5}$ except $\mathrm{GeO}_{2}$. $\mathrm{ZrO}_{2}$ reacts, but slowly. We have studied here the reaction of VO $/ \mathrm{N}_{2} \mathrm{O}_{3}, \mathrm{NbO} / \mathrm{NbO}_{2}$, and $\mathrm{Ta} / \mathrm{Ta}_{2} \mathrm{O}_{5}$ pellets with various electrolytes: YDT, LDT, $\mathrm{ThO}_{2}$, and $\mathrm{CaF}_{2}$. Also, $\mathrm{V}_{2} \mathrm{O}_{3}$ and $\mathrm{Cr}_{2} \mathrm{O}_{3}$ powder have been checked for reaction with the YDT and LDT electrolytes. Our results show that there are reactions taking place at the electrode-electrolyte interface in most of the systems mentioned above. Table 6.3 summarizes the resu'ts observed. 
Table 6.3. Electrode-electrolyte interfacial reactions.

Sintered Pellets

electrode electrolyte temperature duration observation(color)

$P_{\text {He }}=1$ atm:

$\mathrm{Ta} \mathrm{Ta}_{2} \mathrm{O}_{5} \quad \mathrm{YDT}$

$1300^{\circ} \mathrm{C} \quad 20 \mathrm{hr}$.

$1350^{\circ} \mathrm{C} \quad 46 \mathrm{hr} . \quad$ N.R.

$\mathrm{NbO} / \mathrm{NbO}_{2}$ YDT $\quad 1300^{\circ} \mathrm{C} \quad 20 \mathrm{hr}$

$1350^{\circ} \mathrm{C} \quad 46 \mathrm{hr}$ small RXN(light brown)

$\mathrm{VO} / \mathrm{N}_{2} \mathrm{O}_{3} \quad$ YDT $\quad 1300^{\circ} \mathrm{C} \quad 20 \mathrm{hr}$.

$1350^{\circ} \mathrm{C} \quad 46 \mathrm{hr}$. large RXN(black, dark brown)

$P_{\text {He }}=0$ atm:

$\mathrm{NbO} / \mathrm{NbO}_{2} \quad \mathrm{CaF2} \quad 1100^{\circ} \mathrm{C} \quad 24 \mathrm{hr}$ unknown(sliver color)

Ta $\quad$ CaF2 $\quad 1100^{\circ} \mathrm{C} \quad 24 \mathrm{hr} . \quad$ large RXN(brown)

$P_{\text {He }}=0.5 \mathrm{~atm}:$

$\begin{array}{lllll}\text { VO } / \mathrm{N}_{2} \mathrm{O}_{3} & \mathrm{ThO}_{2} & 1000^{\circ} \mathrm{C} & 120 \mathrm{hr} . & \\ & & 1100^{\circ} \mathrm{C} & 8 \mathrm{hr} . & \text { N.R. }\end{array}$

$\mathrm{Ta} / \mathrm{Ta}_{2} \mathrm{O}_{5} \quad \mathrm{ThO}_{2} \quad 1000^{\circ} \mathrm{C} \quad 120 \mathrm{hr}$.

$1100^{\circ} \mathrm{C} \quad 8 \mathrm{hr} . \quad$ N.R. 


\section{Table 6.3 Continued}

Powders

powder electrolyte temperature duration observation

$P_{\text {He }}=0.67$ atm:

$\mathrm{V}_{2} \mathrm{O}_{3} \quad \mathrm{YDT} \quad 1200^{\circ} \mathrm{C} \quad 48 \mathrm{hr} \quad$ large $\mathrm{RXN}$

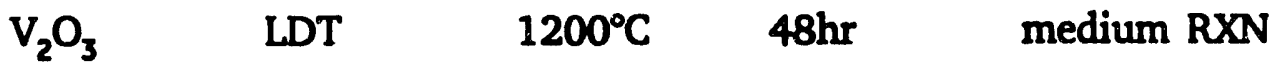

$\begin{array}{llll}\mathrm{Cr}_{2} \mathrm{O}_{3} & \text { YDT } & 1200^{\circ} \mathrm{C} & 48 \mathrm{hr}\end{array}$

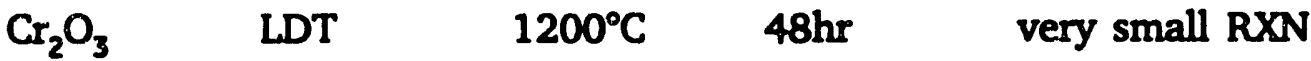

Large $\mathrm{RXN}=$ Discoloring which penetrated several $\mathrm{mm}$ into sample.

Small $\mathrm{RXN}=$ Discoloring present on surface only and easy to remove by sanding.

The interfacial phases were identified by X-ray diffraction. In every case, X-ray diffraction of the electrode in contact with the electrolyte showed no observable reaction. However, the X-ray pattern of the electrolyte often showed some extra peaks from which a likely interfacial phase could be matched.

The reaction layers for most of these samples are very thin and, consequently, are difficult to identify. The peaks for the interfacial compound are barely separable from the noise in most cases. The $d$ spacing and intensity, $I$, values for the suggested interfacial compounds are compared with the $d-I$ values of the suspected interfacial layers in Appendix G. 
Identification of interfaces

The interface on the $\mathrm{CaF}_{2}$ with $\mathrm{Ta}$ or $\mathrm{Ta} / \mathrm{Ta}_{2} \mathrm{O}_{5}$ has not yet been identified. However, for both $\mathrm{Ta}$ or $\mathrm{Ta} / \mathrm{Ta}_{2} \mathrm{O}_{5}$ systems, the same interfacial phase is formed. Therefore, it is likely that the interfacial phase is a $\mathrm{Ca}_{x} \mathrm{Ta}_{y} \mathrm{~F}_{z}$ compound. In other words, it is devoid of oxygen.

In the $\mathrm{V}_{2} \mathrm{O}_{3}-\mathrm{YDT}$ system, the interfacial phase seems to be $\mathrm{YVO}_{3}$, and in the $\mathrm{V}_{2} \mathrm{O}_{3}$-LDT system, the interfacial phase seems to be $\mathrm{LaVO}_{3}$. Our belief is that the $\mathrm{V}_{2} \mathrm{O}_{3}$ is diffusing into the YDT or LDT pellet during the cell experiments. The result being that the electrolyte becomes doped partly with $\mathrm{V}_{2} \mathrm{O}_{3}$ in the surface of the electrolyte. The diffusion continues until the saturation limit of $\mathrm{V}_{2} \mathrm{O}_{3}$ in YDT (or LDT) is reached. At that point $\mathrm{YVO}_{3}$ (or $\mathrm{LaVO}_{3}$ ) precipitates out of the $\mathrm{ThO}_{2}$ solid solution. The $\mathrm{YVO}_{3} / \mathrm{YDT}$ interface has a characteristic $\mathrm{Po}_{2}$ which is probably what gives rise to the characteristic $73 \mathrm{mV}$ at $1050^{\circ} \mathrm{C}$ in the

$$
\mathrm{VO} / \mathrm{V}_{2} \mathrm{O}_{3} / / \mathrm{YDT} / / \mathrm{Ta} / \mathrm{Ta}_{2} \mathrm{O}_{5}
$$

system.

The initial diffusion of $\mathrm{V}_{2} \mathrm{O}_{3}$ into YDT or LDT should not drastically affect the cell EMF or more generally it should not affect the electrolytic properties of the YDT or LDT. It would be worthwhile to confirm this postulate. Some samples doped with $\mathrm{V}_{2} \mathrm{O}_{3}$ in $\mathrm{ThO}_{2}$ should be prepared to see how much $\mathrm{V}_{2} \mathrm{O}_{3}$ can dissolve in $\mathrm{ThO}_{2}$. Additionally, the $\mathrm{ThO}_{2}-\mathrm{V}_{2} \mathrm{O}_{3}$ system should be tested to see how it behaves as an electrolyte. 
For $\mathrm{NbO} / \mathrm{NbO}_{2}$ in contact with YDT the phase $\mathrm{YNbO}_{4}$ seemed to match most closely the residual peaks in the X-ray pattern. This result is consistent with Meschter's result.[4] He also identified $\mathrm{YNbO}_{4}$ as the likely $\mathrm{RXN}$ interface for the $\mathrm{NbO}_{2} / \mathrm{Nb}_{2} \mathrm{O}_{4.8}$ electrode in contact with the YDT electrolyte at slightly higher temperatures.

The search for a good electrolyte

The Third Test - Observed versus calculated EMF.

A large number of electrolytes have been explored in an effort to identify the best electrolyte for use with the vanadium-oxygen system.

Figures 6.11-6.21 encompass examples of all the electrolyte systems tried. In these figures, the natural $\log$ of the time in hours from the beginning of measurement is plotted on the $\mathrm{X}$ axis. The EMF and the temperature are plotted on the $\mathrm{Y}$ axis. The reason for plotting the $\mathrm{X}$ axis on a logarithmic scale is so that the fluctuation of the EMF can be seen at the beginning of the experiment, the long term drift can also be seen toward the end, and the optimum EMF can be seen toward the center of the plot. Note that the initial points plotted are not from the beginning of the experiment, but from the beginning of data acquisition. In every system, the cell EMF at low temperatures can be nearly any value, and it is not correlated to the EMF measured at high temperatures. At low temperatures there is little conductivity in the system, and, consequently, the cell behavior resembles that of a capacitor. Interestingly, at this stage the EMF is 
hypersensitive to static electricity anywhere near the apparatus. Consequently, any movement near the apparatus can cause the cell EMF to change dramatically. This behavior is not observed when the cell is at its operating temperature, $800^{\circ} \mathrm{C}$ $1200^{\circ} \mathrm{C}$. As the electrolyte is heated up, a transition point occurs from capacitor-like behavior to battery-like behavior. At the transition point oxygen ions have started to diffuse into the electrolyte. Since the electrolyte is initially neutral, it will take awhile for the electrolyte to become saturated with oxygen ions and, consequently, for the system to reach a steady exchange rate of ions through the electrolyte. As a result, the EMF will go through dramatic changes during the transition because the exchange rate of ions in and out of the electrolyte is unbalanced. This phenomenon is also observed any time the cell temperature is changed, but it is most pronounced during the initial heating. Note that the transition of the electrolyte from non-conducting to ionically conducting gives rise to the large changes in EMF that can be seen in Figures 6.11-6.21.

While the apparatus is cooling, the same dramatic changes that were observed upon heating are not observed. During this time the EMF changes very little. Presumably the oxygen ions become trapped in the electrolyte upon cooling which causes voltage drop to become fixed. The cell EMF takes a considerable amount of time to decay in this state since the leakage current due to ionic or electronic conductivity is very small at lower temperatures. In every case, the cell EMF is observed to approach a constant as the apparatus is cooled. 
In each of the systems presented in Figures 6.11-6.21, the true EMF can be calculated from heat capacity, entropy, and enthalpy of formation data. These figures reveal that only the system of

$$
\mathrm{NbO} / \mathrm{NbO}_{2} / \mathrm{YDT} / / \mathrm{Ta} \mathrm{Ta}_{2} \mathrm{O}_{5}
$$

Figure 6.19, behaves properly for any length of time. The systems with VO/ $\mathrm{N}_{2} \mathrm{O}_{3}$ and YDT or LDT approach the true value at the beginning of the experiment but slowly decay to some other value, Figures $6.11-6.14$. The EMF for the system

$$
\mathrm{VO} / \mathrm{N}_{2} \mathrm{O}_{3} / / \mathrm{CaF}_{2} / / \mathrm{Ta} / \mathrm{Ta}_{2} \mathrm{O}_{5}
$$

increases slowly with time. This is contrary to the systems

$$
\text { VO } / \mathrm{N}_{2} \mathrm{O}_{3} / / \text { YDT(or LDT) } / / \mathrm{Ta} / \mathrm{Ta}_{2} \mathrm{O}_{5}
$$

which are always observed to decay with time. The drift toward larger EMF's is possible since $\mathrm{CaF}_{2}$ is used as the electrolyte. The $\mathrm{Ta}$ in the $\mathrm{Ta} / \mathrm{Ta}_{2} \mathrm{O}_{5}$ electrode seems to react strongly with $\mathrm{CaF}_{2}$ which in turn lowers the activity of oxygen at the surface of this electrode. Since the EMF is proportional to the ratio of the high partial pressure of oxygen to the low partial pressure of oxygen, and the partial pressure of oxygen will be reduced at the low side, $\mathrm{Ta} / \mathrm{Ta}_{2} \mathrm{O}_{5}$, the cell EMF will be increased.

Since the VO/ $\mathrm{N}_{2} \mathrm{O}_{3}$ electrode reacts with YDT and LDT the use of an intermediate layer as a barrier to reaction was considered. $\mathrm{Cr}_{2} \mathrm{O}_{3}$ can be in equilibrium with a large number of vanadium oxides. [5] Since this was true, it was of interest to place a small layer of $\mathrm{Cr}_{2} \mathrm{O}_{3}$ powder between the VO/ $\mathrm{V}_{2} \mathrm{O}_{3}$ 


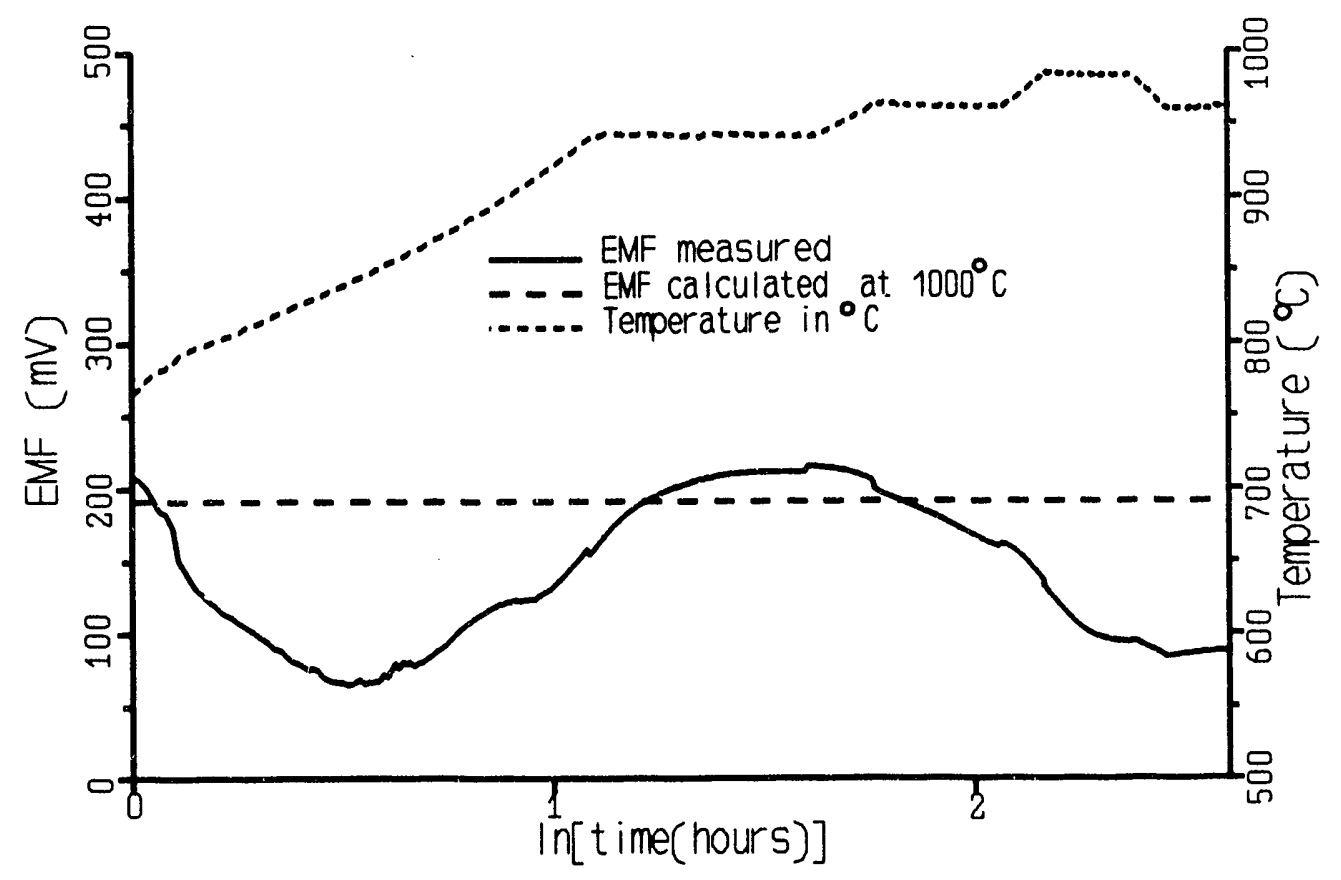

Figure 6.11. EMF and temperature versus the natural log of time in hours for the system $\mathrm{VO} / \mathrm{V}_{2} \mathrm{O}_{3} / / \mathrm{YDT} / / \mathrm{Ta} / \mathrm{Ta}_{2} \mathrm{O}_{5}$.

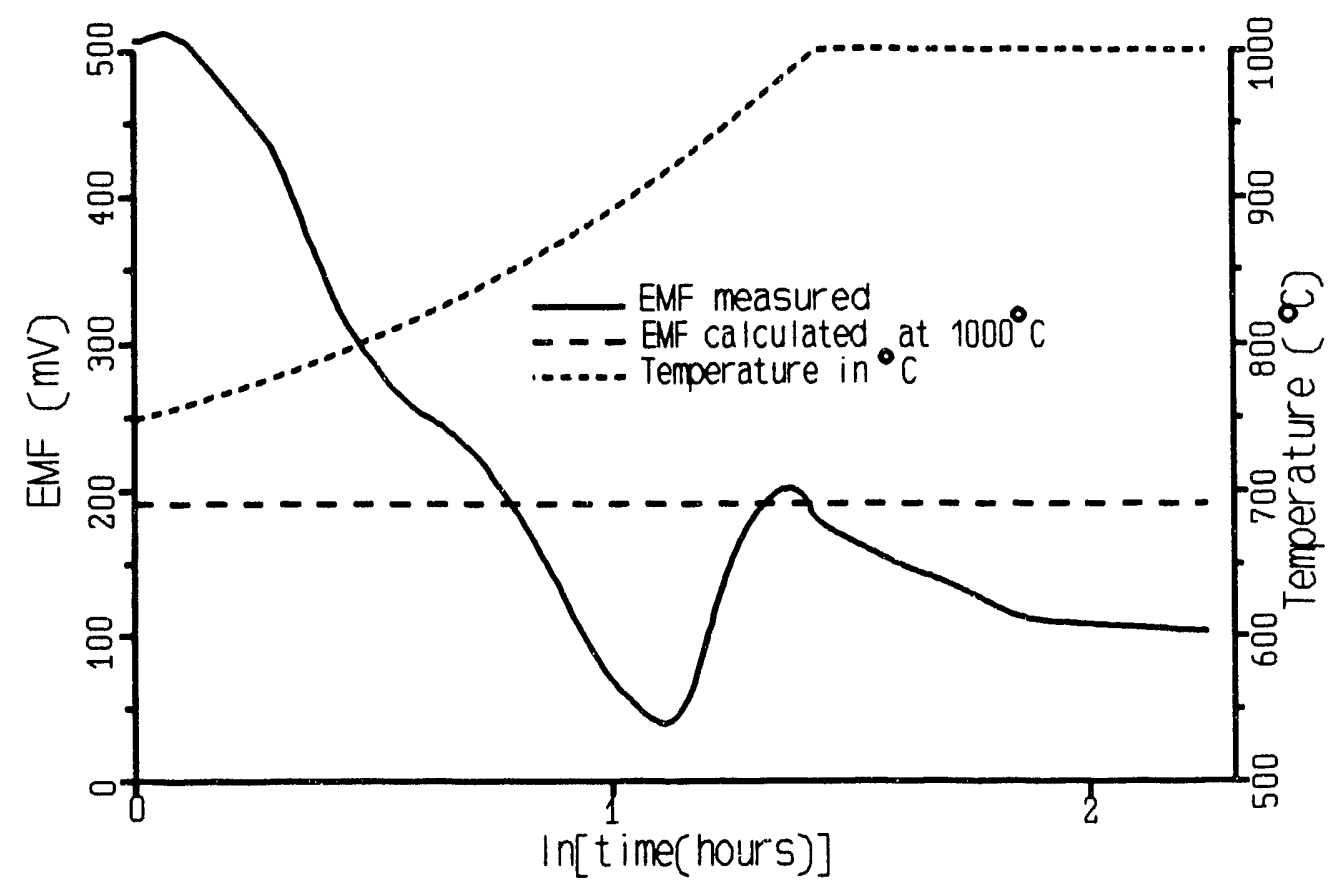

Figure 6.12. EMF and temperature versus the natural log of time in hours for the system $\mathrm{VO} / \mathrm{V}_{2} \mathrm{O}_{3} / \mathrm{YDT} / / \mathrm{Ta} / \mathrm{Ta}_{2} \mathrm{O}_{5}$. 


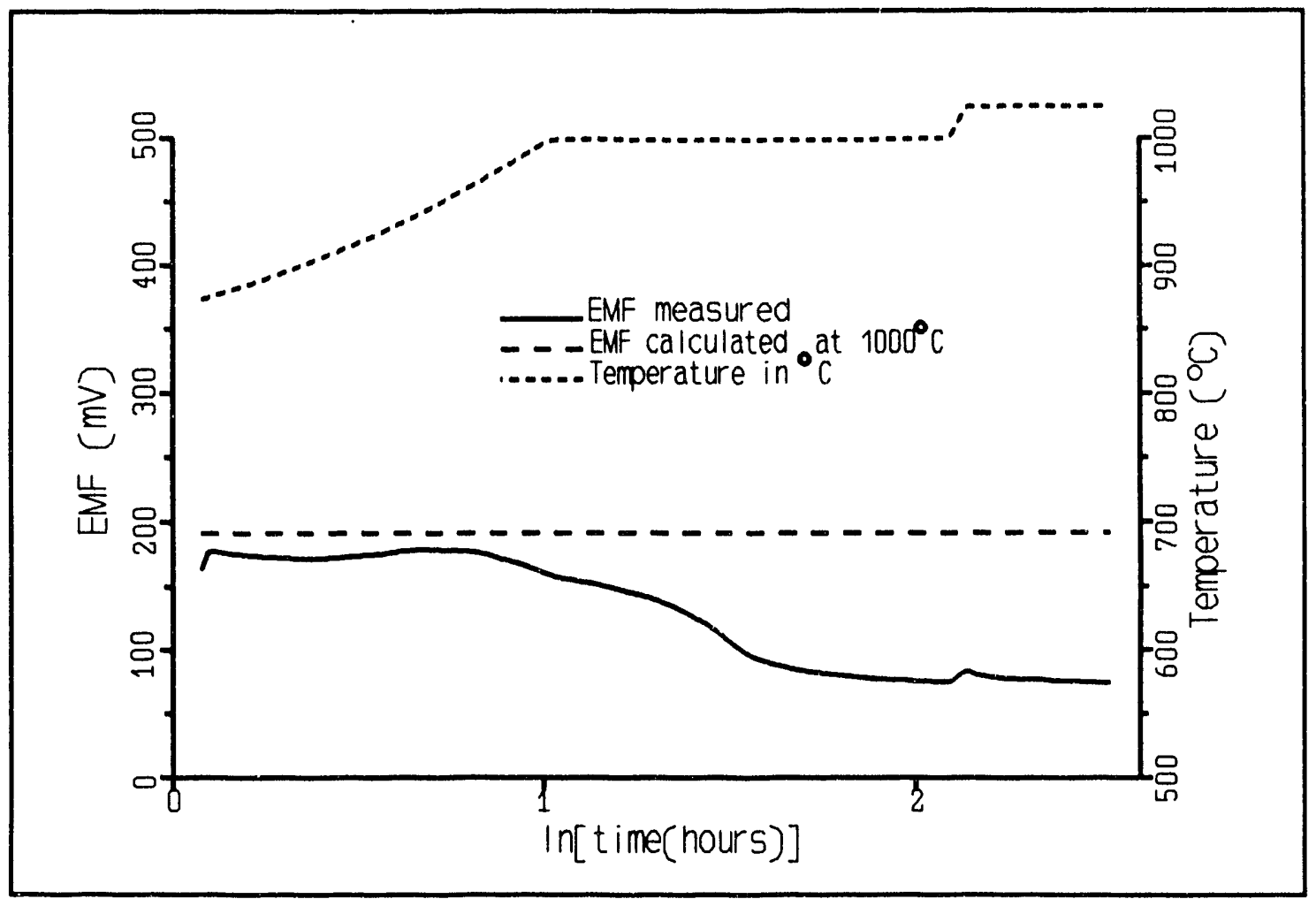

Figure 6.13. EMF and temperature versus the natural log of time in hours for the system $\mathrm{VO} / \mathrm{V}_{2} \mathrm{O}_{3} / / \mathrm{YDT} / / \mathrm{Ta} / \mathrm{Ta}_{2} \mathrm{O}_{5}$.

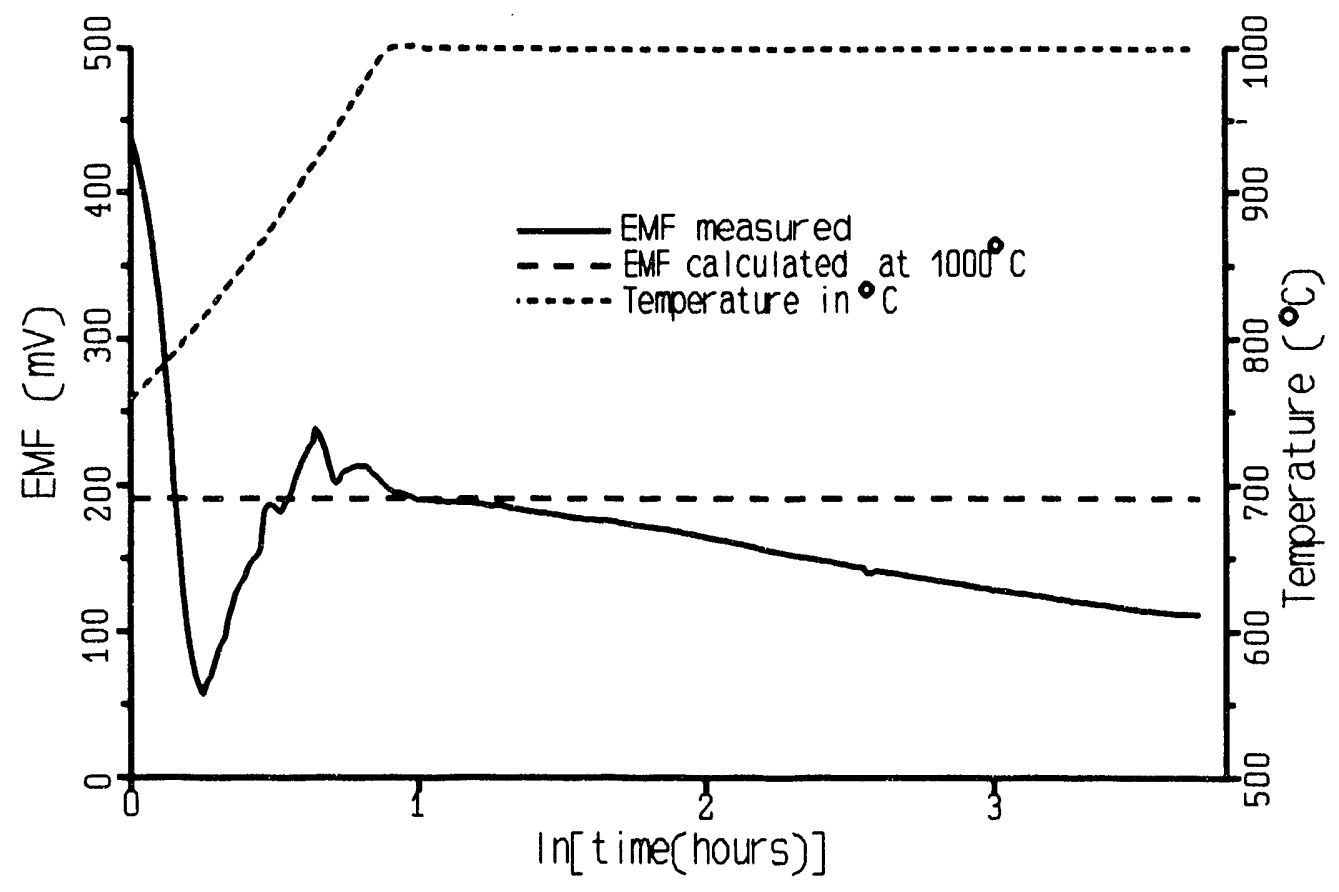

Figure 6.14. EMF and temperature versus the natural log of time in hours for the system $\mathrm{VO} / \mathrm{V}_{2} \mathrm{O}_{3} / / \mathrm{LDT} / / \mathrm{Ta} / \mathrm{Ta}_{2} \mathrm{O}_{5}$. 


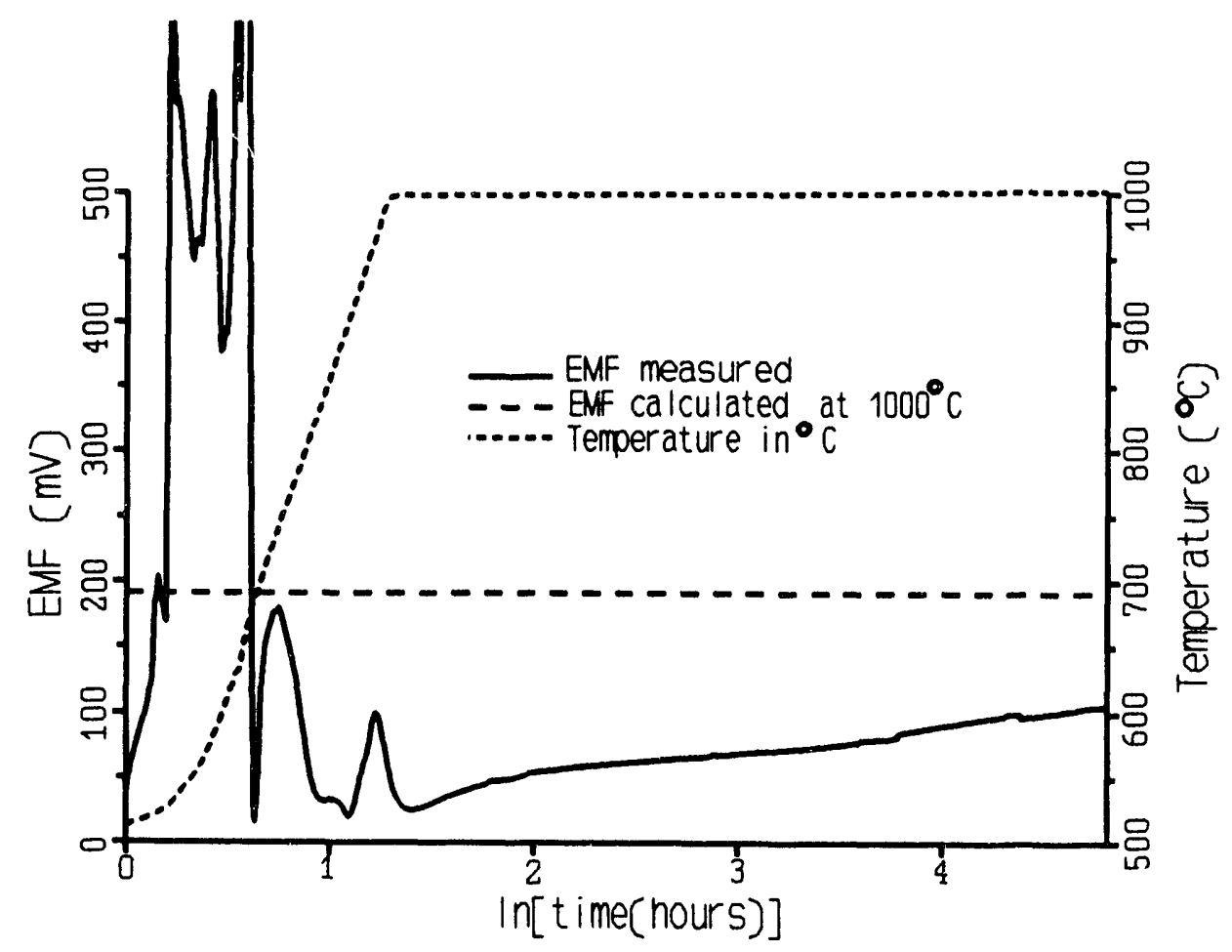

Figure 6.15. EMF and temperature versus the natural log of time in hours for the system $\mathrm{VO} / \mathrm{V}_{2} \mathrm{O}_{3} / / \mathrm{ThO}_{2} / / \mathrm{Ta} / \mathrm{Ta}_{2} \mathrm{O}_{5}$.

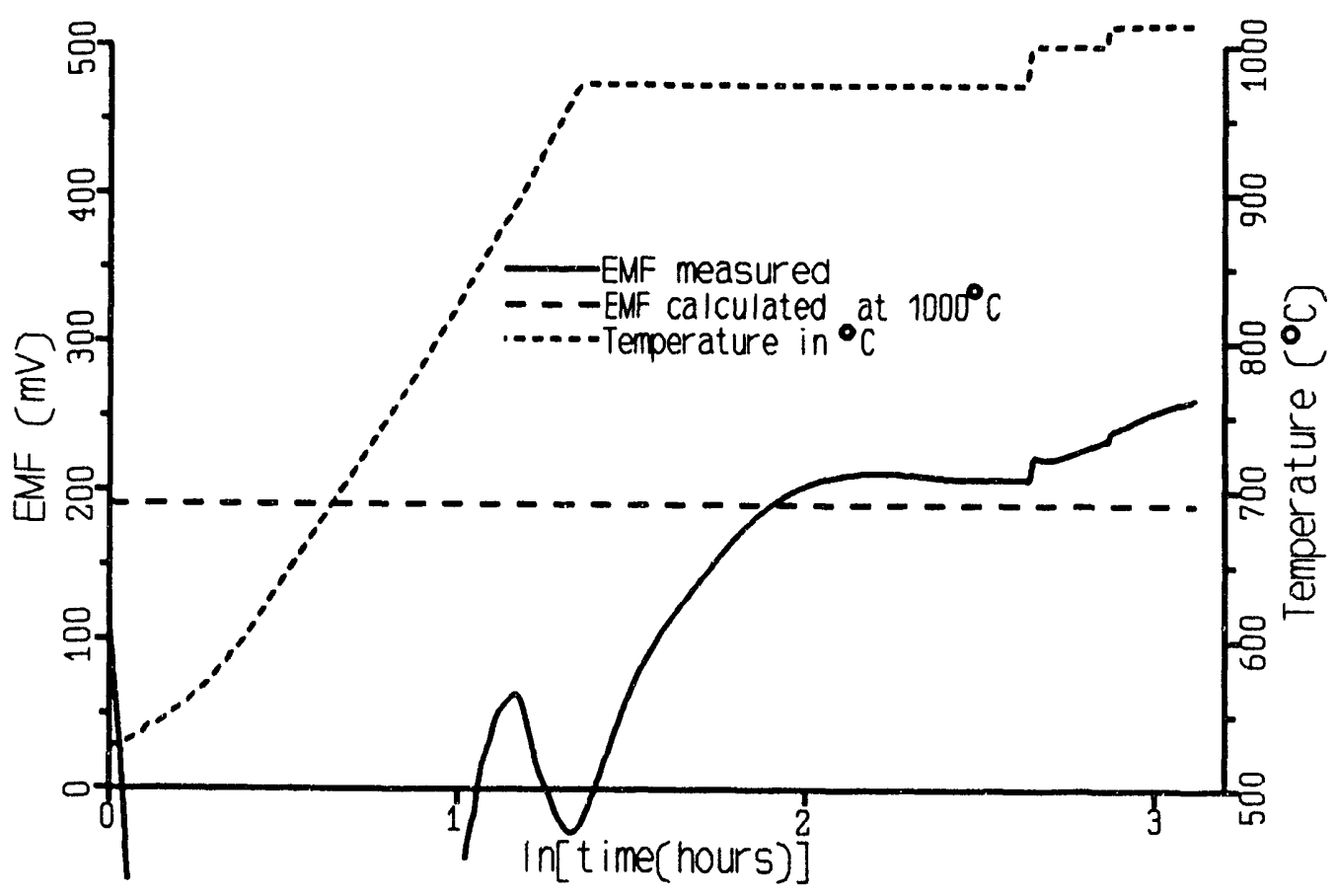

Figure 6.16. EMF and temperature versus the natural log of time in hours for the system $\mathrm{VO} / \mathrm{V}_{2} \mathrm{O}_{3} / / \mathrm{CaF}_{2} / / \mathrm{Ta} / \mathrm{Ta}_{2} \mathrm{O}_{5}$. 


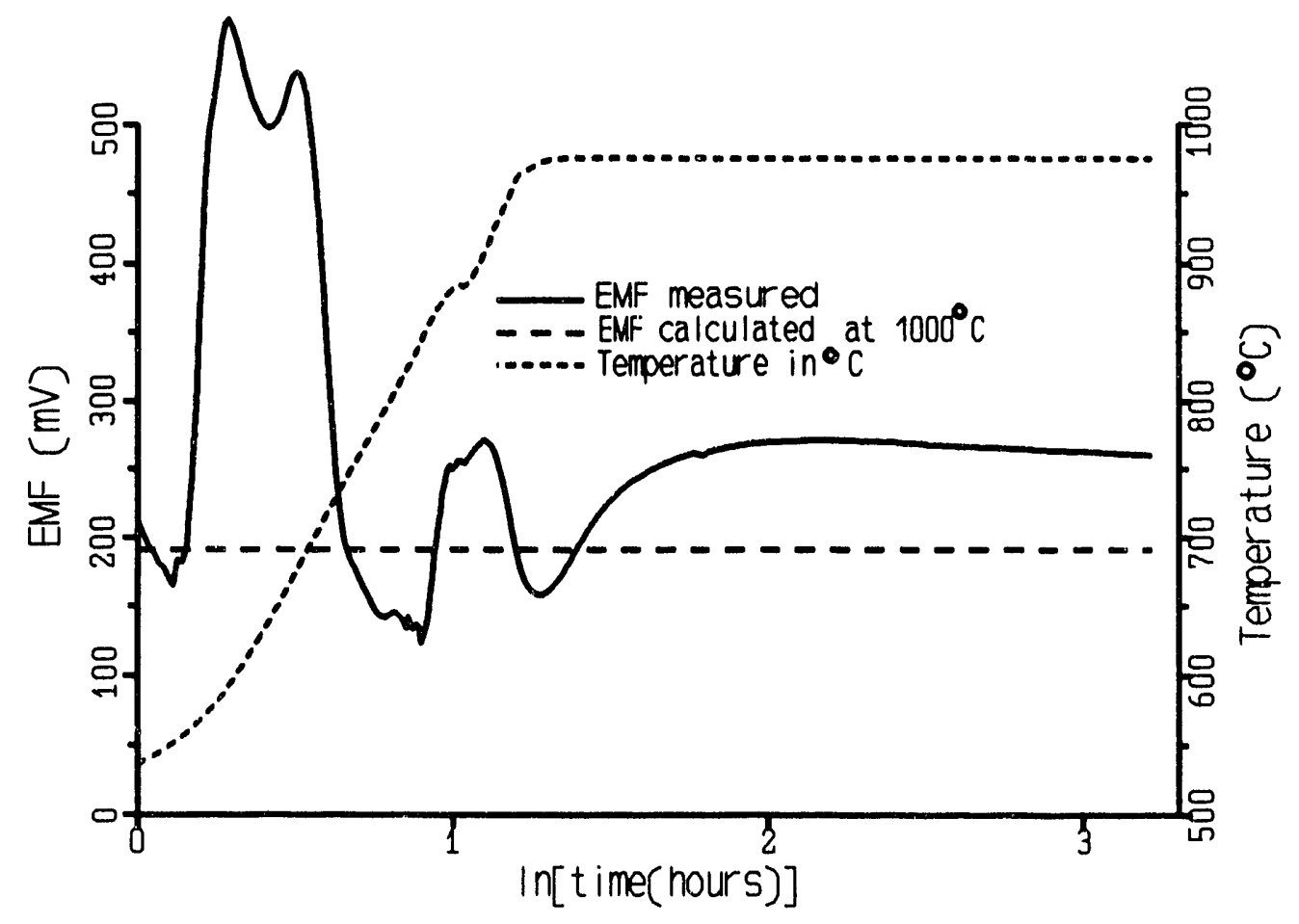

Figure 6.17. EMF and temperature versus the natural log of time in hours for the system $\mathrm{VO} / \mathrm{V}_{2} \mathrm{O}_{3} / / \mathrm{CaF}_{2} / / \mathrm{YDT} / / \mathrm{Ta} / \mathrm{Ta}_{2} \mathrm{O}_{5}$.

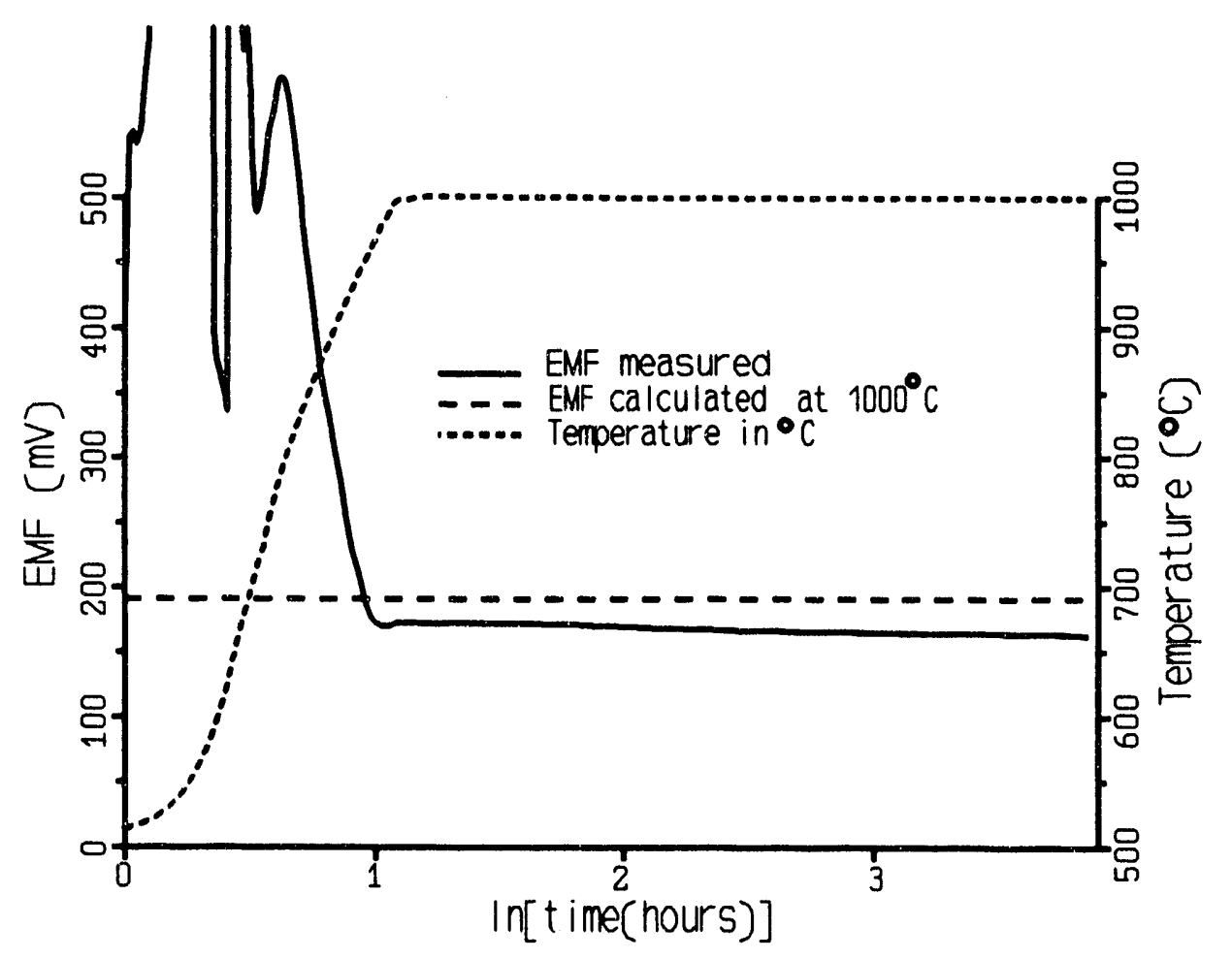

Figure 6.18. EMF and temperature versus the natural log of time in hours for the system $\mathrm{VO} / \mathrm{V}_{2} \mathrm{O}_{3} / \mathrm{Cr}_{2} \mathrm{O}_{3} / / \mathrm{YDT} / / \mathrm{Ta} / \mathrm{Ta}_{2} \mathrm{O}_{5}$. 


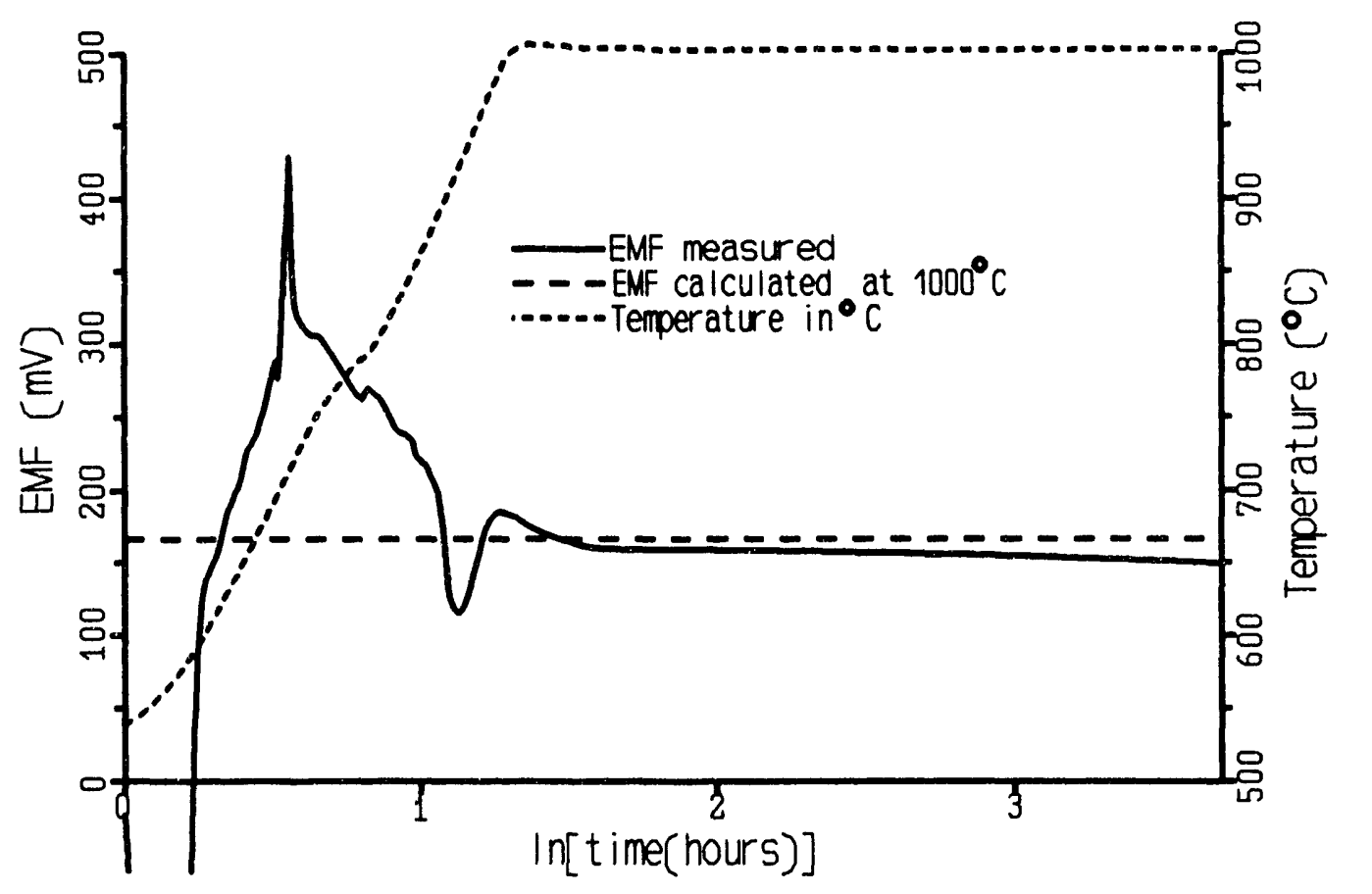

Figure 6.19. EMF and temperature versus the natural log of time in hours for the system $\mathrm{NbO} / \mathrm{NbO}_{2} / / \mathrm{YDT} / / \mathrm{Ta} / \mathrm{Ta}_{2} \mathrm{O}_{5}$.

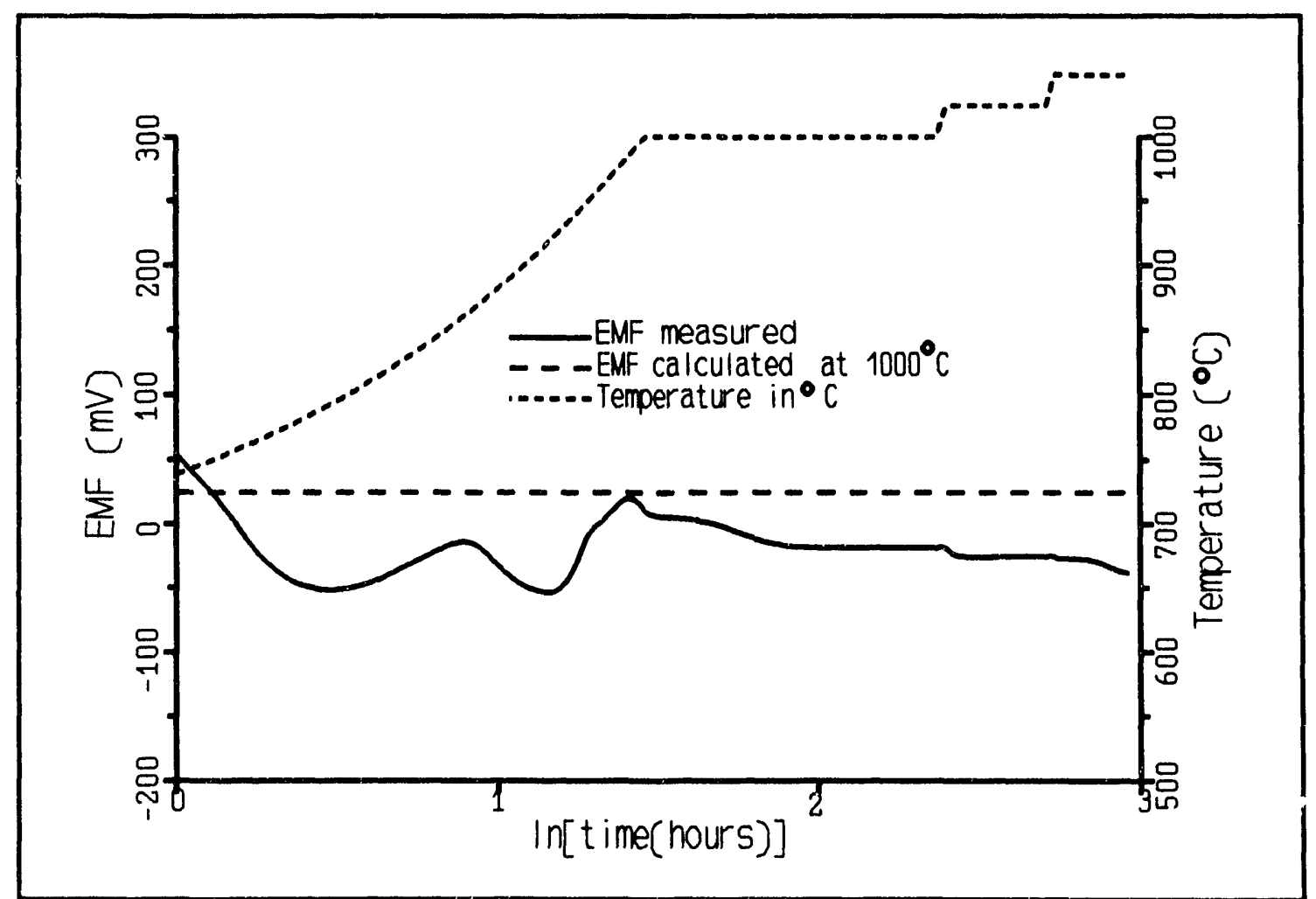

Figure 6.20. EMF and temperature versus the natural log of time in hours for the system $\mathrm{NbO} / \mathrm{NbO}_{2} / / \mathrm{YDT} / / \mathrm{VO} / \mathrm{V}_{2} \mathrm{O}_{3}$. 


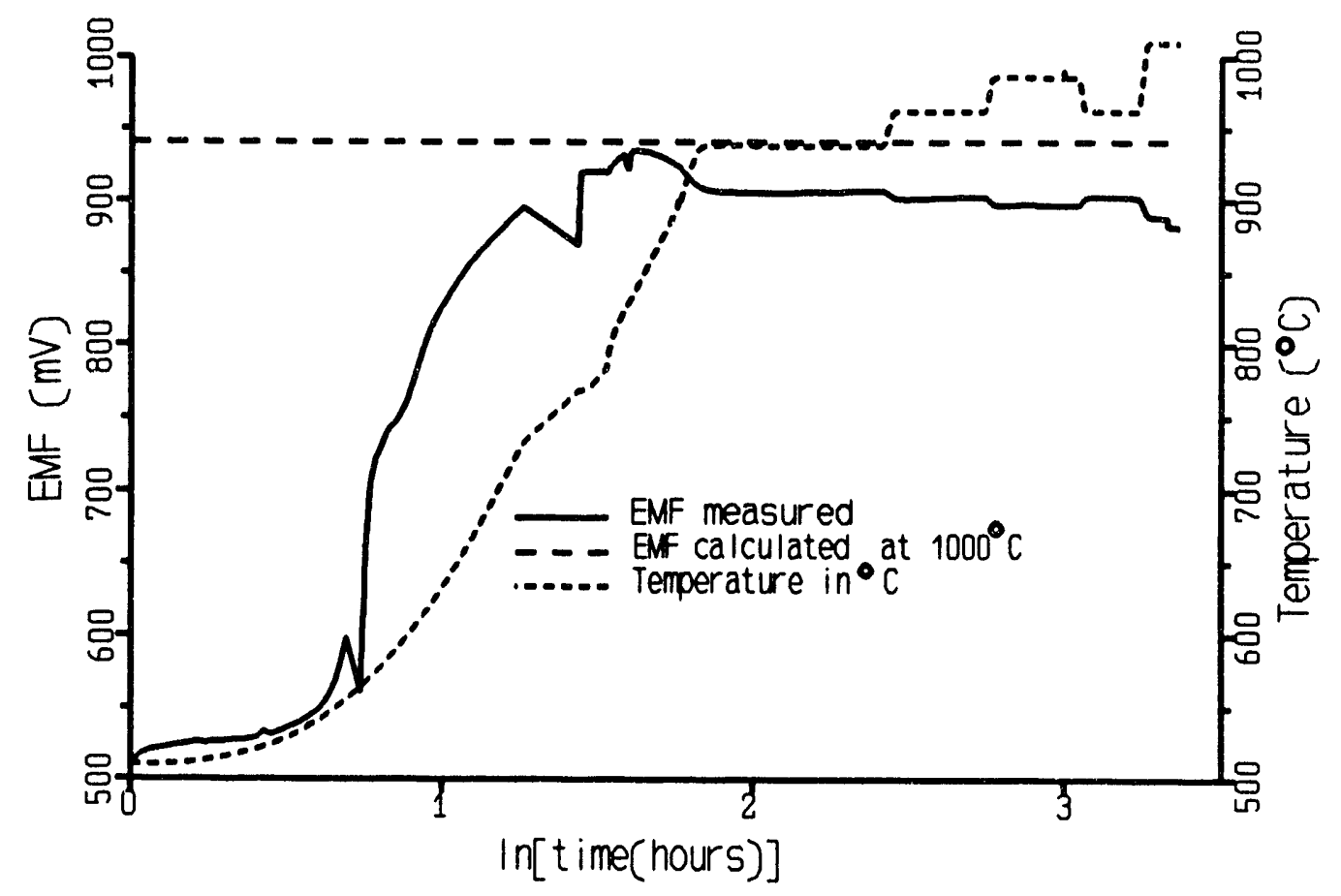

Figure 6.21. EMF and temperature versus the natural log of time in hours for the system $\mathrm{V}_{2} \mathrm{O}_{3} / \mathrm{V}_{3} \mathrm{O}_{5} / / \mathrm{YDT} / / \mathrm{Ta} / \mathrm{Ta}_{2} \mathrm{O}_{5}$.

electrode and the YDT or LDT pellet. Ideally, the drop in the partial pressure of oxygen across the $\mathrm{Cr}_{2} \mathrm{O}_{3}$ interfacial layer would be zero. In this manner, the thermodynamics of the vanadium-oxygen electrode could hopefully be obtained. As can be seen from Figure 6.18, the result is promising. The drawback of this technique is that $\mathrm{Cr}_{2} \mathrm{O}_{3}$ will contaminate the electrode and, consequently, degrade its usefulness. 


\subsection{The Solution to the Galvanic Cell Problems.}

For the short term

Since most of the vanadium-oxygen galvanic cell test experiments, Figures 6.11-6.14, and 6.21 , only operate satisfactorily toward the beginning of the experiment when YDT or LDT is used, only data taken from the first day of the experiment is considered. Normally, it is observed that the EMF approaches the true value toward the beginning of the experiment and then it slowly decays. However, if an electrode contains a large fraction of alloy and hence a small fraction of oxide, the EMF decay rate is more rapid and the true value is not reached even toward the beginning of the experiment.

If a reaction that occurs at the electrode/electrolyte interface is the cause of the erroneous EMF that is approached in the experiments, then it is reasonable to suggest that the larger the exchange of oxygen and oxygen ions through the interface the longer the electrolyte will be useful. If a large fraction of the surface is composed of V-NM alloy, then one would expect the oxygen exchange at the interface to decrease. Consequently, the interfacial reaction interferes with the observed EMF more rapidly, and often the EMF will never reach the true value before decaying.

For high alloy content electrodes a very thin layer of $\mathrm{V}_{2} \mathrm{O}_{3}$ powder is placed between the V-NM-O electrode and the YDT or LDT electrolyte. The $\mathrm{V}_{2} \mathrm{O}_{3}$ layer equilibrates quickly with the electrode during the experiment and provides an 
increased exchange rate of oxygen to oxygen ions at the electrolyte interface. For most of these experimental operations, the electrolyte is replaced while leaving the electrodes and the $\mathrm{V}_{2} \mathrm{O}_{3}$ layer intact and the experiment is repeated a second time to confirm the results. If there is a discrepancy in the results, the second run is accepted as correct since the $\mathrm{V}_{2} \mathrm{O}_{3}$ interfacial layer will be better equilibrated with the vanadium-oxygen electrode in the second run.

For the long run

Ultimately, it would be nice to find an electrolyte which works well for use with the vanadium-oxygen system. A variety of electrolytes have been tried here with only limited success. The best approach now conceived would be to try using YDT or LDT at lower doping concentrations of $\mathrm{Y}_{2} \mathrm{O}_{3}$ and $\mathrm{La}_{2} \mathrm{O}_{3}$ respectively. This should increase the lifetime of the electrolyte since the activity of $\mathrm{Y}_{2} \mathrm{O}_{3}$ or $\mathrm{La}_{2} \mathrm{O}_{3}$ in $\mathrm{ThO}_{2}$ will be reduced and hence the interfacial reaction will be slowed. However, lower doping concentrations will decrease the ionic conductivity of the electrolyte which will in turn increase the time necessary to reach a steady state EMF. Consequently, any net improvement obtained by lower doping of $\mathrm{Y}_{2} \mathrm{O}_{3}$ or $\mathrm{La}_{2} \mathrm{O}_{3}$ is uncertain.

It is interesting to note that in the experiment using $\mathrm{ThO}_{2}$ as the electrolyte, Figure 6.15, the long term limit of the EMF was larger than for the experiments using YDT. $\mathrm{ThO}_{2}$ is a mixed conductor at these partial pressures of oxygen and temperatures.[6] The fact that a mixed ionic conducto: shows a larger EMF than 
a purely ionic conductor confirms our conclusion that there is a significant problem with the purely ionic conductor. X-ray diffraction showed a small reaction of $\mathrm{ThO}_{2}$ with $\mathrm{V}_{2} \mathrm{O}_{3}$ to yield $\mathrm{ThV}_{2} \mathrm{O}_{7}$. This reaction is similar to that observed for YDT and LDT. However, the reaction is much slower and consequently less likely to affect the cell EMF.

Exploration into the use of other electrolytes should eventually yield one which operates well with the V-O system. It is likely that $\mathrm{CaF}_{2}$ can be used with the V-O system but for any length of time only at lower temperatures. However, an alternate reference electrode to $\mathrm{Ta} / \mathrm{Ta}_{2} \mathrm{O}_{5}$ would be required for this system since Ta reacts strongly with the $\mathrm{CaF}_{2}$ electrode and interferes with the coll EMF. Alcock has proposed a novel electrolyte which may be suitable for these systems.[7] This electrolyte contains a mixture of 70 mole percent of $\mathrm{SrF}_{2}$ and 30 mole percent of $\mathrm{LaF}_{3}$ in which a small amount of $\mathrm{SrO}$ is dispersed. The $\mathrm{SrO}$ helps enhance the conduction of oxygen ions. This electrolyte has a iast response time, and it can be used at temperatures up to $1200^{\circ} \mathrm{C}$ which exceeds the useful operating temperature for $\mathrm{CaF}_{2}$ by at least two hundred degrees.

\subsection{The Electrode-Electrolyte Interfacial Reaction}

Since it is clear that the YDT and the LDT electrolytes are interacting with the vanadium oxides, the following question arises. What amount and type of a reaction layer can the interface of the electrode and the electrolyte tolerate before 
the EMF is affected noticeably? There are four types of reaction layer which will be described before an answer to this question can be attempted. The following are the four types: First, the reacting layer is only ionically conductive and not electrically conductive. Second, the reacting layer is only electrically conductive and not ionically conductive. Third, the material is insulating. And fourth, the reaction layer is both electrically conducting and ionically conducting.

6.5.

$$
E=(1 / 49)_{S} \int^{b} t_{E, \text { ion }} d \mu O_{2}+(1 / 4 \xi)_{b} \int c t_{1, \text { ion }} d \mu O_{2}
$$

$t_{E, \text { ion }}=$ the ionic transference number of the electrolyte

$t_{1, i o n}=$ the ionic transference number of the interfacial layer

$a=$ the chemical potential of oxygen at interface a

$b=$ the chemical potential of oxygen at interface $b$

$c=$ the chemical potential of oxygen at interface $c$

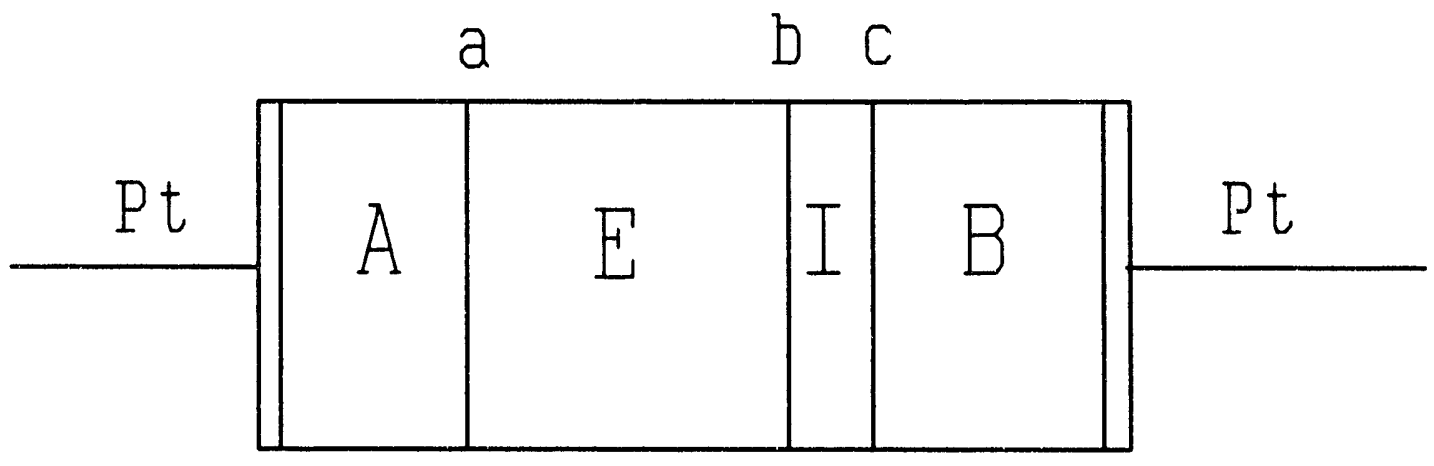

Figure 6.22. Schematic of reaction interface: A and B are the electrodes, $E$ is the electrolyte, and $I$ is the interfacial reaction layer. 


\section{Case 1}

$t_{1, \text { ion }}=1 ; \sigma_{\text {ion }}=$ large and $\sigma_{\bullet}+\sigma_{h}=$ small

If the reaction layer is predominately an ionic conductor, then no change in EMF would be observed. The reaction layer would function as an electrolyte in series with the old electrolyte. This is not the case for the vanadium oxides used with YDT or LDT electrolytes since an erroneous EMF is observed.

\section{Case 2}

$t_{l, i o n}=? ; \sigma_{i o n}=$ small and $\sigma_{e}+\sigma_{h}=$ small

If the reaction layer is predominately an insulator, then the value of the cell EMF will be unpredictable. As the insulating layer becomes thicker, the behavior of the cell will approach that of a capacitor. This type of reaction layer could be tested for by touching the floating lead on the galvanic cell (not grounded) and observing if there is a net change in EMF The static electricity on ones hand will be absorbed by the cell and the measured EMF will change acco-dingly. This behavior is not observed at high temperatures in any of the systems studied here.

\section{Case 3}

$t_{1, \text { ion }}=0 ; \sigma_{\text {ion }}=$ small and $\sigma_{e}+\sigma_{h}=$ large

If the layer is electrically conductive and not ionically conductive, then according to Equation 6.5 the cell EMF will tend toward that EMF which corresponds to the partial pressure of oxygen of the reacting layer at the reaction 
layer-electrolyte interface. However, this case is really a kinetic problem. If the interfacial compound equilibrates quickly with the electrode, then the cell EMF will be nearer the true value. In this instance the $\mathrm{Po}_{2}$ drop across the reaction layer is minimized. Consequently, the partial pressure of oxygen in the reacting layer will be close to that of the electrode. If the kinetics are faster at the reaction layer/electrolyte interface, then the reaction layer will have a different partial pressure of oxygen than the electrode. This will affect the cell EMF. The cell EMF in these errors should not be affected by polarization. From X-ray diffraction data, the reacting layer in these experiments appears to be $\mathrm{YVO}_{3}$ for $\mathrm{V}-\mathrm{O}$ electrodes in contact with YDT and $\mathrm{LaVO}_{3}$ for V-O electrodes in contact with LDT. Consequently, the errors we have observed are best identified as Case 3 errors.

\section{Case 4}

$0<\mathrm{t}_{1, \text { ion }}<1 ; \sigma_{\text {ion }}=$ large and $\sigma_{\mathrm{e}}+\sigma_{\mathrm{h}}=$ large

The reaction layer can be a mixture of electronic and ionic conductivity. In this case, the net effect will be similar to that of Case 3. This effect can be isolated by running the cell under an applied voltage by using the polarization routine described in Chapter 4. If this factor is significant some variation of $\mathrm{EMF}_{\text {cell }}$ as a function of EMF applied should be observed. If the cell EMF, EMF cell, is obtained at zero current, the Case 4 error is reduced to that of Case 3. For the vanadium oxides, this experiment was done and the decay rate seemed to be slowed some, but the situation in our experiments seems to resemble Case 3 more 
closely.

The Case of YDT and LDT with vanadium oxides

It appears that $\mathrm{YVO}_{3}$ and $\mathrm{LaVO}_{3}$ are predominately electrical conductors in which the oxygen exchange rate is considerably faster at the electrolyte-reaction layer interface than at the electrode-reaction layer interface. As the reaction at the electrolyte interface begins, the interfacial layer is too small to interfere with the oxygen equilibrium between the VO/ $\mathrm{V}_{2} \mathrm{O}_{3}$ electrode and the electrolyte. As the reaction layer increases, the EMF of the cell is slowly overpowered by the reacting interface. If an electrode which is about half oxide and half metal is used, it would not be surprising to find that a smaller reaction layer is required to interfere with the EMF. The exchange rate of oxygen to oxide ions at the electrode-electrolyte interface would be smaller to begin with. Consequently, a smaller reaction layer would be required to interfere with the cell

EMF. A thin layer of $\mathrm{V}_{2} \mathrm{O}_{3}$ powder at the interface was tried to insure the maximum exchange rate of oxygen across the electrode-electrolyte interface and, consequently, to maximize the useful time of the electrolyte.

\subsection{Some Other Tests on the Galvanic Cell.}

There are some other tests and effects to consider about the operation of the galvanic cell which have not yet been discussed. Most of these are related to experimental parameters or conditions under which the galvanic cell is operated. 
See Appendix C or Chapter 4 for relevant description of the apparatus and components.

\section{Effect of the liquid nitrogen trap}

The gettering effect of the liquid nitrogen trap in the galvanic cell is unknown. It is designed to help reduce the impurities flowing into and out of the apparatus. Running experiments without liquid nitrogen has not been tried, and it is likely that the experiment will still function properly without it. However, the gettering foil if the trap is not used in the furnaces will be expected to oxidize more rapidly.

Effect of the gettering furnaces.

The two gettering furnaces shown in Figure 4.3 are designed to purify the helium carrier gas. The gettering system is designed to pick up impurities such as carbon monoxide, carbon dioxide, oxygen, and methane gas. The helium carrier gas that is used is ultra high purity helium, rated $99.999 \%$ pure. When the furnaces are turned off the cell EMF remains constant. Such a result indicates that the gettering furnaces are non-essential and that the helium used might be pure enough in itself to run the experiment without a gettering system. However, there is some additional zirconium foil within the cell chamber which getters impurities within the sample chamber. The cell apparatus has not been operated without the gettering foil within the sample chamber so the necessity of its presence is not known. 
Effect of flow rate.

Variation of the helium flow rate through the cell apparatus is a good way to check for gaseous reactions with the electrodes. Periodically in most experiments the flow rate was varied and the cell EMF was checked for any resulting variation. No significant change of the EMF was ever observed. Consequently, it has been concluded that gaseous short circuiting is not affecting the EMF observed. Gary Bullard has discussed this problem in detail for electrodes like the $\mathrm{Mo} / \mathrm{MoO}_{2}$ electrode.[9]

Effect of pressure changes.

Typically the cell chamber is backfilled with $1 / 2$ to $2 / 3$ of an atmosphere of flowing helium. For several runs in the VO/ $\mathrm{V}_{2} \mathrm{O}_{3} / / \mathrm{YDT} / / \mathrm{Ta} / \mathrm{Ta}_{2} \mathrm{O}_{5}$ system, the roughing pump valve was opened during the experiment to force a rapid evacuation of the helium carrier gas from the cell chamber. Oddly, the EMF was observed to increase with a sudden decrease in pressure. If left under vacuum, the EMF then decayed slowly with time. This effect must be caused either by the difference in porosity between the two electrodes or by the temperature gradient created across the sample due to the rapid evacuation of the apparatus.

Effect of oxygen in system.

The operating galvanic cell used here measures a partial pressure of oxygen at least as low as $10^{-25} \mathrm{~atm}$. However, the best that the oxygen partial pressure in the cell chamber could be expected to be is about $10^{-10}$ atm. The observed EMF could only be valid if the kinetics of the electrode-electrolyte equilibrium are 
much faster than the kinetics of the gas-electrolyte equilibrium. In support of this statement, N. L. Robertson and J. N. Michaels report that the equilibrium between gaseous species and the electrolyte is relatively slow. [8]

Despite the slow reaction between the gas and electrolyte, there is a limit to the amount of oxygen the system can tolerate. It has been observed that small leaks or a large amount of degassing from the internal alumina parts can cause the EMF to decay. In other words, oxygen will interfere with the observed EMF, but the partial pressure of oxygen in the carrier gas need not be on the same order of magnitude of that being measured by the electrolyte.

Effect of surface contamination on the electrolyte.

To manipulate the YDT and LDT pellets outside of the apparatus, tweezers coated with teflon tape are used. It was observed that if a metal surface was used to manipulate the electrolytes, the electrolyte surface would inevitably become scratched. A scratch would inevitably leave behind some surface contamination, namely iron, which would interfere with the electrolytes performance. If a scratched electrolyte was used, then the electrolyte lifetime was limited. After running properly for awhile, the cell EMF would decay. By running the polarization routine discussed in chapter 4 , it was discovered that the scratched electrolytes, after time, had become mixed conductors. 


\section{References}

1. P. Maestro, G. Demazeau, M. Pouchard, "The Solid Solution $\mathrm{Cr}_{1-x} \operatorname{Ir}_{\mathrm{x}} \mathrm{O}_{2}$ " J. Solid State Chem., 40, 101-108 (1981) (French).

2. R. Tetot and C. Picard, "High Temperature Thermodynamics of the Vanadium-Oxygen System for $0<0 / N /<1.5$," J. Solid State Chem., 66, 324331 (1987).

3. R. L. Jones, C. E. Williams, and S. R. Jones, "Reaction of Vanadium Compounds with Ceramic Oxides," J. Electrochem. Soc., 133(1), 227-230 (1986).

4. P. J. Meschter, "High-Temperature Thermodynamic Properties in the Platinum-Titanium, Platinum-Zirconium, and Platinum-Hafnium Systems," Ph.D. Thesis, University of Pennsylvania (1975).

5. E. M. Levin, C. R. Robbins, H. F. McMurdie, and M. K. Resen, ed., Phase Diagrams for Ceramists, Vol II, American Ceramic Society, Ohio (1969).

6. M. F. Lasker and R. A. Rapp, "Mixed Conduction in $\mathrm{ThO}_{2}$ and $\mathrm{ThO}_{2}-\mathrm{Y}_{2} \mathrm{O}_{3}$ Solutions," Z. Phys. Chemie Neue Folge, 49, 198-221 (1966).

7. C. B. Alcock and B. Li, "A Fluoride-Based Composite Electrolyte," Solid State Ionics, 39, 245-249 (1990).

8. N. L. Robertson and J. N. Michaels, "Oxygen Exchange on Platinum Electrodes in Zirsonia Cells: Location of Electrochemical Reaction Sites," J. Electrochem. Soc., 137(1),129-135 (1990).

9. G. L. Bullard,"Development of the High-Temperature, Solid-State, Electromotive Force Technique to Study the Thermodynamics of Lewis-AcidBase Transition Metal Alloys," Ph.D. Thesis, U. C. Berkeley, LBL-7691 (1978). 


\section{Chapter 7}

\subsection{Activity Coefficients at Infinite Dilution.}

The experimental values

The activity coefficients at infinite dilution for $\mathrm{V}, \mathrm{Nb}$, and $\mathrm{Ta}$ in the noble metals are reviewed in Table 7.1. Some of these values are known more precisely than others. Some values are not well known because the data available are sparse. However, the infinite dilution parameter can still be estimated. If there is a data point for $\mathrm{V}, \mathrm{Nb}$, or $\mathrm{Ta}$ in a dilute solid solution of noble metal, then the infinite dilution parameter is extrapolated from the regular solution equation as follows.

$$
\left(\log \gamma_{1}\right) /\left(\mathrm{X}_{2}\right)^{2} \approx\left(\log \gamma_{1}{ }^{9}\right)
$$

If there are no data for dilute solutions, then the activity at the noble metal solid solution boundary is set to the lowest known activity in the system and the activity coefficient is extrapolated to zero concentration using Equation 7.1. This approach yields a lower bound on $-\log \gamma^{\circ}$. For some systems the activity of $\mathrm{V}, \mathrm{Nb}$, or Ta is known for the region which is composed of the noble metal and the adjacent phase. For this equilibrium, the activity at the nobie metal phase boundary is easily obtained and the activity coefficient at infinite dilution is 
Table 7.1. Activity coefficients at infinite dilution $(T=1273 \mathrm{~K})$.

\begin{tabular}{|c|c|c|c|}
\hline system & $-\log \gamma^{\circ}$ & technique & reference \\
\hline \multicolumn{4}{|l|}{ Vanadium } \\
\hline V-Co & $0.0 \pm 0.4$ & nitride equilibria & 2 \\
\hline V-Ni & $2.35 \pm 0.10$ & galvanic cell & 3,4 \\
\hline V-Cu & $-2.39 \pm 0.35$ & & 5 \\
\hline V-Ru & $3.4 \pm 0.3$ & carbide equilibria & \\
\hline V-Rh & $5.25 \pm 0.25$ & galvanic cell(YDT/LDT) & \\
\hline V-Pd & $5.93 \pm 0.08$ & galvanic cell(YDT/LDT) & \\
\hline V-Ag & $-2.5 \pm 0.5$ & phase diagram est. & 6 \\
\hline V-Re & $-1.8 \pm 1$ & phase diagram est. & 7 \\
\hline V-Os & $3.0 \pm 0.3$ & carbide equilibria & \\
\hline V-Ir & $8.11 \pm 0.5$ & galvanic cell(YDT/LDT) & \\
\hline V-Pt & $8.8 \pm 1$ & oxide equilibria & \\
\hline V-Au & $0.95^{\bullet} \pm 0.05$ & galvanic cell & 8 \\
\hline \multicolumn{4}{|l|}{ Niobium } \\
\hline Nb-Co & $0.49 \pm 0.02$ & galvanic cell(LDT) & 9 \\
\hline $\mathrm{Nb}-\mathrm{Ni}$ & $0.5<x<3.7$ & carbide,nitride equilibria & 2,10 \\
\hline $\mathrm{Nb}-\mathrm{Cu}$ & $-3.0 \pm 0.4$ & phase diagram est. & 6 \\
\hline $\mathrm{Nb}-\mathrm{Ru}$ & $<4.6$ & carbide equilibria & 2 \\
\hline $\mathrm{Nb}-\mathrm{Rh}$ & $8.71^{b} \pm 0.08$ & galvanic cell(YDT) & 2,11 \\
\hline Nb-Pd & $9.41 \pm 0.10$ & galvanic cell(YDT) & 6,12 \\
\hline $\mathrm{Nb}-\mathrm{Ag}$ & $<-2$ & phase diagram est. & 6 \\
\hline $\mathrm{Nb}-\mathrm{Re}$ & $<3.7$ & carbide equilibria & 2 \\
\hline $\mathrm{Nb}-\mathrm{Os}$ & $4.2 \pm 1$ & carbide equilibria & 2 \\
\hline Nb-Ir & $>5.9$ & carbide equilibria & 2,6 \\
\hline Nb-Pt & $>7.3$ & carbide equilibria & 2,6 \\
\hline $\mathrm{Nb}-\mathrm{Au}$ & -..- & & \\
\hline
\end{tabular}


Table 7.1. Continued.

\begin{tabular}{llll}
\hline system & - log $^{\circ}$ & technique & reference \\
\hline Tanialum & & & \\
Ta-Co & $2.26 \pm 0.25$ & galvanic cell(CDT) & 13 \\
Ta-Ni & $4.6 \pm 0.2$ & from formation energies & 6,14 \\
Ta-Cu & $<-2.3$ & phase diagram est. & 6 \\
Ta-Ru & $<5.0$ & carbide equilibria & 2 \\
Ta-Rh & $10.88^{b} \pm 0.08$ & galvanic cell(YDT) & 2,15 \\
Ta-Pd & $9.5 \pm 2$ & carbide equilibria & 2 \\
Ta-Ag & $<-2$ & phase diagram est. & 6 \\
Ta-Re & $<4.2$ & carbide equilibria & 2 \\
Ta-Os & $4.5 \pm 0.4$ & carbide equilibria & 2 \\
Ta-Ir & $>6.5$ & carbide equilibria & 2,6 \\
Ta-Pt & 12.4 & galvanic cell(YDT) & 16 \\
Ta-Au &.--- & &
\end{tabular}

a Estimated from data at $973 \mathrm{~K}$

b Data actually from $1200 \mathrm{~K}$

estimated from equation 7.1. If the maximum solubility of the acid metal in the noble metal is unknown, then the solid solution boundary is set at a value known to be greater than the true boundary and the activity coefficient is extrapolated to zero using 7.1. In this case, an upper bound for $-\log \gamma^{-}$is fixed.

General trends

Observations by row

From Table 7.1 some observations can be made about the infinite dilution parameters. The $-\log \gamma^{\infty}$ parameter tends to be largest for the group $\mathrm{XB}$ transition 
metals, Pd and Pt, and drops sharply at the group XIB transition metals. From group $\mathrm{X}$ toward the left in the transition series the coefficient deceases. Wengert showed that the activity of zirconium at infinite dilution in platinum group metals demonstrates the same trend.[1]

Observations by column

From Table 7.1 the following trends are observed. Interactions are stronger for niobium than for vanadium, and the interactions are stronger for tantalum than for niobium. Interactions with platinum are stronger than with iridium, interactions with iridium are stronger than with osmium, and interactions with osmium are stronger than with gold. A similar trend is observed with the $4 \mathrm{~d}$ transition metals. In general, interactions for acid-base systems at infinite dilution increase going down a column in the periodic table as summarized in Table 7.2. Table 7.2. Order of decreasing inteructions.

$$
\text { strong to weak comments }
$$

$1 \mathrm{Ta}>\mathrm{Nb}>\mathrm{V} \quad$ acidity with any noble metal

$2 \quad \mathrm{Pt}>\mathrm{Pd}>\mathrm{Ni} \quad$ basity with group $\mathrm{V}$ transition metals

3 Ir $>$ Rh $>$ Co " "

$4 \mathrm{Pt}>\mathrm{Ir}>\mathrm{Os}>\mathrm{Au} \quad "$ "

$5 \quad \mathrm{Pd}>\mathrm{Rh}>\mathrm{Ru}>\mathrm{Ag} \quad$ " "

Some exceptions to the above rules are found for weakly interacting systems. These can be accounted for by remembering that the interaction at infinite dilution 
is only partly due to the bond strength. The is an additional contribution from the stain energy induced by putting an atom of mismatched size into the solvent lattice. This effect is considered in the next section. The relative strength of interaction in Table 7.2 agrees with Brewer's predictions.[17]

Explanation of trends.

The relative strength of the interactions can be explained by considering the size and number of overlapping orbitals. More specifically, the overlap of the nonbonding $\mathrm{d}$ orbitals of the noble metal with the vacant orbitals of vanadium will be the primary contribution to the increased stability of the alloy phases. The trends by periodic row

As atomic number increases across a row in the periodic table, the size of the atomic orbitals decreases. Furthermore the $d$ valence orbitals will decrease in size more than the $\mathrm{s}$ and $\mathrm{p}$ orbitals. For $\mathrm{Pd}$ and $\mathrm{Pt}$, the $\mathrm{d}$ orbitals are extended enough to provide substantial overlap with the acids like vanadium. For $\mathrm{Ag}$ and Au the orbitals are too contracted to provide significant acid-base d-d bonding stability. In other words, the nonbonding pairs on $\mathrm{Ag}$ and $\mathrm{Au}$ do not overlap much with the metals which contain vacant $d$ orbitals.

The trends by periodic column

The $5 \mathrm{~d}$ orbitals are more extended than the $4 \mathrm{~d}$ orbitals which in turn are more extended than the $3 d$ orbitals. Consequently, $5 d-5 d$ overlap would be expected to proved the greatest stability and $3 \mathrm{~d}-3 \mathrm{~d}$ overlap the least stability. This type of reasoning is consistent with the trends observed in Table 7.1. 


\subsection{Modeling the Activity Coefficient at Infinite Dilution.}

The theory

One very important point in the acid-base intermetallic titration curve is the activity coefficient at infinite dilution. Schaller[18-21] has proposed a relatively good model for predicting this parameter. In his model, the partial free energy at any composition is divided into two parts.

7.1

$$
\Delta \bar{G}_{i}{ }^{E}=\Delta \bar{G}_{i}{ }^{E d}+\Delta \bar{G}_{i}{ }^{E e} ; \Delta \bar{G}_{i}{ }^{E}=R T \ln \gamma_{i}
$$

$\Delta \bar{G}_{i}{ }^{E d}$ is the excess free energy due to size effects, and $\Delta \bar{G}_{i}{ }^{\text {Ee }}$ is the excess free energy due to electronic effects. Schaller has calculated the partial free energy due to size effects at infinite dilution by using a continuum elastic approximation.[1821] For $\Delta \bar{G}_{i}$, Sd Schaller, et al obtained the following equation.

$$
7.2 \Delta \Delta \bar{G}_{i}^{\mathrm{Ed}}\left(\mathrm{X}_{i}=0\right)=\left(\overline{\mathrm{V}}_{i}-\mathrm{V}_{8}\right) \mathrm{B}_{8} / \mathrm{b}_{8}-\left[\mathrm{V}_{8} \mathrm{~B}_{8} /\left[\mathrm{b}_{8}\left(1-\mathrm{b}_{8}\right)\right]\right]\left[\left(\overline{\mathrm{V}}_{i}^{\left(1-b_{8}\right)} / \mathrm{V}_{8}\right)-1\right]
$$

$B_{s}$ is the bulk modulus of the solvent, the noble metal, and $b_{s}$ is the derivative of the bulk modulus as a function of pressure. Relevant values for these parameters are tabulated in Table 7.5. $V_{3}$ is the molar volume of the solvent, and $\bar{v}_{i}$ is the partial molar volume at infinite dilution of the solute. Relevant values for $\bar{v}_{i}$ are given in Table 7.6, and relevant values for $\mathrm{V}_{8}$ are given in Table 7.4.

Schaller states that the electrical contribution to the partial free energy at infinite dilution is approximated by the following equation.

$$
7.3 \Delta \bar{G}_{i}{ }^{\mathrm{Ee}}\left(\mathrm{X}_{1}=0\right) \approx \mathrm{z}_{\mathrm{i}}\left(\Phi_{1}{ }^{\mathrm{F}}-\Phi_{\mathrm{B}}{ }^{\mathrm{F}}\right)
$$

Where $z_{i}$ is the valency of the solute in the solvent, $\Phi_{i}{ }^{F}$ is the Fermi level of the solute, and $\Phi_{8}{ }^{F}$ is the Fermi level of the solvent. Schaller's data which are 
given in Table 7.3 demonstrate that his approach to calculating the activity coefficients at infinite dilution is fairly accurate for a wide variety of systems. For some systems like the Th-Pd system, the calculated versus experimental values are well agreed, but for others like the Ce-Pd system, the calculated versus experimental values deviate considerably. Often, the correct choice of the valency, $z_{i}$, is uncertain. A more logical choice for $z_{i}$ or a better equation for the excess partial Gibbs energy at infinite dilution may yield better agreement between the experimental and the calculated values.

Table 7.3. Schaller's Table of comparisons.

solvent is palladium

\begin{tabular}{llllll}
\hline solute & $\Delta \bar{G}_{i}{ }^{E}$ calc. & $\Delta \bar{G}_{i}{ }^{E}$ exp. & $Z_{i}$ & $T\left({ }^{\circ} \mathrm{C}\right)$ & reference \\
\hline $\mathrm{Y}$ & $-450 \pm 60$ & $-320 \pm 3$ & 3 & 750 & 21,26 \\
$\mathrm{Ce}$ & $-697 \pm 80$ & $-390 \pm 10$ & 4 & 750 & 21,26 \\
$\mathrm{Th}$ & $-396 \pm 60$ & $-410 \pm 10$ & 4 & 800 & 18 \\
$\mathrm{Ag}$ & $-70 \pm 20$ & $-21 \pm 8$ & 1 & & 19 \\
$\mathrm{Cd}$ & $-128 \pm 25$ & $-96 \pm 2$ & 2 & & 19,24 \\
In & $-182 \pm 35$ & $-167 \pm 4$ & 3 & & 19,24 \\
Sn & $-153 \pm 40$ & $-209 \pm 4$ & 4 & & 19,24 \\
$\mathrm{Zr}$ & $-334 \pm 30$ & $-352 \pm 4$ & 4 & 950 & 19,24 \\
units of $\Delta \overline{\mathrm{G}}_{\mathrm{i}}^{\mathrm{E}}$ are $\mathrm{kJ} / \mathrm{mole}$ of solute & &
\end{tabular}


Details of the electronic contribution to the partial Gibbs energy

Derivation of the equation

Definition of symbols:

$A=$ acid $=$ left hand transition metal

$\mathrm{B}=$ base $=$ right hand transition metal

$\alpha=$ structure of $\mathrm{A}$ at room temperature(temp. at which work function is obtained)

$\beta=$ structure of $B$ at room temperature

$\Omega_{A}^{\alpha}=$ density of states of element $A$ in structure $\alpha$

More definitions:

$7.4 n_{e}^{A}=E_{E^{\circ}(A, \alpha)} f^{E f(A, \alpha)} \Omega_{A}^{\alpha}(E) d E={ }_{E^{\circ}(A, \beta)} \int^{E f(A, \beta)} \Omega_{A}^{\beta}(E) d E=$ \# valence $e^{-}$on $A$

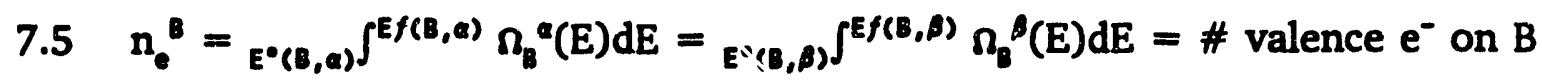

$E^{\circ}(A, \alpha)=$ lnwest energy valence state of $A$ in the $\cong$ structure

$E f(A, \alpha)=$ highest energy valence state of $A$ in the $\alpha$ structure $=$ Fermi level

$E f(A, \alpha)=-\Phi_{A}^{\alpha}$

The following derivation only applies strictly at $\mathrm{OK}$.

Consider the following reaction

$7.6 \quad N_{A} A(s)+N_{B} B(s)=N_{A} B x_{B}(s)$

where

$$
\mathrm{N}_{\mathrm{A}}=\text { \# of } A \text { atoms, } \mathrm{N}_{B}=\text { \# of } B \text { atoms, and } \mathrm{N}=\mathrm{N}_{\mathrm{A}}+\mathrm{N}_{B}
$$

From Equation 7.6 it follows that

$7.7 \Delta \bar{H}^{E e}=\left(N_{A}+N_{B}\right)_{E^{\circ}(A B, \beta)}{ }^{E f(A B, \beta)} \Omega_{A B}^{\beta}(E) E d E$ 


$$
\begin{aligned}
& -N_{A E^{\circ}(A, a)} \int^{E f(A, a)} \Omega_{A}^{\alpha}(E) E d E \\
& -N_{B E^{\circ}(B, \beta)} f^{E f(B, \beta)} \Omega_{B}^{\beta}(E) E d E
\end{aligned}
$$

$\Delta H^{\text {Ee }}$ is the integral excess enthalpy due to electronic effects.

Take the derivative with respect to $N_{A}$ yields

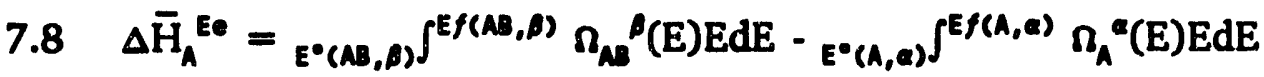

$$
\begin{aligned}
& +\partial / \partial N_{A}\left[_{E^{\circ}(A B, \rho)} f^{E f(A B, A)} \Omega_{A B}{ }^{B}(E) E d E\right]
\end{aligned}
$$

At the limit of $\mathrm{N}_{\mathrm{A}}=0$ or $\mathrm{X}_{\mathrm{A}}=0$ the following are true

$$
E^{\bullet}(A B, \beta) \int^{E f(A B, \beta)} \Omega_{A B}{ }^{\beta}(E) E d E \rightarrow E^{\cdot}(B, \beta) \int^{E f(B, \beta)} \Omega_{B}^{\beta}(E) E d E
$$

and

$$
\begin{aligned}
& \partial / \partial N_{A}\left[_{E^{\circ}(A B, \beta)} f^{E f(A B, \beta)} \Omega_{A B}^{\beta}(E) E d E \sim \Delta H_{A B}^{\beta} / \Delta N_{A}\right. \text { if the delta's are small enough } \\
& \Delta H_{A B}^{\beta} / \Delta N_{A} \rightarrow-\left(n_{Q}^{B}-n_{e}^{A}\right) E f(B, \beta) \text { as } N_{A} \rightarrow 0
\end{aligned}
$$

yields

$$
\begin{aligned}
& 7.9 \Delta \bar{H}_{A}{ }^{E \bullet}\left(X_{A}=0\right)=E_{E^{\bullet}(B, \beta)} f^{E f(B, \beta)} \Omega_{B}^{\beta}(E) E d E-E^{\bullet}(A, a) f^{E f(A, a)} \Omega_{A}^{a}(E) E d E \\
& -\left(n_{e}^{B}-n_{e}^{A}\right) E f(B, \beta)
\end{aligned}
$$

Since

$$
\Delta \bar{G}_{A}^{\text {Eee }}\left(X_{A}=0\right) \approx \Delta \bar{H}_{A}^{E e}\left(X_{A}=0\right) \text { if } \Delta \bar{S}_{A}^{\text {Eee }}\left(X_{A}=0\right) \text { is small }
$$

then

$$
\begin{aligned}
& 7.10 \Delta \bar{G}_{A}^{E^{e}}\left(X_{A}=0\right)=E_{E^{\bullet}(B, \beta)} f^{E f(B, A)} \Omega_{B}^{\beta}(E) E d E-E^{\bullet}(A, \beta) f^{E f(A, \beta)} \Omega_{A}^{\beta}(E) E d E \\
& +{ }_{E^{\circ}(A, \beta)} f^{E f(A, \beta)} \Omega_{A}^{\beta}(E) E d E-E^{\cdot}(A, \alpha) f^{E f(A, \alpha)} \Omega_{A}^{\alpha}(E) E d E-\left(n_{e}^{B}-n_{e}^{A}\right) E f(B, \beta)
\end{aligned}
$$

For the transformation

$$
7.11 A^{\alpha}=A^{\beta}
$$


$\left.7.12 \Delta H_{\alpha>\beta}=E^{\circ}(A, \beta)\right)^{[E f(A, \beta)} \Omega_{A}^{\beta}(E) E d E-E^{\circ}(A, \alpha) \int^{E f(A, \alpha)} \Omega_{A}^{\alpha}(E) E d E$

Next, make the assumption that the density of states function is the same shape for $A^{\beta}$ and $B^{\beta}$. In other words,

$7.13 \Omega_{B}^{A}(E)=\Omega_{A}^{A}(E+C)$

Which implies that

$7.14 E^{\circ}(B, \beta)=E^{\circ}(A, \beta)-C$

and

$7.15 E^{\prime}(B, \beta)=E f(A, \beta)-C$

where

$E^{\prime}(B, \beta)$ is the Fermi level $B$ would be expected to have if $B$ only had $n_{e}^{\wedge}$ electrons instead of $n_{\bullet}^{8}$. Consequently,

$\mathrm{E}^{\prime}(\mathrm{B}, \beta) \leq \mathrm{Ef}(\mathrm{B}, \beta)$

since $\mathrm{n}_{\mathrm{e}}^{\mathrm{B}}>\mathrm{n}_{\mathrm{e}}{ }^{\wedge}$.

Divide the first term into two parts as follows

$$
\begin{gathered}
\left.7.16 \Delta_{\bar{G}^{E e}}\left(X_{A}=0\right)={ }_{E^{\circ}(B, \beta)} E^{E(B, \beta)} \Omega_{B}^{\beta}(E) E d E+{ }_{E^{\prime}(B, \beta)}\right)^{E f(B, \beta)} \Omega_{B}^{\beta}(E) E d E \\
-E^{\cdot}(A, \beta){ }^{E f(A, \beta)} \Omega_{A}^{\beta}(E) E d E-\left(n_{e}^{B}-n_{e}^{A}\right) E f(B, \beta)+\Delta H_{\alpha>\beta}
\end{gathered}
$$

Then substitute the shift in density of states for $A$ in the $\beta$ structure to $B$ in the $\beta$ structure.

$$
E^{\bullet}(B, \beta) f^{E^{\prime}(B, \beta)} \Omega_{B}^{\beta}(E) E d E=E^{*}(A, \beta)-c \int^{E f(A, \beta)-C} \Omega_{A}^{\beta}(E+C) E d E
$$

which implies

$$
E^{\cdot}(A, \beta)-c f^{E f(A, \beta)-C} \Omega_{A}^{\beta}(E+C) E d E=E^{\cdot \cdot(A, \beta)} \int^{E f(A, \beta)} \Omega_{A}^{\beta}(E)(E-C) d E
$$


Then the following is obtained

$7.17 \Delta \bar{G}^{E e}\left(X_{A}=0\right)={ }_{E^{\circ}(A, \beta)} f^{E f(A, \beta)} \Omega_{A}^{\beta}(E)(E-C) d E-E_{E^{\circ}(A, \beta)} f^{E f(A, \beta)} \Omega_{A}^{\beta}(E) E d E$

$$
+E^{\prime}(B, \beta) f^{E f(B, \beta)} \Omega_{B}^{\beta}(E) E d E-\left(n_{e}^{B}-n_{e}^{A}\right) E f(B, \beta)+\Delta H_{\alpha>\beta}
$$

By simplifying this yields

$$
\begin{aligned}
7.18 \Delta \bar{G}^{E e}\left(X_{A}=0\right)= & -C_{E^{*}(A, \beta)} f^{E f(A, \beta)} \Omega_{A}^{\beta}(E) E d E+E_{E^{\prime}(B, \beta)} f^{E f(B, \beta)} \Omega_{B}^{\beta}(E) E d E+\Delta H_{\alpha>\beta} \\
& -\left(n_{e}^{B}-n_{e}^{A}\right) E f(B, \beta)
\end{aligned}
$$

Then using Equations 7.4 and 7.15 gives

$$
\begin{aligned}
7.19 \Delta \bar{G}^{E e}\left(X_{A}=0\right)= & -n_{e}^{A}\left(E f(A, \beta)-E^{\prime}(B, \beta)\right)+E_{E^{\prime}(B, \beta)} \int^{E f(B, \beta)} \Omega_{B}^{\beta}(E) E d E+\Delta H_{\alpha>\beta} \\
& -\left(n_{e}^{B}-n_{e}^{A}\right) E f(B, \beta)
\end{aligned}
$$

Let us make the following approximation

$7.20 E^{\prime}(B, \beta) f^{E f(B, \beta)} \Omega_{B}^{\beta}(E) E d E \approx 1 / 2\left(n_{e}^{B}-n_{e}^{A}\right)\left(E f(B, \beta)+E^{\prime}(B, \beta)\right)$

And substitute to yield

$7.21 \Delta \bar{G}^{E e}\left(X_{A}=0\right)=-n_{e}^{A}\left(E f(A, \beta)-E^{\prime}(B, \beta)\right)+1 / 2\left(n_{e}{ }^{B}-n_{e}{ }^{A}\right)\left(E f(B, \beta)+E^{\prime}(B, \beta)\right)$

$$
-\left(n_{e}^{B}-n_{e}^{A}\right) E f(B, \beta)+\Delta H_{\alpha>\beta}
$$

Upon rearrangement this leads to

$$
\begin{aligned}
7.22 \Delta \bar{G}^{E e}\left(X_{A}=0\right)= & -n_{e}^{A}\left(E f(A, \beta)-E^{\prime}(B, \beta)\right)-1 / 2\left(n_{e}^{B}-n_{e}^{A}\right)\left(E f(B, \beta)-E^{\prime}(B, \beta)\right) \\
& +\Delta H_{\alpha>\beta}
\end{aligned}
$$

Further simplification gives

$$
\begin{aligned}
7.23 \Delta \bar{G}^{E e}\left(X_{A}=0\right)= & -n_{e}{ }^{A}(E f(A, \beta)-E f(B, \beta))-1 / 2\left(n_{e}{ }^{B}+n_{e}{ }^{A}\right)\left(E f(B, \beta)-E^{\prime}(B, \beta)\right) \\
& +\Delta H_{\alpha>\beta}
\end{aligned}
$$

Then substituting the work functions yields 
$7.24 \Delta \bar{G}^{E e}\left(X_{A}=0\right)=n_{e}^{A}\left(\Phi_{A}^{\beta}-\Phi_{B}^{\beta}\right)+1 / 2\left(n_{e}^{B}+n_{e}^{A}\right)\left(\Phi_{B}^{\beta}-\Phi_{B}{ }^{A}\right)+\Delta H_{\alpha>\beta}$

Since $\Phi_{\mathrm{B}}{ }^{\prime}$ is not easy to evaluate, it is noted that

$$
1 / 2\left(\mathrm{n}_{\mathrm{e}}^{B}+\mathrm{n}_{\mathrm{e}}{ }^{\wedge}\right)\left(\Phi_{\mathrm{B}}{ }^{\beta}-\Phi_{\mathrm{B}}\right)=\mathrm{K}\left(\mathrm{n}_{\mathrm{e}}^{B}, \mathrm{n}_{\mathrm{e}}{ }^{\wedge}, \beta\right)
$$

In other words, $\mathrm{K}\left(\mathrm{n}_{e}^{B}, \mathrm{n}_{e}{ }^{A}, \beta\right)$ is a function of the number of valence electrons on $A$ and on B and the structure of B, the solvent. Consequently, for systems where the number of valence electrons on A and on B are constant and the structure of the solvent is constant, then $\mathrm{K}$ is constant. The final equation is

$$
7.25 \Delta \bar{G}^{E e}\left(X_{A}=0\right)=n_{e}{ }^{A}\left(\Phi_{A}^{\beta}-\Phi_{B}^{\beta}\right)+K\left(n_{e}{ }^{A}, n_{e}^{B}{ }^{\beta}, \beta\right)+\Delta H_{a>\beta}
$$

Let us consider each of the three contributions to the excess Gibbs energy at infinite dilution.

$n_{e}{ }^{A}\left(\Phi_{A}{ }^{\beta}-\Phi_{B}{ }^{\beta}\right)$ is Schaller's contribution to the excess partial Gibbs energy at infinite dilution if $\Phi_{A}^{\beta}=\Phi_{A}^{\alpha}$. Equality, in general, is not found, but it may be a fair approximation for some systems where the $\alpha$ and the $\beta$ structures are similar.

$K\left(n_{e}{ }^{A}, n_{e}^{B}, \beta\right)$ is a term which accounts for the effect of electron transfer on the partial Gibbs energy at infinite dilution. As mentioned $\mathrm{K}$ is a function of $\mathrm{n}_{e}^{B}, \mathrm{n}_{e}{ }^{A}$, and $\beta$. Consequently, the value of $\mathrm{K}$ for the V-Pd, Nb-Pd, and the Ta-Pd systems should be equal. In fact, they will surely deviate some, but they should be relatively close compared to the values obtained for other systems.

$\Delta H_{\alpha>\beta}$ is the enthalpy of transition from $A^{\alpha}$ to $A^{\beta}$. If the bonding energy in $A^{\alpha}$ and $A^{\beta}$ are nearly the same, then $\Delta H_{\alpha>\beta}$ can be estimated from the promotion energy of $A^{\alpha}(g)$ to $A^{\beta}(g)$. Where $A^{\alpha}(g)$ is gaseous species of $A$ in the same 
electronic configuration as $A^{a}(s)$. For example, if $V$ is dissolved in $R h$, then enthalpy for the reaction

$$
\mathrm{V}(\mathrm{g})\left[\mathrm{sd}^{4}\right] \rightarrow \mathrm{V}(\mathrm{g})\left[\mathrm{spd}^{3}\right] \quad \Delta \mathrm{H}_{\text {promotion }}=\Delta \mathrm{H}_{\alpha>\beta}
$$

yields approximately the enthalpy of transition.

The assumptions and limitations

In the derivation of Equation 7.25 there are a number of assumptions. Since the validity of the assumptions affects the validity of Equation 7.25 , the primary assumptions are reemphasized here outside of the derivation.

First, the excess entropy at infinite dilution is small.

Second, the density of states function is the same shape for elements in the same structure. That is the value of the function differs only in a constant at any specified energy.

Lastly, the integral in Equation 7.20 is approximated by assuming that it is equal to the difference in the number of valence electrons for elements $B$ and $A$ times the average energy expected for these electrons.

By combining equation 7.25 and 7.2 , a more accurate equation for the partial Gibbs energy at infinite dilution is obtained. This equation still is lacking in the respect that the variation of the parameters as a function of temperature are not considered. 


\section{Interpretations}

The three contributions to Equation 7.25 can be equated to three different effects on the activity coefficient at infinite dilution. An analysis of each contribution yields insight into the interactions which affect the infinite dilution parameters.

$n_{e}^{A}\left(\Phi_{A}^{a}-\Phi_{B}{ }^{\beta}\right)$ is always negative for the systems we have studied. This term accounts for the difference in the energy levels of the solvent and solute atoms.

K or $1 / 2\left(n_{e}^{A}+n_{e}{ }^{8}\right)\left(\Phi_{B}{ }^{\beta}-\Phi_{B}\right)$ is a negative term for these systems. This term accounts for the acid-base effect in the intermetallics. That is the contribution to the stability which arises from electrons being transferred from the $\mathrm{B}$ atoms to a dissolved $\mathrm{A}$ atom.

$\Delta H_{\alpha>\beta}$ is the enthalpy of transition from $A^{\alpha}$ to $A^{\beta}$ and is always positive. This term accounts for the difference in structure of the solvent and solute atoms.

From Equation 7.3, Schaller has interpreted a solute, zirconium, to donate its 4 valance electrons to the neighboring palladium atoms. Since the energy level of electrons is higher in the zirconium than in the palladium, it would seem that electrons in the zirconium band will flow into the palladium band when the two metals are mixed. The increase in bonding he attributes is to electron transfer from zirconium to palladium at infinite dilution of zirconium. 
Schaller's interpretation has some problems. First, on average the orbitals for $\mathrm{Zr}$ dissolved in $\mathrm{Pd}$ are lower in energy than orbitals involving pure $\mathrm{Zr}$. Really the electrons on $\mathrm{Zr}$ are not transferred, but the orbitals they occupy are simply lowered in energy due to the neighboring Pd atoms. Since there are fewer valence electrons on $\mathrm{Zr}$ than in $\mathrm{Pd}$, there will be a tendency for electrons from the Fermi level of the Pd solid solution to be donated to the dissolved $\mathrm{Zr}$ atoms. This agrees with what would be expected from the generalized Lewis acid-base effect discussed in Chapter 2. However, this is opposite to Schaller's description which is incorrect according to the arguments presented here.

\subsection{Calculating Activity Coefficients at Infinite Dilution.}

As shown in Table 7.3 the general trend of Schaller's approach is consistent with observed data. His approach to calculating the activity coefficient at infinite dilution is applied to all the systems reviewed here. The work functions and molar volumes for the related elements are tabulated in Table 7.4. The molar volumes are calculated from lattice parameters. For the work functions of the elements, a wide variation in the literature is present. The variation is large enough that in most of these systems at least one value given in the literature will result in the accurate calculation of the activity coefficient at infinite dilution. Because the reported values ranged dramatically and to prevent choosing convenient values of the work functions, the following selection rules were 
followed. If values of the work function were available for different crystal faces, then the lowest value of the work function was used. This was to maintain consistency with the work functions used for polycrystaline samples. The values available for polycrystaline materials were averaged. However, any unreasonably high or low values were discarded.

Table 7.5 lists the bulk moduli for relevant elements. These data are all taken from Landolt and Bornstein.[27,28] The derivative as a function of pressure is estimated for rhenium and osmium based on the trends for the other elements since no data could be found for these systems.

The partial molar volume at infinite dilution data in Table 7.6 was obtained from lattice constants of the alloys rich in noble metals. Some data were estimated from the molar volume of the nearest phase in composition to the pure noble metal. These values are given in parenthesis to emphasize a greater uncertainty for the partial molar volume at infinite dilution.

From all the data in Table 7.4-7.6, the data in Table 7.7 can be compiled. Table 7.7 is composed of the size effect contribution to the excess Gibbs energy at infinite dilution and the electronic contribution to the excess Gibbs energy at infinite dilution. The valency in every case is chosen to be 3 except for systems where the orbital overlap is expected to be small. For these systems the valency is chosen to be 1 . Although the valency chosen is not the value of 5 expected from equation 7.25, the calculation of the activity coefficient at infinite dilution 
approximates the general trend observed. This is seen by comparing the values for - $\log \gamma$ calculated in Table 7.7 with the experimental values of Table 7.1.

Table 7.4. Work function and density of relevant elements.

$\begin{array}{ccc}\text { element work function } & \begin{array}{c}\text { molar volume } \\ (\mathrm{eV})\end{array} & \left(\mathrm{cm}^{3} / \mathrm{mole}\right)\end{array}$

\begin{tabular}{|c|c|c|c|}
\hline $\mathrm{V}(\mathrm{bcc})$ & 4.44 & & 23 \\
\hline $\mathrm{Nb}(\mathrm{bcc})$ & 4.18 & & 24 \\
\hline $\mathrm{Ta}(\mathrm{bcc})$ & 4.00 & & 24 \\
\hline $\operatorname{Co}(f c c)$ & 4.40 & $6.7048_{0}$ & 23,22 \\
\hline $\mathrm{Ni}(f c c)$ & 4.91 & 6.5840 & 23,22 \\
\hline $\mathrm{Cu}(\mathrm{fcc})$ & 4.48 & $7.1111_{0}$ & 23,22 \\
\hline Ru(hcp) & 4.52 & $8.126_{6}$ & 23,22 \\
\hline$R h(f c c)$ & 4.80 & $8.2832_{4}$ & 23,22 \\
\hline $\operatorname{Pd}(f c c)$ & 4.98 & $8.8442_{6}$ & 23,22 \\
\hline $\mathrm{Ag}(f \mathrm{cc})$ & 4.26 & $10.2649_{3}$ & 25,22 \\
\hline $\operatorname{Re}(h c p)$ & & 8.8602 & 22 \\
\hline Os(hep) & 4.55 & 8.4265 & 23,22 \\
\hline $\operatorname{Ir}(\mathrm{fcc})$ & 5.00 & 8.5180 & 26,22 \\
\hline $\operatorname{Pt}(f c c)$ & 5.12 & $9.0978_{2}$ & 24,22 \\
\hline$A u(f c c)$ & 4.71 & $10.2167_{6}$ & 23,22 \\
\hline
\end{tabular}

The work functions and bulk moduli data which are necessary for the calculation of the activity coefficient at infinite dilution have considerable uncertainties. Consequently, there is a large uncertainty in the calculated activity coefficients at infinite dilution. The use of better data for the work functions and 
the bulk moduli will clarify the degree to which Schaller's approach to calculating activities is valid. I expect that better data will not lead to a significant improvement in the calculation of the infinite dilution parameters unless some modifications to the calculations are made like that in Equation 7.25. It will be interesting to find out if $\mathrm{K}\left(\mathrm{n}_{e}{ }^{A}, \mathrm{n}^{B}, \beta\right)$ from Equation 7.25 is indeed constant for systems where $n_{e}^{\wedge}, n_{e}^{B}$, and structure of the solvent is constant.

Table 7.5. Bulk moduli data for relevant elements.

element bulk modulus, $B_{1} \quad d_{1} / d T$ reference

$$
\left(\mathrm{J} / \mathrm{cm}^{3}\right)
$$

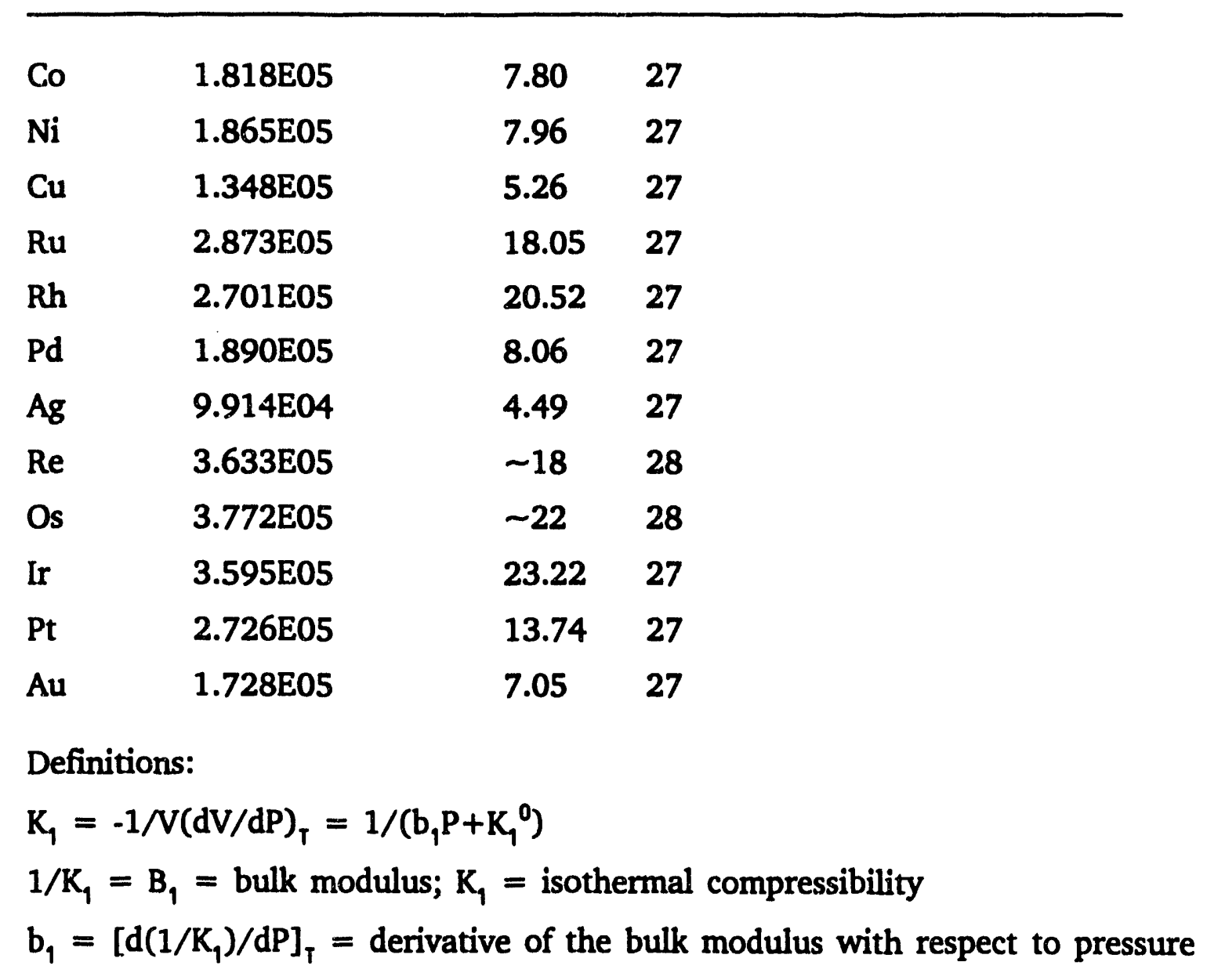


Table 7.6. Partial molar volume at infinite dilution.

\begin{tabular}{|c|c|c|}
\hline system & $\begin{array}{l}\bar{V}_{1}\left(X_{i}=0\right) \\
\left(\mathrm{cm}^{3} / \text { mole }\right)\end{array}$ & reference \\
\hline V-Co & $7.248_{6}$ & 22 \\
\hline V-Ni & $7.986_{0}$ & 22 \\
\hline \multicolumn{3}{|l|}{$\mathrm{V}-\mathrm{Cu}$} \\
\hline $\mathbf{V}-\mathbf{R u}$ & $8.812_{6}$ & 29 \\
\hline V-Rh & $8.022_{6}$ & 30 \\
\hline V-Pd & $8.3864_{7}$ & 31 \\
\hline \multicolumn{3}{|l|}{$\mathrm{V}-\mathrm{Ag}$} \\
\hline V-Re & $4.008_{4}$ & 32 \\
\hline V.Os & $8.122_{4}$ & 33 \\
\hline V-Ir & $7.753_{3}$ & 34 \\
\hline V-Pt & $7.424_{6}$ & 35 \\
\hline V-Au & $9.00_{5}$ & 36 \\
\hline $\mathrm{Nb}-\mathrm{Co}$ & $\left(10.0180_{0}\right)$ & 22 \\
\hline $\mathrm{Nb}-\mathrm{Ni}$ & $9.947_{8}$ & 22 \\
\hline \multicolumn{3}{|l|}{$\mathrm{Nb}-\mathrm{Cu}$} \\
\hline $\mathbf{N b}-\mathbf{R u}$ & $11.947_{8}$ & 22 \\
\hline $\mathrm{Nb}-\mathrm{Rh}$ & $\left(9.703_{9}\right)$ & 22 \\
\hline Nb-Pd & 9.7199 & 22 \\
\hline \multicolumn{3}{|l|}{$\mathrm{Nb}-\mathrm{Ag}$} \\
\hline $\mathrm{Nb}-\mathrm{Re}$ & $\left(11.241_{6}\right)$ & 22 \\
\hline $\mathrm{Nb}-\mathrm{Os}$ & $\left(10.974_{7}\right)$ & 22 \\
\hline Nb-Ir & $10.013_{1}$ & 22 \\
\hline Nb-Pt & $\left(13.762_{5}\right)$ & 22 \\
\hline $\mathrm{Nb}-\mathrm{Au}$ & $10.216_{8}$ & 37 \\
\hline
\end{tabular}


Table 7.6. Continued.

\begin{tabular}{lll}
\hline system & $\begin{array}{l}\overline{\mathrm{V}}_{1}\left(\mathrm{X}_{\mathrm{i}}=0\right) \\
\left(\mathrm{cm}^{3} / \mathrm{mole}\right)\end{array}$ & reference \\
\hline Ta-Co & $\left(9.653_{2}\right)$ & 22 \\
Ta-Ni & $10.05_{6}$ & 22 \\
Ta-Cu & & \\
Ta-Ru & $10.329_{7}$ & 22 \\
Ta-Rh & $9.834_{8}$ & 22 \\
Ta-Pd & $9.6039_{7}$ & 22 \\
Ta-Ag & & \\
Ta-Re & $\left(10.45_{8}\right)$ & 22 \\
Ta-Os & $10.1854_{1}$ & 22 \\
Ta-Ir & $\left(9.784_{8}\right)$ & 22 \\
Ta-Pt & $\left(9.29_{6}\right)$ & 22 \\
Ta-Au & $10.570_{7}$ & 38
\end{tabular}

Some of the partial molar volumes at infinite dilution that are given in Table 7.6 are put in parenthesis. The reason for this is that these values are calculated from lattice parameters of a different phase than the stable phase at infinite dilution. Consequently, some additional error will be added to the calculation and the resulting values will be less certain than given. However, the amount of uncertainty is unknown. From significant figure considerations in the calculations, the subscript on a value signifies that that number is uncertain. 
Table 7.7. Calculated infinite dilution parameters.

\begin{tabular}{|c|c|c|c|c|}
\hline elements & $\begin{array}{c}\Delta \bar{G}_{i}^{E d} / R \\
(\mathrm{kK})\end{array}$ & $\begin{array}{c}\Delta \bar{G}_{i}^{E_{e}} /\left(R z_{i}\right) \\
(k K)\end{array}$ & $z_{i}$ & $-\log \gamma_{0}$ \\
\hline \multicolumn{5}{|l|}{ Vanadium } \\
\hline V-Co & $0.386_{8}$ & $0.4_{6}$ & 1 & -0.3 \\
\hline V-Ni & $1.98_{0}$ & $-5.4_{5}$ & 1 & 1.2 \\
\hline V-Cu & & $-0.4_{6}$ & 1 & 0.2 \\
\hline V-Ru & $0.630_{0}$ & $-0.9_{3}$ & 3 & 0.7 \\
\hline V-Rh & $0.169_{5}$ & $-4.1_{8}$ & 3 & 4.2 \\
\hline V-Pd & $0.317_{6}$ & -6.27 & 3 & 6.3 \\
\hline V-Ag & & 2.0 & 1 & -0.7 \\
\hline V-Re & & $-3.2_{5}$ & 3 & \\
\hline V-Os & $0.33_{2}$ & -1.2 & 3 & 1.2 \\
\hline V-Ir & $3.634_{1}$ & -6.50 & 3 & 5.4 \\
\hline V-Pt & $2.5_{0}$ & -7.8 & 3 & 7.2 \\
\hline V-Au & $2.13_{5}$ & $-3.1_{1}$ & 1 & 0.1 \\
\hline \multicolumn{5}{|l|}{ Niobium } \\
\hline Nb-Co & $6.70_{4}$ & $-2.5_{5}$ & 1 & -1.4 \\
\hline $\mathrm{Nb}-\mathrm{Ni}$ & $6.96_{4}$ & $-8.4_{7}$ & 1 & 0.5 \\
\hline $\mathrm{Nb}-\mathrm{Cu}$ & & -3.48 & 1 & \\
\hline Nb-Ru & $7.20_{3}$ & $-3.9_{5}$ & 3 & 1.6 \\
\hline $\mathrm{Nb}-\mathrm{Rh}$ & $1.60_{8}$ & -7.1 & 3 & 6.8 \\
\hline Nb-Pd & 0.750 & $-9.2_{8}$ & 3 & 9.2 \\
\hline $\mathrm{Nb}-\mathrm{Ag}$ & & $-0.9_{3}$ & 1 & \\
\hline $\mathrm{Nb}-\mathrm{Re}$ & $4.1_{7}$ & & 3 & \\
\hline $\mathrm{Nb}-\mathrm{Os}$ & $4.3_{8}$ & -4.2 & 3 & 2.9 \\
\hline Nb-Ir & $2.089_{8}$ & $-9.5_{2}$ & 3 & 9.0 \\
\hline Nb-Pt & & -10.9 & 3 & $\sim 11$ \\
\hline $\mathrm{Nb}-\mathrm{Au}$ & & $-6.1_{5}$ & 1 & \\
\hline
\end{tabular}


Table 7.7. Continued.

\begin{tabular}{ccccc}
\hline elements & $\begin{array}{c}\Delta \overline{\mathrm{G}}_{\mathrm{i}}^{\mathrm{Ed}} / \mathrm{R} \\
(\mathrm{kK})\end{array}$ & $\begin{array}{c}\Delta \overline{\mathrm{G}}_{\mathrm{i}}^{\mathrm{Ee}} /\left(\mathrm{Rz}_{\mathrm{i}}\right) \\
(\mathrm{kK})\end{array}$ & $\mathrm{z}_{\mathrm{i}}$ & - log $_{\bullet}$ \\
& & \\
\hline
\end{tabular}

Tantalum

$\begin{array}{lllll}\text { Ta-Co } & 5.73_{3} & -4.6_{4} & 1 & -0.4 \\ \text { Ta-Ni } & 7.25_{8} & -10_{6} & 1 & 1.1 \\ \text { Ta-Cu } & & -5.5_{7} & 1 & \\ \text { Ta-Ru } & 3.32_{0} & -6.0_{3} & 3 & 5.1 \\ \text { Ta-Rh } & 1.808_{0} & -9.2_{8} & 3 & 8.9 \\ \text { Ta-Pd } & 0.584_{1} & -11.3_{7} & 3 & 11.4 \\ \text { Ta-Ag } & & -3.0_{2} & 1 & \\ \text { Ta-Re } & 2.4_{7} & & 3 & \\ \text { Ta-Os } & 2.7_{8} & -6.3_{8} & 3 & 5.6 \\ \text { Ta-Ir } & 1.677_{8} & -11.6_{0} & 3 & 11.3 \\ \text { Ta-Pr } & 0.0638_{0} & -13.0_{0} & 3 & 13.3 \\ \text { Ta-Au } & 0.116_{4} & -8.2_{4} & 1 & 2.8\end{array}$

$\Delta \bar{G}_{i}{ }_{i} d R$ is the partial excess Gibbs energy due to dialational effects $\Delta \bar{G}_{i}{ }_{i e} / R$ is the partial excess Gibbs energy due to electronic effects $z_{i}$ is the valency of the solvent $i$ in the solute 


\section{References}

1. L. Brewer and P. R. Wengert, "Transition Metal Alloys of Extraordinary Stability; An Example of Generalized Lewis-Acid-Base Interactions in Metallic Systems," Met. Trans., 4, 83-104 (1973).

2. H. Holleck, Binary and Ternary Carbide- and Nitridesystem, Gebruder Borntraeger, Berlin-Stutgart (1984) (German).

3. V. I. Alekseev and G. A. Levshin, "Study of the Thermodynamic Properties of Nickel-Vanadium Alloys by Electromotive Forces with a Solid Oxide Electrolyte," Diffuzion. Protessy Metallakh., 112-118 (1977).

4. J. F. Smith, O. N. Carlson, and P. G. Nash, "The Ni-V(Nickel-Vanadium) System," Bull. Alloy Phase Diag., 3(3), 342-348 (1982).

5. J. C. Gachon, H. P. Hilger, M. Notin, J. Hertz, "Enthalpies and Free Enthalpies of Formation for Dilute Binary Solid Solutions Cu-M ( $M$ in the First Long Period)," J. Less-Com. Met., 72, 167-192 (1980).

6. T. B. Massalski, H. Okamoto, P. R. Subramanian, and L. Kacprzak, Eds., Binary Alloy Phase Diagrams, $2^{\text {nd }}$ Ed., ASM International, Materials Park, Ohio (1990).

7. J.F. Smith, "The Vanadium Rhenium(V-Re) system," J. Alloy Phase Diag., 4(3), 199-203 (1988).

8. V. N. Eremenko, G. M. Lukashenko, and G. I. Khmelenko, "Thermodynamic Properties of Gold-Vanadium Alloys," Dopov. Akad. Nauk Ukr. RSR Ser. B, 36(9), 807-810 (1974) (Russian).

9. V. N. Drobyshev and T. N. Rezukhina, "Thermodynamic Properties of Alloys in the System Cobalt-Niobium," Zh. Fiz. Khim., 39(1), 151-156 (1965) (Russian). 
10. A.K. Shurin; G.P. Dmitrieva, N.A. Razumova, and E.L. Khandros, "The Phase Diagram of the Ni-VC-NbC System," Porosh. Metall., 296(8), 67-79 (1987) (English Translation).

11. H. Kleykamp, "On the Thermodynamics in the $\mathrm{Nb}-\mathrm{Rh}$ and Nb-Rh-O Systems," J. Less-Comm. Met., 83, 105-113 (1982).

12. M. Cima and L. Brewer, "The Generalized Lewis Acid-Base Titration of Palladium and Niobium," Met. Trans. B, 19B, 893-917 (1988).

13. T. N. Rezukhina and L. I. Kravchenko, "The Thermodynamic Properties of Laves Phases in Mixtures of Ta+Co. Solid Electrolyte Galvanic Cell Studies," J. Chem. Thermo., 4, 655-667 (1972).

14. N. P. Lyakishev, Yu. P. Snitkov, V. I. Alekseev, and G. A. Levshin, "Thermodynamics of the formation of the Intermetallics $\mathrm{Ni}_{3} \mathrm{Ta}$ and $\mathrm{Ni}_{2} \mathrm{Ta}$," Dokl. Akad. Nauk SSSR, 258(6), 1404-1406 (1981).

15. H. Kleykamp, "On the Thermodynamics of the Ta-Rh System," J. Less-Comm. Met., 152, 15-24 (1989).

16. W. L. Worrell and T. A. Ramanarayanan, "Electrochemical Cell Investigations of Platinum Binary Systems at Elevated Temperatures," Chem. Metall. - Tribute to Carl Wagner, Proc. Symp., 69-74 (1981).

17. L. Brewer, "High Strength Materials", V. F. Zuchay, ed., Ch. 2, 12-103, John Wiley (1965).

18. H. J. Schaller, "On the Extreemly High Thermodynamic Stability of Pd-Th Alloys," Z. Naturforsch., 34a, 464-468 (1979) (German).

19. H. J. Schaller, "Activity Coefficient of Zirconium in Palladium and Platinum," Ber. Bunsenges., 80, 999-1002 (1976) (German). 
20. H. J. Schaller; "Effect of the Position of the Fermi energy on the Mixing Behavior of Palladium/Aluminum Alloys," Ber. Bunsenges. Phys. Chem., 82(4), 365-371 (1978) (German).

21. S. Paasch and H. J. Schaller, "Thermodynamic Properties of Pd-X Alloys, with X = Gd, Y, Ce," Ber. Bunsenges. Phys. Chem., 87, 812-814 (1983).

22. P. Villars and L. D. Calvert, Pearson's Handbook of Crystallographic Data for Intermetallic Phases, American Society for Metals, Metals Park, $\mathrm{OH}$ (1985).

23. Landolt and Bornstein, Zahlenwerte und Functionen, Springer, Berlin, 6 Auflage, 1 Band, 2 Tiel, 759-762 (1955).

24. J. Höltz and F. K. Schulte in Solid Surface Physics, Springer, Berlin (1979).

25. S. Ruben, Handbook of the Elements, Open Court Publishing, La Salle, Illinois (1985).

26. R. C. Weast and M. J. Astle, ed., CRC Handbook of Chemistry and Physics$6^{\text {rd }}$ Ed., CRC Press, Boca Raton, Florida, E78-79 (1982).

27. Landolt and Bornstein, Zahlenwerte und Functionen, Springer, Berlin, 6 Auflage, 2 Band, 1 Tiel, pp $422-432$ (1970).

28. Landolt and Bornstein, Zahlenwerte und Functionen-Neue Serie, Springer, Berlin, NS II, 236-237 (1967).

29. J. F. Smith, "The Ruthenium-Vanadium System," J. Alloy Phase Diagrams, 3(3), 133-138 (1987).

30. J. F. Smith, "The Rhodium-Vanadium System," J. Alloy Phase Diagrams, 3(3), 143-147 (1987). 
31. J. F. Smith, "The Pd-V(Palladium-Vanadium) System," J. Alloy Phase Diagrams, 4(1), $1-4$ (1988).

32. J. F. Smith, "The Re-V (Rhenium-Vanadium) System," J. Alloy Phase Diagrams, 4(3), 199-203 (1988).

33. J. F. Smith, "The Os-V (Osmium-Vanadium) System," J. Alloy Phase Diagrams, 4(2), 122-126 (1988).

34. J. F. Smith, "The Ir-V(Iridium-Vanadium) System," J. Alloy Phase Diagrams, 4(2), 117-121 (1988).

35. J. F. Smith, "The Pt-V(Platinum-Vanadium) System," J. Alloy Phase Diagrams, 4(1), 5-13 (1988).

36. J. F. Smith, "The Au-V(Gold-Vanadium) System," Bull. Alloy Phase Diagrams, 2(3), 344-347 (1981).

37. H. Okamoto and T. B. Massalski, "The Au-Nb (Gold-Niobium) System," Bull. Alloy Phase Diagrams, 6(2), 134-136 (1985).

38. H. Okamoto and T. B. Massalski, "The Au-Ta (Gold-Tantalum) System," Bull. Alloy Phase Diagrams, 6(4), 365-368 (1985). 


\section{Chapter 8}

\subsection{Models of the Activity Coefficient as a Function of Concentration.}

Modeling the activity or the activity coefficient as a function of concentration is a difficult problem for acid-base intermetallics. There is presently no suitable model for predicting the thermodynamic data of acid-base intermetallics. However, C. H. P. Lupis has a good review of thermodynamic models available tor two component systems.[1] This chapter focuses on a few of the simpler mathematical functions which can be used to fit the partial thermodynamic data of these acid-base intermetallics. These functions are the Van Laar equation[2], the cubic version of the regular solution equation[3], and an equation derived from symmetry considerations and the Fourier series. The use of the first two of these functions for fitting the partial Gibbs energy in acid-base systems are not expected to work well over large composition ranges since the interactions are so strong in these systems. They, however, fit the data reasonably well over a considerable range of homogeneity. The equation related to the Fourier series also works well.

Two models of a more fundamental nature are the defect species model[4,5] and the associated species model.[6,7] Both of these models are useful for 
understanding the acid-base systems. They are, however, impractical considering the limited number of data available and that the data are fit easily by using a simpler function. A considerable amount of data and insight is still needed to pin down the best approach for fitting and ultimately predicting the activities as a function of concentration.

The regular solution models.

The oldest and the simplest pair-wise interaction model is J. H. Hildebrand's regular solution theory.[3] The regular solution theory states the following.

$$
\mathrm{RT} \ln \gamma_{1}=\alpha \mathrm{V}_{1}\left[\mathrm{X}_{2} \mathrm{~V}_{2} /\left(\mathrm{X}_{1} \mathrm{~V}_{1}+\mathrm{X}_{2} \mathrm{~V}_{2}\right)\right]^{2}
$$

and similarly

$$
\mathrm{RT} \ln \gamma_{2}=\alpha \mathrm{V}_{2}\left[\mathrm{X}_{1} \mathrm{~V}_{1} /\left(\mathrm{X}_{1} \mathrm{~V}_{1}+\mathrm{X}_{2} \mathrm{~V}_{2}\right)\right]^{2}
$$

where $\alpha$ is related to the enthalpy of vaporization and the molar volume in the following way.

$$
\alpha=\left[\left(\Delta \mathrm{H}_{\text {bonding1 }} / \mathrm{V}_{1}\right)^{1 / 2}-\left(\Delta \mathrm{H}_{\text {bonding2 }} / \mathrm{V}_{2}\right)^{1 / 2}\right]^{2}
$$

and

$$
\Delta \mathrm{H}_{\text {bonding }}=\Delta \mathrm{H}_{\text {vap }}+\mathrm{E}_{\text {promotion }}
$$

In Hildebrand's treatment, $\Delta H_{\text {vap }}$ was used in Equation 8.2 instead of $\Delta \mathrm{H}_{\text {bonding }}$. Brewer has proposed elsewhere that $\Delta \mathrm{H}_{\text {bonding }}$ is the better term to use. [8] 
If the molar volumes used in equation 8.1 are assumed to be constant as a function of concentration, then they can be factored out to yield Van Laar's equation.[2] In his model, the activity as a function of concentration is given by

$$
\begin{aligned}
& \ln \gamma_{1}=\mathrm{A} /\left(1+\mathrm{A} / \mathrm{B}\left(\mathrm{X}_{1} / \mathrm{X}_{2}\right)\right)^{2} \\
& \ln \gamma_{2}=\mathrm{B} /\left(1+\mathrm{B} / \mathrm{A}\left(\mathrm{X}_{2} / \mathrm{X}_{1}\right)\right)^{2}
\end{aligned}
$$

where

8.5

$$
\begin{aligned}
& \mathrm{A}=\alpha \mathrm{V}_{1} / \mathrm{RT} \\
& \mathrm{B}=\alpha \mathrm{V}_{2} / \mathrm{RT}
\end{aligned}
$$

If the Van Laar equation is expanded in a series the result is Hildebrand's polynomial regular solution equation.[3]

$$
\begin{aligned}
& \ln \gamma_{1}=b_{1} X_{2}^{2}+c_{1} X_{2}^{3}+d_{1} X_{2}^{4}+\ldots \\
& \ln \gamma_{2}=b_{2} X_{1}^{2}+c_{2} X_{1}^{3}+d_{2} X_{1}^{4}+\ldots
\end{aligned}
$$

where

$$
\begin{aligned}
& b_{1}=\alpha V_{2}^{2} /\left(V_{1} R T\right) \\
& b_{2}=\alpha V_{1}{ }^{2} /\left(V_{2} R T\right) \\
& c_{1}=2 \alpha V_{2}^{2} /\left(V_{1} R T\right)\left[V_{2} / V_{1}-1\right] \\
& c_{2}=2 \alpha V_{1}^{2} /\left(V_{2} R T\right)\left[V_{1} / V_{2}-1\right] \\
& b_{1} / b_{2}=V_{2} / V_{1} \\
& c_{1} / c_{2}=-\left(V_{2} / V_{1}\right)^{2}
\end{aligned}
$$

Often only the $b$ and $c$ terms are needed to fit the data. If $V_{1}=V_{2}$ from Equation 8.1 then $b_{1}=b_{2}$. If only a cubic equation is used, the terms $b$ and $c$ can be 
related through the Gibbs-Duhem equation to yield the following relationships.

$$
\begin{aligned}
& b_{2}=b_{1}+3 / 2 c_{1} \\
& c_{2}=-c_{1}
\end{aligned}
$$

Many intermetallic systems can be fit over large composition ranges by using the two constants $b$ and $c$ for Equation 8.6 and $A$ and $B$ for Equation 8.4. The acid-base systems can also be modeled in these ways, but the accuracy would not be expected to be good because of the large activity changes which occur in acid-base stabilized systems. Consequently, this approach to fitting the activity as a function of concentration must be used cautiously for these systems.

Pair-wise interaction including interactions with defects.

Austin Chang and Joachim Neumann have proposed a method for modeling systems with the $\mathrm{CsCl}$ crystal structure.[4] In their model, not only interactions of A-A, B-B, and A-B are considered, but interactions with the defects are also included. This approach is only valid over a small composition range in acid-base intermetallics since all pairwise bond energies are assumed to be independent of composition. This is a poor assumption for acid-base stabilized alloys. However, this approach works well in these systems if the range of applicability is less than a few mole percent. Chang and Neumann have shown that this approach works well for the AlPd phase(stable at $44-55 \% \mathrm{Pd}$ at $1000^{\circ} \mathrm{C}$ ) which is an acid-base stabilized alloy.[4] The Austin Chang approach to modeling the activity is promising for phases like VPt and $\mathrm{VPt}_{3}$. In most cases, the thermodynamic data 
can be fit with only one parameter called the disorder parameter. Any simple ordered structure in which the types of defects are known can be modeled in this way. For example, Edelin has applied this approach to the CoGa and $\mathrm{NiGa}$ structures.[5]

This model is promising, but not enough data was obtained in the $\mathrm{CsCl}$ or other ordered phases to warrant fitting it by this approach. More information on phases like VPt and $\mathrm{VPt}_{3}$ will be needed before they can be properly modeled using the defect interactions of Austin Chang.

Pair-wise interaction including an associated species.

The associated solution model applies to solutions where the components $A$ and $B$ react in solution to give an associated species, $A_{p} B_{q} \cdot[6,7]$ The associated species has an "effective" concentration in solution and can be treated as a third component. The activity of both A and B will change dramatically at the composition of $A_{p} B_{q}$. This is a convenient model since the acid-base interactions have large characteristic changes in activity at the "endpoints." However, the difficulty for the acid-base alloys is to identify the composition of the associated species.

In an associated solution, the overall composition of species A and B are called $N_{A}$ and $N_{B}$ respectively. Some of the $A$ and $B$ atoms will react to give ApBq.

$$
p A+q B=A_{p} B_{q}
$$


After reaction, the concentration of the species $A, B$, and $A_{p} B_{q}$ are given by $X_{A}$, $\mathrm{X}_{\mathrm{B}}$, and $\mathrm{X}_{\mathrm{ApBq}}$

Using mass balance $X_{A}$ and $X_{B}$ can be given as a function of the initial concentrations, $N_{A}$ and $N_{B}$, and the concentration of the associated species in equilibrium, $X_{\text {Aplq }}$.

$8.10 \mathrm{X}_{\mathrm{A}}=\mathrm{N}_{\mathrm{A}}-\left[\mathrm{p}-\mathrm{N}_{\mathrm{A}}(\mathrm{p}+\mathrm{q}-1)\right] \mathrm{X}_{\mathrm{c}}$

$8.11 X_{B}=N_{B}-\left[q-N_{B}(p+q-1)\right] X_{c}$

using a substitution for convenience

$8.12 C=A_{p} B_{q}$ or $X_{c}=X_{A p B q}$

using the law of mass action from Equation 8.9 yields

8.13 $K=X_{A}{ }^{p} X_{B}^{q} \gamma_{A}{ }^{p} \gamma_{B}{ }^{q} /\left(X_{C} \gamma_{c}\right)$

The regular solution equation for a three component system in its simplest form is given as follows

$$
8.14 \ln \gamma_{A}=a_{12} X_{B}^{2}+a_{13} X_{C}^{2}+X_{B} X_{C}\left(a_{12}+a_{13}-a_{32}\right)
$$

The other activity coefficients, $\gamma_{B}$ and $\gamma_{C}$, can be obtained by cyclic permutation of all the constants. $\mathrm{X}_{\mathrm{c}}$ needs to be determined as a function of concentration of $X_{A}$ and $X_{B}$. This can be achieved with the Gibbs-Duhem relationship

\section{$8.150=\mathrm{X}_{A} \mathrm{~d} \ln \gamma_{A}+\mathrm{X}_{B} \mathrm{~d} \ln \gamma_{B}+\mathrm{X}_{C} \mathrm{~d} l n \gamma_{C}$}

and the relationship in Equation 8.13. The resulting equation is a function of $X_{A}$ and $X_{B}$ which in turn can be changed to a relationship involving $N_{A}$ and $N_{B}$ from Equations 8.10 and 8.11. Unless the associated species $A_{p} B_{q}$ is a simple formula 
like $A B$ or $A B_{2}$, solving for the activity coefficient as a function of $N_{A}$ and $N_{B}$ is difficult. Although, this model is promising for acid-base alloys, its applicability is limited by its complexity. This is emphasized by the fact that the associated species, $A_{p} B_{q}$, will normally be a non-stoichiometric composition for these intermetallics.

Activity through symmetry in the Gibbs-Duhem relationship.

The reason symmetry is an interesting aspect to consider in the GibbsDuhem relationship is that acids and bases are in many ways a symmetric interaction. Real acids and bases, of course, will not be symmetric in the GibbsDuhem relation. However, by examining the symmetric approach some insight can be gained into what sort of functions should be considered for fitting the partial thermodynamics in acid-base reactions.

$$
H A=A^{-}+H^{+} ; K_{A}=\left[A^{-}\right]\left[H^{+}\right] /[H A]
$$

$$
\mathrm{BOH}=\mathrm{B}^{+}+\mathrm{OH}^{-} ; \mathrm{K}_{\mathrm{B}}=\left[\mathrm{B}^{+}\right]\left[\mathrm{OH}^{-}\right] /[\mathrm{BOH}]
$$

If $K_{A}=K_{B}$ then the interaction is symmetric.

Both ideal solutions and regular solutions are symmetric in the GibbsDuhem relation. For a two component system the relation is as follows.

$$
\mathrm{X}_{1} \mathrm{~d} \mu_{1}+\mathrm{X}_{2} \mathrm{~d} \mu_{2}=0
$$

The function for the chemical potential is symmetric if

$$
\mu_{1}=f\left(X_{1}\right) \text { implies that } \mu_{2}=f\left(X_{2}\right)
$$


since

8.20

$$
\mu=\mu^{\circ}+\mathrm{RT} \ln \mathrm{a}
$$

This implies that if the chemical potential is symmetric then the activity and the activity coefficient are symmetric or

$$
a_{1}=g\left(X_{1}\right) \text { implies that } a_{2}=g\left(X_{2}\right)
$$

and

8.22

$$
\gamma_{1}=h\left(X_{1}\right) \text { implies that } \gamma_{2}=h\left(X_{2}\right)
$$

for ideal solutions

$$
a_{1}=X_{1}
$$

for regular solutions

$$
\ln \gamma_{1}=b\left(1-X_{1}\right)^{2}=b X_{2}^{2}
$$

Coincidentally, the two simplest symmetric solutions to the Gibbs-Duhem relationship are the ideal solution and the regular solution. What other symmetric solutions to the Gibbs-Duhem relationship are there? Do any of these solutions have any physical meaning which may prove useful in modeling the activity as a function of concentration. We postulate that all symmetric solutions to the GibbsDuhem relationship can be given by the following equation.

$$
\ln \gamma_{1}={ }_{1} \int^{x 1}[s(y) s(1-y)] / y d y
$$

$s(y)$ can be any function provided that the following limiting condition is true.

$$
s(y) s(1-y) \rightarrow 0 \text { as } y \rightarrow 0 \text { or } 1
$$

Some functions which satisfy these criteria are as follows. 


$$
\begin{aligned}
& s(y)=\text { sinmny } ; n=\text { any integer } \\
& s(y)=0 \text {;ideal solution } \\
& s(y)=y \text {;regular solution } \\
& s(y)=e^{y}-1
\end{aligned}
$$

These functions can also be combined by multiplication or addition to yield others which also satisfy the criteria. The symmetric consideration reduces the number of functions to be considered. However, this still leaves an infinite number of possibilities. For reasons suggested in the next section

$$
s(y)=\sin \pi n y
$$

is an interesting function to consider. Note that

$$
s(y) s(1-y)=(\cos 2 x n y-1)
$$

\section{Conservation of functional form through the Gibbs-Duhem relationship.}

\section{Polynomial Series}

The symmetric version of the activity greatly reduces the number of possible functions. However, any real system is not symmetric. At best any real system could only be approximated by a symmetric function. However, one could postulate that the functional form should be reversible. This is better stated: changing $\mathrm{X}$ with $1-\mathrm{X}$ does not change the functional form but only the constants. The conservation of functional form implies that the physical meaning of each constant, if any, is conserved. Additionally, in functions of this form all constants 
can be interrelated through the Gibbs-Duhem equation independently of composition. For any system the activity can be given by the following equation. 8.6

$$
\ln \gamma=\mathrm{bX}^{2}+\mathrm{cX}^{3}+\mathrm{d \textrm {X } ^ { 4 }}+\ldots
$$

Note that by replacing $\mathrm{X}$ with 1-X does not change the functional form but only the constants. The constant $a$ is normally equated with pairwise interactions, the constant $\mathrm{b}$ with the three way interactions, etc.

\section{Fourier Series}

Using a Fourier series to model the natural log of the activity coefficient as a function of concentration would work, but it is not the most elegant way to use the Fourier series. One reason is that using the Fourier series in this way does not yield a function of the same functional form upon integration through the GibbsDuhem equation.

The more elegant approach using Fourier series follows. Since the GibbsDuhem equation states

$$
\mathrm{X}_{1} \mathrm{~d} \ln \gamma_{1}+\mathrm{X}_{2} \mathrm{~d} \ln \gamma_{2}=0
$$

it then follows

$$
8.26 \mathrm{~d} l n \gamma_{1}=\mathrm{F}\left(\mathrm{X}_{1}\right) / \mathrm{X}_{1} \mathrm{dX} \mathrm{X}_{1} ; \quad \mathrm{d} \ln \gamma_{2}=\mathrm{F}\left(1-\mathrm{X}_{2}\right) / \mathrm{X}_{2} \mathrm{dX}
$$

Let $F\left(X_{1}\right)$ be expanded in a Fourier series.

$$
\text { 8.27 } F\left(X_{1}\right)=a_{0}+{ }_{n=0} \Sigma^{\infty} a_{n} \cos \pi 2 n X_{1}+b_{n} \sin \pi 2 n X_{1}
$$

Through the Gibbs-Duhem relationship this yields the following.

$$
8.28 F\left(1-X_{2}\right)=G\left(X_{2}\right)=a_{0}^{*}+{ }_{n=1} \Sigma^{*} a_{n}{ }^{*} \cos \pi 2 n X_{2}+b_{n}{ }^{*} \sin \pi 2 n X_{2}
$$


where

$$
a_{n}^{*}=a_{n} \text { and } b_{n}^{*}=-b_{n}
$$

or Equation 8.27 could be stated

$$
\text { 8.29 } G\left(X_{2}\right)=a_{0}+{ }_{n=1} \Sigma^{\infty} a_{n} \cos \pi 2 n X_{2}-b_{n} \sin \pi 2 n X_{2}
$$

The coefficients $a_{n}$ and $b_{n}$ are given by

$$
\begin{aligned}
& a_{n}=\int^{1} F\left(X_{1}\right) \cos 2 \pi n X_{1} d X_{1} \\
& b_{n}=\int^{1} F\left(X_{1}\right) \sin 2 \pi n X_{1} d X_{1}
\end{aligned}
$$

As can be seen, the same functional form is retained through the Gibbs-Duhem relation. The only change is in the constants.

Due to the limiting condition,

$$
\begin{aligned}
& \ln \gamma_{1} \rightarrow 0 \text { as } X_{1} \rightarrow 1 \text { and } \\
& \ln \gamma_{1} \rightarrow \text { Constant as } X_{1} \rightarrow 0
\end{aligned}
$$

the following restriction on the constants is obtained.

$$
{ }_{n=0}^{\infty} a_{n}=0
$$

Equation 8.31 is the main restriction on the constants. However, other restrictions also occur. For example, the activity of each species must be a steadily decreasing function with decreasing concentration of that component. This will affect relationships between constants.

Integration of Equation 8.26 results in the following general functional form for the natural $\log$ of the activity coefficient.

$8.31 \ln \gamma_{1}={ }_{1} \int^{x 1}\left\{_{n=1} \Sigma^{\infty} a_{n} \cos 2 \pi n X+{ }_{n=1} \Sigma b_{n} \sin 2 \pi n X\right\} d X$ 


\subsection{Experimental Data: Activity Coefficient versus Concentration.}

Comparisons of curves.

All plots of the log of the activity coefficient versus concentration are given on the same scale for comparison. Recall the definition of activity coefficient defined in Chapter 3. As

$$
x_{v} \rightarrow 1 \text { then } \gamma_{v} \rightarrow 1 \text { and }-\log \gamma_{v} \rightarrow 0
$$

It is easy to see that the plots for V-Ni and V-Au show much weaker interactions than the V-Pd or V-Pt. There is an interesting phenomenon which is apparent if the V-Pd and V-Rh plots are superimposed. The two curves cross at around 15 mole percent vanadium. Cima reported a similar cross over for the $\mathrm{Nb}$-Pd relative to the $\mathrm{Nb}-\mathrm{Rh}$ systems.[12] This cross over implies that the V-Rh interactions are stronger than the V-Pd interactions beyond 15 mole percent vanadium. At high concentrations of noble metal, however, the V-Pd interactions are stronger than the V-Rh interactions. Some reasons why this cross over occurs are mentioned in Chapter 9. From the data for the Ta-Rh and the single point on the Ta-Pd system the same cross over is expected to occur. Consequently, there is a consistent behavior for the VB transition metals interacting with Pd and Rh. As will be discussed later, this phenomena supports the characterization of these materials as acid-like and base-like materials. 


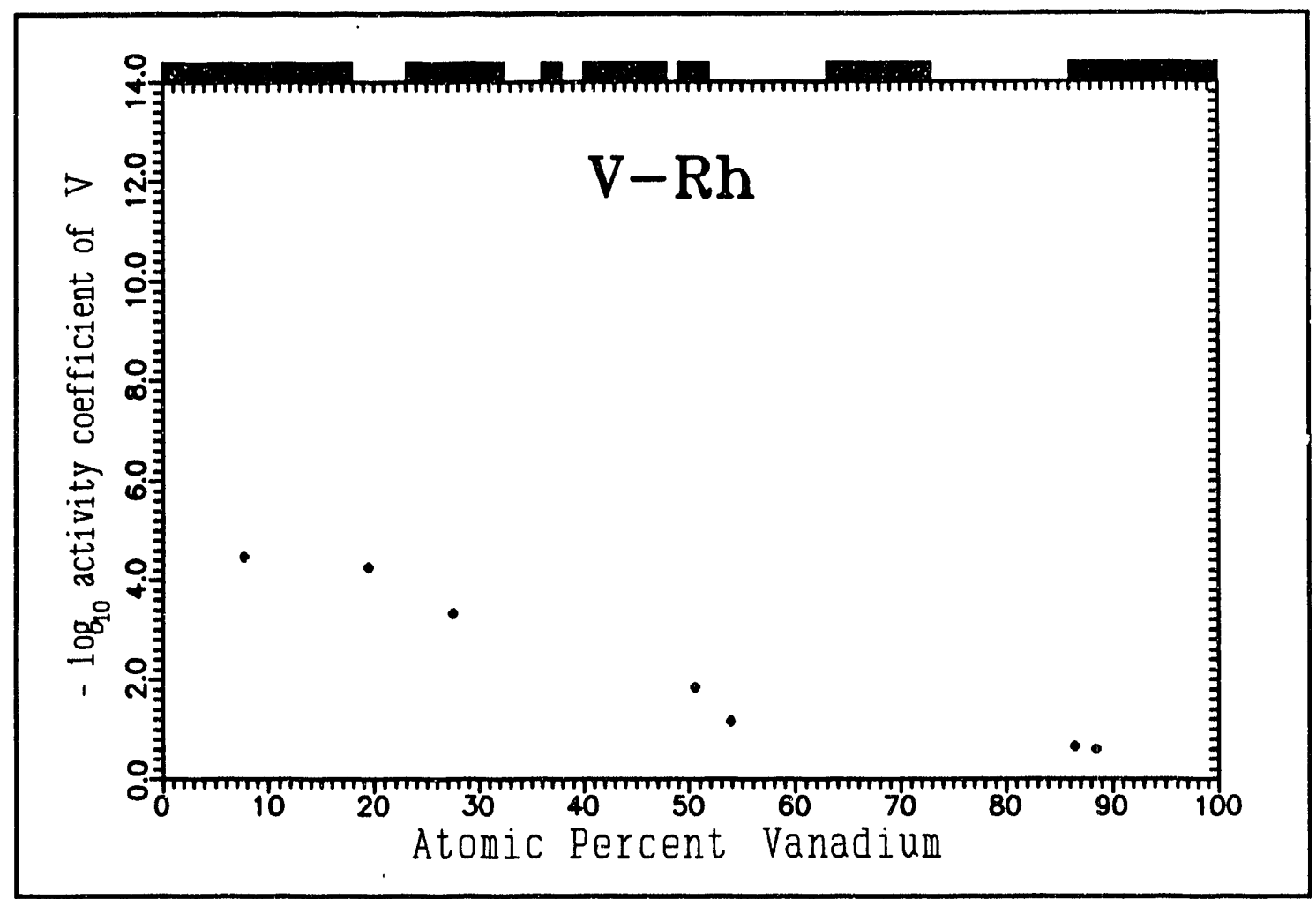

Figure 8.1. The vanadium-rhodium system at $1000^{\circ} \mathrm{C}$

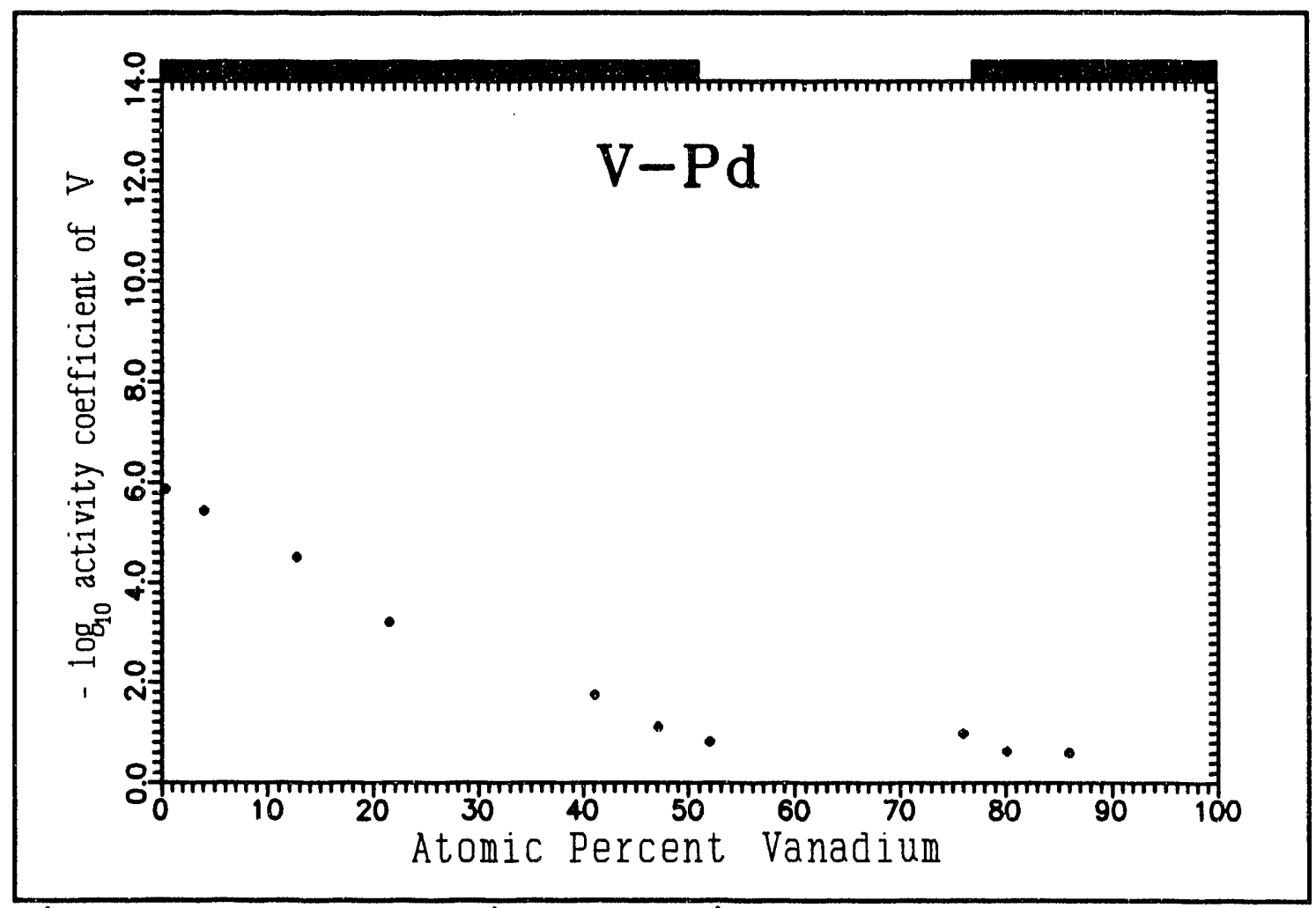

Figure 8.2 . The vanadium-palladium system at $1000^{\circ} \mathrm{C}$ 176 


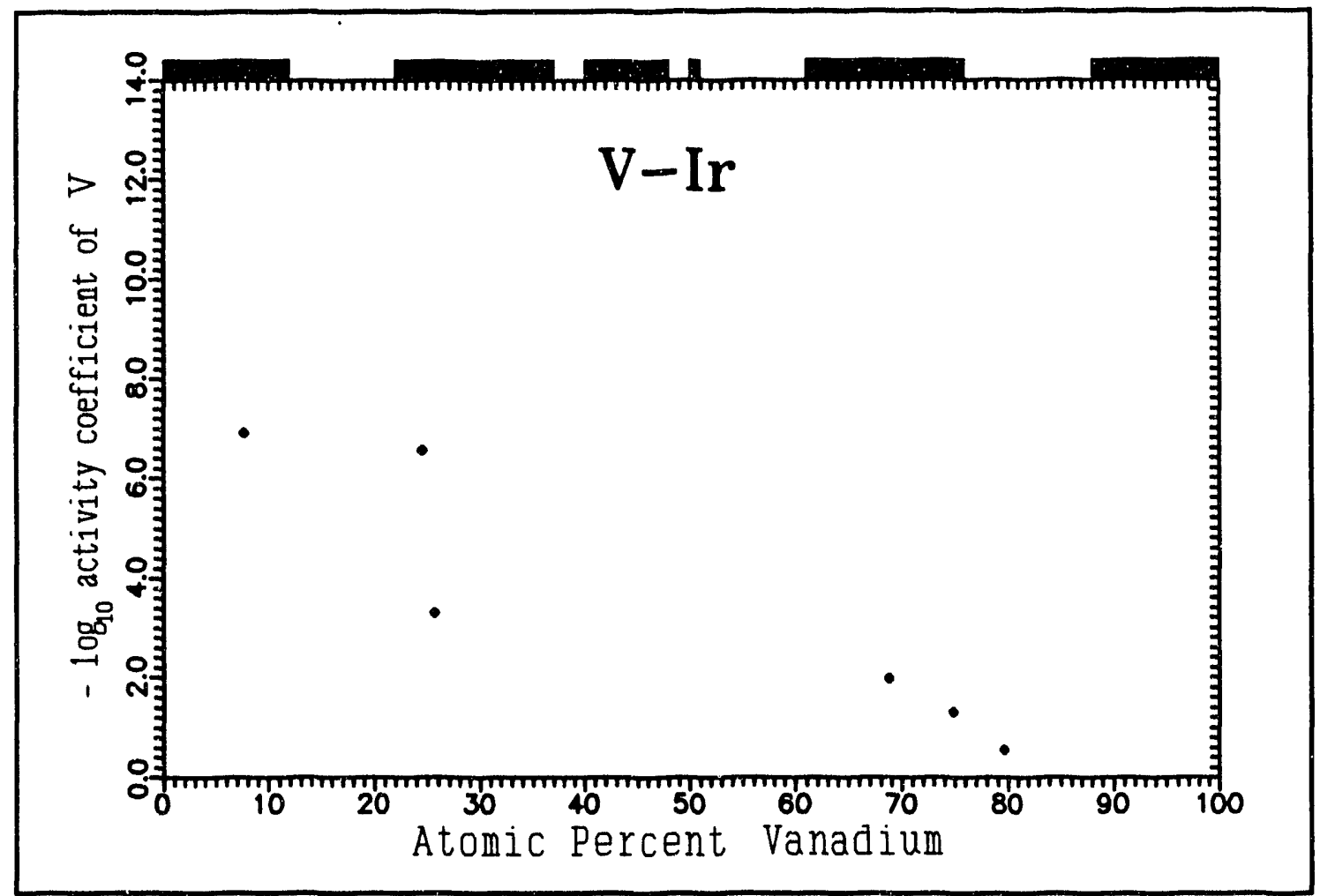

Figure 8.3. The vanadium-iridium system at $1000^{\circ} \mathrm{C}$.

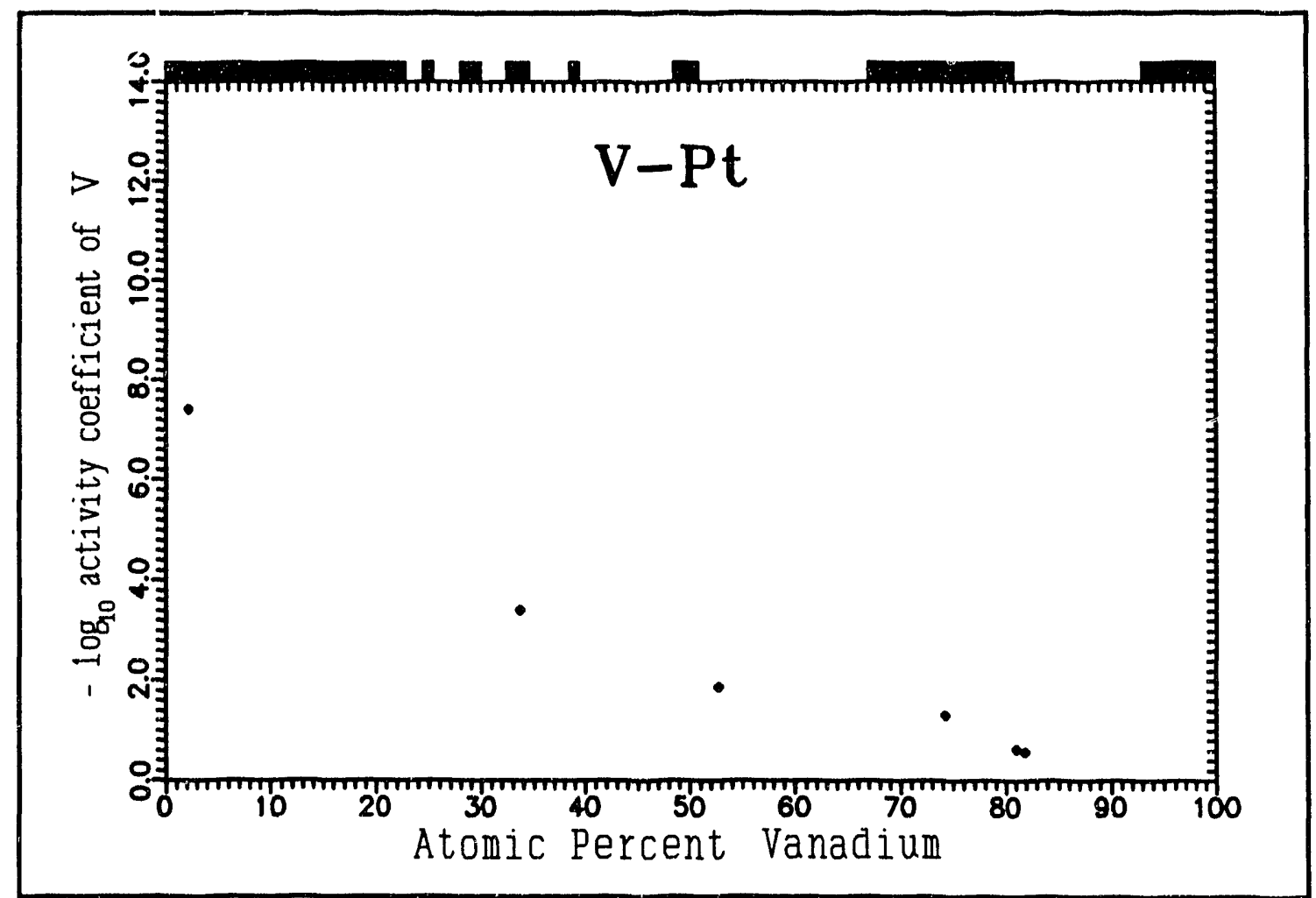

Figure 8.4 . The vanadium-platinum system at $1000^{\circ} \mathrm{C}$. 


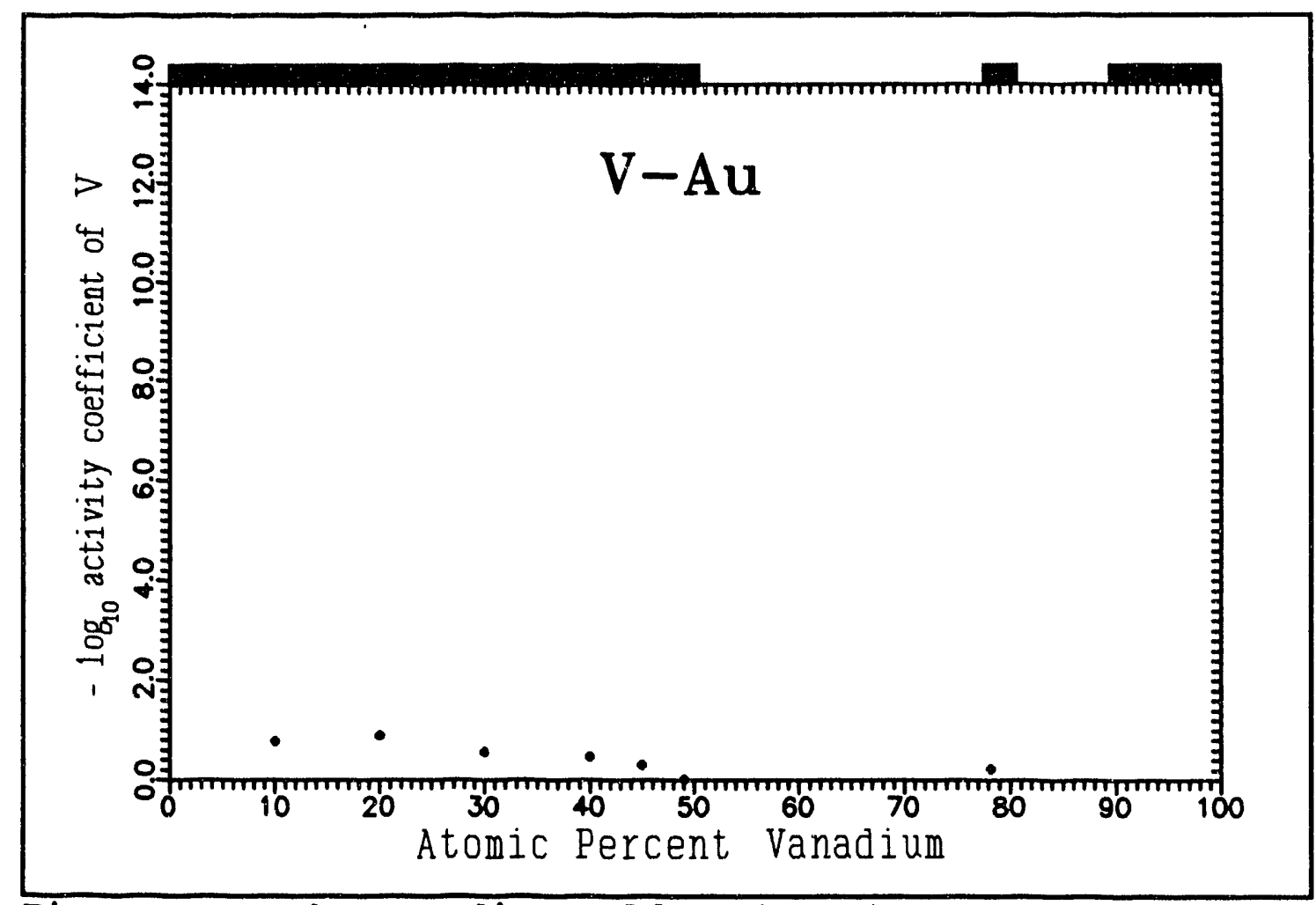

Figure 8.5. The vanadium-gold system at $1000^{\circ} \mathrm{C} .[9]$

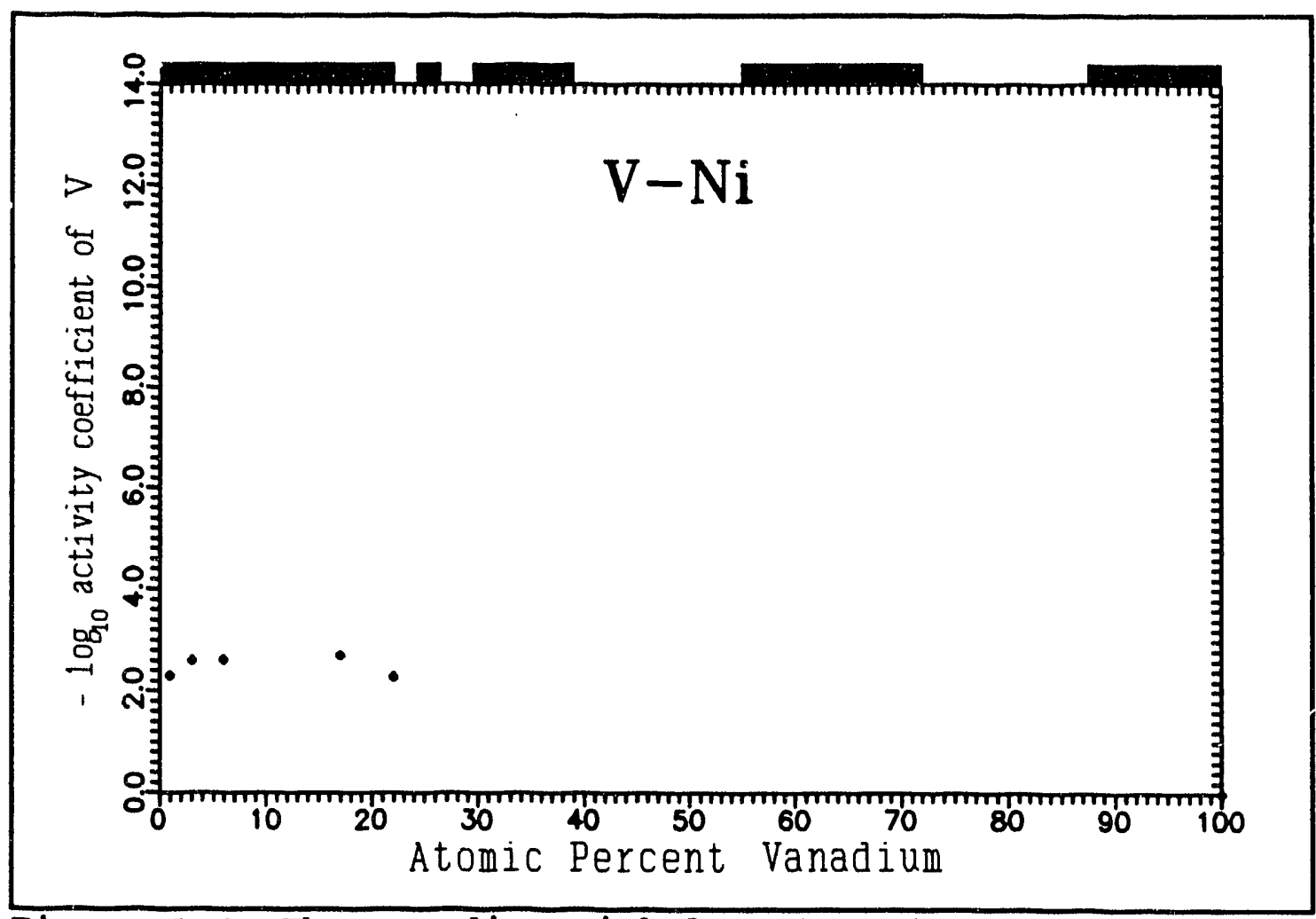

Figure 8.6. The vanadium-nickel system at $1000^{\circ} \mathrm{C} .[10]$ 


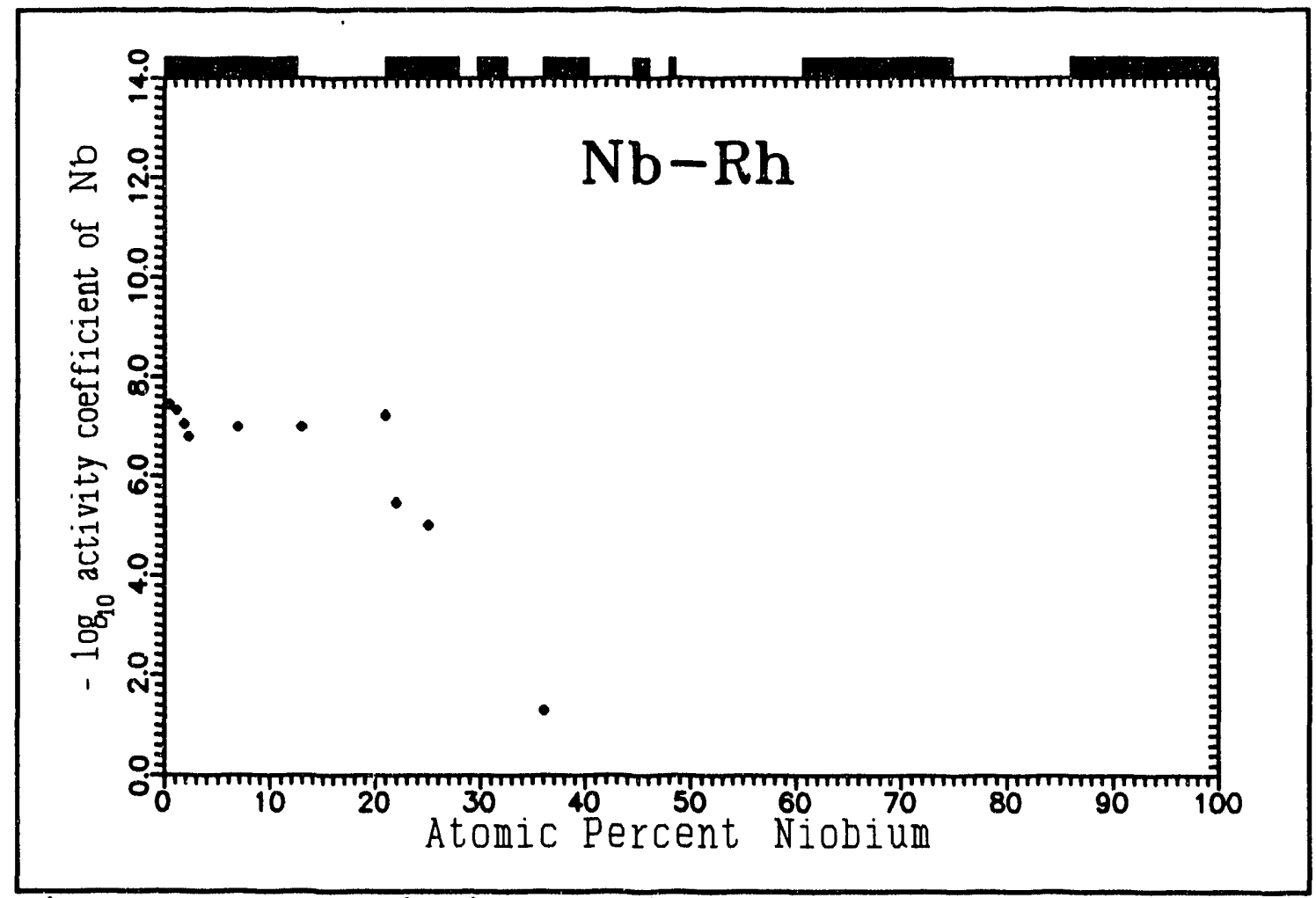

Figure 8.7. The niobium-rhodium system at $1000^{\circ} \mathrm{C} \cdot[11,12]$

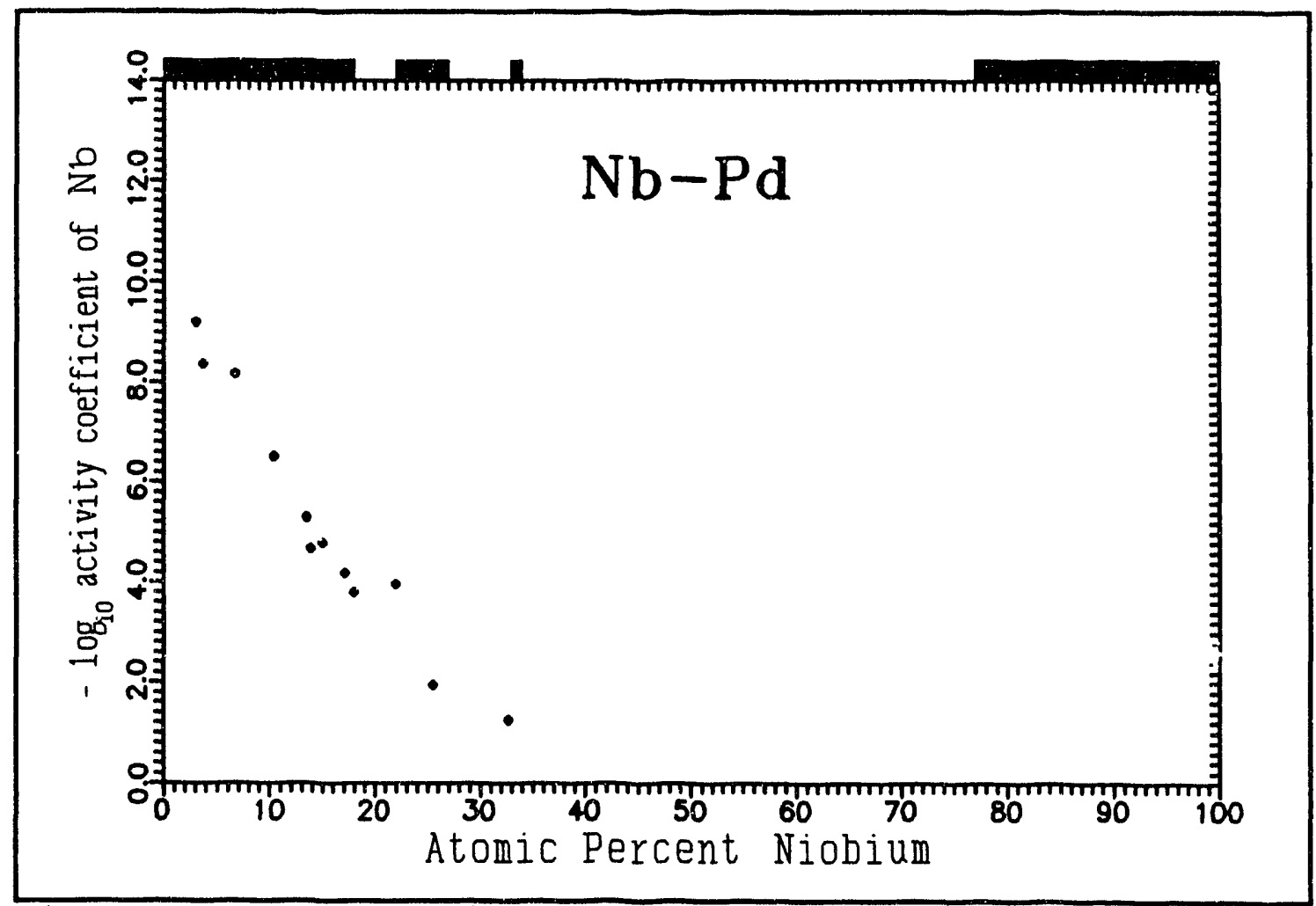

Figure 8.8. The niobium-palladium system at $1000^{\circ} \mathrm{C} \cdot[12]$ 179 


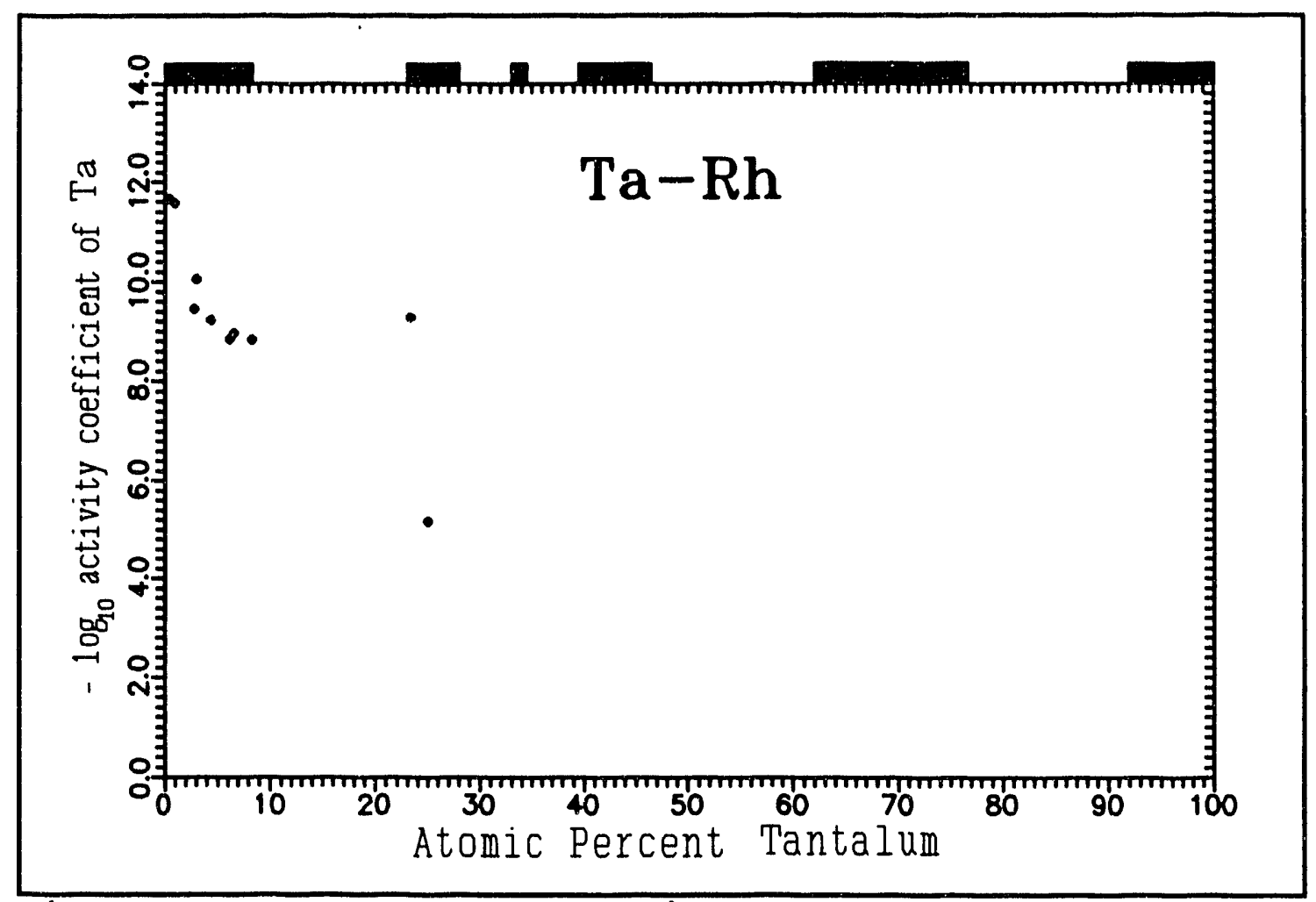

Figure 8.9. The tantalum-rhodium system at $1000^{\circ} \mathrm{C} .[13$ ]

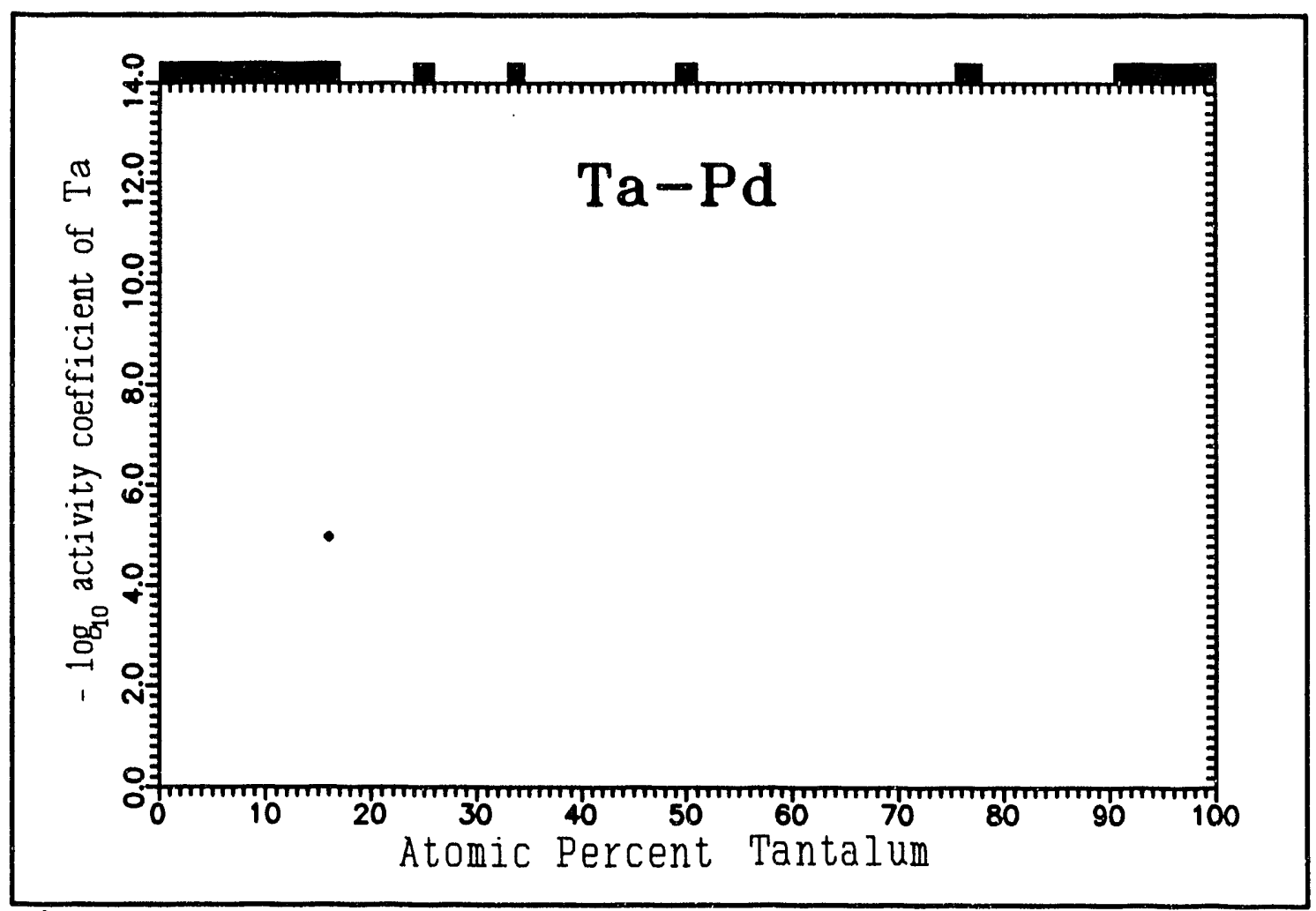

Figure 8.10. The tantalum-palladium system at $1000^{\circ} \mathrm{C} .[11]$ 180 


\subsection{Fitting the Thermodynamic Data.}

\section{The $V$-Pd system}

There are enough data for the V-Pd system to attempt to fit the activity over the entire composition range of the solid solution of vanadium dissolved in palladium, then from this fit to integrate to obtain the activity of $\mathrm{Pd}$ in $\mathrm{V}$ as a function of concentration. The Gibbs free energy of formation of $\mathrm{V}_{0.5} \mathrm{Pd}_{0.5}$ can then be estimated.

Fitting the activity coefficient

Equations 8.4, 8.6, and 8.31 are used to fit the partial Gibbs energy of vanadium in palladium and the partial Gibbs energy of niobium in palladium as a function of composition. With a minimal number of parameters to fit it can be seen that these functions reproduce the data reasonably well.

The Fourier series:

$$
\begin{gathered}
8.32-\log \gamma_{v}=1.63135, \int^{x v}[(1-\cos 2 \pi X)+0.75 \sin 2 \pi X] / X d X \\
\operatorname{enr}^{2}=0.30138
\end{gathered}
$$

The value of $n$ is identified by observing where the largest change in the log of the activity coefficient occurs. For example is the largest change is at $\mathbf{5 0 \%}$ then $\mathrm{n}=1$. If the largest change is around $33 \%$, then $n=2$. If the largest change is around $25 \%$ then $n=3$. If the largest change lies between these areas a weighted average of two functions can be used. The relative contribution of the sine and cosine functions can be estimated from the slope of the curve at zero 
concentration of vanadium. The cosine terms all have a zero slope at zero concentration of vanadium. Lastly, the scaling coefficient is fixed by a representative data point. In this case, it is the value of $-\log \gamma_{v}$ at $\mathrm{X}_{\mathrm{v}}=0.1275$. The Van Laar equation:

Using the Van Laar equation the activity coefficient can be fit to the following equation.

$$
\begin{aligned}
& 8.33-\log \gamma_{v}=6.07241 /\left(1+1.32638 \mathrm{X}_{d} / \mathrm{X}_{p_{d}}\right)^{2} \\
& \mathrm{r}^{2}=0.998375 ; \mathrm{r}=\text { correlation coefficient } \\
& \mathrm{er}{ }^{2}=0.14601
\end{aligned}
$$

The regular solution equation:

Using the regular solution fit with a cubic term the activity coefficient can be fit to the following equation

$$
\begin{aligned}
& 8.34-\log \gamma_{v}=2.60572 \mathrm{X}_{\mathrm{Pd}}^{2}+3.45910 \mathrm{X}_{\mathrm{Pd}}{ }^{3} \\
& \mathrm{r}^{2}=0.998645 \\
& \mathrm{en}{ }^{2}=0.13555
\end{aligned}
$$

The Van Laar fit and the regular solution fit are obtained by the GaussNewton convergence method. The correlation coefficients for the fits give some measure of the goodness of fit for Equations 8.34 and 8.35. The err ${ }^{2}$ term is the sum of the difference of fitted data points to measured data points squared. The smaller $\mathrm{err}^{2}$ is the better is the fit. Consequently, it appears that the regular solution equation yields the best fit. 
Table 8.1. Comparison of experimental versus fitted activity coefficient.

\begin{tabular}{lllll}
\hline $\mathrm{X}_{v}$ & $-\log \gamma_{v} \exp$. & $-\log \gamma_{v} 8.32$ & $-\log \gamma_{v} 8.33$ & $-\log \gamma_{v} 8.34$ \\
\hline 0.004 & 5.880 & 5.681 & 6.008 & 6.003 \\
0.041 & 5.450 & 5.371 & 5.438 & 5.447 \\
0.1275 & 4.511 & $4.511^{\star}$ & 4.261 & 4.281 \\
0.215 & 3.220 & 3.528 & 3.267 & 3.279 \\
0.411 & 1.762 & 1.447 & 1.638 & 1.611 \\
0.471 & 1.116 & 0.958 & 1.277 & 1.241 \\
0.520 & 0.823 & 0.632 & 1.023 & 0.983 \\
0.500 & & 0.757 & &
\end{tabular}

* value used to fit constant

Integrating V-Pd system

Equations 8.32-8.34 can be integrated through the Gibbs-Duhem relationship to yield the following equations.

The Fourier series:

$8.35-\log \gamma_{P d}=1.63135, \int^{X p d}[(1-\cos 2 \pi X)-0.75 \sin 2 \pi X] / X d X$

The Van Laar equation:

$8.36-\log \gamma_{p d}=4.57818 /\left(1+0.75393 X_{p d}\left(X_{v}\right)^{2}\right.$

The regular solution equation:

$8.37-\log \gamma_{P d}=7.79437 X_{v}^{2}-3.45910 X_{v}^{3}$

Table 8.2 lists some values obtained from the Gibbs-Duhem integration. The variation in activity of palladium in vanadium can be seen to be small at high 
concentrations of palladium. However, the deviation increases significantly with increasing vanadium concentration. Consequently, the choice of the function used to fit the data affects the data obtained through the Gibbs-Duhem integration. At $X_{v}=0.50$ the free energy of formation is given by the following.

$0.5 \mathrm{~V}+0.5 \mathrm{Pd}=\mathrm{V}_{0.5} \mathrm{Pd}_{0.5}$

$\Delta G_{f, 1000 \circ} / R=-3.5 \pm 0.6(\mathrm{kK} /$ mole $)$

when the value for the activity of palladium is obtained from the Fourier series integration.

Table 8.2. Integration to obtain the activity coefficient of Pd.

\begin{tabular}{llll}
\hline$X_{p d}$ & $-\log _{p d} 8.35$ & $-\log _{p d} 8.36$ & $-\log _{p d} 8.37$ \\
\hline 1.00 & 0.0000 & 0.0000 & 0.0000 \\
0.95 & 0.0069 & 0.0195 & 0.0191 \\
0.90 & 0.0314 & 0.0755 & 0.0745 \\
0.85 & 0.0786 & 0.1647 & 0.1637 \\
0.80 & 0.1523 & 0.2839 & 0.2841 \\
0.75 & 0.2545 & 0.4303 & 0.4331 \\
0.70 & 0.3852 & 0.6014 & 0.6081 \\
0.65 & 0.5423 & 0.7947 & 0.8065 \\
0.60 & 0.7210 & 1.0082 & 1.0257 \\
0.55 & 0.9147 & 1.2400 & 1.2631 \\
0.50 & 1.1147 & 1.4882 & 1.5162
\end{tabular}


The Nb-Pd system

Using the data of Cima[14] the partial Gibbs energy of niobium in palladium is fit using the Fourier series as has been done in the V-Pd system.

Fitting the activity coefficient

Using the same methods as in the V-Pd system, the log of the activity coefficient can be fit to the following equations.

The Fourier series:

$8.38-\log \gamma_{\mathrm{Nb}}=2.59219, \int^{\mathrm{Xnb}^{\mathrm{n}}}[1-\cos 8 \pi \mathrm{X}] / \mathrm{X} d \mathrm{XX}$

$$
e r^{2}=1.1398
$$

The Van Laar equation:

$$
\begin{gathered}
8.39-\log \gamma_{M b}=10.9771 /\left(1+2.91458 \mathrm{X}_{W b}\left(\mathrm{X}_{\mathrm{Pd}}\right)^{2}\right. \\
\mathrm{r}^{2}=0.997015 \\
\mathrm{er} r^{2}=1.1038
\end{gathered}
$$

The regular solution equation:

$$
\begin{gathered}
8.40-\log \gamma_{\mathrm{Wb}}=-15.8224 \mathrm{X}_{\mathrm{Pd}}{ }^{2}+26.3660 \mathrm{X}_{\mathrm{Pd}}{ }^{3} \\
\mathrm{r}^{2}=0.997858 \\
\mathrm{en}{ }^{2}=0.54602
\end{gathered}
$$

As in the V-Pd system, the fit using the Fourier series is not the best obtainable from this equation. The fit is done more by trial and error than by any mathematical convergence method. The one point indicated in Table 8.3 is used to fix the constants in 8.39. As in the V-Pd system the value of $\mathbf{n}$ is chosen 
from the shape of the titration curve.

For the Van Laar equation and the regular solution equation, the parameters are fit using the Gauss-Newton method of convel gence. the correlation coefficients for the latter two fits are also given. Once again, the regular solution equation yielits the best fit. However, the Fourier series fit seems to be better for this system.

Table 8.3. Fitting of activity coefficient in Nb-Pd system.

\begin{tabular}{lllll}
\hline$X_{\text {Wb }}$ & $-\log \gamma_{W b} \exp$. & $-\log \gamma_{M b} 8.38$ & $-\log \gamma_{M b} 8.39$ & $-\log \gamma_{M b} 8.40$ \\
\hline 0.030 & 9.219 & 9.499 & 9.237 & 9.176 \\
0.037 & 8.379 & 9.317 & 8.878 & 8.873 \\
0.067 & 8.181 & 8.224 & 7.506 & 7.640 \\
0.104 & 6.516 & $6.516^{\star}$ & 6.129 & 6.263 \\
0.135 & 5.300 & 5.188 & 5.186 & 5.226 \\
0.139 & 4.683 & 5.040 & 5.076 & 5.099 \\
0.150 & 4.796 & 4.669 & 4.787 & 4.760 \\
0.171 & 4.192 & 4.117 & 4.282 & 4.148 \\
0.180 & 3.811 & 3.945 & 4.082 & 3.898 \\
* value used to fit coefficient & & \\
Integrating the Nb-Pd system
\end{tabular}

The integration of 8.38-8.40 through the Gibbs-Duhem relation yields the equations given in 8.41-8.43.

The Fourier series:

$8.41-\log \gamma_{\mathrm{pd}}=2.59219, \int^{\mathrm{xpd}}[1-\cos 8 \pi \mathrm{X}] / \mathrm{X} \mathrm{dX}$ 
The Van Laar equation:

$$
8.42-\log \gamma_{p d}=3.76627 /\left(1+0.343103 \mathrm{X}_{\mathrm{pd}} / \mathrm{X}_{\mathrm{ptb}}\right)^{2}
$$

The regular solution equation:

$$
8.43-\log \gamma_{p d}=23.7266 \mathrm{X}_{w b}^{2}-26.3660 \mathrm{X}_{\mathrm{wb}}^{3}
$$

Table 8.4. Integration to obtain the activity coefficient of Pd.

\begin{tabular}{llll}
\hline $\mathrm{X}_{\mathrm{pd}}$ & $-\log \gamma_{\mathrm{pd}} 8.41$ & $-\log \gamma_{\mathrm{pd}} 8.42$ & $-\log \gamma_{\mathrm{pd}} 8.43$ \\
\hline 1.00 & 0.0000 & 0.0000 & 0.0000 \\
0.975 & 0.0043 & 0.0182 & 0.0144 \\
0.95 & 0.0327 & 0.0666 & 0.0560 \\
0.90 & 0.2141 & 0.2254 & 0.2109 \\
0.85 & 0.5009 & 0.4345 & 0.4449 \\
0.82 & 0.6426 & 0.5733 & 0.6150
\end{tabular}

The regular solution equation and the Van Laar equation are the two simplest functions to fit the natural $\log$ of the activity coefficients. They both work satisfactorily in the V-Pd and the Nb-Pd systems over the entire Pd solid solution range, which is surprising since the strong interactions in the V-Pd and $\mathrm{Nb}-\mathrm{Pd}$ systems would seem to disallow the use of these functions over large composition ranges in these systems. It can be seen upon integration that the activity of palladium depends on the functional form used. For this reason, it is important to obtain the best functional form for the most accurate values of the activity of palladium in vanadium or niobium. The use of the proper equation is especially important when limited data are available. 
For both the Nb-Pd and the V-Pd systems, the regular solution equation seems to fit the data the best. However, the uncertainty in the data is large enough so that any of the other functions presented could easily be a better choice if more accurate values were obtained. The Fourier series fit is documented since it was tried. It fits the data reasonably. However, it is cannot be used as easily as the other functions presented.

\subsection{Correlations Between Thermodynamics and Alloy Properties.}

A considerable amount of data on the thermodynamics of acid-base stabilized alloys is presently known. However, any correlations of the increased stability of these alloys on other material properties has not yet been determined. Consequently, some attempt at correlating material properties to acid-base stability is presented here. The density of states at the Fermi level, the Debye temperature, and the hardness can all be correlated, at least in part, to acid-base stability.

\section{Electronic structure of alloys}

The electronic specific heat is related to the density of states at the Fermi level by the following equation.

$$
8.44 \gamma=2 / 3 \pi^{2} k_{B}^{2} n\left(E_{F}\right)=2 / 3 \pi^{2} k_{B}^{2}(1+\lambda) n_{0}\left(E_{F}\right)
$$

The important aspect to note is that the density of states at the Fermi level is directly proportional to the electronic specific heat. Since both V-Pd and V-Pt are acid-base stabilized alloys, the enthalpy of formation of these alloys will be 
considerably negative. For any alloy the enthalpy of formation is given by integrating the density of states function for the product alloy minus that for the constituent elements.

$$
\text { 8.45 } \Delta H_{f}={ }_{0}{ }^{E f, A \times B y} \Omega_{A \times B y}(E) d E-x\left[{ }_{0} \int^{\left.E F, n_{A}(E) d E\right]}-y\left[{ }_{0} \int^{E f, B} \Omega_{B}(E) d E\right]\right.
$$

Note that this equation is only exact at $\mathrm{OK}$. As temperature is increased, the upper limit of the integral must increase. The general form, however, remains the same.

For acid-base stabilized alloys, the net effect is that the density of states will drop in the alloy relative to the elements because of the large enthalpy of formation. Consequently, it is likely that the density of states at the Fermi level will also decrease in the alloys relative to the elements. Considering this argument further, the density of states diagram for the noble metals normally shows a high density of states near the Fermi level.[14] These are the nonbonding electrons in the noble metal. These electrons are donated to the acid in these alloys. Hence the paired electrons at the Fermi level in the base become bonding electrons in the alloy. This, consequently, should decrease the Fermi level of the alloy relative to the elements. Table 8.5 shows that this is indeed what is observed, at least for systems which have a strong acid-base interaction. The only two exceptions are the V-Au system and the V-Os system which are both weakly interacting systems. 
Debye temperatures

The Debye temperature is related to the cut off frequency of lattice vibrations in a solid. This frequency is related to the strength of the bonds in the alloy, the crystal structure, and the reciprocal of the average mass of the atoms. Since the bonds are stronger in the acid-base stabilized alloys, one would expect the Debye temperature to be larger in the alloys relative to the value expected for a hypothetical phase of the same composition having no increased stability. The hypothetical Debye temperature is given as follows

$8.46(x+y)\left(1 / \Theta_{D}^{*}\right)^{3}=x\left(1 / \Theta_{D}^{A}\right)^{3}+y\left(1 / \Theta_{D}^{B}\right)^{3}$

$\Theta_{D}^{*}$ is the hypothetical Debye temperature for an alloy with the formula AxBy. That is $\Theta_{D}^{*}$ is the value of the Debye temperature such that the low temperature limit of the heat capacity is a linear combination of the heat capacity of the elements.

For all the strongly interacting systems, $\theta_{0}$ is larger than $\theta_{0}^{*}$. The exceptions are VOs and $\mathrm{V}_{0.63} \mathrm{Ir}_{0.37}$. The first is a weakly interacting system, but the discrepancy for the second must remain unexplained or attributed to the effect of structure on the Debye temperature. 
Table 8.5. Correlation of electronic properties of alloys.[15-19]

\begin{tabular}{|c|c|c|}
\hline system & $\gamma$ & $\theta_{D}\left(\theta_{D}^{*}\right)$ \\
\hline V & 9.9 & 399 \\
\hline \multicolumn{3}{|l|}{ V-Pt } \\
\hline $1 / 4 \mathrm{~V}_{3} \mathrm{Pt}$ & 7.19 & $511(285)$ \\
\hline $1 / 2 \mathrm{VPt}$ & 3.38 & $335(242)$ \\
\hline $1 / 3 \mathrm{VPt}_{2}$ & 2.00 & $314(224)$ \\
\hline $1 / 4 \mathrm{VPt}_{3}$ & 3.24 & $298(217)$ \\
\hline $\mathrm{Pt}$ & 6.6 & 200 \\
\hline \multicolumn{3}{|l|}{ V-Pd } \\
\hline $1 / 4 V_{3} P d$ & 5.06 & $469(322)$ \\
\hline $1 / 2 \mathrm{VPd}$ & 4.99 & $366(283)$ \\
\hline $1 / 3 V d_{2}$ & 3.59 & $388(265)$ \\
\hline $1 / 4 \mathrm{VPd}_{3}$ & 3.97 & $427(258)$ \\
\hline $\mathrm{Pd}$ & 9.42 & 240 \\
\hline \multicolumn{3}{|l|}{$\underline{V-R h}$} \\
\hline $1 / 4 \mathrm{~V}_{3} \mathrm{Rh}$ & 2.51 & $485(414)$ \\
\hline $\mathrm{Rh}$ & 4.9 & 480 \\
\hline \multicolumn{3}{|l|}{$\underline{\text { V-Ir }}$} \\
\hline $1 / 4 \mathrm{~V}_{3} \mathrm{Ir}$ & 1.94 & $445(404)$ \\
\hline$V_{.69}{ }^{I r} r_{.31}$ & 3.67 & $414(405)$ \\
\hline $\mathrm{V}_{.63}{ }^{\mathrm{Ir}} .37$ & 1.71 & $395(406)$ \\
\hline Ir & 3.1 & 420 \\
\hline
\end{tabular}


Table 8.5. Continued.

system $\gamma \quad \theta_{0}\left(\theta_{0}^{*}\right)$

$\underline{\mathrm{V}-\mathrm{Au}}$

$\begin{array}{lll}1 / 4 \mathrm{~V}_{3} \mathrm{Au} & 11.1 & 398(246) \\ \mathrm{Au} & 0.729 & 165 \\ \mathrm{~V}-\mathrm{Co} & & \\ 1 / 4 \mathrm{~V}_{3} \text { Co } & 2.78 & 560(409) \\ \text { Co } & 4.73 & 445\end{array}$

V-Ni

$\mathrm{V}_{.78} \mathrm{Ni}_{.22} \quad 4.5$

$\mathrm{Ni} \quad \mathbf{7 . 0 2} \quad 450$

V-OS

1/2VOs $\quad 4.76 \quad 385(438)$

Os $\quad 2.4 \quad 500$

$\gamma=$ electronic specific heat $\mathrm{mJ} / \mathrm{g}$ atom $\mathrm{K}^{2}$

$\theta_{0}=$ Debye temperature in $\mathrm{K}$

Physical properties of alloys

The acid-base interaction in metals will affect the physical properties of a material: tensile strength, toughness, hardness, corrosion resistance, etc. Table 8.6. shows how the hardness in the $\mathrm{Zr}$ - $\mathrm{Rh}$ and the $\mathrm{Zr}$-Pd systems is correlated to the heat of formation. Note that in th $:$ zirconium-rhodium system, the hardness is roughly proportional to the heat of formation. Since the acid-base intermetallic interaction is roughly correlated to the enthalpies of formation, it is reasonable to conclude that the hardness is also. This is just another example of how increased 
stability which occurs in acid-base stabilized alloys can be directly related to the material properties. In a like manner the acid-base stabilization will be correlated to the other material properties mentioned and should also be very useful for optimizing material properties.

Table 8.6. Vickers Hardness of some Zr-Rh and Zr-Pt compounds.[20-24]

phase hardness $\left(\mathrm{kgf} / \mathrm{mm}^{2}\right) \quad-\Delta \mathrm{H}_{\mathrm{f}, 298} / \mathrm{R}(\mathrm{kK} / \mathrm{mole})$

\section{$\underline{\mathrm{Zr}-\mathrm{Rh}}$}

$\begin{array}{lll}\mathrm{Rh} & 95 & 0.0\end{array}$

(Rh)lim $\quad 400$

$1 / 4 \mathrm{ZrRh}_{3} \quad 650$

$9.35 \pm 0.48$

$1 / 8 \mathrm{Zr}_{3} \mathrm{Rh}_{5} \quad 870 \pm 10$

10.38

1/2ZrRh --

$9.12 \pm 0.60$

$1 / 3 \mathrm{Zr}_{2} \mathrm{Rh} \quad 440$

$6.66 \pm 0.24$

$\mathrm{Zr}$

0.0

$\underline{\mathrm{Zr}-\mathrm{Pt}}$

Pt

0.00

$\mathrm{Pt}_{.0305} \mathrm{Zr}$.9695 398

Pt.097 ${ }^{\mathrm{Zr}} .9023844$

$\mathrm{Pt} .1350{ }^{\mathrm{Zr}} .8650846$

$\mathrm{ZrPt}_{3}$

$15.35 \pm 1.01$ 


\section{References}

1. C. H. P. Lupis, Chemical Thermodynamics of Materials, Elsevier Science Publishing Co., New York, (1983).

2. J. J. Van Laar, "The Vapor Pressure of Binary Mixtures," Z. Physik. Chem., 72, 723-751 (1910). "Theory of Vapor Pressure of Binary Mixtures," $Z$. Physik. Chem., 83, 599-608 (1913).

3. J. H. Hildebrand, Solubility of Non-Electrolytes $2^{\text {nd }}$ Ed., Reinhold Publishing, New York (1936).

4. Y. A. Chang and J. P. Newman, "Thermodynamics and Defect Structure of the Intermetallic Phases with the B2 ( $\mathrm{CsCl}$ ) Structure," Prog. Solid State Chem., 14, 221-301 (1982).

5. G. Edelin, "A Defect Structure Model for the AB Intermetallic Compounds with Reference to CoGa and NiGa," Acta Metall., 27, 455-461 (1979).

6. R. Schmidt, "A Thermodynamic Analysis of the Cu-O System with an Associated Solution Model," Met. Trans. B, 14B, 473-481 (1983).

7. A. S. Jordan, "A Theory of Regular Associated Solutions Applied to the Liquidus Curves of the $\mathrm{Zn}$-Te and Cd-Te Systems," Met. Trans., 1, 239-249 (1970).

8. L. Brewer and R. H. Lamoreaux, "Thermochemical Properties of Molybdenum and its Compounds and Alloys," in Atomic Energy Review Special Issue No. 7, 1-192, Int'l Atomic Energy Agency: Vienna (1980).

9. V. N. Eremenko, G. M. Lukashenko, and G. I. Khmelenko, "Thermodynamic Properties of Gold-Vanadium Alloys," Dopov. Akad. Nauk Ukr. RSR, Ser. B, 36(9), 807-810 (1974). 
10. V. I. Alekseev and G. A. Levshin, "Study of the Thermodynamic Properties of Nickel-Vanadium Alloys by Electromotive Forces with a Solid Oxide Electrolyte," Diffuzion. Protessy Metallakh, 112-118 (1977).

11. H. Holleck, Binary and Ternary Carbide- and Nitridesystem, Gebruder Borntraeger, Berlin-Stutgart (1984) (German).

12. M. Cima and L. Brewer, "The Generalized Lewis Acid-Base Titration of Palladium and Niobium," Met. Trans. B, 19B, 893-917 (1988).

13. H. Kleykamp, "On the Thermodynamics of the Ta-Rh System," J. LessComm. Met., 152, 15-24 (1989) (English).

14. Landolt and Börnstein, Zahlenwerte und Functionen - Neue Serie, SpringerVerlag Berlin-Heidelberg, III, 13c (1984).

15. A. Amamou and R. Kuentzler, "Electronic Structure and Atomic Arrangement in VPt System," Solid State Comm., 43(6), 423-429 (1982).

16. R. Kuentzler, R. M. Waterstrat, "Electronic Properties and Stability of the Ordered Structures of the V-Pd, Nb-Pd, and Ta-Pd Systems," J. Less-Comm. Met., 120, 317-335, (1986).

17. P. Turek, R. Kuentzler, A. Bieber, and R. Jesser, "Electronic Properties of Atomically Ordered structures in the V-Ni, V-Pd, and V-Pt systems," Solid State Comm., 53(11), 979-983 (1985).

18. P. Spitzli, R. Flukiger, F. Heiniger, A. Junod, J. Muller, and J. L. Staudenmann, "Specific Heat, Superconductivity, and Crystalline Order in V-Base Alloys with the A15 Structure," J. Phys. Chem. Solids, 31, 1531-1537 (1970).

19. C. Kittel, Introduction to Solid State Physics, $6^{\text {th }}$ Ed., John Wiley Sons, Inc., New York (1986). 
20. J. L. Jorda, T. Graf, L. Schellenberg, J. Muller, K. Cenzual, J.C. Gachon, J. Hertz, "Phase Relations, Thermochemistry, and Superconductivity in the $\mathrm{Zr}$ Rh system," J. Less-Comm. Met., 136, 313-328 (1988).

21. J. L. Jorda, J. C. Gachon, J. Charles and J. Hertz, "High Temperature Study of the Zirconium-Rhodium System," J. Therin. Anal., 34, 551-557 (1988).

22. J. R. Handley, "Properties of Binary Rhodium Alloys," Platinum Met. Rev., 33(2), 64-72 (1989).

23. A. S. Darling, G. L. Selman, and R. Rushforth, "Platinum and the Refractory Oxides: III-Constitutional Relationships in the All ys Formed," Platinum Met. Rev., 14(4), 124-130 (1970).

24. V. Srikrishnan and P. J. Ficalora, "Measurement of the Enthalpies of Formation of $\mathrm{ZrPt}_{3}$ and $\mathrm{HfPt}_{3}$ by Fluorine Bomb Calorimetry," Metall. Trans., 5, 1471-1475 (1974). 


\section{Chapter 9}

\subsection{Conclusions.}

There is much more work yet to be done to quantitatively characterize the Lewis acid-base intermetallic interactions. Although, enough data now exist such that some models can be tested. However, much work still needs to be done to develop a model which is physically accurate, relatively simple, alt allows for accurate and easy calculations of the thermodynamic properties of the acid-base alloys.

There are a number of qualitative trends for the relative strength of the interaction. These trends in light of the information presented in this thesis are reviewed in this chapter.

\section{Trends of relative interaction}

If any element of the group VIIIB to XB transition metals(base) is reacted with any element of the group IIIB-VB transition metals(acid), then it is known that interactions with $5 \mathrm{~d}$ transition metals are normally stronger than interactions with 4d transitions which are stronger than interactions with $3 \mathrm{~d}$ transition metals. The complete trend is summarized in Table 9.1. This trend is a result of the fact that the $5 d$ orbitals extend further relative to the core than the group $4 d$ orbitals, 
and the group $4 d$ orbitals extended further relative to the core than the group $3 d$ orbitals. The only factors which can oppose this trend are the effect of the number of radial nodes in the overlapping $d$ orbitals and the elastic strain energy induced from atoms of different size being dissolved into the solvent lattice. The strain energy is usually a small percent of the interaction except in weakly interacting systems. Additionally, the size of the orbitals dominates ov or the effect of matching radial nodes as will be shown in the next section.

Table 9.1. Relative trends within a group

$$
\begin{aligned}
& \text { decreasing } \Delta H_{f} \\
& 5 d-5 d>5 d-4 d>5 d-3 d \\
& 4 d-5 d>4 d-4 d>4 d-3 d \\
& 3 d-5 d>3 d-4 d>3 d-3 d
\end{aligned}
$$

The effect of radial nodes

$3 d$ orbital wave functions have no radial nodes, $4 d$ orbitals have one radial node, and $5 \mathrm{~d}$ orbitals have two radial nodes. One would expect that there would be better overlap for $d$ orbitals with the same number of radial nodes. If sizes are neglected, $4 d$ orbitals will overlap with $4 d$ orbitals better than $4 d$ orbitals with $5 \mathrm{~d}$ orbitals due to the effect of radial nodes. To observe this the effect consider the $\mathrm{Zr}-\mathrm{Pd}(4 \mathrm{~d}-4 \mathrm{~d})$ system versus the $\mathrm{Hf}-\mathrm{Pd}(5 \mathrm{~d}-4 \mathrm{~d})$ system where the relative 
sizes of zirconium and hafnium are nearly equal. Consequently, the $4 \mathrm{~d}$ and $5 \mathrm{~d}$ cores are about the same in size. Remember, however, that the $5 \mathrm{~d}$ orbitals are more extended than the $4 \mathrm{~d}$ orbitals. From the first arguments due to size, one will expect a stronger interaction in $\mathrm{Hf}-\mathrm{Pd}$ than in $\mathrm{Zr}-\mathrm{Pd}$. From the latter argument due to radial nodes, one will expect a stronger interaction in $\mathrm{Zr}-\mathrm{Pd}$ than in Hf-Pd. Due to the opposing effects, the result will probably be that the resulting interaction is nearly equal. Kleppa[1] found that the enthalpy of formation for $\mathrm{ZrPd}$ is $-122.6 \pm 7.0 \mathrm{~kJ} /$ mole and that for HfPd is $-134.8 \pm 7.8$ $\mathrm{kJ} / \mathrm{mole}$. The formation energy of HfPd is more negative by $12.2 \mathrm{~kJ} / \mathrm{mole}$. This supports the claim that the size effect of the orbitals is the dominant effect. Yet from only one example the effect, if any, of the differing number of radial nodes cannot be ascertained. The radial node effect would be expected to be reversed for the $\mathrm{Zr}-\mathrm{Pt}(4 \mathrm{~d}-5 \mathrm{~d})$ system versus the $\mathrm{Hf}-\mathrm{Pt}(5 \mathrm{~d}-5 \mathrm{~d})$ system. From the first arguments due to size of orbitals, one would expect the interaction to be stronger in Hf-Pt than in $\mathrm{Zr}-\mathrm{Pt}$. From the second argument due to the number of radial nodes, one will also expect the interaction to be stronger in $\mathrm{Hf}-\mathrm{Pt}$ than in $\mathrm{Zr}-\mathrm{Pt}$. Consequently, one will expect that the Hf-Pt interaction will be considerably greater than the $\mathrm{Zr}-\mathrm{Pt}$ interaction. Kleppa[2] found the value of $-191.9 \pm 12.4$ $\mathrm{kJ} /$ mole for $\mathrm{ZrPt}$ and $-227.3 \pm 13.2 \mathrm{~kJ} /$ mole for HfPt. The formation energy is $35.4 \mathrm{~kJ} /$ mole more negative for HfPt. This increase in stability from $12.2 \mathrm{~kJ} / \mathrm{mole}$ for opposing effects to $35.4 \mathrm{~kJ} /$ mole for complimentary effects is consistent with 
the explanation of effects due to size and number of radial nodes.

Trends of relative interaction as a function of increasing atomic number

For a particular acid such as vanadium, interactions increase as the atomic number of the base is increased in any particular row of the transition series. In all cases, there seems to be a maximum of interaction around group IXB or XB in dilute solutions of vanadium. The maximum strength of interaction can be at a lower group number at higher concentrations of the acid. This trend in the relative strength of interaction is primarily a combination of two effects, one is due to the number of nonbonding pairs on the base and the other is due to the size of the nonbonding pairs on the base. As the atomic number is increased the number of nonbonding pairs increases.(see Table 2.1) Although, as the atomic number increases the size of the $d$ orbitals decreases. Consequently, by the time the group XIB metals are reached there is very little overlap and very little acidbase interaction. On the other hand, the group VIB transition metals have larger orbitals for overlap, but they only contain a fraction of a nonbonding pair of electrons. As a result, the group VIIB transition metals do not interact strongly with the acids.

The relative strength of interaction as a function of concentration

At infinite dilution of vanadium, the interaction of vanadium with palladium is stronger than the interaction of vanadium with rhodium. However, as the concentration of vanadium is increased the interactions with rhodium become 
stronger than the interactions with palladium. Cima and Brewer have explained this phenomena already for the analogous interaction of niobium with rhodium versus niobium with palladium.[3] Their argument follows.

Assuming that each of the orbitals on the noble metal takes on a different size due to the crystal field effect, the nonbonding electrons on palladium and rhodium are expected to be located in the lest accessible orbitals for bonding. That is the smallest orbitals. The electronic configuration for rhodium is approximately $\mathrm{sp}^{2} \mathrm{~d}^{6}$ and the electronic configuration for palladium is approximately $\mathrm{sp}^{2} \mathrm{~d}^{7}$. Consequently, rhodium has 1 nonbonding electron pair in its least accessible $d$ orbital and palladium has 2 nonbonding electron pairs in the two least accessible $d$ orbitals. The size of each of the $d$ orbitals on rhodium will be expected to be larger than each corresponding $d$ orbital on palladium due to the difference in nuclear charge. As a result, the least accessible nonbonding pair on palladium will be in a more contracted orbital than the nonbonding pair on rhodium. The other nonbonding pair on palladium will be in a more extended orbital than the first pair which is likely to be more extended than the nonbonding pair on rhodium. When vanadium is reacted with the noble metals in small amounts, the strength of the V-Pd interaction is expected to be larger than the $\mathrm{V}-\mathrm{Rh}$ interaction. As the concentration of vanadium is increased, the more extended orbital on the palladium will be used up in bonding and its less extended orbital will begin to be used. At this point the interactions of vanadium with 
rhodium will begin to dominate over the interactions of vanadium with palladium.

This qualitative argument agrees with the observed trends. Another explanation for the curve cross over follows. Consider that rhodium is a monobase (electronic configuration of $\mathrm{sp}^{2} \mathrm{~d}^{6}$ corresponding to 1 nonbonding electron pair) and palladium is a di-base(electronic configuration of $\mathrm{sp}^{2} \mathrm{~d}^{7}$ corresponding to 2 nonbonding electron pairs). Also, note that vanadium is a mono-acid(electronic configuration of $s d^{4}$ corresponding to 1 vacant $d$ orbital). Given this situation, a di-base reacting with a mono-base would be expected to have sharp changes in the activity coefficient at 33.3 mole percent vanadium and 66.6 mole percent vanadium. These points correspond to the "endpoints" of the acid-base titration. However, a mono-base reacting with a mono-acid would be expected to have only one sharp change in the activity coefficient occurring at 50 mole percent vanadium. Using the following equation which is the sum of Equations 8.6 and 8.24 given in Chapter 8, the "endpoint" conditions outlined above are simulated. $9.1-\ln \gamma_{\mathrm{V}}=\mathrm{X}_{\mathrm{MUN}}^{2}+{ }_{0} \int^{\mathrm{X}(\mathrm{MM})}[\sin (\mathrm{xNX})]^{2} /(1-\mathrm{X}) \mathrm{dX}$ For $\mathbf{N}=1$ the mono-acid versus the mono-base condition is simulated, and for $\mathbf{N}=2$ the mono-acid versus the di-base condition is simulated. Changing only the value of $\mathrm{N}$ in Equation 9.1 yields two plots for the natural $\log$ of the activity coefficient as a function of concentration which are superimposed in Figure 9.1. The change in the log of the activity coefficients at the "endpoints" is very gradual for this equation which is reasonable for these metallic systems because the 
"endpoints" are not expected to be well defined. Note, interestingly, that the two curves cross at 15 mole percent of acid. This composition corresponds to the point where the V-Rh versus the V-Pd curves cross, Figures 8.1 and 8.2 , and this also corresponds to the point where the $\mathrm{Nb}-\mathrm{Rh}$ versus the $\mathrm{Nb}-\mathrm{Pd}$ curves cross, Figures 8.7 and 8.8. Note that the two curves in Figure 9.1 cross a second time at $\mathbf{5 2 . 5}$ mole percent of acid. This phenomena is not observed in the V-Rh versus the V-Pd systems. However, the interaction of V-Rh versus V-Pd at high concentrations of vanadium does not differ much. Note that no additional significance to the argument for the curve cross over should be added than the behavior observed is consistent with that expected from acids and bases.

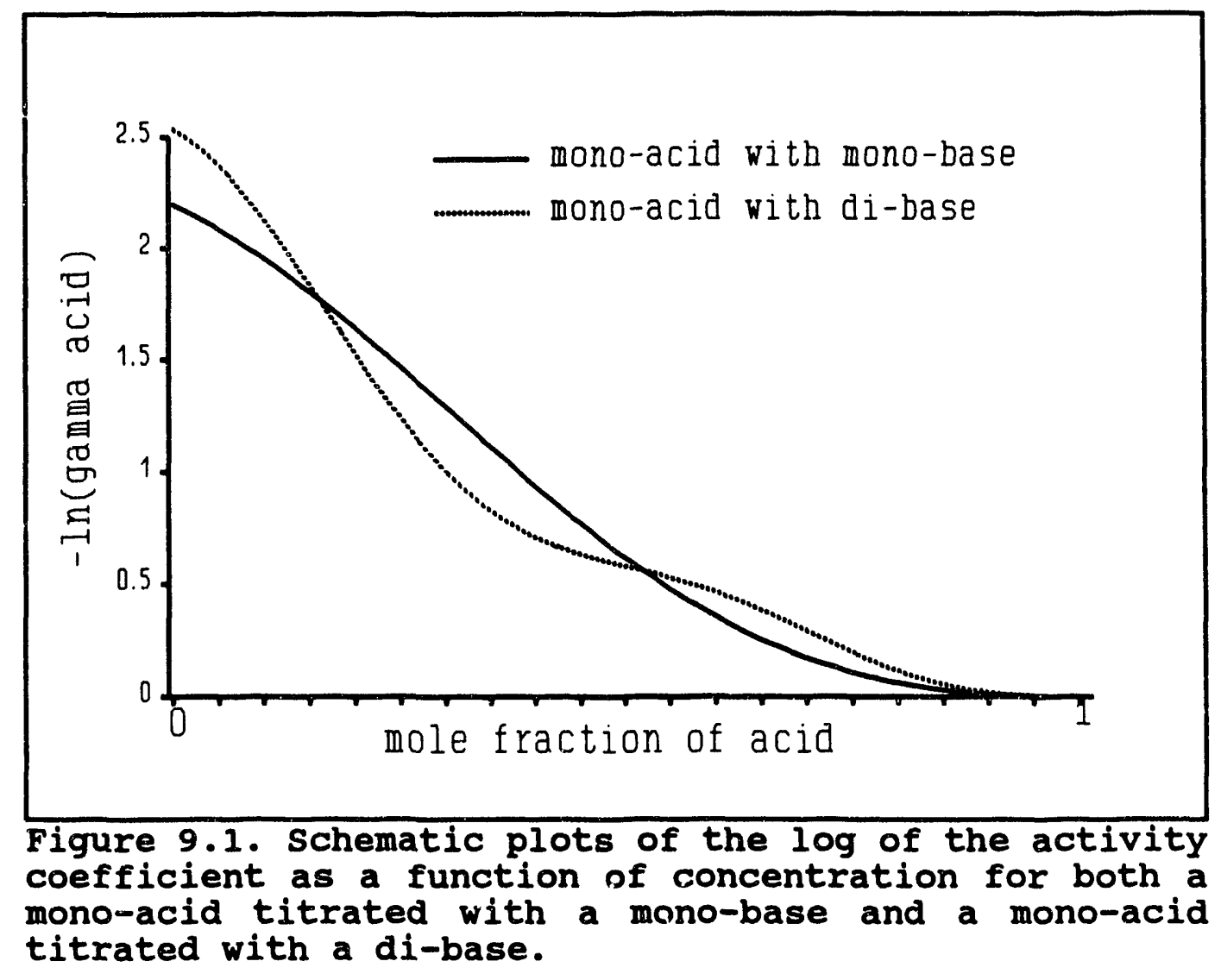


Modeling and fitting data

Infinite dilution parameters

Schaller's[4-6] approach to calculating activity coefficients at infinite dilution is at least representative of the trends observed. More accurate information about the work functions, the bulk moduli, and the lattice parameters for the alloys is required to determine the extent to which this theory is valid. The basic premises by which the activity coefficients at infinite dilution are calculated by Schaller's methud would seem to suggest that implementing better values for the physical constants used will not result in significant improvements to the calculations. However, the moderate success of his functional form would suggest that from experimental values for the activity coefficient at infinite dilution, the physical parameters for each element could be calculated. Then from these calculated pseudo physical parameters accurate values of activity coefficients at infinite dilution could be calculated for systems for which there is no data. Activity coefficient as a function of concentration.

To calculate the activity coefficient as a function of concentration for the $\mathrm{CsCl}$ structure and other simple orciered phases, the best model, provided that the solubility range is small, is that of Austin Chang. For solid solution ranges or complicated crystal structures in any acid-base alloy, another model is necessary. In the V-Pd and Nb-Pd systems, fitting the log of the activity coefficient to the cubic regular solution equation or the Van Laar equation will reproduce the data 
well within the uncertainty of the experimental data. In addition, fitting the data using the functional form obtained from the Gibbs-Duhem equation, symmetry of interaction considerations, and the Fourier series also works well. This approach, however, is questionable in regard to whether the constants fitted have any physical meaning. It, however, works well as a way to fit the data, and also it lends itself to fitting data sets which cannot be fit by the regular solution equation or the Van Laar equation.

\subsection{Remaining Work.}

More data on any of the systems for which acid-base interactions occur is desirable. Of course, more accurate data would also helpful. The absolute accuracy of the activity coefficients tabulated in Appendix $\mathrm{H}$ could be as much as $\pm 1 / 2$ in error in the term $-\log \gamma_{v}$. This is a generous estimate. Note, however, that some of the error is systematic because the same thermodynamic data is used for all the V-NM(noble metal) systems. Consequently, the shape of the activity versus concentration curve is preserved although it may be shifted or distorted slightly. As a result, the relative error between all points in the V-NM(noble metal) systems is much less than $\pm 1 / 2$ in $-\log \gamma_{v}$.

The error in the activity coefficients is a function of several errors and assumptions. The compositional error is given in Appendix $\mathrm{C}$ under the sections on the microprobe and the SEM. Usually, the compositional analysis is within \pm 1 
mole percent. In the future, the compositional error will have to be reduced to obtain more meaningful activity coefficients of vanadium at high concentrations of noble metal. The uncertainty in the thermodynamics used for the vanadium oxides also affects the accuracy of the activity coefficients calculated. These thermodynamic calculations also involve the assumption that the activity of each vanadium oxide phase is equal to 1. This assumption is reviewed in Appendix B. This equilibration technique can be improved by better thermodynamic data for the vanadium oxides and the vanadium carbides. Also, it can be improved by finding better methods for converting the available thermodynamic data activities of vanadium in the vanadium oxides or the vanadium carbides.

More data on the V-Ir, V-Pt, Nb-Ir, Nb-Pt, Ta-Ir, and Ta-Pt systems are needed to see if the interactions of Ir and Pt with the group VB transition me:als exhibit the same behavior as the interactions of $\mathrm{Rh}$ and $\mathrm{Pd}$ with the group VB transition metals. More specifically, are the interactions of group VB transition metals with Pt stronger than with Ir at infinite dilution, and at higher concentrations of vanadium are the interactions with Ir stronger than the interactions with Pt? Experiments of this sort should help to emphasize the similarity of these interactions to that expected from acids and bases.

Ultimately, some characterization of the interaction of mixtures of noble metals with various metallic acids like vanadium would be insightful. For example, titrate a mixture of iridium and platinum or a mixture of iridium and 
gold with an acidic metal like vanadium. This would be helpful in isolating the contribution to stability due to the number of bonding of "base" electrons from the contribution to stability due to the orbital overlap of each "base" electron pair.

\subsection{A Long Term Goal.}

In the end, the characterization of the acid-base interaction which occurs in intermetallic systems will enhance the ability to predict intermetallic phase diagrams and also material properties. This grand expectation does not exclude the need for more fundamental approaches. For the ultimate goal is to determine and quantify the simplest set of factors which dominate the thermodynamic stability. Consequently, all angles of approach to the problem are needed. The Engel-Brewer and atomic size correlations are the least complicated, all encompassing way of predicting phase stability quickly and semi-quantitatively. These correlations, however, are not without their limitations. Consequently, improvements and refinements to these correlations are still needed.

\subsection{The End}

Since the noble metals are not as unreactive as they are often believed to be, they must now be viewed in a new way. The noble metals must be classified as very reactive elements. Consequently, platinum in many high-temperature experiments is not a good choice for use as a supposedly inert crucible. Likewise, 
the use of platinum or palladium as an electrical connection in some hightemperature systems may also be a poor choice. On the other hand, the material properties of these highly stable alloy mixtures will certainly be a strong function of their acid-base strength. For any system which uses noble metals or noble metal alloys, the use of these alloys could be optimized with a knowledge of the relationship of their acid-base strength to the material properties of interest. When alloys are among the most stable known, hard, tough, and oxidation resistant, there can be no end to the number of applications for which they are well suited. 


\section{References}

1. L. Topor and O. J. Kleppa, "Standard Enthalpies of Formation of PdZr and PdHf," Met. Trans. A, 18A, 1989-1994 (1987).

2. L. Topor and O. J. Kleppa, "Standard Enthalpies of Formation of PtTi, PtZr, and PtHf," Met. Trans. A, 19A, 1827-1831 (1988).

3. M. Cima and L. Brewer, "The Generalized Lewis Acid-Base Titration of Palladium and Niobium," Met. Trans. B, 19B, 893-917 (1988).

4. H. J. Schaller, "Activity Coefficient of Zirconium in Palladium and Platinum," Ber. Bunsenges., 80, 999-1002 (1976)(German).

5. H. J. Schaller, "On the Extremely High Thermodynamic Stability of Pd-Th Alloys," Z. Naturforsch., 34a, 464-468 (1979)(German).

6. S. Paasch and H. J. Schaller, "Thermodynamic Properties of Pd-X Alloys, with X $=$ Gd, Y, Ce," Ber. Bunsenges. Phys. Chem., 87, 812-814 (1983). 


\section{Appendix A}

\section{A.1. Compilation of Sample Equilibration Histories.}

The sample histories of all samples prepared are listed in Tables A.1 - A.10. The starting materials, equilibrated phases, percent weight loss, and equilibration times are tabulated for all samples. For equilibrated alloy compositions in the composites see Appendix $\mathrm{H}$.

Annealing times in Tables A.1 - A.10 are given in the format: the number of hours followed by the temperature in ${ }^{\circ} \mathrm{C}$ in parenthesis. The percent weight loss applies to the total weight change which occurred over all heat treatments and does not include weight losses due to sanding, cutting, etc. of the sample outside of the furnace between heat treatments. Weight losses( or gains) are attributed to vaporization of the pellet, reaction with gaseous species, or reaction with the container.

The sample number corresponds to the page number in the notebooks where information about that sample begins. 
Table A.1. V-Pd samples.

\begin{tabular}{|c|c|c|c|c|}
\hline \multicolumn{2}{|c|}{ sample materials } & \multirow{2}{*}{$\begin{array}{l}\text { phases } \\
\text { vO/ } \mathrm{N}_{2} \mathrm{O}_{3} / \mathrm{Pd}\end{array}$} & \multirow{2}{*}{$\frac{\% \text { loss }}{1.26}$} & \multirow{2}{*}{$\begin{array}{l}\text { annealing time, } \operatorname{hrs}\left({ }^{\circ} \mathrm{C}\right) \\
48(800), 570(1000)\end{array}$} \\
\hline 213B & Vo/V/Pd & & & \\
\hline 237A & $\mathrm{V}_{2} \mathrm{O}_{3} / \mathrm{N} / \mathrm{Pd}$ & $\mathrm{V}_{2} \mathrm{O} / \mathrm{V}$ & 0.50 & 264(1150), 95(1000) \\
\hline 237B & $\mathrm{VO} / \mathrm{N}_{2} \mathrm{O}_{3} / \mathrm{Pd}$ & VO/Pd & 0.55 & $503(1000)$ \\
\hline 233A & $\mathrm{V}_{2} \mathrm{O}_{3} / \mathrm{Pd}$ & $\mathrm{V}_{2} \mathrm{O}_{3} / \mathrm{V}_{3} \mathrm{O}_{5} / \mathrm{Pd}$ & $>0.71$ & $>128(1000)$ \\
\hline 233B & $\mathrm{V}_{3} \mathrm{O}_{5} / \mathrm{Pd}$ & $\mathrm{V}_{2} \mathrm{O}_{3} / \mathrm{Pd}$ & 20.9 & $240(1000), 95(1200), 72(1000)$ \\
\hline 217B & $\mathrm{V}_{2} \mathrm{O}_{3} / \mathrm{N} / \mathrm{Pd}$ & $\mathrm{V}_{2} \mathrm{O} / \mathrm{VO} / \mathrm{Pd}$ & 0.78 & $594(1000)$ \\
\hline 238B & $\mathrm{V}_{2} \mathrm{O}_{3} / \mathrm{N} / \mathrm{Pd}$ & $\mathrm{V}_{4} \mathrm{O} / \mathrm{V}_{2} \mathrm{O} / \mathrm{Pd}$ & 0.08 & $503(1000)$ \\
\hline 239B & $\mathrm{V}_{2} \mathrm{O}_{3} / \mathrm{V} / \mathrm{Pd}$ & $\mathrm{V}_{2} \mathrm{O} / \mathrm{V}$ & 0.19 & $503(1000)$ \\
\hline $236 A$ & $\mathrm{~V}_{2} \mathrm{O}_{3} / \mathrm{Pd}$ & $\mathrm{V}_{2} \mathrm{O}_{3} / \mathrm{Pd}$ & 2.64 & $168(1050), 128(1000)$ \\
\hline 236B & $\mathrm{V}_{2} \mathrm{O}_{3} / \mathrm{N} / \mathrm{Pd}$ & $\mathrm{V}_{2} \mathrm{O}_{3} / \mathrm{Pd}$ & 9.6 & $168(1050), 95(1200), 72(1000)$ \\
\hline 291A & V/NO/Pd & V/VO/Pd & 0.40 & $336(1050), 128(1000)$ \\
\hline 291B & $\mathrm{VO} / \mathrm{N}_{2} \mathrm{O}_{3} / \mathrm{Pd}$ & $\mathrm{V}_{2} \mathrm{O}_{3} / \mathrm{Pd}$ & 1.0 & $258(1000)$ \\
\hline $292 A$ & $\mathrm{~V}_{2} \mathrm{O}_{3} / \mathrm{Pd}$ & $\mathrm{V}_{2} \mathrm{O}_{3} / \mathrm{V}_{3} \mathrm{O}_{5} / \mathrm{Pd}$ & $>1.57$ & $>90(1000)$ \\
\hline 292B & VO/Pd & $\mathrm{VO} / \mathrm{N}_{2} \mathrm{O}_{3} / \mathrm{Pd}$ & $>0.12$ & $>128(1000)$ \\
\hline 292C & $\mathrm{V}_{5} \mathrm{O}_{9} / \mathrm{Pd}$ & $?$ & 3.64 & $240(1050), 128(1000)$ \\
\hline 293A & $\mathrm{V}_{2} \mathrm{O}_{3} / \mathrm{N} / \mathrm{Pd}$ & $\mathrm{V}_{3} \mathrm{O}_{5} / \mathrm{Pd}$ & 2.73 & $48(800), 392(1000)$ \\
\hline 293B & $\mathrm{V}_{2} \mathrm{O}_{3} / \mathrm{N} / \mathrm{Pd}$ & $\mathrm{V}_{2} \mathrm{O}_{3} / \mathrm{Pd}$ & 1.93 & $48(800), 354(1000)$ \\
\hline $546 \mathrm{~A}$ & $\mathrm{~V} / \mathrm{N}_{2} \mathrm{O}_{4} / \mathrm{Pd}$ & $\mathrm{V}_{2} \mathrm{O}_{3} / \mathrm{Pd}$ & 7.09 & $208(1100), 170(1000)$ \\
\hline 546B & $\mathrm{V} / \mathrm{V}_{2} \mathrm{O}_{3} / \mathrm{Pd}$ & $\mathrm{V}_{2} \mathrm{O}_{3} / \mathrm{Pd}$ & 4.80 & $208(1100), 170(1000)$ \\
\hline
\end{tabular}


Table A.1. V-Pd samples, cont'd.

\begin{tabular}{lllll}
\hline sample materials & phases & \% loss & annealing time, hrs $\left({ }^{\circ} \mathrm{C}\right)$ \\
\hline 546C V/ $\mathrm{V}_{2} \mathrm{O}_{3} / \mathrm{Pd}$ & $\mathrm{V}_{2} \mathrm{O}_{3} / \mathrm{Pd}$ & 4.08 & $208(1100), 170(1000)$ \\
$301 \mathrm{~B}$ & $\mathrm{~V} / \mathrm{C} / \mathrm{Pd}$ & $?$ & -0.01 & $22(1100), 47(1200), 75(1250)$, \\
& & & & $56(1100)$ \\
$470 \mathrm{~A}$ & $\mathrm{~V} / \mathrm{C} / \mathrm{Pd}$ & $\mathrm{V}_{2} \mathrm{C} / \mathrm{VC} / \mathrm{Pd}$ & 0.83 & $42(1100), 76(1000), 94(1000)$ \\
$470 \mathrm{~B}$ & $\mathrm{~V} / \mathrm{C} / \mathrm{Pd}$ & $\mathrm{V}_{2} \mathrm{C} / \mathrm{VC} / \mathrm{Pd}$ & 0.31 & $76(1000), 94(1000)$ \\
$471 \mathrm{~A}$ & $\mathrm{~V} / \mathrm{C} / \mathrm{Pd}$ & $\mathrm{VC} / \mathrm{C} / \mathrm{Pd}$ & 7.62 & $42(1100), 76(1000), 67(1000)$ \\
$471 \mathrm{~B}$ & $\mathrm{~V} / \mathrm{C} / \mathrm{Pd}$ & $\mathrm{VC} / \mathrm{C} / \mathrm{Pd}$ & 2.17 & $76(1000), 67(1000)$
\end{tabular}


Table A.2. V - Rh samples.

sample materials phases $\%$ loss annealing time, hrs $\left({ }^{\circ} \mathrm{C}\right)$

216A

$\mathrm{VO} / \mathrm{N}_{2} \mathrm{O}_{3} / \mathrm{VRh}$

$4.75168(1050), 90(1000)$

$216 \mathrm{~B}$ VO/Rh

$\mathrm{VO} / \mathrm{N}_{2} \mathrm{O}_{3} / \mathrm{NRh}$

0.23

$168(1200), 45(1000)$

297A $\mathrm{V}_{2} \mathrm{O}_{3} / \mathrm{N} / \mathrm{Rh} \quad \mathrm{VO} / \mathrm{V}$

$0.22336(1050), 292(1000)$

297B $\mathrm{V}_{2} \mathrm{O}_{3} / \mathrm{V} / \mathrm{Rh} \quad \mathrm{V}_{4} \mathrm{O} / \mathrm{N}_{2} \mathrm{O} / \mathrm{V}$

$0.18168(1300), 336(1050)$,

292(1000)

297C $\mathrm{V}_{2} \mathrm{O}_{3} / \mathrm{N} / \mathrm{Rh} \quad \mathrm{V}_{2} \mathrm{O} / \mathrm{NO} / \mathrm{V}$

$0.30168(1300), 336(1050)$,

292(1000)

473A $\mathrm{V} / \mathrm{N}_{2} \mathrm{O}_{3} / \mathrm{Rh}$

$\mathrm{V}_{2} \mathrm{O} / \mathrm{NO}$

$0.4424(1150), 166(1100), 113(1000)$

$605 \mathrm{~A} \quad \mathrm{~V} / \mathrm{N}_{2} \mathrm{O}_{3} / \mathrm{Rh}$

$\mathrm{V}_{2} \mathrm{O}_{3} / \mathrm{Rh}$

$0.37100(1200), 21(1100), 65(1000)$

$605 \mathrm{~B} \quad \mathrm{~V} / \mathrm{V}_{2} \mathrm{O}_{3} / \mathrm{Rh}$

$\mathrm{V}_{2} \mathrm{O}_{3} / \mathrm{NRh}_{3}$

$0.11100(1200), 21(1100), 65(1000)$

$301 \mathrm{~A} \mathrm{~V} / \mathrm{C} / \mathrm{Rh}$

$?$

$-1.0822(1100), 47(1200), 101(1250)$,

33(1225), 35(1150), 99(1100),

56(1000)

583A V/C/Rh

$\mathrm{VC} / \mathrm{C} / \mathrm{VRh}_{3}$

$1.0286(1100), 94(1000), 21(1225)$, 12(1175), 12(1075), 26(1000)

$604 A \mathrm{~V} / \mathrm{C} / \mathrm{Rh}$

$\mathrm{V}_{2} \mathrm{C} / \mathrm{VC} / \mathrm{NRh}$

0.45

$100(1200), 21(1100), 65(1000)$ 
Table A.3. V - Ir samples.

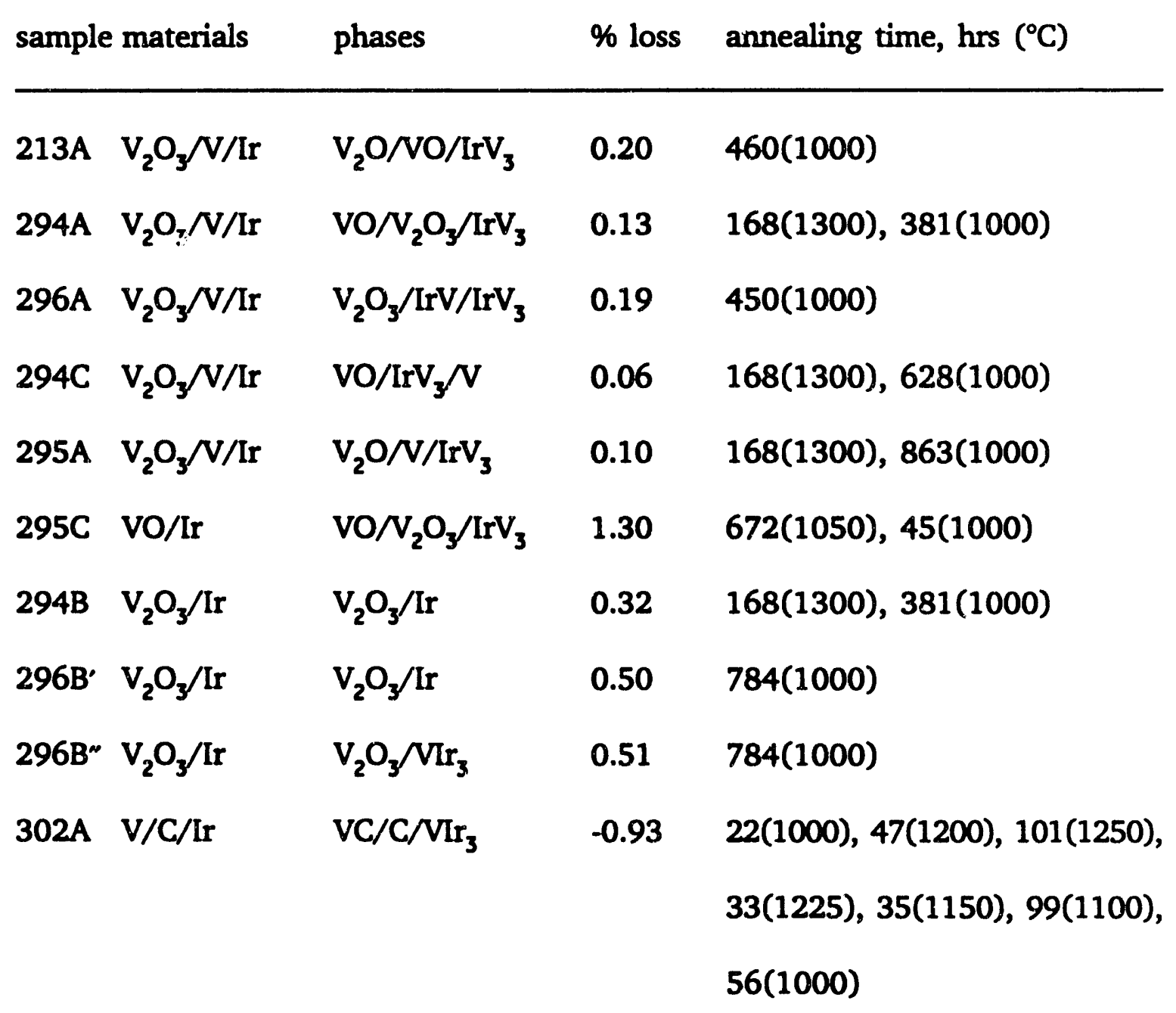

583B V/C/Ir $\quad \mathrm{VC} / \mathrm{C} / \mathrm{VIr}_{3} \quad 0.89 \quad 86(1100), 94(1000), 21(1225)$, 12(1175), 12(1075), 26(1000) 604B V/C/Ir $\quad \mathrm{V}_{2} \mathrm{C} / \mathrm{VC} / \mathrm{V}_{3} \mathrm{Ir} \quad 0.86 \quad 100(1200), 21(1100), 65(1000)$ 
Table A.4. V - Pt samples.

\begin{tabular}{|c|c|c|c|c|}
\hline \multicolumn{2}{|c|}{ sample materials } & \multirow{2}{*}{$\begin{array}{l}\text { phases } \\
\text { VO/PtV/PtV } \\
\text { B }\end{array}$} & \multirow{2}{*}{$\frac{\% \text { loss }}{1.3}$} & \multirow{2}{*}{$\begin{array}{l}\text { annealing time, } \mathrm{hrs}\left({ }^{\circ} \mathrm{C}\right) \\
95(1200), 72(1000)\end{array}$} \\
\hline 214B & $\mathrm{V} / \mathrm{N}_{2} \mathrm{O}_{3} / \mathrm{Pt}$ & & & \\
\hline $214 A$ & $\mathrm{~V} / \mathrm{N}_{2} \mathrm{O}_{3} / \mathrm{Pt}$ & $\mathrm{VO} / \mathrm{N}_{2} \mathrm{O}_{3} / \mathrm{VPt}$ & 1.2 & $95(1200), 72(1000)$ \\
\hline 248B & $\mathrm{V} / \mathrm{N}_{2} \mathrm{O}_{3} / \mathrm{Pt}$ & $\mathrm{VO} / \mathrm{PtV}_{3}$ & 1.6 & 95(1200), 72(1000) \\
\hline $248 A$ & $\mathrm{~V} / \mathrm{N}_{2} \mathrm{O}_{3} / \mathrm{Pt}$ & $\mathrm{V}_{2} \mathrm{O} / \mathrm{NO} / \mathrm{N}_{3} \mathrm{Pt}$ & 2.1 & 95(1200), 72(1000) \\
\hline $128 \mathrm{C}$ & $\mathrm{V}_{2} \mathrm{O}_{3} / \mathrm{VO}_{2} / \mathrm{Pt}$ & $\mathrm{V}_{2} \mathrm{O}_{3} / \mathrm{Pt}$ & 2.13 & $237(1200), 168(1000)$ \\
\hline $128 \mathrm{~B}$ & $\mathrm{~V}_{2} \mathrm{O}_{3} / \mathrm{NO}_{2} / \mathrm{Pt}$ & $\mathrm{V}_{2} \mathrm{O}_{3} / \mathrm{Pt}$ & 1.71 & $237(1200), 168(1000)$ \\
\hline $128 \mathrm{~A}$ & $\mathrm{~V}_{2} \mathrm{O}_{3} / \mathrm{NO}_{2} / \mathrm{Pt}$ & $\mathrm{V}_{2} \mathrm{O}_{3} / \mathrm{NPt}_{3}$ & 0.69 & $237(1200), 168(1000)$ \\
\hline $472 A$ & $\mathrm{~V} / \mathrm{N}_{2} \mathrm{O}_{3} / \mathrm{Pt}$ & $\mathrm{VO} / \mathrm{N}_{2} \mathrm{O}_{3} / \mathrm{Pt}_{3} \mathrm{~V} / \mathrm{Pt}$ & 0.28 & $24(1150), 166(1100), 113(1000)$ \\
\hline 472B & $\mathrm{V} / \mathrm{V}_{2} \mathrm{O}_{3} / \mathrm{Pt}$ & $\mathrm{V}_{4} \mathrm{O} / \mathrm{V}_{2} \mathrm{O} / \mathrm{PtV}_{3}$ & 0.33 & $24(1150), 166(1100), 113(1000)$ \\
\hline $472 C$ & $\mathrm{~V} / \mathrm{N}_{2} \mathrm{O}_{3} / \mathrm{Pt}$ & $\mathrm{V}_{4} \mathrm{O} / \mathrm{N} / \mathrm{PtV}_{3}$ & 0.30 & $24(1150), 166(1100), 113(1000)$ \\
\hline 302B & $\mathrm{V} / \mathrm{C} / \mathrm{Pt}$ & $?$ & -7.53 & $\begin{array}{l}22(1100), 47(1200), 101(1250) \\
33(1225), 35(1150), 99(1100), \\
56(1000)\end{array}$ \\
\hline $582 \mathrm{C}$ & $\mathrm{V} / \mathrm{C} / \mathrm{Pt}$ & $\mathrm{VC} / \mathrm{C} / \mathrm{VPt}_{2}$ & 0.78 & $\begin{array}{l}86(1100), 94(1000), 21(1225), \\
12(1175), 12(1075), 26(1000)\end{array}$ \\
\hline $604 \mathrm{C}$ & $\mathrm{V} / \mathrm{C} / \mathrm{Pt}$ & $\mathrm{V}_{2} \mathrm{C} / \mathrm{VC} / \mathrm{V}_{3} \mathrm{Pt}$ & 0.58 & $100(1200), 21(1100), 65(1000)$ \\
\hline
\end{tabular}


Table A.5. V-Ru samples.

\begin{tabular}{llll} 
sample materials & phases & \% loss & annealing time, hrs $\left({ }^{\circ} \mathrm{C}\right)$ \\
\hline 582A V/C/Ru & VC/C/Ru & 1.09 & $86(1100), 94(1000), 21(1225)$, \\
& & & $12(1175), 12(1075), 26(1000)$
\end{tabular}

Table A.6. V-Os samples.

\begin{tabular}{llll}
\hline sample materials & phases & \% loss & annealing time, hrs $\left({ }^{\circ} \mathrm{C}\right)$ \\
\hline 582B V/C/Os & VC/C/Os & 0.76 & $86(1100), 94(1000), 21(1225)$, \\
& & & $12(1175), 12(1075), 26(1000)$
\end{tabular}

Table A.7. Ta-Pd samples.

\begin{tabular}{lllll}
\hline sample materials & phases & \% loss & annealing time, hrs $\left({ }^{\circ} \mathrm{C}\right)$ \\
\hline $172 \mathrm{~A}$ & $\mathrm{Ta} / \mathrm{Ta}_{2} \mathrm{O}_{5} / \mathrm{Pd}$ & $\mathrm{Ta}_{2} \mathrm{O}_{5} / \mathrm{Ta} / \mathrm{TaPd}$ & 0.13 & $639(1100), 38(1000), 72(1150)$, \\
& & & $218(1000)$ \\
$172 \mathrm{~B}$ & $\mathrm{Ta} / \mathrm{Ta}_{2} \mathrm{O}_{5} / \mathrm{Pd}$ & $\mathrm{Ta}_{2} \mathrm{O}_{5} / \mathrm{TaPd}$ & 0.31 & $639(1100), 38(1000), 72(1150)$, \\
& & & $218(1000)$
\end{tabular}


Table A.8. Zr-Pd samples.

sample materials phases $\%$ loss annealing time, hrs $\left({ }^{\circ} \mathrm{C}\right)$

$173 \mathrm{~A} \quad \mathrm{Zr} / \mathrm{ZrO}_{2} / \mathrm{Pd} \quad \mathrm{ZrO}_{2} / \mathrm{ZrPd} / \mathrm{Zr}_{2} \mathrm{Pd} 0.03 \quad$ 639(1100), 38(1000), 72(1150), 218(1000)

$173 \mathrm{~B} \quad \mathrm{Zr} / \mathrm{ZrO}_{2} / \mathrm{Pd} \quad \mathrm{ZrO}_{2} / \mathrm{ZrPd} \quad 0.07 \quad 639(1100), 38(1000), 72(1150)$, 218(1000)

Table A.9. Hf-Pd samples.

sample materials phases $\quad \%$ loss annealing time, hrs $\left({ }^{\circ} \mathrm{C}\right)$

$174 \mathrm{~A} \mathrm{Hf} / \mathrm{HfO}_{2} / \mathrm{Pd} \quad \mathrm{HfO}_{2} / \mathrm{HfPd} / \mathrm{Hf}_{2} \mathrm{Pd} 0.01 \quad 639(1100), 38(1000), 72(1150)$,

218(1000)

174B $\mathrm{Hf} / \mathrm{HfO}_{2} / \mathrm{Pd} \quad \mathrm{HfO}_{2} / \mathrm{HfPd} \quad 0.04 \quad 639(1100), 38(1000), 72(1150)$, 218(1000) 
Table A.10. Reference electrodes.

\begin{tabular}{lllll}
\hline sample materials & phases & \% loss & annealing time, hrs $\left({ }^{\circ} \mathrm{C}\right)$ \\
\hline $319 \mathrm{~A}$ & $\mathrm{Ta} / \mathrm{Ta}_{2} \mathrm{O}_{5}$ & $\mathrm{Ta} / \mathrm{Ta}_{2} \mathrm{O}_{5}$ & -0.01 & $27(1000)$ \\
$319 \mathrm{~B}$ & $\mathrm{Ta} / \mathrm{Ta}_{2} \mathrm{O}_{5}$ & $\mathrm{Ta}_{\mathrm{Ta}_{2} \mathrm{O}_{5}}$ & 0.00 & $27(1000)$ \\
$319 \mathrm{C}$ & $\mathrm{Ta} / \mathrm{Ta}_{2} \mathrm{O}_{5}$ & $\mathrm{Ta} / \mathrm{Ta}_{2} \mathrm{O}_{5}$ & -0.01 & $27(1000)$ \\
$169 \mathrm{~A}$ & $\mathrm{NbO}_{2} / \mathrm{Nb}_{2} \mathrm{O}_{5}$ & $\mathrm{NbO}_{2}$ & 1.7 & $168(1285), 30(1000)$ \\
$169 \mathrm{~B}$ & $\mathrm{NbO}_{2} / \mathrm{Nb}_{2} \mathrm{O}_{5}$ & $\mathrm{NbO}_{2}$ & 1.4 & $168(1285), 30(1000)$ \\
$169 \mathrm{C}$ & $\mathrm{Ta}_{\mathrm{Ta}_{2} \mathrm{O}_{5}}$ & $\mathrm{Ta}_{\mathrm{Ta}_{2} \mathrm{O}_{5}}$ & 0.70 & $168(1285), 30(1000)$ \\
$169 \mathrm{D}$ & $\mathrm{Zr} / \mathrm{ZrO}_{2}$ & $\mathrm{Zr} / \mathrm{ZrO}_{2}$ & 0.26 & $168(1285), 30(1000)$ \\
$169 \mathrm{E}$ & $\mathrm{Hf} / \mathrm{HfO}_{2}$ & $\mathrm{Hf} / \mathrm{HfO}_{2}$ & 0.40 & $168(1285), 30(1000)$
\end{tabular}




\section{Appendix B}

\section{B.1. Thermodynamics and Assumptions for Solid Phases.}

An important approximation which is used in the calculation of the thermodynamic quantities used here is the assumption that the activity coefficient for solid phases is equal to one. This assumption is not obvious, and in some cases it is a questionable assumption. For phases with a narrow range of stability, this approximation is a good one. For phases with large homogeneity ranges, this approximation may not be reasonable. C. H. P. Lupis has also discussed this topic.[1] A detailed description of this assumption is presented here. Defining the Activity of a Compound

Whereas the activity of an element is a parameter which relates the partial Gibbs energy of an element to the pure element, the activity of a compound relates the Gibbs energy of a compound at some non-stoichiometric composition to the Gibbs energy at a reference composition.

The general relationship between activity and chemical potential for any element is

$$
\mu_{A}=\mu_{A}^{\circ}+R T \ln a_{A}
$$

and it can also be applied to any compound. 


$$
\mu_{A B B b}=\mu_{A \& B b}^{\circ}+R T \ln a_{A \& B b}
$$

$\mathrm{a}$ and $\mathrm{b}$ are the respective amounts of elements $\mathrm{A}$ and $\mathrm{B}$ respectively at the reference composition. The terms $\mu_{A \mathrm{ABb}}$ and $a_{\mathrm{AQBB}}$ correspond to the chemical potential and activity of $\mathrm{AaBb}$ at some composition deviating from the reference composition. At the reference composition,

$$
a_{A \text { ABb }}=1
$$

Using equations B.1 and B.2 a relationship for $\mathrm{a}_{\mathrm{AQBb}}$ can be derived as a function of $a_{A}$ and $a_{B}$ from the balanced reaction of formation.

$$
\begin{aligned}
& a A+b B=A a B b \\
& 0=\mu_{A Q B b}-a \mu_{A}-b \mu_{B} \\
& 0=\mu_{A A B b}^{\circ}-a \mu_{A}^{\circ}-b \mu_{B}^{\circ}+R T \ln \left[a_{A a B b} /\left(a_{A}^{a} a_{B}^{b}\right)\right]
\end{aligned}
$$

since

B.4

$$
\Delta G_{f, A \& B b}^{\circ}=\mu_{A \& B b}^{\circ}-a \mu_{A}^{\circ}-b \mu_{B}^{\circ}
$$

this yields

B.5

$$
R T \ln a_{A}{ }^{\circ} a_{B}^{b}=\Delta G^{\circ}{ }_{f, A a b b}+R T \ln a_{A a B b}
$$

Since $a_{A a B b}$ is $a$ function of the product of $a_{A}{ }^{a}$ and $a_{B}{ }^{b}$ and $a_{A}$ and $a_{B}$ are opposing functions as a function of composition, the product of $a_{A}{ }^{\circ}$ and $a_{B}^{b}$ changes less dramatically as a function of composition than the activity of either chemical component. For this reason the value $a_{\text {A BBb }}$ tends to be a rather slow changing function with respect to composition. As a result, $a_{A a B b}$ can be assumed to be nearly equal to one in many calculations involving solid state equilibria. For small 
deviations from the reference state this is always a good assumption. However, for larger deviations this assumption is questionable and some justification of its use is necessary.

The value of $\mathrm{a}_{\mathrm{ABBb}}$ at a composition of $\mathrm{AxBy}$ corresponds to the adjustment to the Gibbs energy if AxBy is used in thermodynamic calculations as though it were AaBb.

Using Equation B.2 and subtracting the appropriate amounts of the standard state chemical potentials of the elements, the following is obtained.

$$
\mu_{A B B b}-a \mu_{A}^{\circ}-b \mu_{B}^{0}=\mu_{A B B b}^{0}-a \mu_{A}^{0}-b \mu_{B}^{\circ}+R T \ln a_{A B B b}
$$

this yields

$$
\Delta G_{f, A \triangle B b}=\Delta G_{f, A Q B b}^{\circ}+R T \ln a_{A a B b}
$$

Equation B.7 shows how the Gibbs energy of a different composition than the reference composition is related to the reference composition when a non-standard composition is used in thermodynamic calculations.

Vapor pressure and the activity of a compound

Consider the equilibria of $\mathrm{AaBb}$ with a gas of composition $\mathrm{AaBb}$

$$
\mathrm{AaBb}(\mathrm{s})=\mathrm{AaBb}(\mathrm{g})
$$

if the system is in equilibrium, then the following is true

$$
0=\mu_{\text {AQBb(g) }}^{0}-\mu_{\text {ABBb(s) }}^{0}+R T \ln \left[P_{A a B b(g)} / a_{A B B b(s)}\right]
$$

where the approximation

$$
P_{\text {AQBb }}=f_{\text {AQBb }}
$$


is used. Equation B.9 implies that

$$
P_{\text {Aabb(g) }} / a_{\text {Aabb(s) }}=\text { constant }
$$

which then results in the following

$$
a_{A a B b(s)}=P_{A B B b(g)} / P^{*}{ }_{A C B b(g)}
$$

since

$$
\begin{aligned}
& \mathrm{a}^{*}{ }_{\mathrm{AaBb}(\mathrm{s})}=1 ; \text { the activity of } \mathrm{AaBb} \text { at the reference composition } \\
& \mathrm{P}^{*}{ }_{\mathrm{AaBb}(\mathrm{g})}=\text { the partial pressure of } \mathrm{AaBb}(\mathrm{g}) \text { over the compound } \mathrm{AaBb}
\end{aligned}
$$

at the reference composition.

In some cases the vapor species will not be the same in composition as the reference state composition of the solid. The example of $\mathrm{V}_{2} \mathrm{O}_{3}(\mathrm{~s})$ will be used to show how this case can be dealt with.

$$
\begin{aligned}
& \mathrm{V}_{2} \mathrm{O}_{3}(\mathrm{~s})=\mathrm{VO}(\mathrm{g})+\mathrm{VO}_{2}(\mathrm{~g}) \\
& 0=\mu_{\mathrm{VO}(g)}^{\circ}+\mu_{\mathrm{VO2}(g)}^{\circ}-\mu_{\mathrm{V203}(\mathrm{s})}^{\circ}+\mathrm{RT} \ln \left[\mathrm{P}_{\mathrm{VO}(g)}, \mathrm{P}_{\mathrm{VO2}(g)} / \mathrm{a}_{\mathrm{V203}(\mathrm{s})}\right]
\end{aligned}
$$

which implies that

B.14

$$
\left[\mathrm{P}_{\text {vo(g) }} \mathrm{P}_{\text {vo2(g) }}\right] / \mathrm{a}_{\text {v203(s) }}=\text { constant }
$$

which results in the following

$$
a_{\text {v203(s) }}=\left[P_{\text {vo(g) }} / P_{\text {vo(g) }}^{*}\right]\left[P_{\text {vo2 (g) }} / P_{\text {v02(g) }}^{*}\right]
$$

since

$$
\begin{aligned}
& \mathrm{a}^{*}{ }_{\mathrm{v} 203(\mathrm{~s})}=1 \text {; the activity of } \mathrm{V}_{2} \mathrm{O}_{3} \text { at the reference composition } \\
& \mathrm{P}^{*}{ }_{\text {vo(g) }} \text { and } \mathrm{P}^{*}{ }_{\text {Vo2(g) }} \text { are the respective partial pressures of } \mathrm{VO}(\mathrm{g}) \text { and }
\end{aligned}
$$
$\mathrm{VO}_{2}(\mathrm{~g})$ over $\mathrm{V}_{2} \mathrm{O}_{3}$ at the reference composition. 


\section{B.2 The Lower Vanadium Oxides: Accuracy of Assumptions.}

For $\mathrm{V}_{4} \mathrm{O}, \mathrm{V}_{2} \mathrm{O}$, and $\mathrm{VO}$ there are considerable ranges of homogeneity. At $1000^{\circ} \mathrm{C}, \mathrm{V}_{4} \mathrm{O}$ ranges form 10.3 to 26.1 atomic percent oxygen, $\mathrm{V}_{2} \mathrm{O}$ ranges from 31.7 to 34.1 atomic percent oxygen, and vo ranges from 47.2 to 56.7 atomic percent oxygen.[2] For the V-O system there are some data on the gaseous species in equilibrium with the solid. Table B.2 depicts the partial pressures of $\mathrm{V}(\mathrm{g})$, $\mathrm{VO}(\mathrm{g})$, and $\mathrm{VO}_{2}(\mathrm{~g})$ over various compositions of the vanadium oxides at 1900K. At this temperature $\mathrm{V}_{4} \mathrm{O}$ and $\mathrm{V}_{2} \mathrm{O}$ are unstable. The assumption of unit activity is least reasonable for the $\mathrm{VO}(\mathrm{s})$ phase since it has the largest range of homogeneity. As can be seen from the point where $\mathrm{V}(\mathrm{s})$ is in equilibrium with $V O(s)$ and the point near the ideal stoirhiometry of $V O(s)$ the partial pressure of $\mathrm{VO}(\mathrm{g})$ varies little. The assumption of unit activity for the $V O(s)$ phase is reasonable at the oxygen deficient phase boundary. At the oxygen rich phase boundary there is a significant change in the partial pressure of VOig) in equilibrium with $\mathrm{VO}(\mathrm{s})$. Consequently, the assumption of unit activity at this point is less valid. The result will be that the activity calculated for this point will be a little bit in error. 
Table B.1. Reported partial pressures of aseous species at 1900K.[3-6]

\begin{tabular}{|c|c|c|c|c|}
\hline$x_{0}$ & $V(g)$ & $\begin{array}{l}-\log P(\mathrm{~atm}) \\
\mathrm{VO}(\mathrm{g})\end{array}$ & $\operatorname{VO} 2(g)$ & activity \\
\hline & & & & $\underline{\mathbf{a}}_{\mathbf{v}}$ \\
\hline (V) 0.001 & $5.98 \pm 0.58$ & $7.73 \pm 0.91$ & & 1.0 \\
\hline (v) 0.034 & $5.97 \pm 0.44$ & $6.57 \pm 0.54$ & & 1.0 \\
\hline (V) 0.057 & $5.98 \pm 0.33$ & $6.38 \pm 0.58$ & & 1.0 \\
\hline (v) 0.077 & $5.93 \pm 0.44$ & $6.17 \pm 0.69$ & & 1.1 \\
\hline (v) 0.127 & $5.98 \pm 0.45$ & $5.77 \pm 0.58$ & & 1.0 \\
\hline$(v)+(v 0)$ & 6.11 & 5.66 & & 0.7 \\
\hline$(v)+(v O)$ & $6.11 \pm 0.25$ & $5.66 \pm 0.29$ & & $\begin{array}{l}\mathrm{a}_{\mathbf{v}} \\
0.9\end{array}$ \\
\hline (vo)0.505 & $6.03 \pm 0.29$ & $5.62 \pm 0.29$ & & 1.0 \\
\hline \multirow[t]{2}{*}{$(\mathrm{VO})+\left(\mathrm{V}_{2} \mathrm{O}_{3}\right)$} & $6.58 \pm 0.52$ & $6.07 \pm 0.40$ & 6.91 & 0.4 \\
\hline & & & & $\underline{a}_{\sqrt{203}}$ \\
\hline$(\mathrm{VO})+\left(\mathrm{V}_{2} \mathrm{O}_{3}\right)$ & 6.58 & 6.07 & 6.91 & 0.3 \\
\hline$\left(\mathrm{V}_{2} \mathrm{O}_{3}\right) 0.5996$ & & 6.23 & 6.23 & 1.0 \\
\hline$\left(\mathrm{V}_{2} \mathrm{O}_{3}\right) 0.6032$ & & 6.25 & 6.14 & 1.2 \\
\hline$\left(\mathrm{VO}_{2}\right) 0.6710$ & & & 3.91 & \\
\hline
\end{tabular}

Table B.1 shows the data reported for the gasenus equilibrium of oxides in equilibrium with the solids. These values are from W. Banchorndhevakul, et al.[36] The data show a significant deviation of $a_{\text {vo(s) }}$ when in equilibrium with $\mathrm{V}_{2} \mathrm{O}_{3}(\mathrm{~s})$ and $\mathrm{a}_{\mathrm{vzos}(\mathrm{s})}$ when in equilibrium with VO(s). The activity of these two points being 0.4 and 0.3 respectively. There is however a considerable error in these poinis. The assumption of unit activity results in about a $\pm 30 \mathrm{mV}$ error in the calculated EMF for $\mathrm{VO}$ and $\mathrm{V}_{2} \mathrm{O}_{3}$ and about \pm 0.5 error in $-\log \gamma_{\mathrm{v}}$ for vO $/ \mathrm{N}_{2} \mathrm{O}_{3}$ equilibrium. 


\section{References}

1. C. H. P. Lupis, Chemical Thermodynamics of Materials, Elsevier Science Publishing, New York, 339-343 (1983).

2. H. A. Wreidt, "The O-V(Oxygen-Vanadium) System," Bull. Alloy Phase Diag., 10(3), 271-277 (1989).

3. W. Banchorndhevakul, T. Matsui, and K. Naito, "Vaporization Study on Vanadium Monoxide and Two-Phase Mixture of Vanadium and Vanadium Monoxide by Mass-Spectroscopic Method," J. Nucl. Sci. Technol., 23(7), 602611 (1986).

4. W. Banchorndhevakul, T. Matsui, and K. Naito, "Vaporization Study on Vanadium-Oxygen Solid Solution by Mass Spectroscopic Method," J. Nucl. Sci. Technol., 23(10), 873-882 (1986).

5. W. Banchorndhevakul, T. Matsui, and K. Naito, "Vaporization Study on $\mathrm{V}_{2} \mathrm{O}_{3}$ and Two-Phase Mixture of $\mathrm{V}_{2} \mathrm{O}_{3}$ and Vo by Mass Spectroscopic Method," Thermochimica Acta, 88, 301-306 (1985).

6. T. Masui and K. Naito, "Thermodynamic Properties of the Phases in the VO and Nb-O Systems at High Temperature," Netsu Sokutei, 15(1), 27-41 (1988). 


\section{Appendix C}

\section{C.1. Apparati Descriptions.}

Every operation that a sample undergoes can affect its integrity. Consequently, the conditions of sample preparation and analysis are of importance in an overall assessment of the accuracy of experimental data. Therefore, some of the relevant specifications of the instruments used for sample preparation and analysis are given in this appendix.

\section{C.2. The Thoria Furnace.}

The thoria furnace is a high-temperature vacuum furnace. It was originally designed for sintering yttria doped thoria pellets. It is also used for equilibrating oxide-alloy and carbide-alloy composites. Quenching at the end of heat treatment was achieved by turning off the furnace power. If the furnace was shut off when under vacuum at $1000^{\circ} \mathrm{C}$, the following quench rate was observed: $800^{\circ} \mathrm{C}$ was reached in less than 3 minutes, $600^{\circ} \mathrm{C}$ in less than 15 minutes, and $400^{\circ} \mathrm{C}$ in less than an hour. This furnace can be backfilled with gases such as helium and hydrogen at high-temperatures. 
Temperature measurement by

optical pyrometer: Pyrometer Instrument Co., NJ, No. 96

thermocouple: Pt-Pt(10\%Rh)

Operating parameters

Maximum operating temperature: $2300^{\circ} \mathrm{C}$

Optical pyrometer accuracy: $\pm 20^{\circ} \mathrm{C}$

Thermocouple accuracy: $\pm 5^{\circ} \mathrm{C}$

Temperature fluxuation: $\pm 20^{\circ} \mathrm{C}$

Vacuum: $<10^{-5}$ torr

\section{C.3. The Hot Press.}

The hot press is a vacuum furnace in which a graphite die is insertable. The primary purpose of this instrument is to sinter and densify our alloy-oxide or alloy-carbide composites. Hot pressing insures good contact between the alloy grains and the oxide or carbide grains. Samples are typically hot pressed in a $1 / 2^{\prime \prime}$ graphite die in which the sample is incased in boron-nitride powder.

\section{Operating Parameters}

Maximum operating temperature: $1700^{\circ} \mathrm{C}$

Optical pyrometer accuracy: $\pm 30^{\circ} \mathrm{C}$

Applied pressure capability: 350 lbs - 2000 lbs

Vacuum: $<10^{-4}$ torr 
Temperature measurement by

optical pyrometer: Leeds \& Northrop Co., No. 8632-C

\section{C.4. The Brew Annealing Furnace.}

The annealing furnace is our secondary vacuum furnace. It has a lower temperature capability than the thoria furnace, but it is has been more reliable for temperature measurement. Like the thoria furnace, quenching after heat treatment was achieved by turning off the furnace power. The quenching rate for this instrument is nearly the same as that for the thoria furnace.

Temperature measurement by

thermocouple: Pt-Pt(10\%Rh)

Operating Parameters

Maximum operating temperature: $1400^{\circ} \mathrm{C}$

Thermocouple accuracy: $\pm 2^{\circ} \mathrm{C}$

Temperature fluxuation: $\pm 5^{\circ} \mathrm{C}$

Vacuum: $<10^{-5}$ torr

\section{C.5. High-Temperature Galvanic Cell.}

The galvanic cell is composed of a number of components. The primary components and related specifications are mentioned here. Refer to Figures 4.4 
and 4.6 to see how each of the components listed fits into the configuration and operation of the apparatus.

Instrument components

Main furnace: Lindberg 3 zone resistance heating furnace, type 54357

Tube material in main furnace: Inconel 601

Tube material in gettering furnace: Inconel 601

Temperature measurement by thermocouple: $\mathrm{Pt}-\mathrm{Pt}(10 \% \mathrm{Rh})$

EMF measurement by: Keithley $610 \mathrm{C}$ voltmeter with input impeadance greater than $10^{14}$ ohms. Also the $0-1 \mathrm{~mA}$ output in back is modified to $\pm 1 \mathrm{~V}$. Data Acquisition Control by: IBM PC with data acquisition cards

Data Acquisition Cards from: MetraByte Corporation as follows

DAS08: 8 channel 12 bit analog to digital converter

DAC02: 2 channel 12 bit digital to analog converter

EXP16: converts 1 AVD channel into a port for 16 thermocouples

STA08: terminal accessory card with $\pm 1 \mathrm{~V}$ to $\pm 5 \mathrm{~V}$ amplifier installed

Operating Parameters

Maximum operating temperature: $1250^{\circ} \mathrm{C}$

Thermocouple accuracy: $\pm 1^{\circ} \mathrm{C}$ EMF accuracy: $\pm 1 \mathrm{mV}$

Temperature fluxuation: $\pm 2^{\circ} \mathrm{C}$ Applied voltage accuracy: $\pm 1 \mathrm{mV}$ 


\section{C.6. The X-Ray Diffractometer.}

The X-ray diffractometer used is a Siemens model D500 with an enclosed beam which is designed for powder diffraction. Siemens Diffrac-11 software for the PC was used to automate the instrument and to process the data to obtain d spacings and intensities. The $2 \theta$ value operates in discrete steps down to a step size of $0.002^{\circ}$. For these experiments $\mathrm{Cu} \mathrm{K}_{\alpha 1,2} \mathrm{X}$-ray source was used which was operated at $40 \mathrm{KV}$ and $30 \mathrm{~mA}$. Typical parameters for diffraction were $2 \theta$ start $=10^{\circ}, 2 \theta$ end $=110^{\circ}$, step size $=0.1^{\circ}$, time $/$ step $=1 \mathrm{sec}$.

Normally the solid pellet surface of the composite was X-rayed rather than grinding the sample to obtain a powder pattern. Because of this the relative intensity measurements are out of proportion. Regardless, most phases are still easy to identify. The extra effort to grind up these samples is in most cases an unwarranted effort. This is also fortunate because some samples are so hard and tough that grinding the sample to a powder is a difficult project.

To identify phases in analyzed samples, the JCPDS X-ray powder diffraction file is used. For any phases not listed in JCPDS, the possible patterns are calculated from lattice constants and structure factors using a program written by Jeff Bierach.[1] 


\section{C.7. The Electron Microprobe.}

Most of the compositional analysis of the composite samples was performed on an ARL SEMQ wavelength dispersive electron beam micro-probe. The apparatus is equipped with 8 channels, four are fixed( $\mathrm{Si}, \mathrm{Fe}, \mathrm{Ca}, \mathrm{Al})$ and four are tunable. Since the four fixed elements are usually not of interest in our analyses, only four elements could be detected in each composite at a time. Before use in the instrument, samples are polished in 1" mounts in steps down to $1 / 4$ micron diamond paste. The mounts are then carbon coated with $99.999 \%$ pure graphite 200-250 angstroms thick.

\section{Operating parameters}

Operating voltage: $15 \mathrm{KeV}$

Sample current: $\sim 30$ nano-amps

Counting time: $10 \mathrm{sec}($ or $20 \mathrm{sec})$

Take off angle: $52.5^{\circ}$

\section{Data analysis}

The raw counts are adjusted for background and ZAF corrections. The Background corrections are based on the mean atomic number method. Elements used for backgrounds and standards normally exceed $99.99 \%$ purity. The ZAF corrections are from the CITZAF FORTRAN library compiled by John Armstrong[2]. The instrument operation, data collection, and data analysis is interfaced with a PC program written by John Donovan[3]. 
Accuracy of analysis

Compositional accuracy: \pm 1 mole $\%$

Compositional reproducibility: \pm 0.2 mole $\%$

\section{C.8. The Scanning Electron Microscope.}

The scanning electron microscope used is an ISI model WB6. The energy dispersive X-ray analysis available on the SEM is also used for obtaining alloy compositions in the V-Os, V-Ru, and three V-Pd samples(546A-546C). All other sample compositions were obtained from microprobe analysis. The instrument is operated and data analyzed using the EG\&G Ortec System 5000 software. Compositional analysis was standardless but included background corrections and ZAF corrections.

Operating parameters

Accelerating voltage: $20 \mathrm{kV}$

Counting time: $-5 \mathrm{~min}$

Data analysis

accuracy: \pm 2 mole percent

reproducibility: \pm 0.5 mole percent 
References

1. J. W. Bierach, "The Formation of Barium Titanate Ceramics by Solid State Reaction," Masters Thesis, U. C. Berkeley (1988).

2. J. T. Armstrong, "Quantitative Analysis of Silicates and Oxide Minerals: Comparison of Monte-Carlo, ZAF and Phi-Rho-Z Procedures," Microbeam Analysis (1988).

3. J. J. Donovan and Mark L. Rivers, "PRSUPR: A PC Based Automation and Data Reduction Software Package for Wavelength Dispersive Electron Beam Micro-Analysis," Proceedings of the XIIth International Congress for Electron Microscopy (1990). 


\section{Appendix D}

\section{D.1. Equilibration Time versus Diffusion Rate.}

In equilibration techniques, the problem of obtaining thermodynamic equilibrium throughout a defined system is always of concern. During the annealing process of the ceramic-alloy composite, there is interdiffusion of the constituent elements. Mass transfer occurs between all phases until equilibrium is reached. The primary question of concern for these alloy/ceramic composites is how long must each sample be annealed such that it is, for analytical purposes, in equilibrium? To estimate the equilibration times necessary, the interdiffusion coefficients and the average particles sizes of the constituents must be known. Generally we test samples for equilibration after each annealing according to the method outlined in chapter 4 . There are some data available on the interdiffusion of vanadium in rhodium and on the interdiffusion of vanadium in palladium. $[1,2]$ From these data, a worst case scenario for the equilibration time can be calculated for these systems. Of the other alloy systems reviewed in this thesis, only data on the interdiffusion of niobium in palladium and tantalum in palladium are also available. $[3,4]$ 
Table D.1. The Interdiffusion Coefficient of Vanadium and Rhodium.

\begin{tabular}{lll}
\hline mole percent $V$ & $\mathrm{D}\left(\mathrm{cm}^{2} / \mathrm{s}\right)$ at $1000^{\circ} \mathrm{C}$ \\
\hline 70 & $\left(\mathrm{~V}_{3} \mathrm{Rh}\right)$ & $5.45 \mathrm{E}-12$ \\
50 & $(\mathrm{VRh})$ & $4.10 \mathrm{E}-12$ \\
45 & $\left(\alpha_{1}\right)$ & $3.85 \mathrm{E}-12$ \\
30 & $\left(\mathrm{VRh}_{3}\right)$ & $4.89 \mathrm{E}-12$
\end{tabular}

Table D.2 The Interdiffusion Coefficient of Vanadium and Palladium

\begin{tabular}{lll}
\hline mole percent $V$ & $D\left(\mathrm{~cm}^{2} / \mathrm{s}\right)$ at $1000^{\circ} \mathrm{C}$ \\
\hline 10 & (Pd) & $4.19 \mathrm{E}-10$ \\
20 & (Pd) & $5.56 \mathrm{E}-11$ \\
25 & (Pd) & $4.16 \mathrm{E}-11$ \\
30 & (Pd) & $4.23 \mathrm{E}-11$ \\
33.3 & (Pd) & $2.72 \mathrm{E}-11$ \\
40 & (Pd) & $2.87 \mathrm{E}-11$ \\
70 & (V) & $2.11 \mathrm{E}-09$ \\
75 & (V) & $3.86 \mathrm{E}-10$ \\
80 & (V) & $1.11 \mathrm{E}-10$ \\
85 & (V) & $2.81 \mathrm{E}-11$
\end{tabular}

Table D.1 lists the interdiffusion coefficients for vanadium in rhodium at $1000^{\circ} \mathrm{C}$, and Table D.2 lists the interdiffusion coefficients for vanadium in palladium at $1000^{\circ} \mathrm{C}$. For the V-Rh-O system and the V-Pd-O system the interdiffusion of V-Rh and V-Pd are normally the rate limiting step toward equilibration. Likewise, in the V-Rh-C system and the V-Pd-C system, the 
interdiffusion of V-Rh and V-Pd are the rate limiting steps. The interdiffusion of oxygen or carbon throughout the sample is much more rapid primarily due to its size and mass, and it is not normally the rate limiting step toward equilibrium in the composites.

\section{D.2. Estimation of Equilibration Time}

To estimate the equilibration time we will assume that the interdiffusion of V-Pd and V-Rh are the rate limiting steps toward equilibration in each of their respective systems. In each system, there will be vanadiurn particles, vanadium oxide particles, and noble metals particles. If all particles are randomly distributed, a reasonable starting configuration to consider would be a vanadium particle that is surrounded by a noble metal particles or a noble metal particle that is surrounded by vanadium particles. In other words, we ignore the equilibration with $\mathrm{V}_{2} \mathrm{O}_{3}$. For the applicable starting materials commonly used, the average particle size is given in Table D.3.

Table D.3. Average Particle Sizes of Some Starting Materials.

\begin{tabular}{lll} 
material & mesh & average particle size \\
\hline $\mathrm{V}$ & -325 & $<42 \mu \mathrm{m}$ \\
$\mathrm{Pd}$ & & $<1 \mu \mathrm{m}$ \\
$\mathrm{Rh}$ & -400 & $<35 \mu \mathrm{m}$ \\
$\mathrm{V}_{2} \mathrm{O}_{3}$ & -325 & $<42 \mu \mathrm{m}$
\end{tabular}


As a simplification of the starting configurations of these composites, consider an infinitely long rod of material $A$ in which a short section of the rod is replaced with component $B$, where $R$ is the radius of particle $B$. This configuration is depicted in Figure D.1. From this initial configuration, the equilibration time can be estimated. The interdiffusion as a function of time is given by Fick's law.

Fick's law states

D.1

$$
\partial \mathrm{X}_{\mathrm{b}} / \partial \mathrm{t}=\mathrm{D} \partial^{2} \mathrm{X}_{\mathrm{b}} / \partial \mathrm{x}_{2}
$$

Given the following initial conditions

$$
X_{B}(x, 0)=1 \text { when }|x|<R \text { and } X_{B}(x, 0)=0 \text { when }|x| \geq R
$$

and given the following boundary conditions

$$
\mathrm{X}_{\mathrm{B}}(-\infty, \mathrm{t})=0 \text { and } \mathrm{X}_{\mathrm{B}}(+\infty, \mathrm{t})=0
$$

yields

$$
X_{B}(x, t)=1 / 2\left[\operatorname{erf}\left((x+R) / 2(t D)^{1 / 2}\right)-\operatorname{erf}\left((x-R) / 2(t D)^{1 / 2}\right)\right]
$$

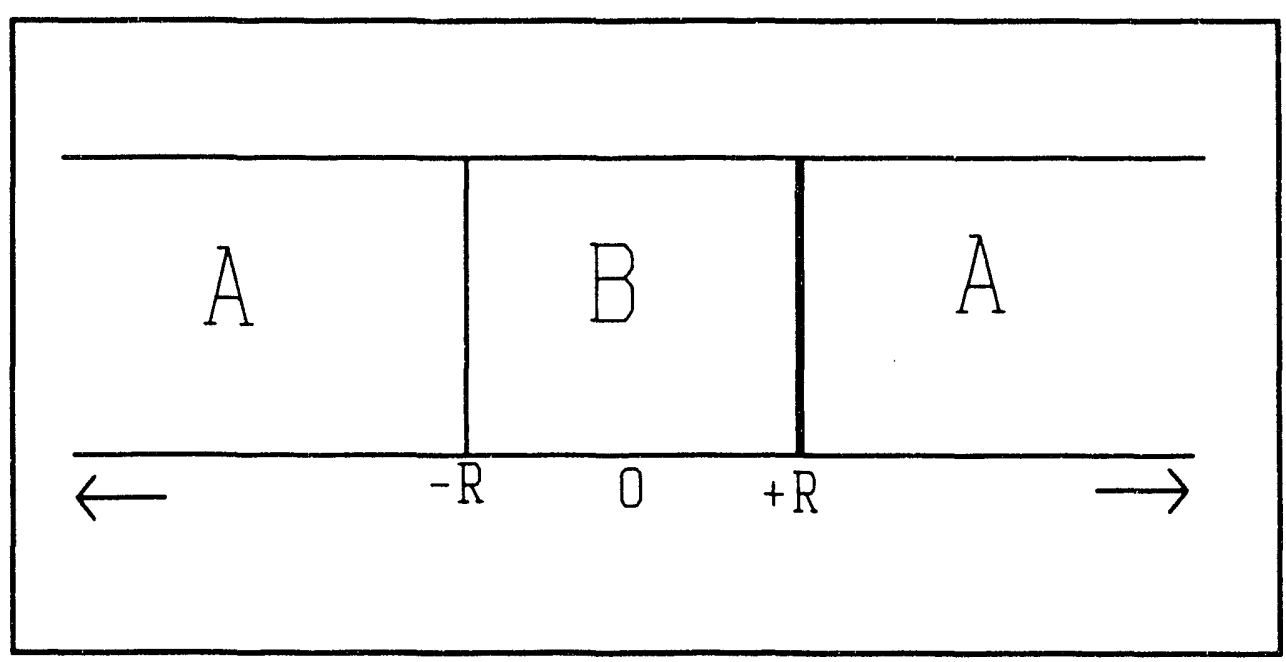

Figure D.1. A schematic of the initial configuration considered for estimating equilibration times. 
$\underline{\mathbf{V}-\mathrm{Rh}}$

For the V-Rh system the limiting diffusion coefficient is about $3.85 \mathrm{E}-12$ $\mathrm{cm}^{2} / \mathrm{s}$ which occurs in the vanadium rich alloys. Since the size of the vanadium particle is about $42 \mu \mathrm{m}$ and that of the rhodium is about $35 \mu \mathrm{m}$, it would seem that the best approximation would be to let $A$ be rhodium and $B$ be vanadium in Figure D.1. However, these samples are also largely composed of vanadium oxides and the vanadium particles will be reacting with the oxides which will deplete their size during equilibration. In this system, perhaps the more realistic approximation would be to let $\mathrm{Rh}$ be the center particle and to let $\mathrm{V}$ be the surrounding particles. Nevertheless, both configurations are presented in Table D.4 since the equilibration time is also a large function of the final composition desired.

Table D.5. Some Estimated Equilibration Times in the V-Rh System. limiting diffusion coefficient $D=5.45 E-12 \mathrm{~cm}^{2} / \mathrm{s}$

$R_{v}=21.0 \mu \mathrm{m} \quad R_{\text {Rh }}=17.5 \mu \mathrm{m}$

\begin{tabular}{lll}
\hline$X_{v}$ & $B=V$ & $B=R h$ \\
\hline 10 & $594 d$ & $2.40 d$ \\
30 & $63.1 d$ & $6.06 d$ \\
40 & $34.1 d$ & $9.18 d$ \\
50 & $20.6 d$ & $14.3 d$ \\
70 & $8.72 d$ & $43.8 d$ \\
90 & $3.46 d$ & $412 d$
\end{tabular}


For the V-Rh-O systems, $20-30$ days at $1000^{\circ} \mathrm{C}$ is a reasonable equilibration time based on Table D.4. Note that the times given using $\mathrm{V}$ as the center particle are overestimated because the $\mathrm{V}$ particle will be interacting with the $\mathrm{V}_{2} \mathrm{O}_{3}$ particles as well as the $\mathrm{Rh}$ particles.

V-Pd

For the V-Pd system the limiting diffusion coefficient is about 2.72E-11 $\mathrm{cm}^{2} / \mathrm{s}$ which is also at the vanadium rich end. The small size of the palladium particles as given in Table D.3 would suggest that diffusion of vanadium into palladium is not the rate limiting step toward equilibration. In this system, the vanadium particles are so much larger that the equilibration will be fixed by the time for palladium to diffuse into vanadium. The time for the center of the particle to reach various compositions of alloy is given in Table D.5. Note that in both Table D.4 and D.5 the times are estimated using the rate limiting diffusion coefficient for the alloy system and ignoring time effects due to phase nucleation or miscibility gaps. In addition, the palladium particles are considerably smaller that the $\mathrm{Rh}$ and $\mathrm{V}_{2} \mathrm{O}_{3}$ particles. If $\mathrm{Pd}$ was surrounded by $4 \mathrm{~V}$ particles, the resulting tetrahedron would allow for a cluster of Pd particles of up to $17.4 \mu \mathrm{m}$ in diameter. This is the value for the Pd particles size used since the Pd particles are likely to agglomerate in the holes. 
Table D.5. Some Estimated Equilibration Times in the V-Pd System. limiting diffusion coefficient $D=2.81 \mathrm{E}-11 \mathrm{~cm}^{2} / \mathrm{s}$

\begin{tabular}{lll}
$\mathrm{R}_{\mathrm{v}}=21.0 \mu \mathrm{m}$ & $\mathrm{R}_{\mathrm{Pd}}=8.7 \mu \mathrm{m}$ \\
\hline $\mathrm{X}_{\mathrm{v}}$ & $\mathrm{B}=\mathrm{V}$ & $\mathrm{B}=\mathrm{Pd}$ \\
\hline 10 & $115 \mathrm{~d}$ & $0.12 \mathrm{~d}$ \\
20 & $28.3 \mathrm{~d}$ & $0.17 \mathrm{~d}$ \\
30 & $12.2 \mathrm{~d}$ & $0.29 \mathrm{~d}$ \\
40 & $6.61 \mathrm{~d}$ & $0.44 \mathrm{~d}$ \\
50 & $3.99 \mathrm{~d}$ & $0.69 \mathrm{~d}$ \\
80 & $1.11 \mathrm{~d}$ & $4.86 \mathrm{~d}$ \\
90 & $0.67 \mathrm{~d}$ & $19.8 \mathrm{~d}$
\end{tabular}

For the V-Pd-O system, 4-7 days is a reasonable equilibration time at $1000^{\circ} \mathrm{C}$ base on Table D.5.

The necessary equilibration times as calculated here are consistent with the equilibration times that were necessary in our experiments as can be seen in Appendix A. The V-Pd samples indeed equilibrate faster than the V-Rh samples. For the V-Rh system, annealing at $1000^{\circ} \mathrm{C}$ requires annealing times which are impractically long. Consequently, for this system and others, like V-Pt or V-Ir, the samples are heat treated at a higher temperature usually around $1300^{\circ} \mathrm{C}$ first. They are then equilibrated a few days at $1000^{\circ} \mathrm{C}$ for the final heat treatment. This combination of steps shortens the net equilibration time to under two weeks which is considered a reasonable equilibration time. 


\section{References}

1. O. V. Aksenova, O. V. Arkhangel'skaya, V. B. Bernnard, V. V. Kurprina, "Study of Kinetic and Diffusional Characteristics in Bimetalic RhodiumVanadium Combinations," Vestnik Moskouskogo Universitet Khimiia, 28(3),268271 (1987) (Russian).

2. P. Lamparter, T. Krabichler, S. Steeb,"Diffusion in the system PalladiumVanadium by means of an Electron Microprobe," Z. Naturforsch, 27A, 960965 (1972) (German).

3. A. Brunsch and S. Steeb, "Diffusion in the System Niobium-Palladium by means of an electron Microprobe," Z. Metalkunde, 62, 247-251 (1971) (German).

4. A. Brunsch and S. Steeb, "Diffusion in the System Pd-Ta by Means of an Electron Microprobe," Z. Naturforsch., 26A, 274-279 (1971) (German).

5. C. Wagner, "The Evaluation of Data Obtained with Diffusion Couples of Binary Single-Phase and Multi-Phase Systems," Acta Metall., 17, 99-107 (1969).

6. W. Jost, Diffusion in Solids, Liquids, Gasses, Academic Press Inc., NY, NY (1965). 


\section{Appendix E}

\section{E.1 The Giauque Punction}

The Giauque function is a convenient function to use in conjunction with the enthalpy of formation at $298 \mathrm{~K}$ to yield the Gibbs free energy.

The variation of enthalpy and entropy as a function of temperature are given in Equations E.1 and E.2 respectively.

$$
S_{T}=S_{298}+{ }_{298}{ }^{T} C_{P} / T d T
$$

E.2

$$
\mathrm{H}_{\mathrm{T}}=\mathrm{H}_{298}+{ }_{298} \int^{\mathrm{T}} \mathrm{C}_{\mathrm{p}} \mathrm{dT}
$$

Since the free energy is related to the entropy and the enthalpy by the following relation

$$
G_{T}=H_{T}-T S_{T}
$$

and for the standard state, usually the pure substance, this becomes

$$
\mathrm{G}_{\mathrm{T}}^{\circ}=\mathrm{H}_{\mathrm{T}}^{\circ}-\mathrm{TS}_{\mathrm{T}}^{\circ}
$$

then E.1 and E.2 can be substituted to give a relationship for the Gibbs free energy as a function of the entropy and enthalpy at $298 \mathrm{~K}$ and the heat capacity as a function of temperature. Then by rearranging the expression Equation E.5 is obtained.

E.5 $\quad-\left(G_{T}^{\circ}-H_{298}^{\circ}\right) / R T=S_{298}^{\circ}+{ }_{298}{ }^{T} C_{P}^{\circ} / T d T-1 / T{ }_{298} \int^{T} C_{p}^{\circ} d T$ 
Equation E.4 is the Giauque function. The contribution to the heat capacity from the enthalpy and entropy terms are in opposite directions. Consequently, they largely cancel each other out. This results in a function which changes slower as a function of temperature than either the entropy or the enthalpy constituents.

Consequently, the Giauque function is an easier function to fit than the enthalpy or the entropy. Usually the Giauque function is easily fit by a cubic or quartic polynomial. 


\section{Appendix F}

\section{F.1. Starting Materials.}

\begin{tabular}{|c|c|c|c|}
\hline material & supplier & purity & form/size \\
\hline $\mathbf{V}$ & Cerac/PURE & 99.5 & powder -325 mesh \\
\hline C & Cerac/PURE & $99.99+$ & powder \\
\hline $\mathrm{Ru}$ & Alfa Division & 99.9 & powder -80 mesh \\
\hline Os & Engelhard & & powder -200 mesh \\
\hline Pt & Aesar & 99.99 & powder $1.4 \mu \mathrm{m}$ \\
\hline Rh & Alfa Products & 99.95 & powder -400 mesh \\
\hline Ir & Orion Chemical Co. & 99.9 & powder -400 mesh \\
\hline Pt & & $99.5+$ & powder $-200+400$ mesh \\
\hline Ir & Orion Chemical Co. & 99.9 & powder -325 mesh \\
\hline VO & Cerac/PURE & 99.5 & powder -100 mesh \\
\hline $\mathrm{V}_{2} \mathrm{O}_{5}$ & Cerac/PURE & 99.5 & powder -325 mesh \\
\hline $\mathrm{V}_{2} \mathrm{O}_{3}$ & Cerac/PURE & 99.5 & powder -200 mesh \\
\hline $\mathrm{Pd}$ & Aesar & 99.9 & $0.4-0.5 \mu \mathrm{m}$ \\
\hline $\mathrm{NbO}$ & Cerac/PURE & 99.8 & powder -100 mesh \\
\hline
\end{tabular}


F.1. Starting Materials, contd.

\begin{tabular}{llll}
\hline material & supplier & purity & form/size \\
\hline $\mathrm{NbO}_{2}$ & Cerac/PURE & 99.9 & powder -200 mesh \\
$\mathrm{Nb}_{2} \mathrm{O}_{5}$ & Cerac/PURE & 99.9 & powder -325 mesh \\
$\mathrm{Ta}$ & Cerac/PURE & $99.98(25 \mathrm{ppmNb})$ & powder -325 mesh \\
$\mathrm{Ta}_{2} \mathrm{O}_{5}$ & Cerac/PURE & 99.95 & powder -325 mesh \\
$\mathrm{VO}_{2}$ & Cerac/PURE & 99.5 & powder -100 mesh \\
$\mathrm{Zr}$ & Atomergic Chemicals & $99.6+$ & powder -325 mesh \\
$\mathrm{ZrO}_{2}$ & Wah Chang & $\mathrm{RGS}$ & powder -325 mesh \\
$\mathrm{Hf}$ & Orion Chem. & $99.9(2.4 \mathrm{Zr})$ & powder -400 mesh \\
$\mathrm{HfO}_{2}$ & Wah Chang & $\mathrm{RGS}$ & powder -325 mesh \\
$\mathrm{ThO}_{2}$ & Cerac/PURE & 99.9 & powder -325 mesh \\
$\mathrm{Y}_{2} \mathrm{O}_{3}$ & Cerac/PURE & 99.9 & powder -325 mesh \\
$\mathrm{La}_{2} \mathrm{O}_{3}$ & Kleber Labs & 99.9 & powder -100 mesh \\
\end{tabular}

The purity given is the percent metals purity and does not apply to oxygen or carbon contamination. RGS stands for reagent grade standard. 


\section{Appendix G}

\section{G.1. Comparison of d and I Values for Interfacial Layers.}

The intensity and $d$ spacings for the interfacial phases obtained in the galvanic cell experiments are given in this appendix. The most intense peaks listed in the JCPDS X-ray powder diffraction file for the closest match are also given. Since the interfacial layer is very thin in most cases, the intensities are very small for the interfacial layer. Consequently, there is some uncertainty in the phases identified. The intensities listed are relative to the most intense peaks present. For the YDT and LDT pellets, this is the $\mathrm{ThO}_{2}$ peaks. The intensities listed for the interfacial layer give some indication of the degree of reaction. For the YDT and LDT systems, the maximum relative intensity of the interfacial phase is 1 percent

relative to the maximum peak in $\mathrm{ThO}_{2}$. For the $\mathrm{CaF}_{2}$ system the interfacial layer usually has more intense peaks than the $\mathrm{CaF}_{2}$. From this fact it is easily concluded that the interfacial reactions are greater with the $\mathrm{CaF}_{2}$ system than with the YDT, LDT, or $\mathrm{ThO}_{2}$ systems. Since the X-ray pattern taken is of a pellet surface, the relative intensities of the peaks of any phase can be out of proportion relative to that expected from the purely random orientation of a powder pattern. There is some preferred orientation of the microcrystals of the pellet surface which gives 
rise to some peaks being preferred over others. Consequently, the mismatch of peak intensities of the interfacial phase and its like pattern from JCPDS is not a major concern.

Anything resembling a peak in the X-ray pattern is listed. In other words, the identification of peaks is stretched to the limit, and, consequently, some of the peaks listed are actually background noise. Additionally, some peaks for interfacial phases are not observed since they coincide with $\mathrm{ThO}_{2}$ or $\mathrm{CaF}_{2}$ peaks and are ,consequently, inseparable.

For the YDT, LDT, and $\mathrm{ThO}_{2}$ electrolytes, the d-I spacings for only the more intense peaks from the interfacial layers are listed in Tables G.1-G.6. The less intense peaks of the suspected phase are assumed to be unobservable. 
Table G.1

\begin{tabular}{|c|c|c|}
\hline $\mathrm{VO} / \mathrm{N}_{2} \mathrm{O}_{3}$ on YDT & $\mathrm{V}_{2} \mathrm{O}_{3}$ on YDT & $\mathrm{YVO}_{3}$ \\
\hline I & d I & d $\quad$ I \\
\hline & 3.8480 .6 & \\
\hline \multirow[t]{2}{*}{3.3941 .5} & 3.4420 .7 & \multirow[t]{2}{*}{3.41916} \\
\hline & 3.1461 .3 & \\
\hline masked $\left(\mathrm{ThO}_{2}\right)$ & masked $\left(\mathrm{ThO}_{2}\right)$ & 2.79220 \\
\hline 2.7043 .0 & 2.7091 .3 & 2.695100 \\
\hline \multirow[t]{2}{*}{2.6441 .3} & 2.6570 .5 & \multirow[t]{2}{*}{2.63430} \\
\hline & 2.2360 .3 & \\
\hline \multicolumn{3}{|l|}{1.9000 .7} \\
\hline \multirow[t]{3}{*}{1.8640 .7} & & 1.86112 \\
\hline & 1.7160 .5 & 1.71216 \\
\hline & 1.5730 .5 & \\
\hline $\begin{array}{lll}1.541 & 0.8\end{array}$ & 1.5410 .5 & 1.53560 \\
\hline 1.3520 .4 & & 1.3488 \\
\hline
\end{tabular}


Table G.2.

\begin{tabular}{|c|c|}
\hline $\mathrm{NbO} / \mathrm{NbO}_{2}$ on YDT & $\mathrm{YNbO}_{4}$ \\
\hline d $\quad$ I & d $\quad$ I \\
\hline 8.6031 .4 & noise \\
\hline 7.6821 .4 & noise \\
\hline 3.1252 .5 & 3.120100 \\
\hline $2.966 \quad 1.7$ & 2.95595 \\
\hline $\operatorname{masked}\left(\mathrm{ThO}_{2}\right)$ & 2.73450 \\
\hline 2.6470 .7 & 2.63850 \\
\hline 2.5340 .7 & 2.52535 \\
\hline 1.9021 .3 & 1.90075 \\
\hline 1.8570 .8 & 1.85665 \\
\hline 1.7560 .6 & 1.75640 \\
\hline masked $\left(\mathrm{ThO}_{2}\right)$ & 1.62745 \\
\hline & 1.50840 \\
\hline
\end{tabular}


Table G.3.

\begin{tabular}{|c|c|}
\hline $\mathrm{V}_{2} \mathrm{O}_{3}$ on LUT & $\mathrm{LaVO}_{3}$ \\
\hline d $\quad$ I & d $\quad$ I \\
\hline missing & 3.92060 \\
\hline masked $\left(\mathrm{ThO}_{2}\right)$ & 2.771100 \\
\hline 2.4490 .2 & 2.61230 \\
\hline 2.3870 .4 & 2.36230 \\
\hline 2.2610 .4 & 2.26360 \\
\hline 2.0690 .8 & 1.96080 \\
\hline 1.7920 .3 & 1.75140 \\
\hline 1.7710 .2 & noise \\
\hline 1.7530 .3 & 1.75140 \\
\hline 1.5990 .5 & 1.60080 \\
\hline 1.4590 .4 & 1.45620 \\
\hline 1.3040 .4 & 1.30730 \\
\hline 1.2970 .4 & noise \\
\hline 1.2400 .4 & 1.24860 \\
\hline missing & 1.18240 \\
\hline 1.1300 .3 & 1.13230 \\
\hline
\end{tabular}


Table G.4.

\begin{tabular}{|c|c|}
\hline $\mathrm{V}_{2} \mathrm{O}_{3}$ on $\mathrm{ThO}_{2}$ & $\mathrm{ThV}_{2} \mathrm{O}_{7}$ \\
\hline d $\quad$ I & d $\quad$ I \\
\hline missing & 6.66070 \\
\hline $5.569 \quad 1.1$ & 5.69795 \\
\hline missing & 5.13975 \\
\hline 4.4880 .8 & 4.88860 \\
\hline missing & 4.18860 \\
\hline missing & 3.80085 \\
\hline missing & 3.60960 \\
\hline 3.4370 .6 & 3.43955 \\
\hline 3.3500 .5 & 3.37145 \\
\hline 3.1290 .8 & 3.141100 \\
\hline 3.0690 .5 & 3.05080 \\
\hline 2.9690 .3 & 2.95145 \\
\hline 2.7170 .4 & 2.74570 \\
\hline 2.5660 .3 & noise \\
\hline 1.8440 .3 & 1.84525 \\
\hline
\end{tabular}


Table G.5.

\begin{tabular}{|c|c|c|}
\hline $\mathrm{Cr}_{2} \mathrm{O}_{3}$ on YDT & $\mathrm{Cr}_{2} \mathrm{O}_{3}$ & $\mathrm{YCrO}_{3}$ \\
\hline d $\quad$ I & d $\quad$ I & $d$ \\
\hline missing & 3.63475 & \\
\hline 2.6780 .7 & 2.667100 & 2.675100 \\
\hline missing & & 2.62127 \\
\hline missing & 2.47995 & \\
\hline 2.2240 .4 & 2.26412 & \\
\hline 2.1670 .3 & 2.17640 & \\
\hline missing & & 1.90224 \\
\hline missing & 1.81640 & \\
\hline masked $\left(\mathrm{ThO}_{2}\right)$ & 1.67290 & \\
\hline missing & & 1.52427 \\
\hline 1.4220 .3 & 1.43140 & \\
\hline $\begin{array}{lll}1.355 & 0.3\end{array}$ & noise & noise \\
\hline $\begin{array}{ll}1.181 & 0.3\end{array}$ & noise & noise \\
\hline 1.1540 .3 & noise & noise \\
\hline 1.1160 .3 & noise & noise \\
\hline
\end{tabular}

The identification the interfacial layer is uncertain. Perhaps, it is composed of both $\mathrm{Cr}_{2} \mathrm{O}_{3}$ and $\mathrm{YCrO}_{3}$. 
Table G.6.

\begin{tabular}{llll}
\hline $\mathrm{Cr}_{2} \mathrm{O}_{3}$ on LDT & $\mathrm{Cr}_{2} \mathrm{O}_{3}$ & & $\mathrm{LaCrO}_{3}$ \\
$\mathrm{~d} \quad \mathrm{I}$ & $d$ & $\mathrm{~d} \quad \mathrm{I}$ \\
\hline
\end{tabular}

\subsection{0 .4}

3.6260 .4

3.4850 .5

masked( $\left.\mathrm{ThO}_{2}\right)$

2.7410 .6

2.4750 .4

2.4220 .3

missing

missing

missing

masked( $\left.\mathrm{ThO}_{2}\right)$

missing

1.7300 .4

1.7300 .4

masked $\left(\mathrm{ThO}_{2}\right)$

1.5840 .4

1.5660 .4

1.4920 .3

1.2250 .3
3.89730

3.63475

noise

noise

2.667100

2.768100

2.744100

2.47995

noise

noise

2.25670

2.23050

2.17640

1.94770

1.81640

\subsection{0}

1.73730

1.67290

1.58014

1.59260

1.57730

noise

noise

1.22950

The identification of the interfacial layer is uncertain. Perhaps, it is composed of both $\mathrm{Cr}_{2} \mathrm{O}_{3}$ and $\mathrm{LaCrO}_{3}$. 
Table G.7. Unidentified Interfacial Phase

\begin{tabular}{llllllll}
\hline \multicolumn{2}{l}{$\mathrm{Ta} / \mathrm{Ta}_{2} \mathrm{O}_{5}$ on $\mathrm{CaF}_{2}$} & & & & & \\
$\mathrm{~d}$ & $\mathrm{I}$ & $\mathrm{d}$ & $\mathrm{I}$ & $\mathrm{d}$ & $\mathrm{I}$ & $\mathrm{d}$ & $\mathrm{I}$ \\
\hline 6.033 & 58.8 & 2.004 & 13.2 & 1.460 & 8.7 & 1.144 & 4.1 \\
4.647 & 2.8 & 1.840 & 31.3 & 1.357 & 7.2 & 1.092 & 2.8 \\
3.010 & 100.0 & 1.755 & 9.6 & 1.301 & 4.4 & 1.063 & 4.8 \\
2.728 & 2.3 & 1.588 & 5.6 & 1.203 & 2.7 & 1.042 & 1.4 \\
2.603 & 28.6 & 1.571 & 39.5 & 1.196 & 12.8 & 1.004 & 6.6 \\
2.388 & 8.4 & 1.504 & 10.0 & 1.165 & 6.4 & &
\end{tabular}


Table G.8. Unidentified Interfacial Phase

\begin{tabular}{llllllll}
\hline \multicolumn{3}{l}{$\mathrm{NbO} / \mathrm{NbO}_{2}$ on $\mathrm{CaF}_{2}$} & & & & & \\
$\mathrm{~d}$ & $\mathrm{I}$ & $\mathrm{d}$ & $\mathrm{I}$ & $\mathrm{d}$ & $\mathrm{I}$ & $\mathrm{d}$ & $\mathrm{I}$ \\
\hline 6.005 & 13.4 & 1.992 & 9.0 & 1.401 & 5.6 & 1.113 & 1.2 \\
4.211 & 9.5 & 1.881 & 8.4 & 1.331 & 3.5 & 1.087 & 1.7 \\
3.717 & 1.1 & 1.829 & 38.1 & 1.295 & 7.6 & 1.057 & 6.2 \\
2.986 & 100.0 & 1.751 & 4.9 & 1.268 & 10.2 & 1.020 & 1.7 \\
2.584 & 21.7 & 1.715 & 9.2 & 1.215 & 10.6 & 0.997 & 5.4 \\
2.427 & 35.0 & 1.578 & 3.7 & 1.188 & 11.7 & 0.966 & 7.1 \\
2.336 & 1.9 & 1.562 & 41.0 & 1.157 & 4.7 & 0.941 & 8.0 \\
2.220 & 1.6 & 1.487 & 12.5 & 1.136 & 1.4 & & \\
2.103 & 12.9 & 1.449 & 2.6 & 1.124 & 5.3 & &
\end{tabular}


Table G.9. Unidentified Interfacial Phase

\begin{tabular}{|c|c|c|c|c|c|c|c|}
\hline \multicolumn{8}{|c|}{$\mathrm{VO} / \mathrm{N}_{2} \mathrm{O}_{3}$ on $\mathrm{CaF}_{2}$} \\
\hline$d$ & I & d & I & $d$ & I & d & I \\
\hline 4.567 & 0.9 & 2.731 & 0.4 & 1.694 & 0.4 & 1.428 & 0.3 \\
\hline 3.464 & 0.6 & 2.401 & 0.7 & 1.606 & 0.2 & 1.331 & 0.3 \\
\hline 2.837 & 0.4 & 2.111 & 0.4 & 1.572 & 0.3 & & \\
\hline 2.774 & 0.7 & 2.023 & 0.6 & 1.532 & 0.4 & & \\
\hline
\end{tabular}




\section{Appendix H}

\section{H.1. The Activity Coefficient versus Concentration Data.}

The activity versus concentration data for all samples analyzed is listed in Table H.1. $\mathrm{X}_{\mathrm{v}}$ is the mole fraction of vanadium in the alloy. It is not the overall composition of vanadium in the composite. The EMF corresponds to the EMF generated when the composite was used in the high temperature galvanic cell when a $\mathrm{Ta} / \mathrm{Ta}_{2} \mathrm{O}_{5}$ pellet was used as the reference electrode. The data in all tables are for $\mathrm{T}=1000^{\circ} \mathrm{C}$. The values in parenthesis are the mole fractions of vanadium in the alloy that are calculated from the initial weight of materials used.

Table H.1. V-Ru: The Vanadium - Ruthenium System

\begin{tabular}{llllll}
\hline sample & phases & $\mathrm{X}_{v}$ & $\mathrm{a}_{v}$ & $-\log \gamma_{v}$ & EMF \\
\hline $582 \mathrm{~A}$ & VC-C-Ru & 0.0873 & $1.2954 \mathrm{E}-04$ & 2.829 &
\end{tabular}

Table H.2. V-Os: The Vanadium - Osmium System

\begin{tabular}{llllll}
\hline sample & phases & $\mathrm{X}_{\mathrm{v}}$ & $\mathrm{a}_{\mathrm{v}}$ & $-\log \gamma_{\mathrm{v}}$ & EMF \\
\hline 582B & VC-C-Os & 0.0581 & $1.2954 \mathrm{E}-04$ & 2.652 &
\end{tabular}


Table H.3. V-Rh: The Vanadium - Rhodium System

\begin{tabular}{llllll}
\hline sample & phases & $\mathrm{X}_{\mathrm{v}}$ & $\mathrm{a}_{\mathrm{v}}$ & $-l o g \gamma_{\mathrm{v}}$ & $\mathrm{EMF}$ \\
\hline $297 \mathrm{~B}$ & $\mathrm{~V}_{4} \mathrm{O} / \mathrm{V}_{2} \mathrm{O} / \mathrm{V}$ & 0.8842 & $2.332 \mathrm{E}-01$ & 0.5788 & \\
$297 \mathrm{C}$ & $\mathrm{V}_{2} \mathrm{O} / \mathrm{NO} / \mathrm{V}$ & 0.8645 & $2.105 \mathrm{E}-01$ & 0.6135 & \\
$216 \mathrm{~B}$ & $\mathrm{VO} / \mathrm{V}_{2} \mathrm{O}_{3} / \mathrm{VRh}$ & 0.50542 & $7.106 \mathrm{E}-03$ & 1.8520 & \\
$604 \mathrm{~A}$ & $\mathrm{~V}_{2} \mathrm{C} / \mathrm{VC} / \mathrm{VRh}$ & 0.53847 & $3.604 \mathrm{E}-02$ & 1.174 & \\
$583 \mathrm{~A}$ & $\mathrm{VC} / \mathrm{C} / \mathrm{Rh}_{3} \mathrm{~V}$ & 0.2747 & $1.2954 \mathrm{E}-04$ & 3.326 & \\
$605 \mathrm{~A}$ & $\mathrm{~V}_{2} \mathrm{O}_{3} / \mathrm{Rh}$ & 0.07708 & & & \\
$605 \mathrm{~B}$ & $\mathrm{~V}_{2} \mathrm{O}_{3} / \mathrm{Rh}_{3} \mathrm{~V}$ & 0.19482 & & &
\end{tabular}

Table H.4. V-Pd: The Vanadium - Palladium System

\begin{tabular}{llllll}
\hline sample & phases & $\mathrm{X}_{\mathrm{v}}$ & $\mathrm{a}_{\mathrm{v}}$ & $-\log \gamma_{v}$ & $\mathrm{EMF}$ \\
\hline $292 \mathrm{~A}$ & $\mathrm{~V}_{2} \mathrm{O}_{3} / \mathrm{V}_{3} \mathrm{O}_{5} / \mathrm{Pd}$ & $<0.00313$ & $3.409 \mathrm{E}-11$ & $<7.96$ & \\
$236 \mathrm{~B}$ & $\mathrm{~V}_{2} \mathrm{O}_{3} / \mathrm{Pd}$ & 0.04098 & $1.453 \mathrm{E}-07$ & 5.450 & 0.5755 \\
$291 \mathrm{~B}$ & $\mathrm{~V}_{2} \mathrm{O}_{3} / \mathrm{Pd}$ & 0.12743 & $3.932 \mathrm{E}-06$ & 4.511 & 0.4549 \\
$213 \mathrm{~B}$ & $\mathrm{VO} / \mathrm{V}_{2} \mathrm{O}_{3} / \mathrm{Pd}$ & 0.41119 & $7.106 \mathrm{E}-03$ & 1.762 & \\
$217 \mathrm{~B}$ & $\mathrm{~V}_{2} \mathrm{O} / \mathrm{NO} / \mathrm{V}$ & 0.80150 & $2.015 \mathrm{E}-01$ & 0.600 & \\
$238 \mathrm{~B}$ & $\mathrm{~V}_{4} \mathrm{O} / \mathrm{N}_{2} \mathrm{O} / \mathrm{V}$ & 0.86016 & $2.332 \mathrm{E}-01$ & 0.567 & \\
$291 \mathrm{~A}$ & $\mathrm{VO} / \mathrm{V} / \mathrm{Pd}$ & 0.7600 & $7.813 \mathrm{E}-02$ & 0.988 & 0.044 \\
$291 \mathrm{~A}$ & $\mathrm{VO} / \mathrm{N} / \mathrm{Pd}$ & 0.5200 & $7.813 \mathrm{E}-02$ & 0.823 & 0.044 \\
$233 \mathrm{~B}$ & $\mathrm{~V}_{2} \mathrm{O}_{3} / \mathrm{Pd}$ & 0.00377 & $4.974 \mathrm{E}-09$ & 5.880 & 0.6989 \\
$546 \mathrm{~A}$ & $\mathrm{~V}_{2} \mathrm{O}_{3} / \mathrm{Pd}$ & 0.0179 & & & \\
$546 \mathrm{~B}$ & $\mathrm{~V}_{2} \mathrm{O}_{3} / \mathrm{Pd}$ & 0.1990 & & & \\
$546 \mathrm{C}$ & $\mathrm{V}_{2} \mathrm{O}_{3} / \mathrm{Pd}$ & 0.3057 & & & \\
$471 \mathrm{~A}$ & $\mathrm{VC} / \mathrm{C} / \mathrm{Pd}$ & 0.2149 & $1.295 \mathrm{E}-04$ & 3.220 & \\
$470 \mathrm{~A}$ & $\mathrm{~V}_{2} \mathrm{C} / \mathrm{VC} / \mathrm{Pd}$ & 0.4709 & $3.604 \mathrm{E}-02$ & 1.116 &
\end{tabular}


Table H.5. V-Ir. The Vanadium - Iridium System

\begin{tabular}{|c|c|c|c|c|c|}
\hline sample & phases & $x_{v}$ & $a_{v}$ & $-\log \gamma_{v}$ & EMF \\
\hline $213 A$ & $\mathrm{~V}_{2} \mathrm{O} / \mathrm{VO} / \mathrm{IrV}_{3}$ & 0.79653 & $2.105 \mathrm{E}-01$ & 0.597 & \\
\hline $294 A$ & $\mathrm{VO} / \mathrm{N}_{2} \mathrm{O}_{3} / \mathrm{IrV}_{3}$ & 0.68790 & $7.106 \mathrm{E}-03$ & 1.986 & \\
\hline 583B & $\mathrm{VC} / \mathrm{C} / \mathrm{VIr}_{3}$ & 0.2568 & $1.295 \mathrm{E}-04$ & 3.297 & \\
\hline 604B & $\mathrm{V}_{2} \mathrm{C} / \mathrm{VC} / \mathrm{V}_{3} \mathrm{Ir}$ & 0.7483 & $3.604 \mathrm{E}-02$ & 1.317 & \\
\hline $295 \mathrm{C}$ & $\mathrm{V}_{2} \mathrm{O}_{3} / \mathrm{IrV}_{3}$ & 0.51227 & & & \\
\hline 294B & $\mathrm{V}_{2} \mathrm{O}_{3} / \mathrm{Ir}$ & 0.04867 & & & \\
\hline 296B' & $\mathrm{V}_{2} \mathrm{O}_{3} / \mathrm{Ir}$ & 0.07695 & & & \\
\hline $296 B^{\prime \prime}$ & $\mathrm{V}_{2} \mathrm{O}_{3} / \mathrm{Ir}_{3} \mathrm{~V}$ & 0.24520 & & & \\
\hline $296 A$ & $\mathrm{~V}_{2} \mathrm{O}_{3} / \mathrm{IrV} / \mathrm{Ir}_{3} \mathrm{~V}$ & 0.5178 & & & \\
\hline $296 A$ & $\mathrm{~V}_{2} \mathrm{O}_{3} / \mathrm{IrV} / \mathrm{Ir}_{3} \mathrm{~V}$ & 0.6678 & & & \\
\hline
\end{tabular}

Table H.6. V-Pt: The Vanadium - Platinum System

\begin{tabular}{|c|c|c|c|c|c|}
\hline sample & phases & $x_{v}$ & $a_{v}$ & $-\log \gamma_{v}$ & EMF \\
\hline $248 A$ & $\mathrm{~V}_{2} \mathrm{O} / \mathrm{NO} / \mathrm{N}_{3} \mathrm{Pt}$ & 0.8102 & 2.105E-01 & 0.604 & \\
\hline $214 A$ & $\mathrm{VO} / \mathrm{N}_{2} \mathrm{O}_{3} / \mathrm{VPt}$ & 0.5276 & $7.106 \mathrm{E}-03$ & 1.871 & \\
\hline 472B & $\mathrm{V}_{4} \mathrm{O} / \mathrm{V}_{2} \mathrm{O} / \mathrm{PtV}_{3}$ & 0.8191 & 2.332E-01 & 0.546 & \\
\hline $582 \mathrm{C}$ & $\mathrm{VC} / \mathrm{C} / \mathrm{VPt}_{2}$ & 0.3372 & $1.295 \mathrm{E}-04$ & 3.416 & \\
\hline $604 C$ & $\mathrm{~V}_{2} \mathrm{C} / \mathrm{VC} / \mathrm{N}_{3} \mathrm{Pt}$ & 0.7428 & $3.604 \mathrm{E}-02$ & 1.314 & \\
\hline $128 \mathrm{~A}$ & $\mathrm{~V}_{2} \mathrm{O}_{3} / \mathrm{Pt}$ & 0.2116 & & & \\
\hline 128B & $\mathrm{V}_{2} \mathrm{O}_{3} / \mathrm{Pt}$ & 0.02851 & & & \\
\hline $128 \mathrm{C}$ & $\mathrm{V}_{2} \mathrm{O}_{3} / \mathrm{Pt}$ & 0.02153 & & & \\
\hline 214B & $\mathrm{VO} / \mathrm{PtV} / \mathrm{PtV}_{3}$ & & & & \\
\hline 214B & $\mathrm{VO} / \mathrm{PtV} / \mathrm{PtV}_{3}$ & & & & \\
\hline 248B & $\mathrm{VO} / \mathrm{PtV}_{3}$ & 0.79984 & & & \\
\hline
\end{tabular}




\section{Appendix I}

\section{I.1. Containers Used for Sample Heat Treatments.}

Annealing samples in appropriate containers is crucial to preparing pure equilibrated samples of the desired composition. Table I.1 summarizes the containers used for the V-O-NM(NM = noble metal), and V-C-NM composites. In general, most samples are annealed on tungsten foil. However, this procedure does not seem to work very well for the higher oxides of vanadium. The oxides above $\mathrm{V}_{2} \mathrm{O}_{3}$ interait with the tungsten foil. The result is that the sample becomes reduced and as a consequence it is difficult to obtain oxides above $\mathrm{V}_{2} \mathrm{O}_{3}$ after annealing on tungsten foil. To alleviate this problem, oxides above $\mathrm{V}_{2} \mathrm{O}_{3}$ are annealed on alumina which seems to work reasonably well.

The VC/C samples are best annealed on graphite since the samples are in equilibrium with graphite. For samples 301A, 301B, 302A, and 302B the graphite powder on which the samples were laid was placed directly on an alumina crucible. The graphite reacted with the alumina and produced, most likely, an aluminum oxide gaseous species which interacted with and contaminated the samples. This explains the large weight gain of these samples. Additionally, aluminum was found to be in them from microprobe analysis. Finally, the best approach to annealing these samples was to place some graphite powder in a 
platinum crucible and then rest the samples on the graphite powder.

The $\mathrm{V}_{2} \mathrm{C} / \mathrm{VC}$ samples were annealed on tungsten foil. These samples seemed to react some with the tungsten foil. They tended to stick to the tungsten foil during the annealing. The amount of reaction was considered small enough to not significantly affect the integrity of the samples.

A particularly large amount of degassing is observed in the vanadium oxide samples. This degassing is attributed to a small oxidized layer of vanadium $\left(\mathrm{V}_{2} \mathrm{O}_{5}\right)$ on the surface of the oxide particulates of the unannealed composite. $\mathrm{V}_{2} \mathrm{O}_{5}(\mathrm{~s})$ at temperatures above its melting point has a tendency to decompose to $\mathrm{VO}_{2}(\mathrm{~s})$ and $\mathrm{O}_{2}(\mathrm{~g})$. The partial pressure of $\mathrm{O}_{2}$ in equilibrium with $\mathrm{V}_{2} \mathrm{O}_{5}$ and $\mathrm{VO}_{2}$ at a variety of temperatures is given in Table I.2. This degassing effect is best minimized by heating the oxide samples slowly or maintaining the temperature at least $6 \mathrm{hr}$ at $600-700^{\circ} \mathrm{C}$ before taking the temperature above $1000^{\circ} \mathrm{C}$. 
Table I.1. Containers used.

sample container/lining

Low oxides $\left(<\mathrm{V}_{2} \mathrm{O}_{3}\right) \quad$ Tungsten foil

High oxides $\left(>\mathrm{V}_{2} \mathrm{O}_{3}\right) \quad$ Alumina (or tungsten foil)

Low carbides $\left(\mathrm{VC}_{2} \mathrm{~V}_{2} \mathrm{C}\right) \quad$ Tungsten foil

High carbides(VC-C) Graphite Powder on platinum

All other materials Tungsten foil

Table I.2 Pressure versus temperature for $\mathrm{O}_{2}$ gas

$2 \mathrm{~V}_{2} \mathrm{O}_{5}(\mathrm{~s}, \mathrm{l}) \rightarrow 4 \mathrm{VO}_{2}(\mathrm{~s})+\mathrm{O}_{2}(\mathrm{~g})$

\begin{tabular}{ll} 
temperature $\left({ }^{\circ} \mathrm{C}\right)$ & pressure of $\mathrm{O}_{2}(\mathrm{~g})$ in atm. \\
\hline 400 & $1.33 \mathrm{E}-11$ \\
500 & $6.34 \mathrm{E}-09$ \\
600 & $7.31 \mathrm{E}-07$ \\
700 & $2.23 \mathrm{E}-05$ \\
800 & $1.03 \mathrm{E}-04$ \\
900 & $3.63 \mathrm{E}-04$ \\
1000 & $1.04 \mathrm{E}-03$ \\
1100 & $2.57 \mathrm{E}-03$
\end{tabular}



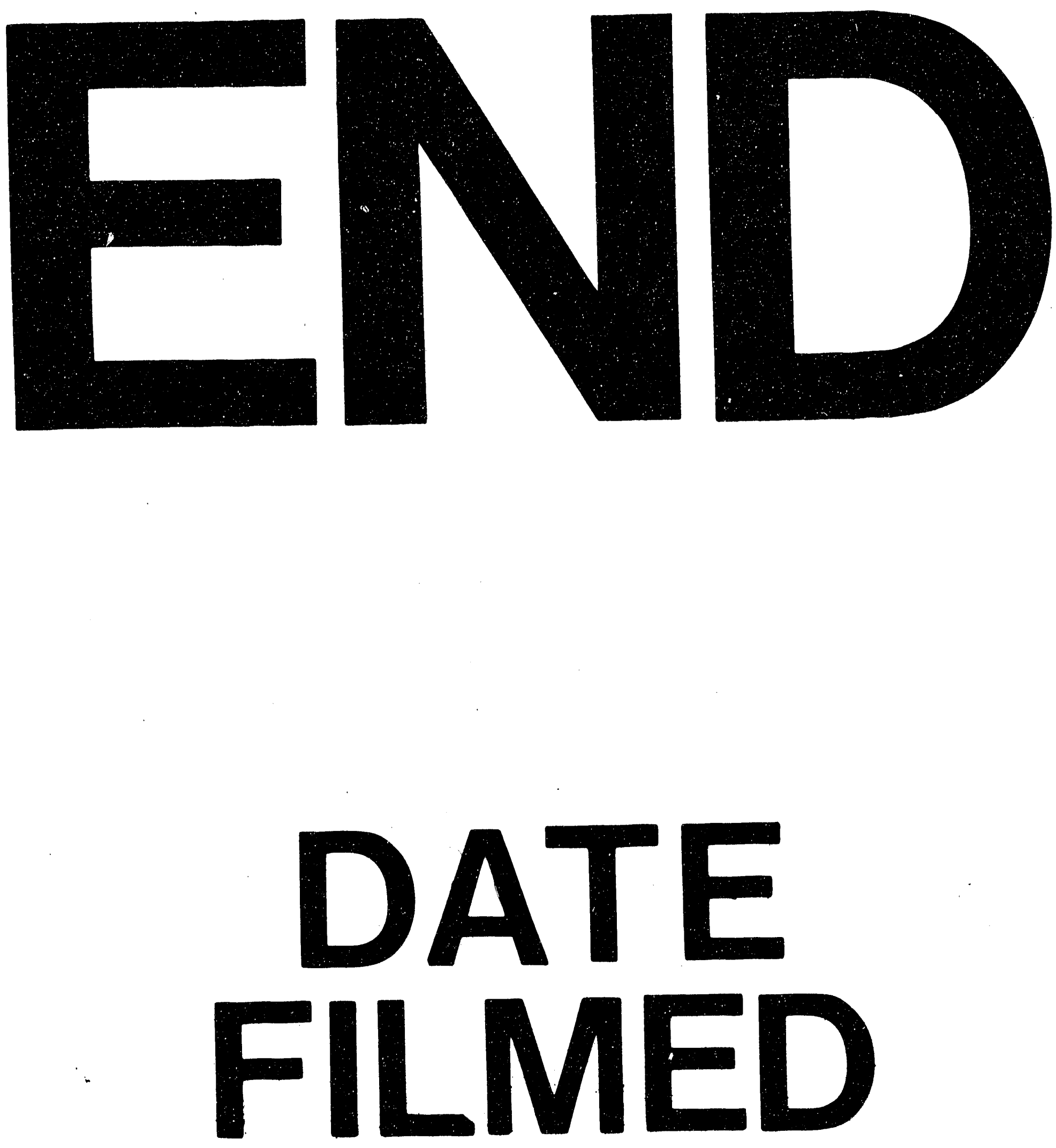

1

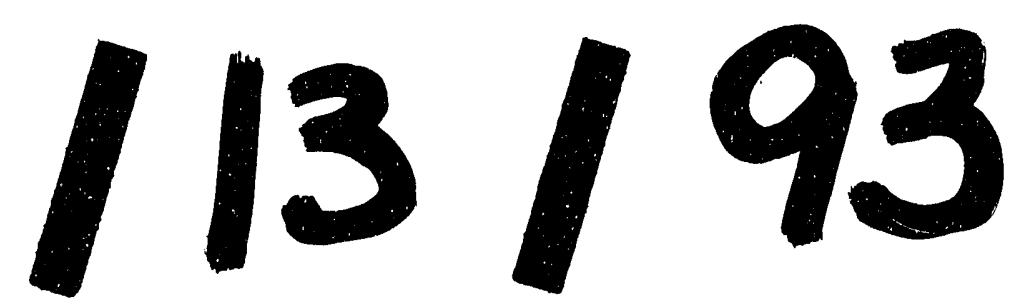


